National Library

of Canada

Canadian Theses Service

Ottawa, Canada

KIA ON4
Bibliothèque nationale

du Canada

\section{Service des thèses canadiennes}

\section{NOTICE}

The quality of this microform is heavily dependent upon the quality of the original thesis submitted for microfilming. Every effort has been made to ensure the highest quality of reproduction possible.

If pages are missing, contact the university which granted the degree.

Some pages may have indistinct print especially if the original pages were typed with a poor typewriter ribbon or if the university sent us an inferior photocopy.

Reproduction in full or in part of this microform is governed by the Canadian Copyright Act, R.S.C. 1970, c. C-30, and subsequent amendments.

\section{AVIS}

La qualité de cette microforme dépend grandement de la qualité de la thèse soumise au microfilmage. Nous avons tout fait pour assurer une qualité supérieure de reproduc. tion.

S'il manque des pages, veuillez communiquer avec l'université qui a conféré le grade.

La qualité d'impression de certaines pages peut laisser à désirer, surtout si les pages originales oni éfé dactylographiées a l'aide d'un ruban usé ou si l'université nous a fait parvenir une photocopie de qualité inférieure.

La reproduction, méme parielle, de cette microforme est soumise a la Loi canadienne sur le droit d'auteur, SRC 1970 , c. C-30, et ses amendements subséquents. 


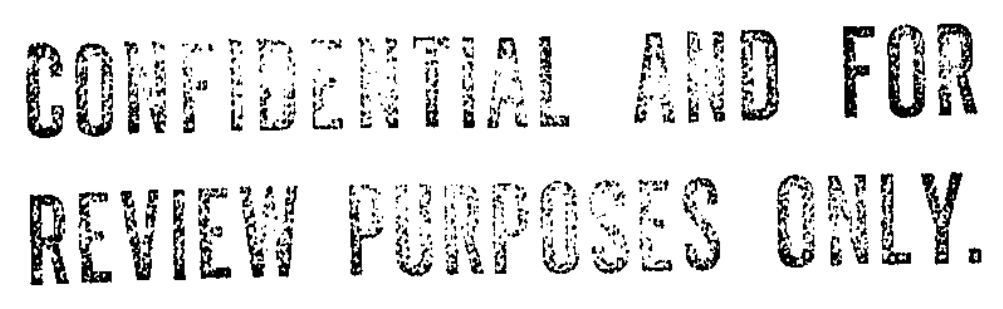

\title{
THE PQYCHOLOGICAL AND PHYSTCAL HEALTH OF FAMILY MEMBERS CARING FOR AN ELDERLY RERSON WITH DEMENTIA
}

\author{
Mona Baumgarten \\ Department of Epidemiology and Biostatistics \\ McGill University, Montreal
}

March 1990

A thesis submitted to the Faculty of Graduate studies and Research in partial fulfillment of the requirements for the degree of Ph.D.

(c) Mona Baumgarten, 1990 
The author has granted an irrevocable nonexclusive licence allowing the National Library - of Canada to reproduce, loan, distribute or sell copies of his/her thesis by any means and in any form or format, making this thesis available to interested persons.

The author retains ownership of the copyright in his/her thesis. Neither the thesis nor substantial extracts from it may be printed or otherwise reproduced without his/her permission.
L'auteur a accordé une licence irrévocable et non exclusive permettant à la Bibliothèque nationale du Canada de reproduire, prêter, distribuer ou vendre des copies de sa thèse de quelque manière et sous quelque forme que ce soit pour mettre des exemplaires de cette thèse à la disposition des personnes intéressées.

L'auteur conserve la propriété du droit d'auteur qui protège sa thèse. Ni la thèse ni des extraits substantiels de celle-ci ne doivent être imprimés ou autrement reproduits sans son autorisation. 
An aged man is but a paltry thing, A tattered coat upon a stick...

William Butler Yeats

I get by

with a little help from my friends

John Lennon \& Paul McCartney 


\section{DEDICATION}

To the memory of my loving parents, who dreamed of seeing this day 


\section{ACKAOWLEDGMENTS}

I am grateful to my thesis supervisor, Renaldo Battista, and to the other members of my thesis committee, Claire Infante-Rivard, Rubin Becker, Jim Hanley, and Serge Gauthier, for their help and enthusiasm. I acknowledge the support of the st. Justine Community Health Department (DSC) where this work was carried out. I am particularly grateful to Abby Lippman for nudging me down this road and to claire Infante-Rivard for her unfailing encouragement. I thank Mark Goldberg for his last-minute technical help. Thanks also to Rubin Becker, Howard Bergman, Marlene Levine, Caryn Letovsky, and Sandy Feldman of the Geriatric Assessment Unit of the Jewish General Hospital for their help in recruiting patients. 


\section{ABSTRACT}

Most elderly persons with dementia are cared for at home, usually by a spouse or adult child. The objective of the present study was to determine whether there is an excess of psychological and physical health problems among family caregivers of elderly persons with dementia. Data were obtained by interview from close family members of dementia patients, and from a comparison group made up of close family members of patients undergoing cataract surgery. Caregivers had significantly higher levels of depression and physical symptoms than noncaregivers. The association between caregiving and the outcome variables was stronger among subjects who were married to the patient than among those who were the patient's child. Furthermore, greater behavioral disturbance in the patient was associated with higher levels of morbidity in the caregiver. The results suggest that caregivers might benefit from careful monitoring of their health status, and from greater access to specialized support services. 


\section{RESUME}

La majorité des personnes âgées atteintes de démence habitent à domicile, supportées par leur conjoint ou un de leurs enfants. L'objectif de cette étude était de déterminer si la fréquence des problèmes de santé psychologique et $\therefore$ sique était plus élevée parmi les aidants familiaux des personnes âgées démentes, comparativement à un groupe constitué des proches de patients qui avaient subi une chirurgie pour les cataractes. L'étude démontre que les aidants avaient un niveau significativement plus élevé de dépression et de symptômes physiques que le groupe de comparaison. De plus, un niveau plus élevé de perturbation du comportement chez le patient était associé à un niveau plus élevé de morbidité chez la personne soutien. Ces résultats soulignent l'importance d'une meilleure surveillance de l'état de santé des aidants familiaux, et la pertinence d'augmenter le réseau de services spécialisés de support et de répit. 


\section{PREFACE}

Although there have been a large number of studies on the health of family caregivers for persons with dementia, methodological shortcomings limit their validity. The present study avoided many of the methodological weaknesses observed in earlier research: an appropriate comparison group was included, specific rather than multidimensional measures of health status were used, sample size was adequate, and confounding variables were controlled for. The originality of this research, then, lies in the application of rigorous methods of design and analysis to the problem of estimating excess morbidity among caregivers.

The study reported in this thesis is part of a larger project for which funding was obtained from the Fonds de la recherche en santé du Québec (FRSQ) and from the Alzheimer Society of Canada. The protocol was written by the author of the thesis, with input from her thesis committee (Drs. Renaldo N. Battista, Claire Infante-Rivard, Rubin Becker, James A. Hanley, and Serge Gauthier). Although the larger study has a longitudinal component, the results presented in the thesis represent only the cross-sectional portion.

A substudy was carried out which involved the development of a scale to measure behavior disturbance among patients with dementia. This work was coordinated by the author of the thesis, in collaboration with Drs. Rubin Becker and Serge Gauthier. A paper reporting the development 
PREFACE (continued)

and psychometric properties of the scale appeared in the Journal of the American Geriatrics Society: this paper was written by the author of this thesis with input from Drs. Becker and Gauthier.

An earlier version of the literature review chapter of this thesis appeared as a paper in the Journal of Clinical Epidemiology.

The fieldwork was coordinated by Anita Heller and Caryn Letovsky, under the direct supervision of the author of the thesis. Four interviewers administered the questionnaire to the study subjects. Clinical and secretarial staff of the Jewish General Hospital's Geriatric Assessment Unit helped in identifying patients for the study. The statistical analysis was carried out by the author, with input from Dr. James A. Hanley. 


\section{TABLE OF CONTENTS}

Page

Dedication $\ldots \ldots \ldots \ldots \ldots \ldots \ldots \ldots \ldots \ldots \ldots \ldots \ldots \ldots \ldots \ldots \ldots \ldots \ldots$

Acknowledgments $\ldots \ldots \ldots \ldots \ldots \ldots \ldots \ldots \ldots \ldots \ldots \ldots$ iv

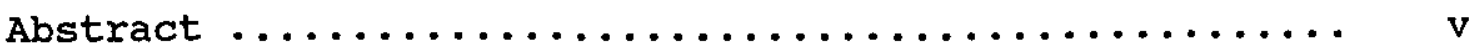

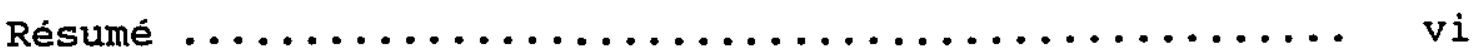

Preface $\ldots \ldots \ldots \ldots \ldots \ldots \ldots \ldots \ldots \ldots \ldots \ldots \ldots \ldots \ldots \ldots \ldots$

CHAPTER I

CLINICAL AND EPIDEMIOLOGIC ASPECTS OF DEMENTIA ....... 1

1. Definition $\ldots \ldots \ldots \ldots \ldots \ldots \ldots \ldots \ldots \ldots \ldots \ldots \ldots \ldots$

2. Etiology $\ldots \ldots \ldots \ldots \ldots \ldots \ldots \ldots \ldots \ldots \ldots \ldots \ldots \ldots \ldots \ldots \ldots$

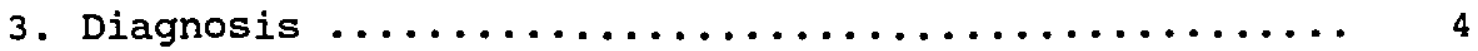

4. Clinical course $\ldots \ldots \ldots \ldots \ldots \ldots \ldots \ldots \ldots \ldots \ldots \ldots \ldots \ldots$

5. Treatment $\ldots \ldots \ldots \ldots \ldots \ldots \ldots \ldots \ldots \ldots \ldots \ldots \ldots \ldots$

6. occurrence $\ldots \ldots \ldots \ldots \ldots \ldots \ldots \ldots \ldots \ldots \ldots \ldots \ldots \ldots \ldots$

A. Incidence $\ldots \ldots \ldots \ldots \ldots \ldots \ldots \ldots \ldots \ldots \ldots \ldots \ldots$

B. Prevalence ............................. 10

c. Social and economic impact ............... 12

CHAPTER II

CAREGIVING AND HEALTH $\ldots \ldots \ldots \ldots \ldots \ldots \ldots \ldots \ldots \ldots \ldots$

1. Background .................................. 14

2. Stressfulness of caring for a demented person ..... 18 
TABLE OF CONTENTS (continued)

Page

CHAPTER III

LITERATURE REVIEW

1. Methods used to identify, review, and summarize

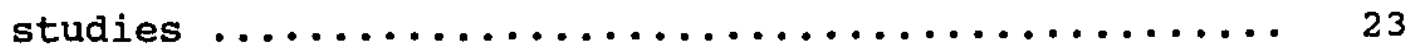

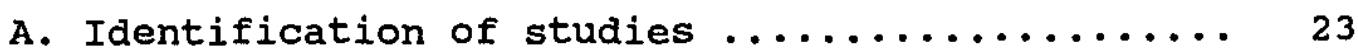

B. Methodologic review of studies ........... 26

c. Substantive review of studies ............ 27

2. Results and discussion of literature review ...... 28

A. Overview of the studies ............... 28

B. Methodological characteristics of the

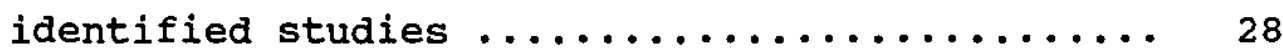

c. Substantive findings of the reviewed studies .. 34

3. Summary of literature review ............... 45

CHAPTER IV

OBJECTIVES

CHAPTER V

METHODS .................................... 48

1. Overview ........................... 48

2. Selection of study subjects ................. 49

A. Identification of demented patients ......... 49

B. Identification of nondemented patients ...... 50

c. Identification of caregivers ............. 51

D. Identification of noncaregivers .......... 52 
TABLE OF CONTENTS (continued)

Page

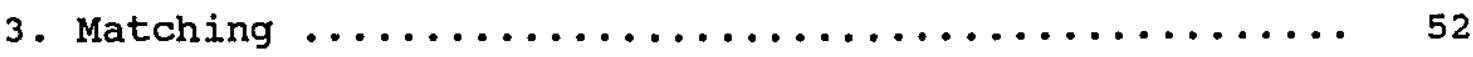

4. Definition and measurement of study variables ..... 53

A. Outcome variables ................... 53

B. Explanatory variables ................. 57

c. Potential confounding variables ........... 61

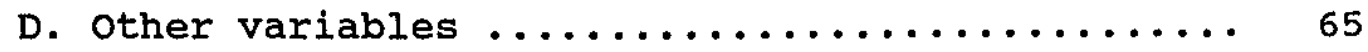

E. Translation of questionnaire ........... 66

5. Data collection procedures ................. 66

6. Analysis ............................. 68

A. Difference between caregivers and noncaregivers 71

B. Modifying effect of caregiver characteristics 72

C. Association between the health indicators and characteristics of the demented patient's

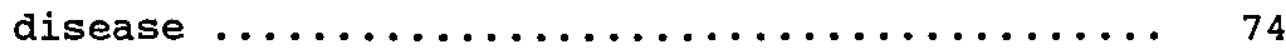

D. Other analyses .............................. 74

7. Sample size ........................... 75

CHAPTER VI

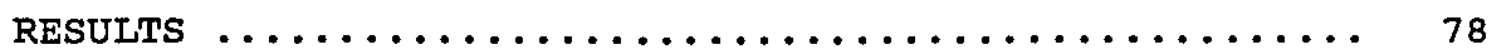

1. Description of sample and instruments ......... 78

A. Recruitment of study sample ............ 78

B. Description of the interviewing process ...... 84

C. Description of study patients ............ 88

D. Description of caregivers and noncaregivers ... 91

E. Internal consistency of study scales ........ 95 
TABLE OF CONTENTS (continued)

Page

2. Depression and physical symptoms among caregivers and noncaregivers $\ldots \ldots \ldots \ldots \ldots \ldots \ldots \ldots \ldots \ldots \ldots$

3. Effect modification $\ldots \ldots \ldots \ldots \ldots \ldots \ldots \ldots \ldots \ldots, 106$

4. Caregiver health in relation to characteristics of the demented patient's disease ............. 110

CHAPTER VII

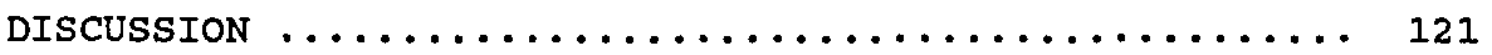

1. Depression ............................ 121

2. Physical symptoms ...................... 125

3. Effect modification $\ldots \ldots \ldots \ldots \ldots \ldots \ldots \ldots \ldots \ldots \ldots, 127$

4. Association between patient characteristics and caregiver health ...................... 131

5. Methodological consicierations $\ldots \ldots \ldots \ldots \ldots \ldots \ldots . \ldots 133$

A. Internal validity .................. 133

B. Generalizability .................... 137

6. Implications ......................... 140

REFERENCES ............................. 144

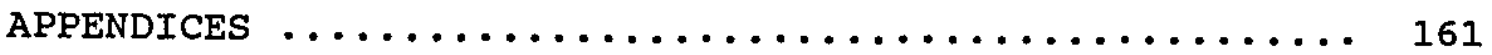




\section{IIST OF TABLES}

Table

Page

1 Estimated prevalence rates of dementia, by age ..

2 Methodological characteristics of 46 studies reviewed ........................... 29

3 Recruitment of demented patients ........... 79

4 Interview of caregivers of demented patients .... 81

5 Recruitment of cataract patients ........... 82

6 Interview of close family members of cataract

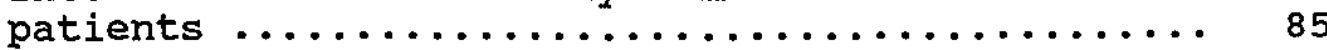

7 Study participation of demented patients and cataract patients, by age and sex .......... 86

8 Characteristics of interviews, by caregiver status ................................. 87

9 Demographic characteristics of study patients ... 89

10 Clinical characteristics of demented patients and cataract patients .................. 90

11 Functional status of demented patients ........ 92

12 Formal services received, demented patients

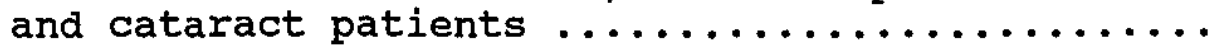

13 Characteristics of caregivers and noncaregivers ......................... 94

14 Internal consistency of study scales ......... 96

15 Unadjusted and adjusted CESD total scores and subscale scores, by caregiver status .......... 99

16 Frequency (\% in previous month) of physical symptoms, by caregiver status .............. 104

17 Unadjusted depression scores by caregiver status, and adjusted difference between caregivers and noncaregivers, in subgroups defined by certain caregiver variables ..................... 
18 Modifying effect of certain caregiver variables on the depression-caregiving association, con-

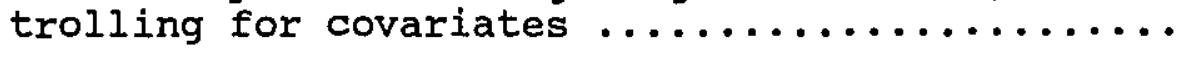

19 Unadjusted number of physical symptoms by caregiver status, and adjusted difference between caregivers and noncaregivers, in subgroups defined by certain caregiver variables ........

20 Modifying effect of certain caregiver variables on the association between physical symptoms and caregiving, controlling for covariates..........

21 Correlations among patient variables ......... 114

22 Mean CESD score among caregivers, by characteristics of the demented patient's disease .....

23 Results of regression of CESD score among caregivers on various characteristics of the demented patient's disease, controlling for covariates...

24 Number of physical symptoms among caregivers, by characteristics of the demented patient's

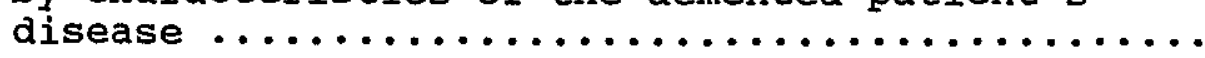

25 Results of regression of physical symptoms among caregivers on various characteristics of the demented patient's disease, controlling for covariates ......................... 
1 A model for studying tine relationship between dementia and caregiver health ............ 22

2 Studies on the health of caregivers of persons with dementia, by year of publication ....... 25

3 Recruitment of demented patients and caregivers .......................... 80

4 Recruitment of cataract patients and their close family members ..................

5 Distribution of depression scores among

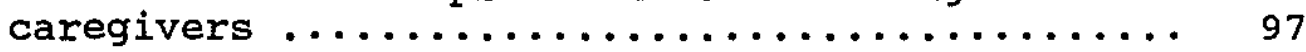

6 Distribution of depression scores among noncaregivers ...................... 98

7 Distribution of physical symptoms among caregivers .......................... 102

8 Distribution of physical symptoms among noncaregivers ...................... 103 


\section{APPENDICES}

Appendix

Page

1 The health of persons giving care to the demented elderly: a critical review of the

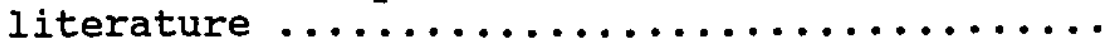

2 Sample description and major findings of 46 reports reviewed .................... 174

3 Center for Epilemiologic Studies Depression scale ............................ 191

4 Aday and Andersen's physical symptoms checklist .......................... 195

5 Mini-Mental state Examination ............ 199

6 OARS Activities of Daily Living questionnaire ...................... 204

7 Validity and reliability of the Dementia Behavior Disturbance scale .............. 210

8 Sociodemographic questions asked at interview

9 Chronic conditions as asked in Canada Health Survey .......................... 221

10 LOPES life events scale ................ 225

11 Cigarette smoking questions from Canada Health Survey ..................... 229

12 Alcohol consumption questions from EPESE survey instrument ................. 232

13 F-COPES (coping skills scale) ........... 234

14 Social Provisions scale ................ 240

15 Social support satisfaction scale .......... 244

16 Formal services used by household ......... 246

17 Consent forms .................... 248 
APPENDICES (continued)

18 Detailed results of regression analysis of CESD score on the caregiving variable, adjusting

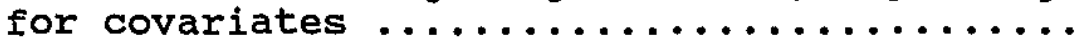

19 Detailed results of regression analysis of number of physical symptoms on the caregiving variable, adjusting for covariates .......... 
CHAPTER I

CLINICAL AND EPIDEMIOLOGIC ASPECTS OF DEMENTIA

\section{DEFINITION}

Dementia is a clinical syndrome characterized by global and progressive decline in intellectual functioning as a result of organic brain degeneration. The severity of the condition may vary from moderate cognitive deficit to severe disorientation, and it may be accompanied by behavioral, psychiatric, and motor disturbances.

Dementia is a nonspecific clinical syndrome, related to several illnesses of different etiology. Three categories of disease have been identified in which dementia is a clinical manifestation. First, there are degenerative brain diseases of unknown etiology, which are referred to as primary degenerative dementias in the Diagnostic and statistical Manual (DSM-III) of the American Psychiatric Association (1). In most cases, patients with this type of dementia are found, at autopsy, to have the histopathological changes (neuritic plaques and neurofibrillary tangles) which are characteristic of Alzheimer's disease (AD) (2). Therefore, this condition, when it occurs in old age, is often referred to as senile dementia of the Alzheimer type (SDAT). One of the major features of SDAT is a marked reduction of choline acetyltransferase (CAT) in the cerebral cortex. CAT is the enzyme responsible for the synthesis of acetylcholine which, 
in turn, is a neurotransmitter implicated in higher mental function in the brain $(3,4)$.

The second category of disease in which dementia is a distinctive manifestation is arteriosclerotic brain disease, referred to as multi-infarct dementia (MID). In patients with this type of disease, multiple infarcts destroy brain tissue in scattered areas of the brain, resulting in a dementia syndrome accompanied by focal signs and symptoms, with a relative preservation of personality $(3,5)$.

Finally, dementia may be present in patients with other neurological diseases (e.g., Parkinson's disease, multiple sclerosis), and in patients suffering from nutritional deficiencies, central nervous system infection, brain trauma, toxic-metabolic disturbances, alcoholism, or brain tumor $(1,6,7)$. A small proportion of these dementias are potentially reversible.

It is estimated that about $50 \%$ or $60 \%$ of elderly demented patients suffer from $A D, 10 \%$ to $15 \%$ have MID, while the remaining patients suffer from mixed $A D$ and MID or one of the potentially reversible types of dementia $(4,8,9)$.

\section{ETIOLOGY}

Advancing age is an acknowledged risk factor for SDAT and some data suggest that women are at higher risk (10-12). There is strong evidence for a genetic influence on SDAT risk, in that SDAT and Down's syndrome are more common among relatives of patients with SDAT (13-17), and in that 
virtually all individuals with Down's syndrome who survive to age 40 or 50 are found, at autopsy, to have the plaques and tangles characteristic of $A D(16,18,19)$. The pattern of inheritance is consistent with an autosomal dominant mode of transmission with incomplete penetrance (20). Recent work (21) suggests that the genetic defect causing familial AD may be located on chromosome 21 .

Several other hypotheses have been proposed concerning the etiology of SDAT. The viral hypothesis is based on analogy with several transmissible degenerative neurologic disorders with long incubation periods (22). However, up to now, attempts to transmit $A D$ experimentally to nonhuman primates have been unsuccessful $(23,24)$. Since abnormalities in cellular and humoral immune activities have been reported in patients with $A D$, and since the senile plaques found in the patients' brains are made up largely of amyloid, immunologic factors have been suggested in the etiology of $A D$ (23). However, there is currently no empirical evidence to support this hypothesis. Finally, several environmental agents, notably aluminum, have been studied in relation to SDAT $(4,24-28)$; however, no conclusive statements about possible environmental causes can be made at this time. Furthermore, little is known about the incidence of SDAT in different racial, social, or occupational groups, or in different geographic regions.

Several case-control studies of SDAT have been carried out in which numexous toxic, infectious, and environmental 
exposures were examined (29-34). A history of head injury was reported more frequently for cases than controls in some but not all of the studies in which this factor was considered. However, as in all case-control studies of this type, recall bias may explain the findings (23). In one study (29), thyroid disease was found to be associated with $\mathrm{AD}$ among women; however, this finding was not confirmed by subsequent studies. A history of cigarette smoking was found to be more frequent among cases than controls in the one study in which this factor was examined (33). Because of small sample size and the poor quality of historical data. obtained from surrogate respondents, results from these case-control studies have generally been inconclusive (20). MID is equally common in men and women (35). The frequency of the disease increases with age, up to about the age of 50 years (5). Furthermore, there is some evidence that genetic factors may play a role in this type of dementia (36). The disorder is almost always accompanied by a history of cardiovascular disease, stroke, or hypertension $(35,37,38)$. Smoking and obesity are suspected factors in the etiology of MID $(5,38)$. Furthermore, as many as $30 \%$ of MID patients have overt or occult diabetes mellitus (39).

\section{DIAGNOSIS}

The DSM-III criteria for dementia are: A. Loss of intellectual abilities of sufficient severity to interfere with social or occupational functioning. B. Memory impair- 
ment. c. One or more of the following: (i) impairment of abstract thinking; (ii) impaired judgment; (iii) other disturbances of higher cortical function (e.g., aphasia, apraxia, agnosia); (iv) personality change. D. No clouding of consciousness. E. Evidence of a specific organic factor or the possibility of ruling out non-organic mental disorders (1). The presence of dementia is established by mental status examination and by careful history-taking from the patient and his or her family or close friends $(8,40)$. Confirmation of dementia, especially in the early stages, is often complicated by the fact that changes in cognitive function may be very subtle, may be denied by the patient, and may be difficult to quantify in the absence of knowledge of premorbid cognitive status $(8,41)$. Patients rarely complain specifically of symptoms characteristic of dementia, but may present with somatic and affective symptoms that point to other diagnoses (42). The two most important differential diagnoses to be considered are memory loss associated with normal aging, and various psychiatric disorders, notably depression. Follow-up periods of at least six months may be necessary to confirm that "benign senescent forgetfulness" (43) or affective disorder are not the cause of the observed cognitive decline.

After the presence of dementia has been confirmed, the clinician attempts to identify the underlying disease process. Using neurological examination, laboratory tests, and imaging techniques, MID and secondary dementias can often be 
diagnosed. If no specific etiology is identified, a presumptive diagnosis of $\operatorname{SDAT}$ is made $(6,13)$. However, a definitive diagnosis of Alzheimer's disease can only be made on the basis of brain biopsy or autopsy.

\section{CLINICAL COURSE}

MID and SDAT often have different clinical characteristics. In patients with SDAT, the clinical course as a whole is relatively smooth, although the rate of disease progression may vary greatly. Some individuals show a steady, severe decline in cognitive function over one or two years, while others regress more slowly. The average duration of SDAT from diagnosis to death is estimated to be between five and seven years, with a range of one to 10 years $(40,44-46)$. Reisberg et al. (47) have described six stages of cognitive decline in SDAT. The forgetfulness stage is characterized by subjective complaints of memory deficit, with no objective evidence of memory deficit on clinical interview. In the early confusional stage, the patient may manifest decreased performance in demanding employment and social settings and may have difficulty concentrating, remembering names, retaining information from written material, and travelling to an unfamiliar location. In the late confusional stage, there may be deficits with respect to knowledge of recent or current events, memory of personal history, ability to perform serial subtractions, and ability to travel and handle finances. In the early dementia phase, 
the patient may become disoriented in time or space and may have difficulty carrying out simple self-care tasks such as dressing. The middle dementia phase is characterized by personality and emotional changes, and by an inability to recall recent events of one's own life, and the names of close family members. The patient may be unaware of his or her surroundings, and may require assistance with many activities of daily living. In the late dementia stage, the patient requires assistance with toileting and feeding, and all verbal abilities and basic psychomotor skills are lost. In contrast, the clinical course of MID is characterized by abrupt onset, stepwise deterioration, frequent fluctuations, nocturnal confusion, and emotional lability (48). The earliest signs are loss of operational judgment and impairment of memory. In later stages of disease, there is general deterioration of intellectual function often accompanied by dysarthria, dysphagia, and generalized rigidity. Furthermore, MID is often associated with behavior disturbances, such as impulsiveness and agitation, as well as depression and delusional syndromes (35). The mean duration of the disease from diagnosis to death is about five years (45) .

Life expectancy among patients with dementia is lower than in the age-matched normal population. Five-year survival subsequent to the diagnosis of SDAT in elderly individuals has been found to be about $80 \%$ or $90 \%$ of expected $(46,49)$. Male sex, severe behavioral impairment, and early 
onset have been found to predict poor survival $(46,49,50)$, whereas severe cognitive impairment has not (49). For MID, life expectancy is lower than for SDAT. A six-year survival rate of $21 \%$ has been found, compared to an expected rate of $45 \%(45)$.

\section{TREATMENT}

Pharmacologic agents that can retard or reverse the cel?.ular or clinical manifestations associated with SDAT are not yet known, although a considerable amount of research is being done in this area (51). As for MID, it is not possible to recover function in infarcted brain tissue, although aspirin may prove to be effective in maintaining or improving cognitive status (52).

In the absence of an effective pharmacotherapeutic strategy, management goals for demented patients involve maintaining the patient's safety, general state of health, independence, and dignity, avoiding catastrophic reactions and injury to others, supporting those who care for the patient, and slowing or compensating for the progressive decline in cognitive function $(4,53,54)$. Close medical surveillance is necessary, since a demented patient with concomitant physical illness may not be able to communicate his or her pain or discomfort (53). Counseling can help to reassure and support the patient and his or her family $(4,6)$. Finally, day care can help the patient and the family to cope with the problems of dementia, and may encourage the 
maintenance or improvement of the patient's physical, cognitive, emotional, and social condition $(4,55)$.

\section{OCCURRENCE}

Given the importance of dementia as a clinical and social problem, it may be surprising that valid descriptive data are not more abundant. Routinely collected hospitalization data cannot be used to approximate incidence rates, since many cases are not hospitalized. Death certificates cannot be used to determine mortality rates, since dementia, SDAT, and MID are rarely cited as the cause of death $(11,56)$. Cross-sectional surveys are expensive and difficult to carry out, while longitudinal studies require even more time and resources in order to ensure adequate follow-up of subjects over long periods. Also, investigators wishing to carry out population-based studies must succeed in accurately diagnosing dementia on the basis of a single interview, often administered by a lay person, and without the benefit of clinical or neuropsychological assessment procedures.

\section{A. Incidence}

There have been few studies on the incidence of dementia, and the studies which have been done have yielded variable results. Schoenberg et al.'s recent study $(12,57)$ provides the only population-based estimates of the incidence of dementia in the United states. The investigators 
ascertained all cases of dementia which came to medical attention between 1960 and 1975 in Rochester, Minnesota, and estimated that the annual incidence rates (per 100,000) were 96 among those aged 60 to 69 years, 531 among those aged 7079 years, and 1,432 among those aged 80 years or more.

\section{B. Prevalence}

Studies of prevalence of organic brain syndromes, carried out in northern Europe, the British Isles, and the United states in the past 35 years, have yielded widely inconsistent results. The large differences among results from different studies can probably be partly explained by real disparities between geographic regions in the frequency of dementia among the aged. Variation in the rates may also be affected by differences in the average duration of disease, by variations in the overall age-specific mortality rates in different places and at different times, by factors influencing incidence rates (58), by the use of widely differing definitions, diagnostic criteria and methods of case ascertainment, and by differences in the age structures of the populations studied $(59,60)$. On the basis of the results of 22 published studies, Jorm et al. (60) developed a statistical model to predict the prevalence of moderate or severe dementia for different ages. Application of the model yielded the age-specific estimates of prevalence shown in table 1 . 


\section{Table 1*}

Estimated** prevalence rates of dementia, by age

\begin{tabular}{lc} 
Age-group & Estimated prevalence $(\%)$ \\
\hline $60-64$ & 0.7 \\
$65-69$ & 1.4 \\
$70-74$ & 2.8 \\
$75-79$ & 5.6 \\
$80-84$ & 10.5 \\
$85-89$ & 20.8 \\
$90-95$ & 38.6 \\
\hline
\end{tabular}

* From Jorm et al. (60)

** Estimates were derived from a statistical model using data from 22 published studies. 
Data from a longitudinal study carried out in a rural county of sweden (10) indicate that the prevalence of dementia has been rising over time, probably due to the fact that the average duration of the disease has been increasing (61). Clearly, the absolute number of cases is growing, and will continue to grow, because of the increasing number of persons at risk. In Canada, the proportion of the population aged 65 or more was $7.8 \%$ in 1951 and $8.7 \%$ in 1976 ; it is estimated that, by 2001 , this proportion will reach $12.1 \%$ (62). It is projected that, in Quebec, the number of people between the ages of 60 and 74 will increase by $86 \%$ from 1979 to 2000 , whereas the number of people aged 75 or more will increase by $150 \%$ (63). On the basis of projected demographic changes, it has been estimated that the number of cases of dementia in Canada will be $73 \%$ more in 2025 than in 1980 (64).

\section{Social and economic impact}

The majority of people suffering from a dementing disease live in the community, often cared for by a close family member, usually the spouse or an adult child $(65,66)$. It has been estimated that for every American suffering from dementia, as many as three close family members are affected by the burden of caring (67). The elderly demented often require specialized medical, social, and home care services; therefore, dementia has important implications in terms of the cost of the health care system. For example, Huang et 


\begin{abstract}
al. (68) estimated that the total, direct annual cost of senile dementia in the United states is $\$ 13.3$ billion. The indirect cost for community home care is $\$ 31.5$ billion, while the costs associated with premature death and loss of productivity due to dementia are about $\$ 43.2$ billion. Thus, dementia has, and will continue to have, an important impact on the planning of health services and on health care costs.
\end{abstract}


CHAPTER II

CAREGIVING AND HEALTH

\section{BACKGROUND}

Living with and caring for a dependent demented old person constitutes a situation of chronic stress for the individual who provides the care. Thus, the study of the effects of caregiving on health fits easily into the field of investigation concerning the causal link between stress and health status. In the following paragraphs, a theoretical framework defining the stress-health association will be summarized, and an overview of some of the studies which have been carried out in this field will be given.

stress is usually defined in terms of an organism's ability to maintain homeostasis. For example, Caplan (69) defines stress as a condition in which "...there is a marked discrepancy between the demands made on an organism and the organism's capability to respond, the consequences of which will be detrimental to the organism's future in respect to conditions essential to its well-being... by 'demands' I mean the loss or threatened loss of appropriate levels and quality of essential information and energy".

Kasl's definition (70) is similar but more succinct: stresses are "demands that tax the adaptive resources". Kasl also points out that, in common usage, the term "stress" has connotations both of stimulus and of response. Different authors use the term to denote: (i) an environmental condi- 
tion; (ii) the appraisal of an environmental situation; (iii) a response to the environmental condition or its appraisal; or (iv) an interaction between environmental demands and the person's capacity to meet these demands. In the present study, stress is conceptualized as being an environmental condition, that is, a situation external to the individual which taxes his or her ability to adapt, and which may result in undesirable outcomes.

When the organism's homeostasis is threatened by a stressor, it may go into a state of disequilibrium or breakdown. This state may be temporary, pending readjustment via the organism's adaptive capacities, or it may cause a more profound disturbance leading to a pathological state (71). Specific types of stressors do not necessarily lead to specific pathologic states. Thus, individuals exposed to stressful situations are thought to suffer an increase in nonspecific vulnerability to physical and mental illness (72). The nature of the illness is determined by the complex interactions between the nature of the stressful event and of its evolution, and the individual's response to the event (69) .

The pathway linking stress and health status is not well understood. In its simplest form, the paradigm can be depicted as follows (70): 


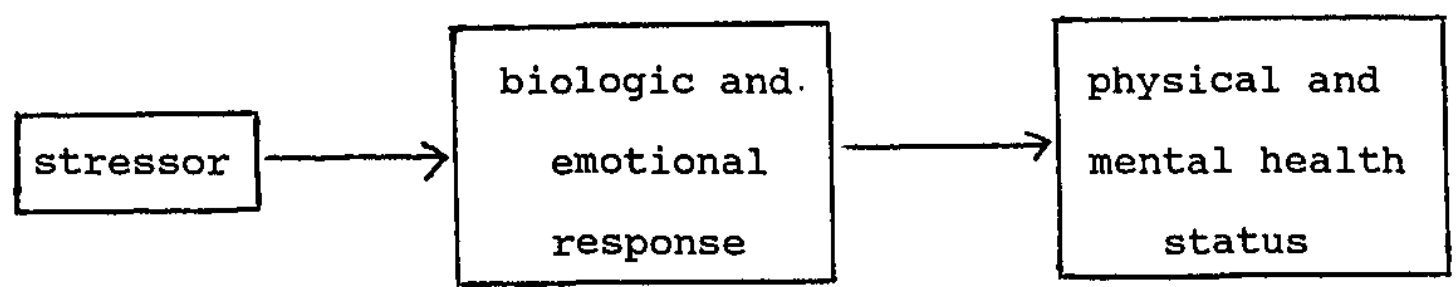

Considerable laboratory evidence exists concerning the biologic effects of acute stressors, and various physiologic indicators of stress (e.g., corticosteroid and catecholamine levels) are well known (70). However, the complex mechanism by which chronic exposure to stress affects pathogenesis has not been satisfactorily described in humans (73).

An individual's adaptive response to a stressful situation is referred to as coping. Coping refers to the complex set of cognitive and behavioral processes which moderate the impact of stressors on physical, social, and emotional functioning (74). From a physiologic point of view, two coping mechanisms, active and passive, have been identified. During active coping, the defense response predominates and the individual feels it necessary and possible to fight against threats. During passive coping, the conservation-withdrawal response predominates and the individual feels powerless to overcome the stressful situation (75). It has been postulated that these two types of coping mechanism are accompanied by different types of neurohormonal response (73). From the psychological point of view, two types of coping have been defined: problem focused coping (in which overt behaviors are directed at the stressful situation), and emo- 
tion focused coping (in which feelings of distress are reduced by managing emotional response) (75).

Among humans, social support is believed to play a significant role in buffering the effect of stress on health. Numerous physical and psychological disorders have been studied in relation to stress and social support (76) and, despite some serious conceptual and methodological difficulties (77), there is consensus concerning the ability of a supportive social network to protect the individual from the negative effects of stress.

The effects of stress on health, often taking account of coping efficacy and social support, have been studied in three different ways. In the first type of study, the association between exposure to stressors and the onset of specific diseases is investigated. The disorder most frequently studied with respect to stress has been cardiovascular disease (CVD). Urbanization, geographic mobility, and intercultural change have been found to have an impact on CVD incidence. Furthermore, conjugal bereavement has been shown to cause an excess of CVD mortality in the period shortly following the spouse's death (73). Finally, clusters of certain stress-associated symptoms and complaints (e.g., poor sleep, exhaustion, inability to relax) are associated with the incidence of myocardial infarction (70).

In the second category are studies in which stress is quantified on the basis of an inventory of recent life events, such as divorce, illness, unemployment, etc. (78). 
Numerous studies of this type have been carried out in the last 20 years and, in many of these, a significant link was found between the number of recent stressful life events and the onset of psychiatric illness (79) or physical health disorders (70). A large number of these studies have been criticized, however, on conceptual and methodological grounds: confounding of life events with outcome measures, the need to establish the temporal association between events and outcomes, and underreporting of life events $(70,78)$

The third type of approach to the study of stress and health has focused on the impact on health of specific stressful situations. For example, a large body of research exists on the health consequences of widowhood and divorce, separation from parents in childhood, and war and natural disasters (69). This is the approach which will be adopted in the present study.

\section{STRESSFULNESS OF CARING FOR A DEMENTED RERSON}

The effects of caregiving have been studied in relation to many chronic diseases, particularly diseases for which community care is a cost-effective alternative to institutionalization. For example, studies on the families of community-residing schizophrenics $(80,81)$, stroke patients (82), and chronically and terminally ill children (83-85) have provided information about the strains experienced by these caregivers. In the field of gerontology, several 
studies have been reported in which the burden of caring for a frail elderly person was examined (86-92). However, the effects of dementia are likely to be different from those of other diseases. In fact, it has been suggested (93-95) that caring for a close relative, especially a spouse, who has become demented is one of the most stressful situations which can be encountered. It may be even more stressful than the death of the victim, since the caregivers must adjust to the loss of their relative as they knew them, and yet must face a chronic situation of caring for the patient's most basic needs (96). The following characteristics of dementia make it a particularly difficult disease to tolerate:

(a) The demented person gradually loses his or her ability to carry out the usual activities of daily living. Thus, the caregiver must take over more and more domestic tasks and financial responsibility. The caregiver must also help with self-care tasks, such as bathing, dressing, and eating. Frustration and physical exhaustion may result.

(b) Dementia is a chronic, irreversible, degenerative disease, with little hope for an effective cure in the foreseeable future. The caregiver may therefore become demoralized and depressed, and may develop symptoms of anxiety associated with worry about the future.

(c) Although the etiology of dementia is unknown, the possibility of infectious or hereditary transmission is widely discussed in the scientific and popular press. This may provoke anxiety over the possibility that the condition 
will be transmitted to the caregiver or other family members.

(d) One of the behavioral disturbances associated with dementia is night wandering. Caregivers may therefore suffer from sleeplessness, chronic fatigue, and associated psychological problems.

(e) The demented person may lose the ability to recognize the people in his or her environment, even close family members. This may cause anger and resentment in the caregiver, because of the lack of acknowledgment of his or her efforts.

(f) The demented person may become incontinent and may exhibit inappropriate social and sexual behavior. This may cause friends and relatives to feel uncomfortable in the presence of the patient, and to gradually decrease the amount of time spent at the patient's home. Thus, the caregiver may become socially isolated.

(g) Since the demented patient may exhibit behaviors which are dangerous to the patient or to others, he or she may require constant supervision. If the caregiver curtails normal work or recreational activities, increased social isolation may result.

(h) The intensity and chronicity of the demented person's symptoms may engender a situation in which serious family conflicts arise or are rekindled (97).

Another factor which distinguishes caregiving for a person with dementia from caregiving for patients with other 
conditions is that the caregivers, themselves, are often old, and may not be well prepared to tolerate the physical and psychological strain of caregiving. They may, therefore, be particularly vulnerable to the effects of this life stress.

A conceptual model of the relationship between dementia and caregiver health is shown in figure 1. This nodel is adapted from the work of Morycz (98), Wilder et al. (99), and Montgomery et al. (100), and is consiscent with most theoretical work and empirical findings in this field. In this framework, the health of the caregiver is influenced by his or her age, sex, ethnic group, and prior health status, and by characteristics of the caregiving situation which are, in turn, influenced by characteristics of the impaired person. Characteristics of the demented patient and of the caregiver affect the caregiver's coping efficacy and social support system which, in turn, may influence the caregiver's health. 
Figure 1

A model for studying the relationship between dementia isd caregiver health

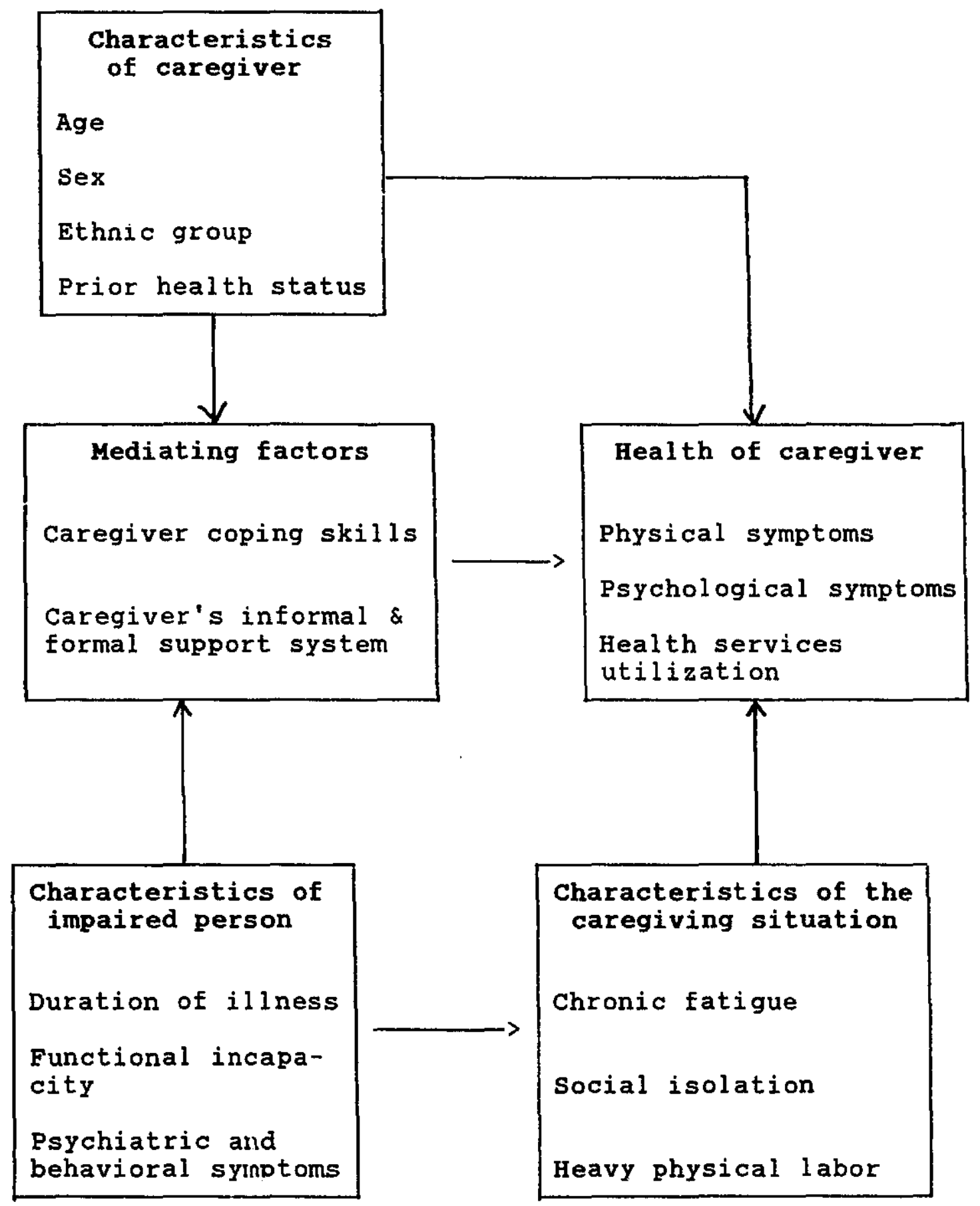




\section{CHAPTER III}

\section{LITERATURE REVIEF*}

In the present chapter, a critical review of studies on the effect of caring for a demented elderly person on the caregiver's physical and psychological health will be presented. The results of the studies will be examined from three major viewpoints: the frequency of health problems among caregivers, changes in the frequency of problems over time, and factors which affect the frequency of problems. These findings will be summarized, methodological characteristics of the studies will be presented, and theoretical considerations will be discussed.

\section{METHODS USED TO IDENTIFY, REVIEW, AND SUMMARIZE STUDIES}

\section{A. Identification of studies}

The scientific literature in medicine and social science since 1970 was searched, in order to identify all studies on the health of persons giving care to the dependent elderly. An initial automated search was carried out, using MEDLINE and PSYCINFO; subsequently, the reference lists of the identified articles were manually examined in order to identify additional papers. Studies were excluded if less than $80 \%$ of the study patients suffered from

\footnotetext{
* An earlier version of this chapter was published as a paper in the Journal of Clinical Epidemiology (see appendix i).
} 
Alzheimer's disease or some other dementing disorder, unless the specific purpose was to compare health problems among caregivers of demented and nondemented persons. The choice of $80 \%$ as a minimum proportion of demented patients, although arbitrary, corresponded to the goal of selecting studies in which all or most of the patients were demented. Anecdotal, nonquantitative reports were excluded as were studies where the major focus was on institutionalization of the demented patient, on service utilization in households where there is a demented elderly person, or on the evaluation of interventions aimed at alleviating problems among caregivers. Studies which aimed simply to list the kinds of problems which caregivers found particularly difficult to cope with were also eliminated. No attempt was made to exclude studies on the basis of the type of health variable studied: thus, all studies which included a measurable outcome in terms of physical, psychological, or social wellbeing of caregivers were considered. There were 46 reports $(96,99,101-144)$, all published since 1980, which met the above criteria. The study samples and a summary of the major findings of these 46 reports are described in appendix 2. The distribution of these studies, by year of publication, is shown in figure 2 . 
Figure 2. Studies on the health of caregivers of persons with dementia, by year of publication

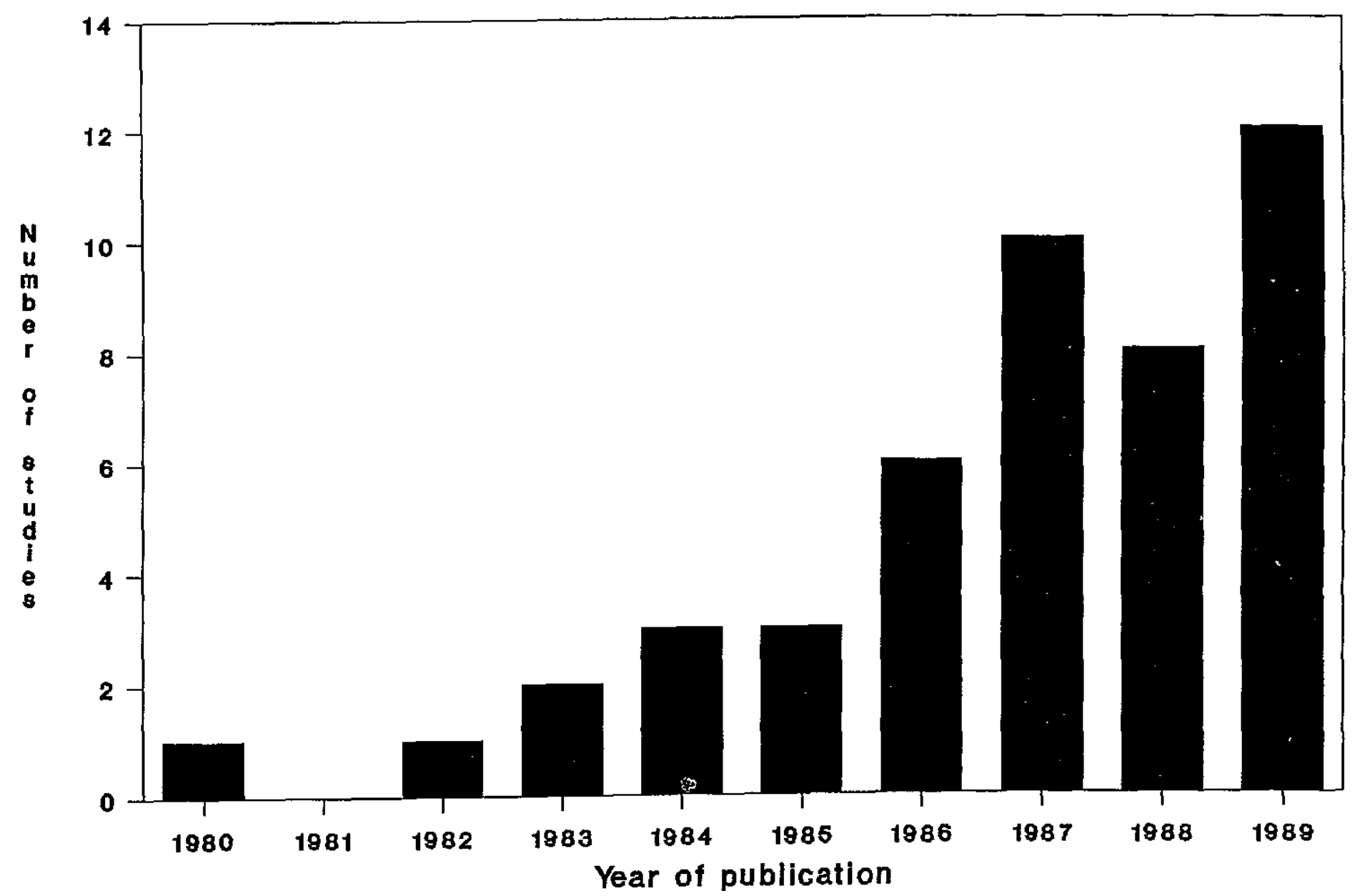




\section{B. Methodologic review of studies}

Six aspects of the design and analysis of the 46 studies were examined. First, the source of demented study subjects was classified into one of four categories: (i) general population; ( $i$ ) referrals to a medical or diagnostic service; (iii) users of a specialized service (e.g., day hospital, specialized treatment center); and (iv) volunteers (usually recruited through the media, selected physicians, community groups, and/or chapters of the Alzheimer's disease society). In several cases $(110,119,131,132,137,138,140)$, subjects were recruited from two sources (e.g., a specialized service and the Alzheimer's disease society): the subjects of these studies were classified as volunteers. Second, the studies were categorized according to the number of study subjects. Studies which included $8 \mathrm{E}$ subjects or more were considered to be large enough to produce reliable results. Although rather arbitrary, this cutoff point was chosen because a sample size of about 85 is required to detect a moderately-sized correlation between two variables (Pearson correlation coefficient of 0.30 ) with power of $80 \%$ and risk of type I error of 0.05 (145). In studies where two or more groups of unequal size were included, the study was classified according to the number of caregivers of patients with dementia.

Third, studies were classified according to whether they were cross-sectional or included a follow-up period. Fourth, studies were divided into those which included a 
comparison group and those which did not. Studies in which results for caregivers were compared with normative data or with data from earlier surveys $(109,120,143)$ were not considered to include a comparison group.

Fifth, studies were categorized according to whether a multidimensional measure was used as the outcome variable. Multidimensional measures were defined as scales designed to assess global levels of caregiver strain or burden. These scales usually combine various aspects of burden, such as physical health, psychological well-being, and financial problems, into one overall score. Measures of specific constructs such as depression, life satisfaction, or negative family relationships were not considered to be multidimensional measures.

Finally, studies were categorized according to whether an attempt was made to control for confounding factors. If some factors were controlled for (by stratification or statistical analysis), but it was felt that important potential confounders had been neglected, the study was classified in the category "partial control".

\section{Substantive review of studies}

The 46 identified research reports were reviewed in the light of three major questions concerning dementia and caregiver health: (1) What is the frequency of health problems among caregivers for the demented elderly relative to the risk among noncaregivers? (2) How does the frequency or 
severity of health problems among caregivers change over time? (3) Which characteristics of the caregiver and of the demented patient tend to be associated with higher levels of morbidity among the caregivers?

\section{RESULTS AND DISCUSSION OF LITERATURE REVIEW}

\section{A. Overview of the studies}

As can be seen from appendix 2, the 46 identified studies were characterized by a diversity of outcome variables. More than 20 different outcomes were studied, the most common ones concerning some aspect of mental health. The large number and range of outcomes which have been considered by different investigators suggest that there is little conceptual clarity about what the impact of caregiving might be. This, in itself, is an interesting finding and suggests that this research field would benefit from a more solid theoretical basis.

\section{B. Methodological characteristics of the identified studies}

Methodoiogical characteristics of the 46 studies are shown in table 2. Only two of the studies reviewed used a population-based study sample whereas, in about $9 \%$ of the studies, the source of demented subjects was a medical or diagnostic service. In the remaining studies, subjects were selected from sources which would be likely to produce a 
Table 2

Methodological characteristics of 46 studies reviewed

\begin{tabular}{|c|c|c|c|}
\hline Characteristic & $\begin{array}{l}\text { Reference } \\
\text { numbers }\end{array}$ & $\begin{array}{l}\text { Studies } \\
\text { Number }\end{array}$ & $\%$ \\
\hline \multicolumn{4}{|l|}{$\begin{array}{l}\text { Source of demented } \\
\text { subjects }\end{array}$} \\
\hline General population & 99,133 & 2 & 4.3 \\
\hline Medical service & $108,112,113,135$ & 4 & 8.7 \\
\hline Specialized service & $\begin{array}{l}101-103,107,117,120- \\
122,127,130,136,141 \\
142\end{array}$ & 13 & 28.3 \\
\hline Volunteers & $\begin{array}{l}96,104-106,109-111 \\
115,116,118,119,123- \\
126,128,129,131,132, \\
134,137,138,140,143 \\
144\end{array}$ & 25 & $54 \cdot 3$ \\
\hline Other & 139 & 1 & 2.2 \\
\hline Not stated & 114 & 1 & 2.2 \\
\hline \multicolumn{4}{|c|}{ Number of study subjects } \\
\hline 85 or more & $\begin{array}{l}99,102,105,109,114 \\
116,120,121,129,133 \\
134,137,139,143,144\end{array}$ & 15 & 32.6 \\
\hline Fewer than 85 & $\begin{array}{l}96,101,103,104,106- \\
108,110-113,115,117- \\
119,122-128,130-132, \\
135,136,138,140-142\end{array}$ & 31 & 67.4 \\
\hline \multicolumn{4}{|l|}{ study design } \\
\hline Longitudinal & $102,104,126,138$ & 4 & 8.7 \\
\hline Cross-sectional & $\begin{array}{l}96,99,101,103,105- \\
125,127-137,139-144\end{array}$ & 42 & 91.3 \\
\hline
\end{tabular}


Table 2 (continued from previous page)

\begin{tabular}{|c|c|c|c|}
\hline Characteristic & $\begin{array}{l}\text { Reference } \\
\text { numbers }\end{array}$ & $\begin{array}{l}\text { Stuc } \\
\text { Number }\end{array}$ & \% \\
\hline \multicolumn{4}{|c|}{ Comparison group } \\
\hline Yes & $\begin{array}{l}111-113,117-119,122, \\
127,128,133,139,142\end{array}$ & 12 & 26.1 \\
\hline No & $\begin{array}{l}96,99,101-110,114- \\
116,120,121,123-126, \\
129-132,134-138,140, \\
141,143,144\end{array}$ & 34 & 73.9 \\
\hline
\end{tabular}

Multidimensional outcome variables

None

$96,99,102-104,106$,

54.3

$109,111,113-115$,

$119,123-128,133,135$,

$139,140,142-144$

with others

$101,108,112,116-118$,

$120,121,129,131,132$,

13

28.3

134,137

only

$105,107,110,122,130$,

$136,138,141$

8

17.4

Control of confounding

Multivariate

analysis

$96,99,101,102,104$,

15

32.6

$106,108,109,114,115$,

$117,119,125,126,133$

Partial control

$110-112,113,116,118$,

12

26.1

$120,121,123,134,141$,

143

No control

$103,105,107,122,124$, $127-132,135-140,142$, 
sample which was highly unrepresentative with respect to important study variables: caregivers of patients receiving specialized services (such as those offered by day hospitals), caregivers participating in some specialized support group, or volunteer subjects recruited through media and community publicity. Since persons who require specialized services or who volunteer for participation in research projects may be unusually resourceful or unusually distressed, one should be cautious in generalizing the results of these studies to the majority of community caregivers for dementia patients $(146,147)$.

The sample sizes used in the studies which were reviewed ranged between 11 and 586, with a median of 54 subjects. About one third of the studies had sample sizes smaller than 40 whereas another third had sample sizes between 40 and 84. Thus, only about one third of the studies had sample sizes large enough to detect a moderately-sized correlation between two variables with $80 \%$ power. A heavy reliance on significance testing in the absence of sufficient sample size may have produced very low power in many of the studies and this may, in some cases, explain the inconsistency in the results from study to study.

only four of the studies used a longitudinal study design whereas all of the others were cross-sectional. It should be remembered that data obtained from cross-sectional studies cannot be used to infer causal relationships, since the temporal sequence of events cannot be determined. An- 
other problem with cross-sectional studies is the serious possibility of selection bias. A cross-section of patients and their caregivers represent a group of "survivors", in which those who took up the caregiving role but had to abandon it along the way are not included. Thus, a sample of caregivers chosen at one point in time may not be representative of the entire cohort of caregivers of patients diagnosed around the same time. The longer the duration of the dementia, the more likely it is that the subjects represent a particularly healthy or resistant group. This phenomenon, which, if confirmed, could be referred to as a "healthy caregiver effect", is conceptually similar to the "healthy worker effect" observed in occupational health research (148).

A comparison group was included in 12 of the studies. In six of these studies $(111-113,119,128,133)$, caregivers were compared with noncaregivers whereas, in six studies $(117,118,122,127,139,142)$, caregivers for demented patients were compared with caregivers of patients with other impairments. In the absence of a comparison group, it is impossible to quantify the impact of caregiving, since "background" levels of morbidity cannot be controlled for. Comparison groups are also necessary if one is to study effect modification, that is, the differential effect of certain factors on caregivers and noncaregivers.

In more than $45 \%$ of the studies, a multidimensional measure of caregiver burden or strain was used alone or in 
combination with other measures. These multidimensional scales are typically made up of a series of items related to physical, psychological, social, and financial problems and provide a summary score of the strain associated with caregiving. Some of the multidimensional scales are made up of subscales which can be used to characterize different facets of the caregiving experience, but most of the studies reviewed did not use the scales in this way. Although summary scores have been widely used and provide a convenient way of obtaining a global measure of overall impact, they are of little value in understanding specific dimensions of caregiving. Furthermore, since the questions in these scales usually refer specifically to the caregiving situation, they cannot be used in studies where the objective is to compare caregivers and noncaregivers. Another drawback of these scales is that the questions often explicitly require the respondent to relate caregiving to its impact. For example, the caregiver may be asked whether caring for the demented patient has affected his or her social activities. Therefore, the stressful situation and its impact are intertwined, making it impossible to quantify the effect of the stressor on the outcome $(109,111,133)$.

Finally, almost $60 \%$ of the studies did not use an adequate analytic technique to control for potential confounding factors. Lack of control of confounding could lead investigators to identify spurious associations between vari- 
ables or to overlook significant associations between variables.

\section{c. Substantive findings of the reviewed studies}

(a) Frequency of health problems:

only six of the studies reviewed provided information on the frequency of hea.lth problems among caregivers relative to the frequency anong noncaregivers. Eagles et al. (112) found that supporters of demented and nondemented subjects did not differ with respect to their scores on the General Health Questionnaire (GHQ), a widely-used measure of psychiatric morbidity and emotional distress. However, supporters of demented patients had much higher scores on the Relatives' Stress Scale (RSS), and marginally higher scores on the Relatives' Mood Scale (RMS). This finding is not surprising, since the RSS and RMS were developed specifically to measure the impact of caring for a demented relative and the questions are phrased in such a way that caregivers for the demented would be more likely to report distress. In another study by the same group of investigators, Eagles et al. (113) reported no significant difference between spouses of demented and nondemented elderly subjects with respect to various measures of psychological health. This negative finding may be explained by the fact that the demented subjects in this study did not suffer from a high level of behavioral disturbance. Haley et al. (111) found that care- 
givers had more chronic conditions, prescription medications, doctor visits, and depression than noncaregivers. They also had lower self-rated overall health, lower life satisfaction, and worse family relationships. There was little difference between the groups with respect to their scores on a health status questionnaire, the frequency of physical symptoms, or the number of social contacts and close relationships. Kiecolt-Glaser et al. $(119,128)$ found no significant differences between caregivers and noncaregivers with respect to physician visits, sick days, self-rated health, sleep habits, social support or loneliness. However, caregivers had significantly more depression, lower life satisfaction, and worse mental health. They also had significantly lower immune function than noncaregivers on four out of six measures of immune function; the differences could not be explained by differences in nutritional status. Moritz et al. (133) found that spouses of cognitively impaired subjects had significantly higher depression scores than spouses of normal subjects, after controlling for several confounding variables. Caregivers were also more limited than other spouses in their participation in certain social activities outside the home. However, sleep complaints were not more common among caregivers. In summary, given the small number of studies and the diversity of outcomes studied, it is difficult to draw reliable conclusions about the magnitude of the impact of caregiving on health. 
In six studies, caregivers of patients with dementia were compared to caregivers of patients with other impairments. Drinka et al. (117) found no significant difference in depression scores between caregivers of dementia patients and caregivers of other severely impaired elderly patients. Similarly, Liptzin et al. (122) found no significant difference in the burden scores of caregivers of depressed and demented patients admitted to the geriatric unit of a psychiatric hospital. Birkel (118), on the other hand, found that caregivers of demented patients experienced more strain and psychological distress than caregivers of physically impaired patients. In the study by Whittick (127), daughters caring for a demented elderly parent had significantly higher GHQ scores than mothers caring for a mentally handicapped child or adult. She also found (142) that daughters had more negative perceptions of the caregiving role and were more inclined to favor institutional care. Scharlach (139), on the basis of a survey among employees of a large California insurance company, determined that caregivers of cognitively impaired older persons reported higher levels of physical, emotional and financial strain than carers for physically impaired older persons. They also reported more impact on employment-related events. In summary, the evidence concerning the impact of caring for patients with dementia as opposed to caring for patients with other health problems is inconclusive. 
(b) Changes in caregiver health over time:

only four studies have provided data on changes in caregiver health over time. Gilleard et al. (102) found, at three-month follow-up, a significant increase in the frequency of psychological symptoms but no change in physical health rating. Pagel et al. $(104,126)$ found that changes in depression over 10 months were small. Zarit (138) contacted spouses caring for a demented patient at home two years after initial interview and found that, among those whose spouse was still living at home, perceived burden had slightly decreased; among those whose spouse had been institutionalized, perceived burden had greatly decreased. Haley and Pardo (149) have proposed several models to predict changes in caregiver health over time. The first model is based on the "wear and tear" hypothesis. According to this model, both dementia patients and their caregivers experience a progressive deterioration in their functioning as the patient's symptoms worsen and the caregiver becomes more and more overwhelmed by the stressful situation. According to the second model, the caregiver learns to adapt to the caregiving situation despite progressive worsening of the patient's symptoms, and either stabilizes or improves in functioning over time; this model is called the "adaptation model". The third model is based on the "trait hypothesis". In this model, the caregiver's pre-existing level of coping skills, resources, and social supports allow him or her to maintain a constant level of functioning despite worsening 
of the patient's condition. Unfortunately, it is impossible, on the basis of the sparse evidence furnished by the existing literature, to refute or support the proposed models of change in caregiver health over time.

(c) Correlates of health problems among caregivers: In most of the studies reviewed, the objective was to identify correlates of various health problems among individuals caring for a demented person. A very large number of different correlates and outcomes were considered in the 46 studies reviewed: in fact, more than 200 different correlate/outcome associations were reported in these studies. Clearly, it would be nearly impossible to summarize the findings of these studies with respect to all variables which might be associated with health problems among caregivers. Therefore, only a small number of selected variables will be discussed.

CAREGIVER'S AGE. In five studies $(102,103,105,125,129)$, no association was found between the caregiver's age and the outcome variable. Fiore et al. (96) found that older caregivers had more psychological symptoms than younger caregivers, but that physical symptoms and depression did not vary much with age. In contrast, Gilleard et al. (121) found that younger supporters experienced more strain and burden than older supporters. Haley et al. (115) found that there was a significant negative correlation between caregiver age and self-rated health, but that there was no significant 
correlation between caregiver age and life satisfaction or depression. When interpreting these inconsistent results with respect to caregiver's age, several methodological factors must be kept in mind. First, age may be predictive both of greater health problems and of "survival" as a caregiver: older and sicker caregivers may be more likely to abandon the caregiving role and, therefore, to be underrepresented in cross-sectional samples. Second, different health outcomes may be affected in different ways by caregiver age: given the large variety of outcomes examined in these studies, the inconsistent results may not be surprising. Finally, the effect of increasing age on a large number of psychological and physical health measures is well known: what would be of more interest is the modifying effect of age on the association between caregiving and health. Effect modification can only be studied when a comparison group is included.

KINSHIP TIE BETWEEN CARER AND PATIENT. Several investigators have studied the variable "kinship tie" by, for example, comparing the health of caregivers who are close relatives of the patient with the health of caregivers who are more distantly related. The rationale for studying this variable is that those who are more closely related may experience more stress as a result of adopting the caregiving role than those who have a more distant kinship tie. However, it should be recognized that the variable "kinship tie" comprises three components: age, sex, and family close- 
ness. Therefore, in order to study the association between family closeness per se and caregiver health, it is essential to control for caregiver age and sex. Six investigators $(102,107,112,116,123,128)$ found no effect of kinship tie on various measures of caregiver health. Gilhooly (103) found no association between kinship tie and morale; however, the mental health of those who were closely related to the patient was poorer than those who were more distantly related. None of these studies adjusted for caregiver age or sex. On the other hand, George and Gwyther (109) found that spouse caregivers reported more doctor visits, lower self-rated health, more stress symptoms, more psychotropic medication use, lower affect balance, and less life satisfaction than nonspouse caregivers, even after adjusting for caregiver age.

SEVERITY OF PATIENT'S DISEASE. If the demented patient's disease is viewed as the stressor to which the caregiver is exposed, then it seems plausible that the more severe the disease symptoms, the more likely it is that the caregiver will suffer negative health consequences. However, the association between disease severity and caregiver health may be a complex one. There are at least three dimensions of disease severity in dementia: cognitive impairment, functional impairment, and behavioral disturbance. Caregivers may respond quite differently to these three manifestations of decline in the patient. In fact, it has been suggested that caregivers perceive behavioral problems as 
being more stressful than either functional impairment or cognitive symptoms $(114,150)$. This increased stressfulness may be related to the unpredictability and uncontrollability of behavioral disturbance (150), or to the fact that behavioral symptoms necessitate more care and supervision of the patient than do cognitive or functional deficits (114).

The empirical evidence regarding disease severity and caregiver health is conflicting. With respect to cognitive status, several investigators $(99,103,107,110,115,136)$ found no association between the patient's cognitive status and caregiver health. Eagles et al. (112) found a significant correlation between the patient's cognitive status and the Relatives' Stress Scale but not the Relatives' Mood Scale or the GHQ. The same investigators (113) found a significant correlation between the mental status scores of female patients and their husband's level of depression; however, there was no association between the patients' mental status scores and the caregivers' anxiety or GHQ score. Similarly, Moritz et al. (133) found that lower cognitive status among wives was significantly associated with depression among husbands, although lower cognitive status among husbands was not significantly associated with depression among wives. Deimling and Bass (114) found, using path analysis, that cognitive status was strongly associated with the patient's behavioral and functional problems which, in turn, had a strong influence on the caregiver's activity restriction, physical health, family relationships, and depression. 
Pruchno and Resch (137) determined that the association between the frequency of forgetful behaviors in the patient and impact on the caregiver was not linear. Thus, increases in frequency of forgetful behaviors from "none" to "sometimes" were associated with increased caregiver burden, perceived consequences of caring, and impact on social life. However, a high level of forgetful behavior was associated with lower caregiver impact. Thus, notwithstanding a few exceptions, it would seem that the association between the patient's cognitive status and caregiver health is not strong. Six investigators $(101,103,104,107,127,129)$ found no association between the patient's functional status and caregiver health. In one study, the patient's activity limitation was a significant predictor of perceived "inconvenience" of caregiving (99). Deimling and Bass (114) found that the patients' functional status was significantly correlated with the caregivers' activity restriction and physical health change but not with their family relationships or depressive symptoms. Haiey et al. (115) found that the patient's ability to perform basic activities of daily living (ADL) (such as bathing, eating, and walking) was not significantly correlated with caregiver's depression, life satisfaction, or self-rated health problems; the patient's ability to perform instrumental ADL (such as meal preparation, banking, and housework) was highly correlated with the caregiver's depression score but not with life satisfaction or self-rated health problems. In the study by Fitting et 
al. (108), the patient's impairment was associated with perceived burden among younger wives and older husbands only. Finally, Novak and Guest (130) observed a significant correlation between the patient's functional impairment and the caregiver's perception of burden. The large variety of outcome measures used in these studies may explain the diversity of results obtained. Also, it may be that the association between patient functional status and caregiver health is not strong and that large sample sizes would be required in order to identify statistically significant correlations.

Finally, in most studies $(99,101,102,106,109,112,114$, $119,121,128,131,134,136,137)$, a strong association between the severity of the patient's behavioral disturbance and caregiver health was found although, in two studies with small sample sizes $(107,115)$, no such association was found. overall, then, there seems to be some support for the hypothesis that behavioral manifestations of dementia are more predictive of problems for the caregiver than are cognitive or functional impairment.

SOCIAL SUPPORT. Objective and subjective dimensions of social support have been found to be associated with a large number of health measures, both in clinical samples and in the general population (151-154). However, contradictory results have been obtained concerning the effect of social support on well-being among caregivers. In six studies $(96,102,103,105,121,129)$, no such effect was identified. In 
seven other studies $(107,109,110,115,123,125,131)$, high levels of support were found to be associated with better caregiver outcomes. Pagel et al. (126), as well as KiecoltGlaser et al. (128), found that the amount of upset produced by the social network was positively correlated with depression, while the amount of perceived helpfulness of the social network was not correlated with depression. Social support was operationalized in very different ways (e.g., presence of a confidant, amount of instrumental help) in the studies that were reviewed, and this may explain the divergent findings. The caregiver's satisfaction with the social support he or she received was associated with better health in both of the studies in which this question was considered $(96,103)$.

It has been suggested that social support may be an effect modifier in the stress/health association by acting as a protective buffer for individuals experiencing a stressful situation while having little effect on those who are not exposed to stress $(77,155,156)$. Comparing caregivers and noncaregivers with respect to the effect of social support on health could shed light on the potential buffering effect of social support. In the only study which examined this phenomenon, Moritz et al. (133) found that social support was not a statistically significant effect modifier of the caregiving-depression association. Although the small number of subjects in the various subgroups limited the statistical 
power of this analysis, most of the associations were in the hypothesized direction.

\section{BUMMARY OF IITERATURE REVIEW}

In summary, despite the fact that there is now a relatively large number of studies on the impact of caring for an elderly person suffering from dementia, several important questions remain unanswered. Specifically, very little is known about the frequency of health problems among caregivers relative to noncaregivers, or about changes in caregiver health over time. Furthermore, although much information is available on correlates of health problems among caregivers, the large number of health variables studied and the methodological shortcomings of the studies (in particular, small sample size, cross-sectional study design, and unsatisfactory control of confounding factors) make it difficult to draw reliable conclusions from this information.

Investigators involved in studying the health consequences of caring for a demented elderly person are faced with numerous difficulties. First, the relationship between caregiving and health varies greatly from individual to individual, and from situation to situation. Thus, simple dose-response or stressor-outcome models are not likely to be adequate. Secondly, the relationship between health and various aspects of the caregiving situation is a dynamic one; one cannot assume that the factors which one chooses to 
study as independent variables will be stable over time. In fact, these factors may change as a function of the caregiver's health, producing a complex web of potentially confounded associations. Even in longitudinal research, the instability of predictor variables over time poses a serious challenge for the analysis and interpretation of results. Thirdly, difficult measurement problems plague this area of research and investigators may encounter difficulties in selecting or developing conceptually piausible, methodologically sound outcome measures. Finally, serious practical problems may arise when attempting to design methodologically adequate studies. In many communities, it may be difficult to identify adequate sampling frames, and sufficient numbers of study subjects may simply not be available. Finally, in longitudinal studies, attrition by hospitalization, institutionalization, or death is likely to be a substantial problem. The present study was designed to overcome some of the shoutcomings observed in the existing research. 


\section{CHAPTER IV}

\section{OBJECTIVES}

The major objectives of the study were to determine whether caregivers have a higher frequency of depressive symptoms and physical symptoms than noncaregivers, and to quantify the association between caregiving and the two outcome variables.

Two secondary research questions were also addressed: (i) Do certain characteristics of the caregiver (age, sex, ethnic group, education, chronic disease status, recent life events, social support, support satisfaction, coping skills, and kinship tie with the patient) modify the association between caregiving and the outcome variables? and (ii) Among caregivers, what is the strength of the association between the two outcome variables and characteristics of the demented patient's disease (severity of functional impairment, severity of cognitive impairment, degree of behavioral disturbance, and duration of the dementia)? 


\section{CHAPTER V}

METHODS

\section{OVERVIEW}

A cross-sectional design was used in which a group of caregivers for demented patients was compared with a group of noncaregivers. The caregiving group was made up of the close family members of demented patients seen at a geriatric assessment clinic. The noncaregiving group was made up of the close family members of elderly patients undergoing cataract surgery at the same hospital as the geriatric unit. Caregivers and noncaregivers were interviewed in order to assess the frequency of depression and physical symptoms, and to obtain all the other necessary data.

In the present study, an attempt was made to avoid most of the methodological shortcomings observed in previous studies, namely, small sample size, volunteer study samples, lack of comparison groups, inadequate control of confounding, and use of multidimensional outcome variables. However, the cross-sectional design may limit the validity of some of the study results. It should be mentioned that the present thesis represents one portion of a funded study of which the author is principal investigator and which is presently in progress. In this larger study, caregivers are reinterviewed one year after initial interview. Because of time constraints, only the results of the first wave of interviews were considered for the thesis. 


\section{BELECTION OF STUDY SUBJECTS}

The study sample was made up of two groups: caregivers (close family members of a group of elderly patients with dementia), and noncaregivers (close family members of a group of elderly patients who did not have dementia or other significant impairment). Identification of the study subjects proceeded in two steps: (i) identification of the demented and nondemented patients; and (ii) identification of these patients' close family members.

\section{A. Identification of demented patients}

Patients with dementia were recruited from the Geriatric Assessment Unit (GAU) of the Jewish General Hospital (JGH). The GAU's multidisciplinary team is made up of four physicians, two nurses, one social worker, and one occupational therapist. The team assesses elderly patients with complicated medical, social, and functional problems, many of whom suffer from dementia. Patients were included in the study if they:

(i) were aged 55 years or more;

(ii) had a clinical diagnosis of dementia, according to DSM-III criteria (1), on the basis of complete medical history-taking, physical examination with thorough neurologic evaluation, and mental status testing; and

(iii) had a history of cognitive decline of at least six months duration. 
Patients were excluded if they:

(i) had been referred to the GAU for the purpose of assessment prior to foster home or nursing home placement;

(ii) had been referred to the GAU for a major, acute medical problem; or

(iii) did not have a close family member who was eligible for inclusion in the study.

\section{B. Identification of nondemented patients}

Patients undergoing cataract surgery were chosen as the source of subjects without dementia. Modern surgical techniques and very short hospital stays mean that even patients who are quite old or who have chronic health problems are eligible for this procedure. Thus, although cataract surgery patients cannot be considered to be a random sample of the general population, they are likely to be representative of elderly individuals who are neither unusually healthy nor unusually ill and who do not require significant amounts of care from their close family members.

Elderly patients undergoing cataract surgery at the JGH were selected. Patients were included if they were aged 55 years or more. They were excluded if:

(i) they were found, at interview, to be cognitively impaired (defined as a score of less than 25 on the Mini-Mental state Examination (157)); 
(ii) they were found, at interview, to have a significant functional impairment (severely or totally impaired according to the functional subscale of the older Americans Research and Services (OARS) Multidimensional Functional Assessment Questionnaire (158)); or

(iii) they did not have a close ramily member who was eligible for inclusion in the study.

There were two sources of cataract patients: (i) patients who underwent cataract surgery at the JGH on an inpatient basis, and (ii) the patients of two ophthalmologists who do a large number of cataract operations at the JGH, both on an inpatient and an outpatient basis. To ensure that any stress experienced by the patient and his or her family as a result of the surgery had subsided, and to ensure that the improvement in the patient's functional status had stabilized (159), four months were allowed to elapse after the surgery before the subjects were contacted for interview.

\section{c. Identification of caregivers}

The demented patient's primary caregiver was defined as the person who had the most responsibility for, and provided the most care to the patient. The identification was made by the clinic staff in consultation with the patient and the family. Only caregivers who were the patient's spouse or child, and who spoke English or French, were included. 


\section{Identification of noncaregivers}

In the case of the nondemented patients, the objective was to identify the close family member who would provide care to the patient if he or she became seriously impaired. Each cataract patient was asked to name the person who currently provided the most assistance in his or her daily life. Subjects were excluded if the person named was not the patient's spouse or child, or if he or sine could not spisak English or French.

\section{MATCRING}

Although the two patient groups were recruited from the same hospital, referral patterns for the two clinical services involved (geriatrics and ophthalmology) are quite different. Since the proportion of Jews was much higher among patients of the geriatric clinic, and since ethnic origin might be an important confounding or modifying factor in the caregiving-health association, frequency matching on this factor was desirable. However, since the ethnic composition of the patient populations was quite different, the time required for obtaining exactly the same proportion of Jews in the two study groups would have been prohibitively long. The solution that was adopted was to aim, at the design stage, for the most balanced distribution possible with respect to ethnic group, while still ensuring that the study was completed within a reasonable period of time. Residual con- 
founding due to ethnic group was then controlled for at the analysis stage.

The matching scheme proceeded as follows. First, an estimate was made of the number of subjects who had to be interviewed per month in order to ensure that the required sample size would be attained within the study period; this number was referred to as T. Each month, the list of cataract patients who had signed consent forms and were eligible to be contacted for interview was examined and the number of Jewish patients (referred to as $J$ ) was determined. If $J$ was equal to $T$, all the Jewish patients were selected. If $J$ was larger than $T$, a random sample of size $T$ was selected from among the Jewish patients. If $J$ was smaller than $T$, all the Jewish patients were selected and a random sample of size $T$ - $J$ was selected from among the non-Jewish patients.

\section{DEFINITION AND MEASUREMENT OF STUDY VARIABLES}

\section{A. Outcome variables}

Depression and physical symptoms were chosen as the major outcome variables for this study. The choice of these outcomes was made after consideration of the stresses which are specific to caring for a demented person, and after examination of the results of previous descriptive studies of caregivers' perceived health problems. Thus, depression was chosen since caring for a demented person involves most of the features included in psychosocial explanations of de- 
pression (loss of a previously close relationship, social isolation, impaired relations with an intimate other, chronic stress including guilt and reduced control over one's own life, and curtailment of opportunities for positive reinforcement) $(96,147,160,161)$. Furthermore, some previous studies have shown unusually :aigh levels of depression among caregivers $(111,125,162,163)$. With respect to physical health, it was felt that caregiving was unlikely to have a detectable effect on the incidence of major diseases such as heart disease or cancer. A more plausible effect would be on the frequency of physical symptoms, such as backache, headache, fainting, dizziness, and heartburn, which are likely to be influenced by specific features of the caregiving situation (psychological strain, anxiety, chronic fatigue, and sleep disturbances).

\section{(a) Depression:}

Depression was measured using the center for Epidemiologic Studies Depression (CESD) scale (164). The CESD scale (see appendix 3) includes 20 items, most of which were derived from earlier depression instruments used in clinical settings. In contrast to earlier scales, the CESD does not include any particularly sensitive questions, such as those related to sexual interest and suicidal ideation. The items are graded on a four-point scale corresponding to the frequency of each symptom in the preceding week $(0=$ rarely, $3=$ most or all of the time). The total score can 
vary from 0 to 60 , with a higher score indicating a higher level of depressive symptoms.

In addition to the total score, four subscales (negative affect, positive affect, somatic symptoms, anà interpersonal relationships) were constructed from the CESD items, using the definitions of Berkman et al. (151) = The items making up the various subscales are shown in appendix 3.

The CESD has been widely tested among adults, using clinical samples as weil as large numbers of communityresiding subjects (165). The scale has been found to differentiate psychiatric patients from community normals, to differentiate among groups of psychiatric patients classified according to their clinically-determined severity of depression, to distinguish between acutely depressed patients and recovered depressives, and to be substantially correlated with results of other depression rating scales (165). Using the Research Diagnostic Criteria structured diagnostic interview as the gold standard, specificities of $94 \%$ and $83 \%$, and sensitivities of $64 \%$ and $60 \%$ in two different samples have been found (166).

The investigators who developed the scale maintain that it is useful in detecting depressive symptomatology and changes in symptoms over time, although they do not advocate it: as a diagnostic instrument for psychiatric disorder (165). Extensive use of the CESD in previous population surveys among the elderly $(151,167-171)$ has generated useful 
comparison data and has allowed cutoff points for the definition of a "case" to be derived (172). The CESD has been used to measure the impact of caring for patients with dementia $(133,134)$ and as an outcome measure in studies of services to caregivers (173).

(b) Physical symptoms:

The choice of a physical symptoms checklist posed several problems. Many of the instruments used in health research to assess physical health consist primarily of items related to the existence of chronic disease, major impairment, and functional incapacity. Since it seemed unlikely that caregivers would be found to have significantly more major illnesses than noncaregivers, scales in which this type of item predominates were not likely to be sensitive to differences between our study groups. Furthermore, since caregivers must achieve and maintain a relatively high level of functional ability in order to assume the caregiving role, functional status would not likely be an adequate outcome measure. In the field of psychology, physical symptom checklists have been developed and validated, but usually with the intention of measuring some psychological construct such as hypochondriasis $(174,175)$. Conceptually, it did not seem appropriate to use such scales in this study. Therefore, we decided to use Aday and Andersen's 24-item symptom checklist (see appendix 4), which is conceptually appropriate and has been widely used 
in studies of access to health care (176-179). The content validity of this index is supported by the fact that the items included are almost identical to those found in other symptom checklists. The original checklist asks respondents about symptoms occurring in the past year; in this study, as in the study by shapiro et al. (179), a reference period of 30 days was used. Furthermore, respondents were asked to rate the frequency of each symptom on a four-point scale (not at all, once or twice during the month, about once a week, almost every day) and a frequency-weighted measure of physical symptoms was constructed. Since the weighted and unweighted measures were highly correlated (Pearson's $r=$ 0.95 ) and since use of the two variables gave almost identical results, only the unweighted results will be presented.

\section{B. Explanatory variables}

(a) Duration of dementia:

The GAU physicians routinely determine the approximate date of onset of their patien's' dementia, by asking family members to estimate when the patient first exhibited memory and functional problems. This information, which is systematically recorded in the medical chart, was used to determine the duration of dementia. 
(b) Cognitive status:

The Mini-Mental state Examination (MMSE) (180) was ussd to measure the severity of the demented patient's cognitive impairment. The MMSE is one of the most widely used mental status questionnaires, and it is the one on which the most methodologic work has been done (181). The test includes 11 items and takes five to 10 minutes to administer. The MMSE tests orientation, registration, attention and calculation, recall, language, praxis, and graphic copy of a geometric design (see appendix 5). The score can vary from 0 to 30 , with a higher score indicating less cognitive impairment. The MMSE has been found to discriminate well between demented and nondemented psychiatric patients (157). In a study in which the MMSE was administered to 97 consecutive patients admitted to a medical ward, Anthony et al. (180) found a sensitivity of $87 \%$ and a specificity of $82 \%$. In a study of 810 community-residing subjects aged 18 yearis or more, the same authors (182) found a sensitivity of $32 \%$ and a specificity of $99 \%$.

The MMSE was also used to determine tine eligibility of cataract patients for inclusion in the study. Subjects scoring less than 25 were excluded from the study. With this cutpoint, a negative predictive value of at least $98 \%$ can be expected (180). 
(c) Functional status:

The functional status subscale of the OARS Multidimensional Functional Assessment Questionnaire (158) was administered to the demented and nondemented index patients' close family members at interview in order to quantify the patients' level of functional autonomy. The OARS instrument includes a seven-item basic activities of daily living ( $A D L$ ) scale and a seven-item instrumental ADL scale (see appendix 6). The items are scored 2 (can perform activity independently), 1 (can perform activity with some help), or 0 (cannot perform the activity without help). If the patient had never carried out the activity in question (e.g., male patients who had never done any housework or meal preparation), the item was rephrased to reflect the patient's potential rather than actual performance of the activity. As the OARS instrument was originally designed, a trained interviewer assigns an overall summary rating on the basis of the information gathered in the course of the interview. However, rules for computerized summary ratings are now available (183), allowing objective scores to be obtained. The summary ratings permit classification of subjects into one of the following six categories of functional capacity (range 1 to 6): excellent, good, mildly impaired, moderately impaired, severely impaired, and completely impaired: a higher value indicates greater impairment. 
The OARS instrument is probably the most widely used and widely tested community based assessment method (184). OARS ratings have been found to have moderate correlations with clinical evaluation, and to discriminate well among community residents, clinic referrals, and institutionalized patients. In one study, test-retest correlations were found to be 0.82 for basic $A D L$ and 0.71 for instrumental ADL. The correlation between scores obtained by different raters was about 0.75 . Although the reliability and validity of objective scores generated from the OARS ADL questions are unknown, it can be assumed that they are at least as high as, if not higher than, the subjective interviewer ratings.

The OARS interview, and Lawton's instrumental ADL scale (185), which is almost identical to the OARS instrumental ADL scale except for different scoring procedures, have been used in several studies of burden in families caring for demented elderly patients $(98,103,107,186)$.

(d) Behavior disturbance:

Several scales were identified which aim to quantify behavior disturbance in demented patients $(101,187-190)$. However, they were all found to be made up of heterogeneous sets of items, including many which do not refer to behavioral disturbaice as such, but rather to cognitive, psychological or somatic symptoms, or functional impairments. since none of the existing scales seemed adequate for the purposes of this study, the Dementia Behavior Disturbance 
scale was developed. The 28-item scale was designed to include only items which refer to specific observable behaviors, and not to psychological or cognitive symptoms. The report of a reliability and validity study, based partly on data from the present study, is shown in appendix 7. The scale was designed to be used in an interview format, with the patient's primary caregiver as the respondent. Each behavior is rated on a Likert-type scale with five possible responses corresponding to the frequency of the behavior in the preceding week ( $D=n e v e r, 4=a l l$ the time). The scores can vary from 0 to 112 , with higher scores indicating more disturbance. This variable was not measured for the cataract patients.

\section{c. Potential confounding variables}

Information was gathered on variables which are known to be associated with the outcomes under study and which, in addition, may have been distributed differently among caregivers and noncaregivers in this study. The following potential confounding variables were included:

(a) Demographic characteristics:

The age, sex, ethnic group, and educational status of the caregivers and noncaregivers were determined at interview (see appendix 8). 
(b) Chronic disease:

The caregivers and the subjects in the comparison group were asked to indicate whether they had any of a series of chronic diseases. The list consisted of the 21 chronic diseases included in the Canada Heaith Survey questionnaire (191) (see appendix 9). The total number of diseases for which the subject answered yes was used as a measure of his or her chronic disease status.

(c) Other stressful life events:

The subjects' experience of other stressful life events was determined using a checklist of life events called the Louisville older Person Events Scale (LOPES) which was developed and tested by Murrell and Norris for their largescale population study of stress and depression among the elderly (192) (see appendix 10). The reference period for the LOPES is the six months preceding interview: this period is shorter than that used in much previous research and was chosen in order to increase the accuracy of event recall (192). The undesirability of each of the 54 LOPES items was assessed by 2,860 randomly selected elderly adults in Kentucky and the mean undesirability rating for each event was evaluated (192). For this study, only the 34 events which received a negative mean rating, that is, those events which were considered to be undesirable in the Kentucky survey, were retained. This approach is justified by the fact that the stress associated with the occurrence of 
undesirable events is more strongly related to physical and psychiatric pathology than the stress associated with the occurrence of positive events $(78,193,194)$.

(d) Smoking and alcohol use:

The subjects' smoking status was determined at interview, using questions from the Canada Health Survey (191) (see appendix 11). In order to quantify lifetime exposure to cigarette smoking (in pack-years), the total number of years during which the subject smoked was multiplied by the average number of packs smoked per day.

To obtain information on the frequency and quantity of alcohol consumption, questions from the Established Populations for Epidemiologic studies of the Elderly (EPESE) (195) survey instrument were used (see appendix 12). Total alcohol consumption was calculated using the EPESE formula, that is:

Ounces of alcohol consumed in last month $=$ $(.4)\left(\right.$ freq $\left._{B}\right)\left(\right.$ quant $\left._{B}\right)+(.67)\left(\right.$ freq $\left._{W}\right)\left(\right.$ quant $\left._{W}\right)+\left(\right.$ freq $\left._{L}\right)\left(\right.$ quant $\left._{L}\right)$

where freq $=$ frequency of consumption in last month quant = approximate quantity consumed each time (number of containers of beer, glasses of wine, drinks of liquor)

$\mathrm{B}=$ beer

$\mathrm{W}=$ wine

$L=1$ iquor 
(e) Coping skills:

The coping efficacy of both groups of study subjects was assessed using olson et al.'s (196) inventory of family coping strategies (F-COPES). This instrument, which was created to identify approaches and behaviors used by families in response to problems or difficulties, consists of 29 items, graded on a five-point likert scale (see appendix 13). Scores range from 0 to 145 ; a higher score represents a higher level of coping skills.

The scale has been used and tested with over 2,000 subjects. Internal consistency has been found to be around 0.86 , and the test-retest correlation coefficient was 0.81 (196). For this study, the wording of F-COPES was changed so that the questions did not refer to the subject's family, but only to the subject. This was the approach used by Pratt et al. (105) and Barber (197) in their studies of coping and burden among persons giving care to elderly family members.

\section{(f) Social support:}

The caregivers' and noncaregivers' social support was determined using Russell and Cutrona's 20-item Social Provisions Scale (SPS) $(198,199)$ (see appendix 14). This scale is based on Weiss's conceptualization of the six provisions of social relationships: attachment, social interaction, reassurance of worth, reliable alliance, guidance, and opportunity for nurturance (200). Factor analysis has confirmed a six-factor structure that corresponds to these six social 
provisions (199). Internal consistency coefficients of the individual subscales range from 0.64 to 0.76 , and the internal consistency coefficient for the total score ranges from 0.85 to 0.92 , depending on the population (198). Convergent and discriminant validity are supported by significant positive correlations with life satisfaction, and by significant negative correlations between the SPS and depression (198). Furthermore, this scale has been used in a study of stress and social support among the aged (198). Scores can vary between 0 and 96 , and a higher score indicates a higher level of social support.

An index of social support satisfaction, similar to one designed by stokes (201), was used to measure the subjects' assessment of the quality of their social contacts. The index included three questions that assessed satisfaction with instrumental support, emotional support, and overall support (appendix 15). Each question was rated on a four-point scale, ranging from not at all satisfied to very satisfied. Thus, the total score can range from 0 to 12 points, with a higher score indicating a higher level of satisfaction.

\section{Other variables}

(a) Use of formal services:

Both caregivers and noncaregivers were asked to state how many hours of assistance per month were received for each of 12 possible formal services (see appendix 16). This 
was similar to the approach used by Noelker and Wallace (202) and Gilleard et al. (102) in their studies of burden in the families of the impaired elderly.

(b) Amount of time spent caring for the patient:

The amount of time required to help the patient accomplish day-to-day tasks was determined in conjunction with the questions regarding functional status. For each of the basic and instrumental ADL items, the caregiver was asked how many hours per week he or she devoted to helping the patient, and the total number of hours was calculated. This is the same approach as that used by Noelker and Wallace (202) and stoller (203) in their studies of caregiving to the impaired elderly.

\section{E. Translation of questionnaire}

A French version of the CESD, which has been validated and widely used in France and Quebec, was adopted for this study. The remainder of the questionnaire was translated from English into French by a professional translator and revised by the author, who has complete verbal and written fluency in both languages.

\section{DATA COLLECTION PROCEDURES}

All patients seen at the GAU who fulfilled the eligibility criteria were asked by one of the physicians or nurses to participate in the study (see consent forms, ap- 
pendix 17). The patient and the person accompanying him or her to the clinic were asked to provide the name and telephone number of the patient's caregiver, as well as the kinship tie between the patient and the caregiver (husband, wife, son, daughter). This information was recorded on special information forms which were subsequently collected by the project coordinator.

For patients admitted to hospital for cataract surgery, the nurses on the ophthalmology ward gave the patients an introductory letter explaining the study, filled in the information form, and then asked them to sign the consent form (see appendix 17). For the second source of study subjects (patients of the two JGH ophthalmologists), our procedure was based on the fact that patients who are to have cataract surgery undergo axial biometry ("A-scan") several weeks before their operation. A research assistant went to the ophthalmology office each time there was an A-scan clinic, approached the patients as they waited to be examined, explained the study, filled in the information form, and asked them to sign the consent form. In both cases, the project coordinator collected the information forms and consent forms.

The coordinator assigned the interviews to the interviewers on the basis of language and practical considerations. The interviewers contacted the patient's close family member and set up an appoiniment to carry out the interview at home. For the cataract surgery patients, four months vere 
allowed to elapse before the subjects were contacted. The study used two English-speaking interviewers and one Frenchspeaking interviewer. They received three days of intensive training, during which various issues specific to the interviewing of elderly subjects were emphasized. The specific hypotheses of the study were never discussed with the interviewers.

All the questions in the interview were addressed to the patient's close family member, even though some of the questions referred to the patient. Only the MMSE was administered directly to the patient.

Data collection began in June 1987 and ended in November 1989 .

\section{ANALYSIS}

For all variables which were scales, the sum of the individual items was calculated. If the answers to three or fewer of the questions were missing, the missing values were replaced by the mean of the remaining items. If more than three answers were missing, the whole scale was considered to be missing.

Simple means and proportions were calculated to describe the patients' clinical and demographic characteristics, to describe the caregivers' and noncaregivers' demographic characteristics, and to compare caregivers and noncaregivers with respect to mean values of the outcome variables. 
In the caregiver group, the study participation rate was determined by dividing the total number who were interviewed by the sum of the number interviewed and the number who refused (either at the clinic or when contacted for interview). The following formula was used:

$$
\begin{aligned}
R= & {\left[\frac{I}{C+N+I}\right] \times 100 } \\
\text { where } \mathrm{R}= & \text { response rate } \\
\mathrm{I}= & \text { number interviewed } \\
\mathrm{C}= & \text { number who refused to sign consent } \\
\mathrm{N}= & \text { number not reached or who refused to be } \\
& \text { interviewed }
\end{aligned}
$$

In the comparison group, the recruitment procedure involved three steps: (i) subjects were approached for consent, (ii) sampling was carried out among those who agreed to participate, and (iii) those who were selected into the sample were approached for interview. It was not appropriate, when calculating the number of nonrespondent: : to simply add the numbers of subjects who were lost before and after the sampling step. Rather, both the number interviewed and the number who refused interview had to be multiplied by the inverse of the sampling fraction, in order to project 
the numbers up to what they would have been if sampling had not been carried out. The following formula was used:

$$
R=\left[\frac{(I \times 1 / k)}{C+(N \times 1 / k)+(I \times 1 / k)}\right] \times 100
$$

where $\mathrm{k}=$ sampling fraction.

In order to address the major study questions, linear regression analyses were carried out. For each of the two dependent variables, the analytic procedure consisted of estimating the association with the caregiving variable, after controlling for all relevant confounding variables. For depressive symptoms, the following nine covariates were included: age (coded as a continuous variable); sex ( $1=$ female, $0=$ mais) ; ethnic group ( $1=$ Jewish, $0=$ other); education ( $0=0$ nly high school completed, l=more than high school completed); number of chronic diseases (coded as a continuous variable); number of stressful life events in preceding six months (coded as a continuous variable); coping score (coded as a continuous variable); social support score (coded as a continuous variable); and support satisfaction score (coded as a continuous variable). For physical symptoms, two additional covariates were included: lifetime exposure to cigarette smoking, in pack-years (coded as a continuous variable); and number of ounces of alcohol consumed in previous month (coded as a continuous variable). The spe- 
cific analytic approaches which were used for the major research questions and the two secondary questions are described below.

\section{A. Difference between caregivers and noncaregivers}

The independent var:ables included in this analysi were caregiving status and the relevant covariates mentioned above. The statistical model that was considered in this analysis can be represented as follows:

$$
\begin{aligned}
& Y=B_{0}+B_{1} X_{1}+\sum B_{i} x_{i}+E \\
& \text { where } \mathrm{Y}=\text { outcome variable } \\
& B=\text { regression coefficient } \\
& \mathrm{x}_{1}=\text { caregiving status ( } 0 \text { =nonceregiver, } \\
& 1=\text { caregiver) } \\
& x_{i}=\text { covariates }(i=2, \ldots 10 \text { for analyses with } \\
& \text { depression as dependent variable, } \\
& i=2, \ldots 12 \text { for anaiyses with physical } \\
& \text { symptoms as dependent variabic) } \\
& \mathrm{E}=\text { residual variation }
\end{aligned}
$$

Because the caregiver variable was coded 0 or 1 , the regression coefficient associated with this variable estimates the difference in means between caregivers and noncaregivers with respect to the dependent variable, after controlling for the covariates. Therefore, this coefficient 
was interpreted as a measure of the association between caregiving and the dependent variable and is referred to, in the Results section, as the adjusted difference between caregivers and noncaregivers.

The appropriateness of the linear regression model was assessed by examining the correlations among the independent variables in the model, the distribution of standardized residuals, and plots of observed versus expected residuals.

\section{B. Modifying effect of caregiver characteristics}

To assess whether certain characteristics of the caregiver modified the association between caregiving and the health indicators, two approaches were used. First, subgroups were created by dichotomizing each of the variables of interest. The cutoff points used for dichotomization were chosen so as to create groups of approximately equal size. In the first approach, statistical models of the following form were considered for each health indicator:

$$
\begin{array}{ll}
Y=B_{0}+B_{1} X_{1}+\sum B_{i} X_{i}+E & \left(\text { for } X_{j}=0\right) \\
Y=B_{0}+B_{1} X_{1}+\sum B_{i} X_{i}+E & \left(\text { for } X_{j}=1\right)
\end{array}
$$

where $x_{j}=$ characteristic of interest (coded as dichotomous variable with values 0 and 1 ) and the other terms are as defined above. 
Under the null hypothesis of no effect modification, the difference between the coefficients associated with the caregiving variable $\left(B_{1}\right)$ in the two subgroups should not be greater than that expected on the basis of sampling variation. Thus, differences between the $B_{1}$ coefficients in the pairs of subgroups were interpreted as evidence of effect modification.

The aim of the second approach was to test the significance of the difference between the coefficients in each pair of subgroups. This was done by creating interaction terms equal to the product of the caregiver variable with the variable of interest. Then, for each variable of interest, a statistical model of the following form was considered:

$Y=B_{0}+B_{1} X_{1}+B_{2} X_{2}+\beta_{3} X_{1} X_{2}+\Sigma B_{i} X_{1}+E$

where $\mathrm{x}_{2}=$ characteristic of interest (coded as dichotomous variable with values 0 and 1 ) $x_{i}=$ covariates $(i=4, \ldots 12$ for analyses with depression as dependent variable, $i=4, \ldots 14$ for analyses with physical symptoms as dependent variabie) and the other tierms are as defined above. 
The coefficient $B_{3}$ was interpreted as a measure of the modifying effect of the characteristic of interest on the caregiving-health association.

\section{Association between the health indicators and characteristics of the demented patient's disease}

These analyses were carried out using only subjects in the CG group. For each outcome variable and for each patient characteristic of interest, a statistical model of the following form was considered:

$$
Y=B_{0}+B_{j} X_{j}+Z B_{i} x_{i}+E
$$$$
\text { where } x_{j}=\text { characteristic of interest }(j=1, \ldots 4)
$$$$
\text { and the other terms are as defined above. }
$$

The regression coefficient $\beta_{j}$ was interpreted as a measure of the strength of the association between the dependent variable and the characteristic of interest, while controlling for the covariates.

\section{Other analyses}

For each of the scales, Cronbach's $\alpha$ coefficient of internal consistency (204) was calculated, using the following formula:

$$
\alpha=\frac{k}{k-1} \times\left[1-\frac{\Sigma \sigma^{2} i}{\sigma^{2} t}\right]
$$


where $\mathrm{k}=$ number of items in scale

$\sigma^{2} i=$ variance of the individual items

$\sigma^{2}{ }_{t}=$ variance of the total score

The correlations between each of the items and the total score were calculated, and the mean of the item-total correlations determined.

The existence of a depressive state was defined as a CESD score of 16 or more (151). Subjects who had more than the sample's median number of physical symptoms were considered to have a high level of symptoms. Logistic regression was used for analyses involving these dichotomous outcome variables. The same covariates were included as in the linear regression analyses, and prevalence odds ratios (POR) with their $95 \%$ confidence intervals (CI) were calculated for the caregiving variable. The same approach was used for calculating PORs for each of the individual physical symptoms.

\section{SAMPLE SIZE}

The original proposal was that the thesis would be based on an analysis of the data obtained after the first year of patient recruitment. It was expected that about 200 subjects per group would be available after one year: with this number of subjects, it would be possible to detect an effect size of 0.28 with power of $80 \%$. However, as the data collection progressed, it became clear that the number of patients with dementia who could be recruited was much 
smaller than had been estimated. This discrepancy could be explained by the fact that the staff of the GAU did not keep detailed statistics on its clientele. Therefore, when the protocol was being prepared, estimates of the number of eligible patients had to be done in an informal manner by the director of the unit. These projections were overly optimistic. In fact, after several months of data collection, it was estimated that it would take about 4.4 years to recruit 200 subjects.

Two solutions to this problem were considered: (i) extend the study to other centers in order to increase the number of potential subjects, or (ii) reduce the projected sample size. The first option posed several problems. First, at the time, there were few centers in Montreal with clinical populations which were comparable to that of the JGH geriatric assessment unit. Second, these centers generally do not treat a large number of patients. Therefore, extending the study to several centers would make the data collection procedures considerably more cumbersome without adding much benefit in terms of the number of patients recruited. Finally, constituting an appropriate comparison group would be difficult if the demented patients were recruited from several different hospitals.

The second option, reducing the number of subjects to be recruited, seemed more reasonable. It was decided to aim for a sample of 100 subjects per group. It was estimated that it would take about 2.5 years to recruit this number of 
subjects. Use of a sample of this size would allow us to detect an effect size of 0.40 with power of $80 \%$. Estimates of the effect size using preliminary data from the study revealed that differences as large as 0.60 of a standard deviation could be expected: thus, it was likely that the revised sample size would be adequate. 


\section{CHAPTER VI}

\section{RESULTS}

\section{DESCRIPTION OF SAMPLE AND INSTRUMENTS}

\section{A. Recruitment of study sample}

Details concerning the recruitment of demented patients are shown in table 3 and figure 3. A total of 678 patients were seen at the GAU during the study period, of whom more than $80 \%$ were not eligible for study. The most common reason for ineligibility was the patient's diagnosis: $49.4 \%$ did not have a documented history of cognitive decline of at least six months duration. A further $27.2 \%$ did not have a spouse or child caregiver (CG). Of the 130 patients who were eligible, $10(7.7 \%)$ refused to sign the consent form; this made it impossible for us to approach them and their CG for interview.

Of the $120 \mathrm{CGs}$ who were eligible for interview, 12 $(10.0 \%)$ refused to be interviewed, and five were found to be ineligible when they were contacted by the interviewer (table 4). Thus, a total of 103 CGs were interviewed, yielding a study participation rate of $82.4 \%$.

A total of 613 cataract patients were seen during the study period, of whom 250 (40.8\%) were not eligible and 83 (13.5\%) refused to sign consent (table 5 and figure 4 ). of the remaining 280 patients, 199 were sampled (sampling fraction $=0.71$ ) and became eligible for inclusion in the study. 
Table 3

Recruitment of demented patients

\begin{tabular}{|c|c|c|}
\hline & & \\
\hline & Number & $q$ \\
\hline Total patients seen at GAU & 678 & 100.0 \\
\hline Did not meet eligibility criteria & & \\
\hline - Not demented & 271 & 49.4 \\
\hline - Referred for immediate placement & 57 & 10.4 \\
\hline - Acute medical problem & 29 & 5.3 \\
\hline - No spouse or child caregiver & 149 & 27.2 \\
\hline - Clinical contra-indication & 12 & 2.2 \\
\hline - Reason unknown & 30 & 5.5 \\
\hline Total not eligible & 548 & 80.8 \\
\hline Refused to sign consent & 10 & 1.5 \\
\hline Eligible for inclusion & 120 & 17.7 \\
\hline
\end{tabular}


Figure 3

Recruitment of demented patients and caregivers

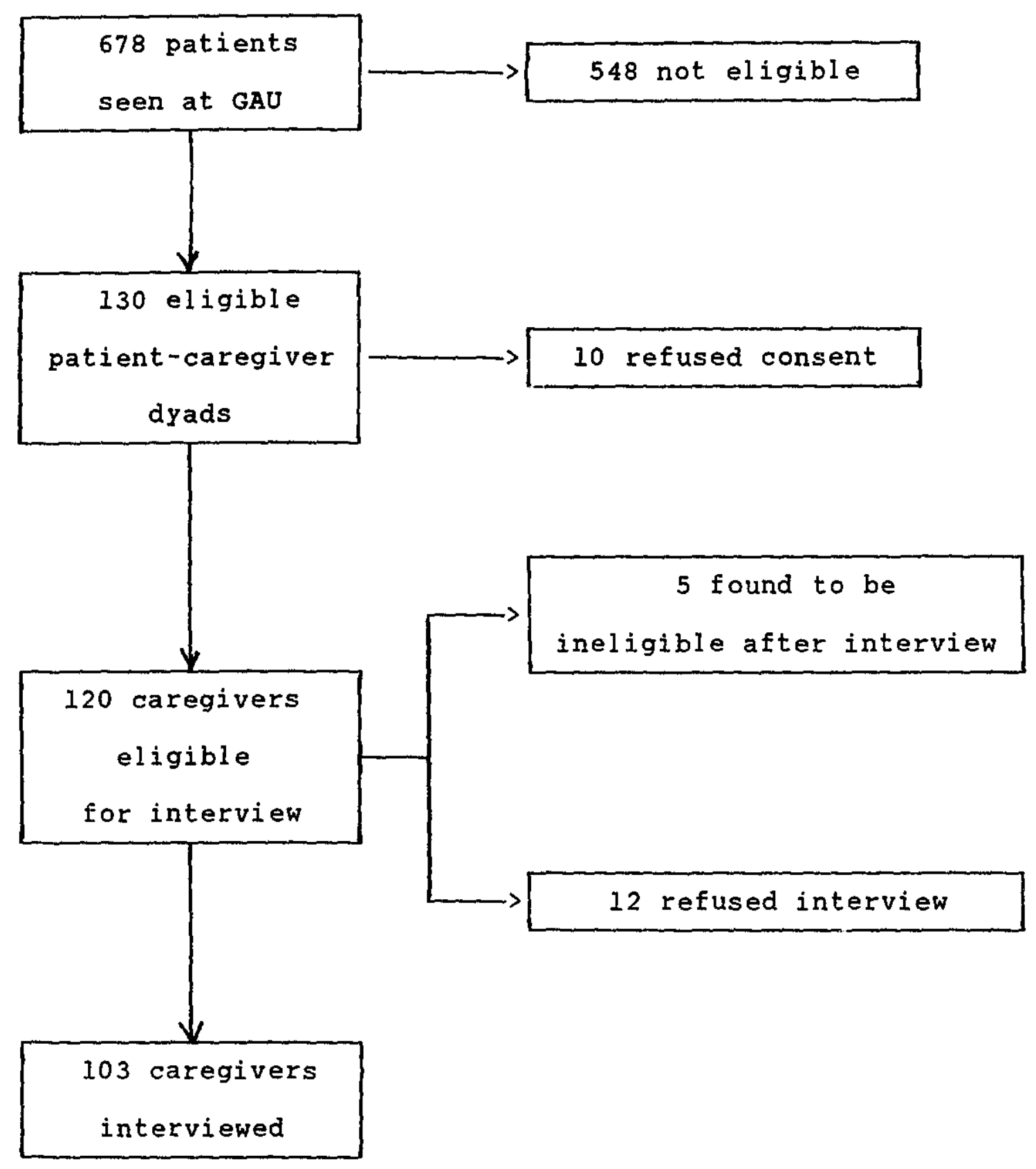


Table 4

Interview of caregivers of demented patients

\begin{tabular}{|c|c|c|}
\hline & \multirow[b]{2}{*}{ Number } & \\
\hline & & $q$ \\
\hline Total eligible for interview & 120 & 100.0 \\
\hline - Ineligibility discovered at interview & 5 & 4.2 \\
\hline - Refused interview & 12 & 10.0 \\
\hline - Interviewed & 103 & 85.8 \\
\hline
\end{tabular}




\section{Table 5 \\ Recruitment of cataract patients}

\begin{tabular}{lcc}
\cline { 2 - 2 } & Number & $\%$ \\
\hline Total cataract surgery patients & 613 & 100.0 \\
Did not meet eligibility criteria & 250 & 40.8 \\
Refused to sign consent & 83 & 13.5 \\
Eligible for sampling & 280 & 45.7 \\
- Not sampled & 81 & 13.2 \\
- Eligible for inclusion & 199 & 32.5 \\
\hline
\end{tabular}


Figure 4

Recruitment of cataract fatients and their close family members

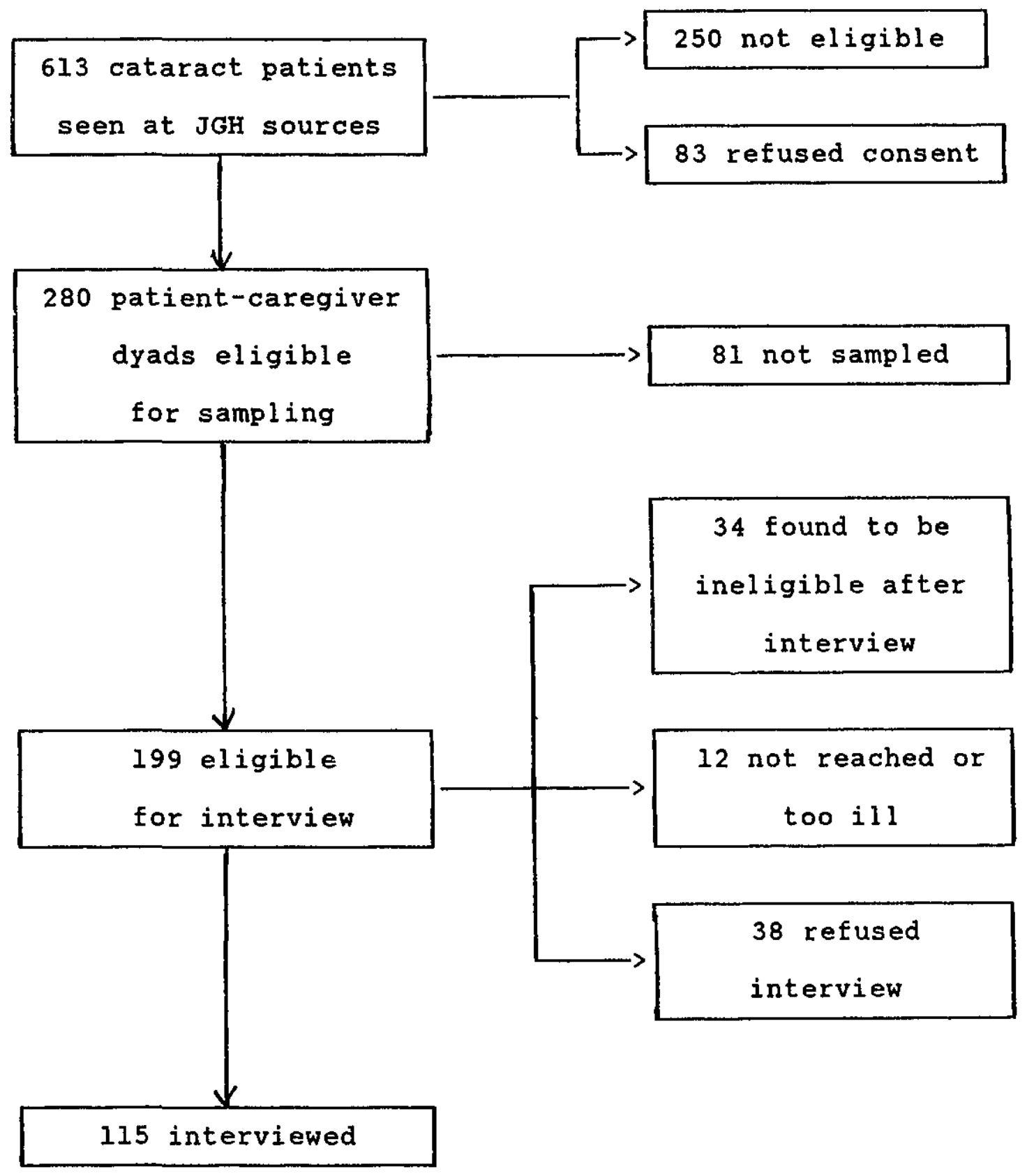


of the 199 CGs, 34 turned out to be ineligible when contacted by the interviewer, 12 could not be reached, 38 refused interview, and 115 were interviewed (table 6). The study participation raite was calculated as follows:

$$
\left[\frac{(115 \times 1 / 0.71)}{83+(50 \times 1 / 0.71)+(115 \times 1 / 0.71)}\right] \times 100=51.4 \%
$$

The overall study participation rate was equal to the weighted average of the response rates for the two study groups:

$$
\frac{(82.4 \% \times 103)+(51.4 \% \times 115)}{(103+115)}=66.0 \%
$$

Among the demented patients, those who participated in the study were slightly older and more likely to be male than those who did not participate (table 7). Among cataract patients, there were more women among participants than nonparticipants; there was no difference with respect to mean age. On the whole, differences between participants and nonparticipants with respect to sex and age were very small.

\section{B. Description of the interviewing process}

In the CG group, more than $80 \%$ of the interviews were carried out within 60 days after being assigned to the interviewer (table 8). Among NCGs, it was more difficult to contact respondents, and only about $62 \%$ of the interviews 


\section{Table 6}

Interview of close family members of cataract patients

\begin{tabular}{lcr} 
& Number & $\%$ \\
\hline Eligible for interview & 199 & 100.0 \\
- Ineligibility discovered at interview & 34 & 17.1 \\
- Not reached or too ill & 12 & 6.0 \\
- Refused interview & 38 & 19.1 \\
- Interviewed & 115 & 57.8 \\
\hline
\end{tabular}




\section{Table 7}

study participation of demented patients and cataract patients, by age and sex

\begin{tabular}{llll}
\hline Demented patients & Cataract patients \\
\hline $\begin{array}{l}\text { Pligible } \\
\text { pants }\end{array}$ & $\begin{array}{l}\text { nonparti- } \\
\text { cipants }\end{array}$ & $\begin{array}{l}\text { Partici- } \\
\text { pants }\end{array}$ & $\begin{array}{l}\text { Eligible } \\
\text { nonparti- } \\
\text { cipants }\end{array}$
\end{tabular}

$\begin{array}{lcccc}\text { Mean age (years) } & 79.7 & 76.4 & 73.4 & 73.5 \\ \begin{array}{l}\text { Sex (\%) } \\ \text { Male }\end{array} & 48.5 & 42.9 & 40.9 & 48.7 \\ \text { Female } & 51.5 & 57.1 & 59.1 & 51.3 \\ \begin{array}{l}\text { Total number of } \\ \text { patients }\end{array} & 103 & 22 & 115 & 121 \\ \end{array}$


Table 8

Characteristics of interviews, by caregiver status

$\begin{array}{cc}\text { Caregivers } & \text { Noncaregivers } \\ (n=103) & (n=115)\end{array}$

Interval between assignment and interview (\%)

$\begin{array}{lcc}0-30 \text { days } & 52.4 & 16.5 \\ 31-60 \text { days } & 28.2 & 46.1 \\ \text { More than 60 days } & 19.4 & 37.4\end{array}$

Language of interview (\%)

English

French

Place of interview (\%)

Respondent's home

Patient's home

Elsewhere

Interviewer's assessment of reliability of interview (\%)

Satisfactory

Fair

others present at interview $(\%)$

No others present

Patient present

others present

Mean length of interview (minutes)
95.1

74.8

4.9

25.2

75.7

83.5

4.9

6.1

19.4

10.4

91.3

95.7

8.7

$4 \cdot 3$

48.5

50.4

43.7

45.3

7.8

4.3

80.3

54.9 
were completed within 60 days of assignmert. Nearly all of the CGs and about three quarters of the NCGs were interviewed in English, and most of the interviews were carried out at the respondent's home. In more than $90 \%$ of cases, the interviewer judged that the reliability of information provided by the respondent was satisfactory. In approximately one half of the interviews, only the respondent was present; in about $45 \%$ of the cases, the patient was also present while the interview was being conducted. On average, the NCGs' interviews lasted just under an hour; for the CGs, the mean length was about 80 minutes.

\section{c. Description of study patients}

Demented patients were slightly older than cataract patients, and they were less likely to be female or to live alone (table 9). On the other hand, they were considerably more likely to be Jewish and to have no more than high school education.

More than one half of the demented patients suffered from severe or total functional impairment (table 10). None of the cataract patients had this level of functional impairment since, by design, those who had severe or total impairment were excluded from study. The mean MMSE score was 17.3 among demented patients and 28.1 among cataract patients. Since the maximum possible MMSE score is 30 , these results confirm that the patients classified as demented suffered from a significant degree of cognitive impairment 


\section{Table 9}

Demographic characteristics of study patients

\begin{tabular}{lcc}
\cline { 2 - 3 } Characteristics & $\begin{array}{c}\text { Demented patients } \\
(\mathrm{n}=103)\end{array}$ & $\begin{array}{c}\text { Cataract patients } \\
(\mathrm{n}=115)\end{array}$ \\
\hline Mean age (years) & 79.7 & 73.4 \\
$\%$ female & 51.5 & 59.1 \\
$\%$ married & 63.1 & 60.9 \\
$\%$ lives alone & 21.4 & 28.7 \\
$\%$ Jewish & 84.5 & 57.9 \\
\% completed high & 89.1 & 78.8 \\
school only & & \\
\hline
\end{tabular}


Table 10

Clinical characteristics of demented patients and cataract patients

Characteristics

Demented

Cataract patients

patients

$\%$ severe or total functional

52.4

0

impairment

Mean MMSE score

17.3

28.1

Mean number of hours of ADL help provided per week

13.4

1.0

Mean duration of dementia (years)

3.0

NA

Mean behavior score

19.8

NA

$\mathrm{NA}=$ not applicable 
whereas the cataract patients had a very low level of impairment. The demented patients also required a considerably greater amount of help with ADL than cataract patients (13.4 versus 1.0 hours per week, respectively). The mean interval between onset of dementia and interview was about three years. The mean behavior score among the demented was 19.8, equivalent to the frequent occurrence of about six symptoms or the occasional occurrence of about nine symptoms in the week preceding interview.

The prevalence of individual functional impairments among the demented patients is shown in table 11. Although relatively few patients required assistance with eating or bed transfers, the prevalence of the other impairments was quite high. The proportion of patients requiring help was particularly high for instrumental ADL, such as shopping, preparing meals, housework, and handling money.

As expected, the use of formal services among demented patients was higher than for cataract patients (table 12). A mean of almost 27 hours per month of formal services were received by this group, relative to a mean of only 8.1 hours per month in the cataract group.

\section{Description of caregivers and noncaregivers}

Characteristics of the study subjects are shown in table 13. The CGs were older than the noncaregivers (NCGs). They were more likely to live with the patient, to be Jewish, to be married, and to have only a high school educa- 
Table 11

Functional status of demented patients

\begin{tabular}{|c|c|}
\hline Activity & $\begin{array}{l}\% \text { of patients } \\
\text { who require help }\end{array}$ \\
\hline Eating & 2.9 \\
\hline Dressing & 36.9 \\
\hline Grooming & 30.1 \\
\hline Walking & 13.6 \\
\hline Getting in and out of bed & 8.7 \\
\hline Bathing & 52.4 \\
\hline Going to the toilet & 21.4 \\
\hline Using the telephone & 38.8 \\
\hline $\begin{array}{l}\text { Going to places outside } \\
\text { of walking distance }\end{array}$ & 80.6 \\
\hline Shopping & 78.2 \\
\hline Preparing meals & 74.5 \\
\hline Housework & 80.4 \\
\hline Taking medications & 76.5 \\
\hline Handling money & 87.4 \\
\hline
\end{tabular}


Table 12

Formal services received, demented patients and cataract patients

Demented patients

$\%$ with cleaner or homemaker

\% with home nurse

$\%$ with physiotherapist

\% with occupational therapist

$\%$ with social worker

$\%$ attending day hospital

$\%$ attending day center

\% with home respite care

$\%$ with hospital respite care

$\%$ with meals-on-wheels

\% with paid companion

Hours of formal services received during previous month

Mean number of services received
52.4

14.6

1.0

1.0

22.3

1.9

5.8

3.9

2.9

8.7

4.9

26.6

1. 2
Cataract patients

40.9

3.5

0.9

0

0.9

0

0.9

0

0

0.9

1.7

8.1

0.5 
Table 13

Characteristics of caregivers and noncaregivers

\begin{tabular}{|c|c|c|}
\hline Characteristics & $\begin{array}{l}\text { Care- } \\
\text { givers } \\
(n=103)\end{array}$ & $\begin{array}{c}\text { Non- } \\
\text { caregivers } \\
(\mathrm{n}=115)\end{array}$ \\
\hline Mean age (years) & 66.7 & 60.4 \\
\hline$\%$ female & 61.2 & 60.0 \\
\hline$\%$ married & 89.3 & 84.3 \\
\hline o livess with patient & 73.8 & 67.8 \\
\hline \multicolumn{3}{|l|}{ Kinship tie } \\
\hline \% wife & 40.8 & 34.8 \\
\hline \& husband & 22.3 & 25.2 \\
\hline$\%$ daughter & 20.4 & 25.2 \\
\hline \& son & 16.5 & 14.8 \\
\hline \& Jewish & 84.5 & 57.0 \\
\hline \% completed high school only & 67.0 & 58.3 \\
\hline f works full time or part time & 30.1 & 39.1 \\
\hline $\begin{array}{l}\text { Lifetime cigarette smoking } \\
\text { (mean number of pack-years) }\end{array}$ & 18.3 & 24.0 \\
\hline $\begin{array}{l}\text { Mean alcohol consumption in previous } \\
\text { month (ounces of alcohol) }\end{array}$ & $4 \cdot 3$ & 8.4 \\
\hline Mean coping score & 84.5 & 85.5 \\
\hline Mean number of Iife events & 3.4 & 3.2 \\
\hline Mean social provisions score & 77.1 & 79.0 \\
\hline $\begin{array}{l}\text { Mean social support } \\
\text { satisfaction score }\end{array}$ & 9.1 & 9.6 \\
\hline Mean number of chronic conditions & 2.1 & 2.0 \\
\hline
\end{tabular}


tion, but less likely to work outside the home. The distribution with regard to kinship tie was slightly different in the two groups, with more wives and fewer daughters among CGs. Overall, about $60 \%$ of subjects were the patient's spouse. Consumption of tobacco and alcohol was much lower among CGs than NCGs. The two groups were similar with respect to the other variables.

\section{E. Internal consistency of study scales}

All of. the scales and subscales used in the study had coefficients of internal consistency which were higher than 0.70 and many of the coefficients were higher than 0.80 (table 14). The mean item-total correlations ranged from 0.36 to 0.89 ; item-total correlations of more than 0.30 are often considered to be satisfactory (205).

\section{DEPRESSION AND PHYSICAL SYMPTOMS AMONG CAREGIVERS AND NONCAREGIVERS}

The distribution of depression scores are shown in figures 5 and 6 . The distribution for NCGs was more skewed to the right than that for CGs. The average CESD score was 15.5 among CGs and 8.2 among NCGs (table 15). After adjusting for covariates, the difference between the groups was 6.6 (95\% $C I=3.9,9.3)$, which is equivalent to a difference of more than two very frequent depressive symptoms or three occasional symptoms. 
Table 14

Internal consistency of study scales

\begin{tabular}{lcc}
\hline & $\begin{array}{c}\text { Coefficient } \\
\text { of internal } \\
\text { consistency } \\
(\alpha)\end{array}$ & $\begin{array}{c}\text { Mean } \\
\text { item-total } \\
\text { correlation }\end{array}$ \\
\hline Depression & 0.92 & 0.61 \\
Negative affect subscale & 0.87 & 0.81 \\
\multicolumn{1}{c}{$\begin{array}{c}\text { Somatic subscale } \\
\text { Positive affect subscale }\end{array}$} & 0.71 & 0.79 \\
Interpersonal subscale & 0.76 & 0.75 \\
Physical symptoms & 0.72 & 0.88 \\
Coping & 0.75 & 0.36 \\
Social provisions & 0.78 & 0.37 \\
Support satisfaction & 0.93 & 0.62 \\
Behavioral disturbance & 0.87 & 0.89 \\
Mini-Mental state Exam & 0.84 & 0.43 \\
\hline
\end{tabular}


4

$\infty$

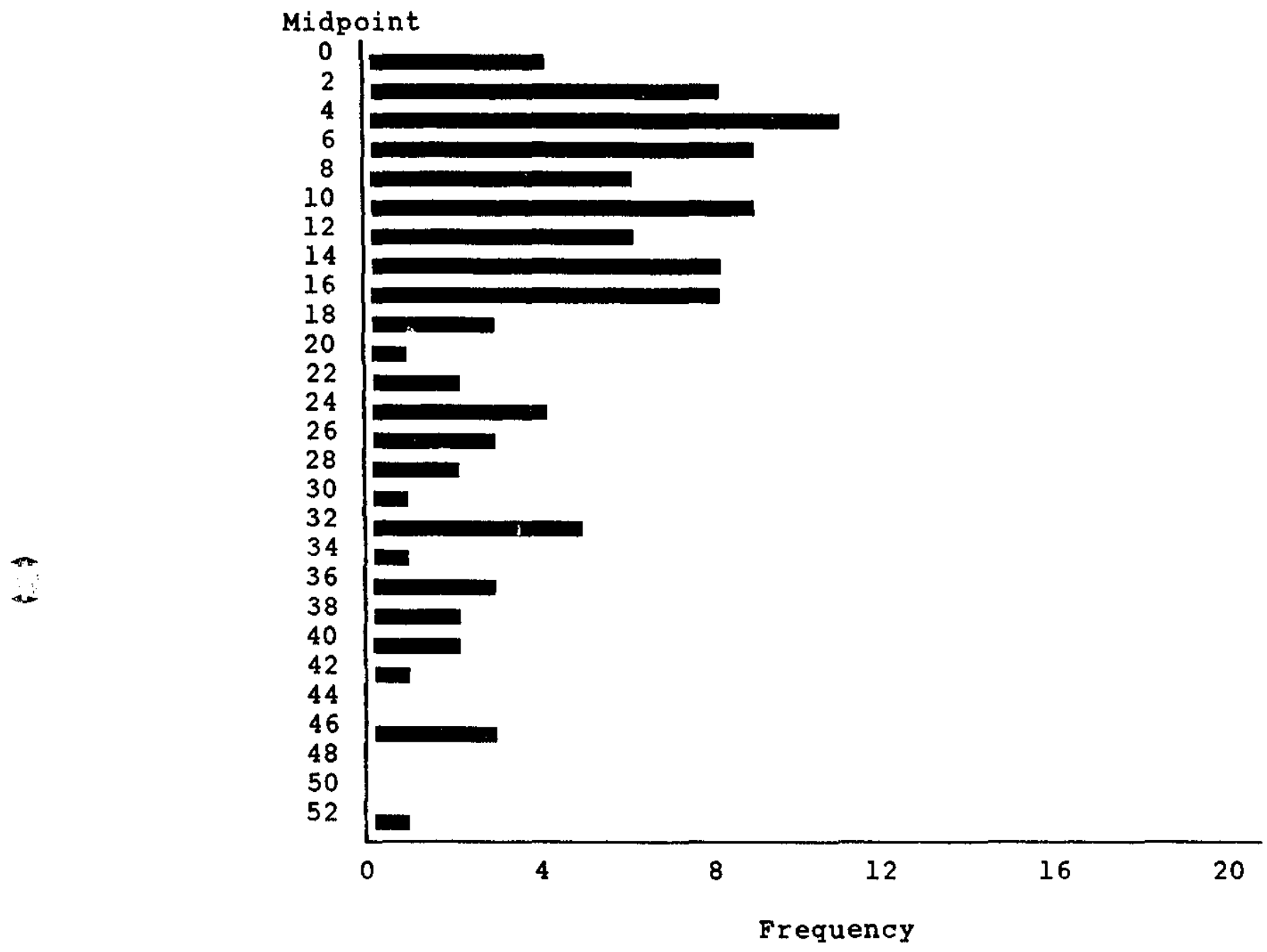

Figure 5

Distribution of depression scores among caregivers 
Figure 6

Distribution of depression scores among noncaregivers

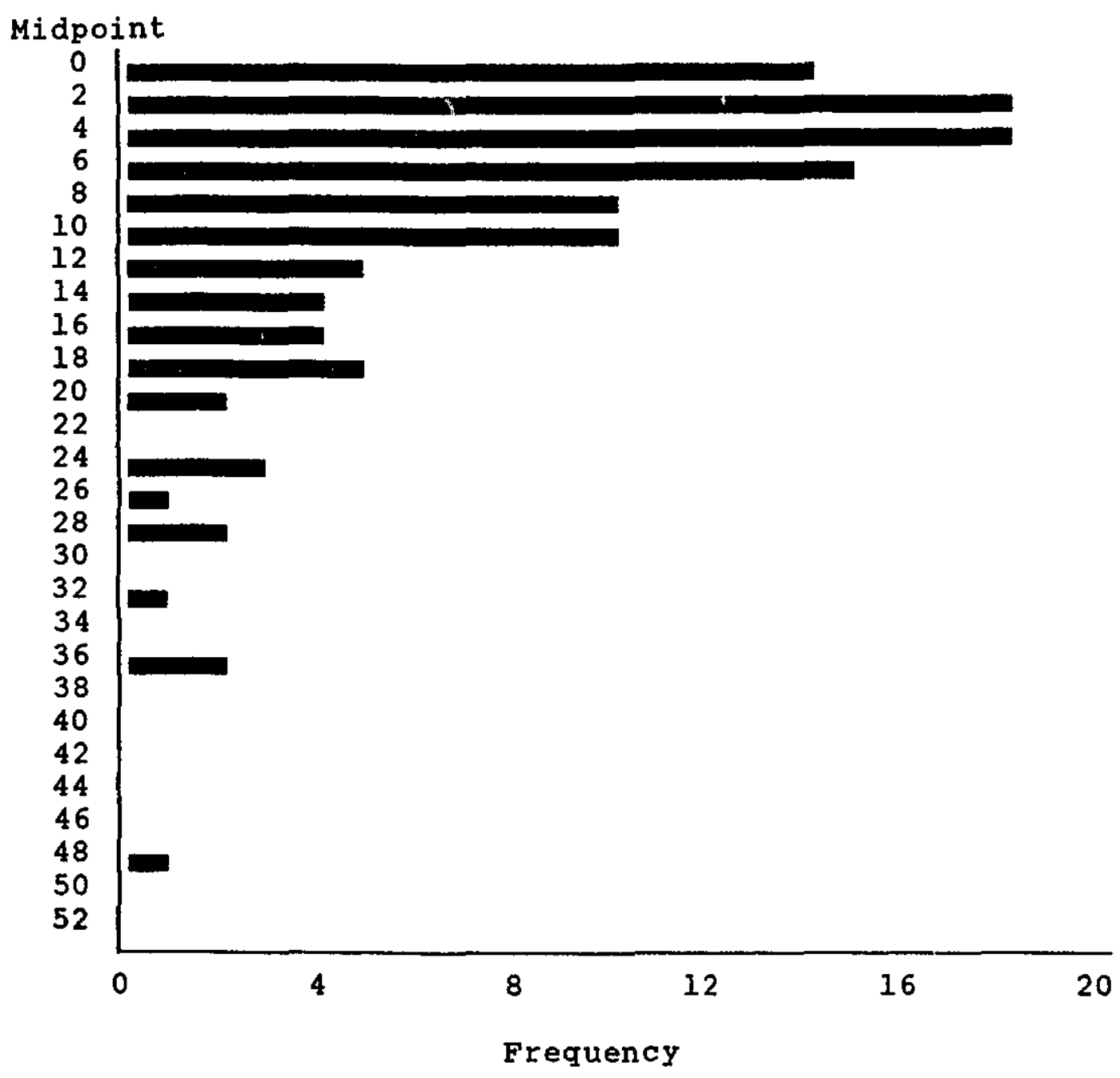


Table 15

Unadjusted and adjusted CESD total scores and subscale scores, by caregiver status

\begin{tabular}{|c|c|c|c|c|}
\hline & $\begin{array}{l}\text { Care- } \\
\text { givers }\end{array}$ & $\begin{array}{l}\text { Non- } \\
\text { care- } \\
\text { givers }\end{array}$ & $\begin{array}{l}\text { Adjusted* } \\
\text { difference }\end{array}$ & $\begin{array}{l}95 \% \text { CI } \\
\text { of ad- } \\
\text { justed } \\
\text { difference }\end{array}$ \\
\hline $\begin{array}{l}\text { CESD score } \\
\text { (range } 0-60 \text { ) }\end{array}$ & 15.5 & 8.2 & 6.6 & $3.9,9.3$ \\
\hline \multicolumn{5}{|l|}{ CESD subscales**: } \\
\hline $\begin{array}{l}\text { Negative affect } \\
\text { (range } 0-15 \text { ) }\end{array}$ & 4.8 & 1.8 & 2.7 & $1.7,3.6$ \\
\hline $\begin{array}{l}\text { Somatic } \\
\text { (range 0-9) }\end{array}$ & 2.1 & 1.4 & 0.9 & $0.3,1.4$ \\
\hline $\begin{array}{l}\text { Positive affect } \\
\text { (range } 0-12 \text { ) }\end{array}$ & 8.2 & 9.9 & -1.5 & $-0.7,-2.2$ \\
\hline $\begin{array}{l}\text { Interpersorial } \\
\text { (range } 0-6 \text { ) }\end{array}$ & 0.3 & 0.3 & 0.0 & $-0.2,0.3$ \\
\hline
\end{tabular}

* Adjusted for age, sex, education, ethnic group, coping score, social provisions score, support satisfaction score, number of stressful life events, and number of chronic conditions

** Not all items are part of a subscale. Therefore, the sum of the subscale scores is not equal to the total score. 
The details of the regression analysis of CESD score on the caregiving variable are shown in the appendix 18. The model including the caregiving variable and the set of nine covariates explained $37 \%$ of the variance in CESD scores. None of the correlations among the independent variables was high enough to result in multicollinearity. The distribution of the standardized residuals was approximately normal, and the observed and expected residuals were very highly correlated. Thus, there was no evidence of systematic departures from the assumptions required for the valid use of linear regression methods. However, two observations had standardized residuals greater than three, indicating that they might be influential observations. The analysis was redone, excluding the two observations: the results were virtually identical to those obtained when the two observations were included.

The mean scores for the negative affect and somatic symptoms subscales of the CESD were higher for CGs than for NCGs, and the positive affect subscale scores were lower; the adjusted differences between the groups for these three subscales were statistically significant (table 15). Using the conventional cutoff point of 16 or more to define a depressive state on the basis of CESD score (151), the prevalence of depression was $38.8 \%$ among CGs and $16.5 \%$ in the other group (adjusted prevalence odds ratio $[P O R]=3.8,95 \%$ CI $=1.6,9.1)$ (data not tabulated). 
The distribution of number of physical symptoms among CGs and NCGs is shown in figures 7 and 8 . CGs experienced a mean of 5.2 physical symptoms in the month preceding interview, compared to 3.7 for NCGs; the adjusted difference between the two groups was 1.2 (95\% $\mathrm{CI}=0.3,2.0)$ (data not tabulated).

The details of the regression analysis of physical symptoms on the caregiving variables are shown in appendix 19. The model including the caregiving variable and the set of 11 covariates explained $38 \%$ of the variance in physical symptoms. None of the correlations among the independent variables was high enough to suggest the existence of collinearity. The distribution of the standardized residuals was approximately normal, and there was a very high correlation between observed and expected residuals.

Those with greater than the median number of four physical symptoms were considered to have a high level of symptoms. The prevalence of a high level of symptoms was $54.4 \%$ among CGs and $31.3 \%$ among NCGs. The adjusted POR was 3.1 (95\% CI $=1.5,6.3)$ (data not tabulated).

Almost all of the physical symptoms were more common among CGs and, for some of the symptoms (persistent cough, persistent fatigue, morning fatigue, headaches, shortness of breath, and chest pain), the adjusted POR was statistically significant (table 16). It should be noted that, in these analyses, the total number of chronic conditions, but not the presence of individual chronic conditions, was adjusted 
Figure 7

Distribution of physical symptoms among caregivers

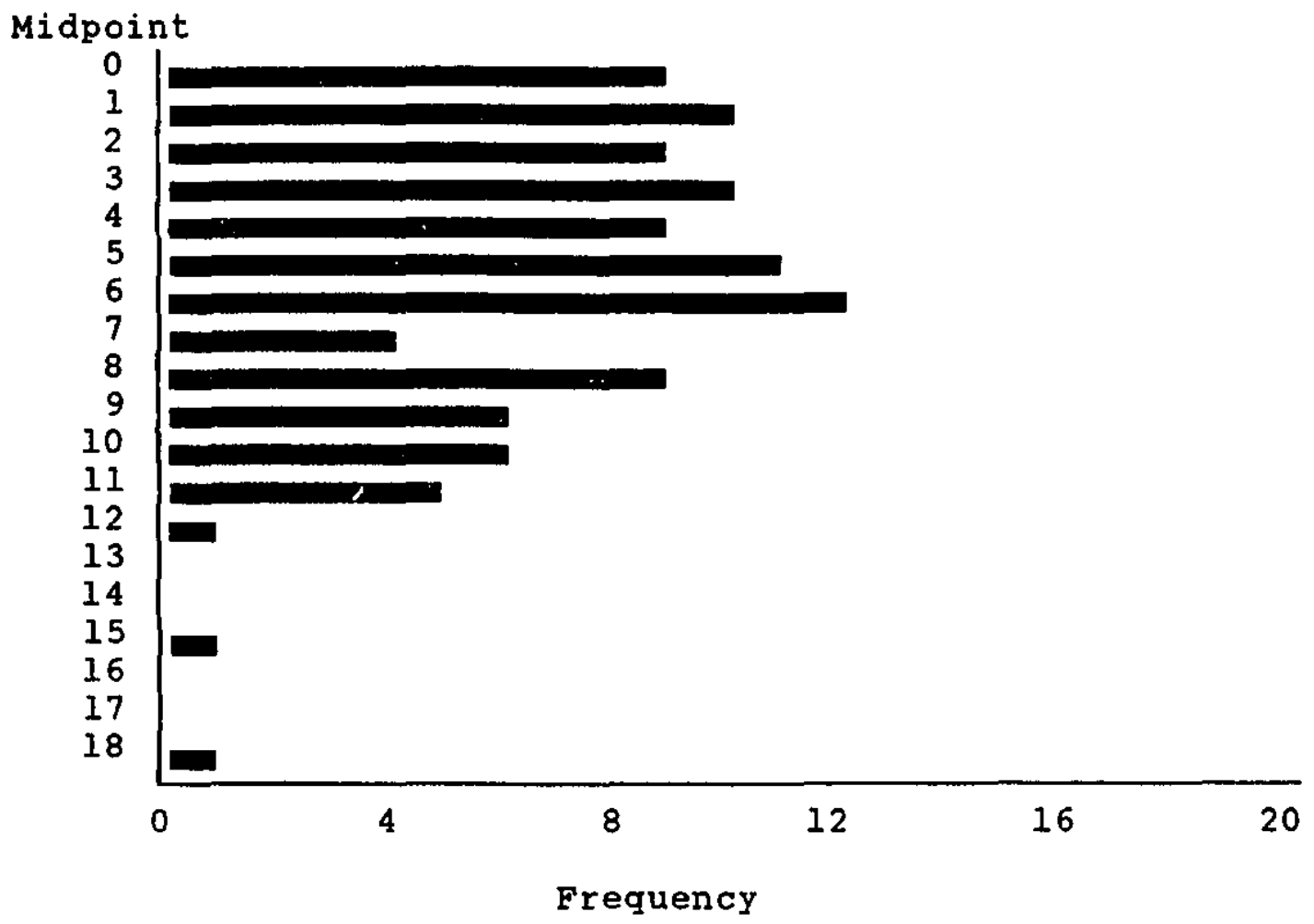


$\rightarrow$

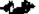

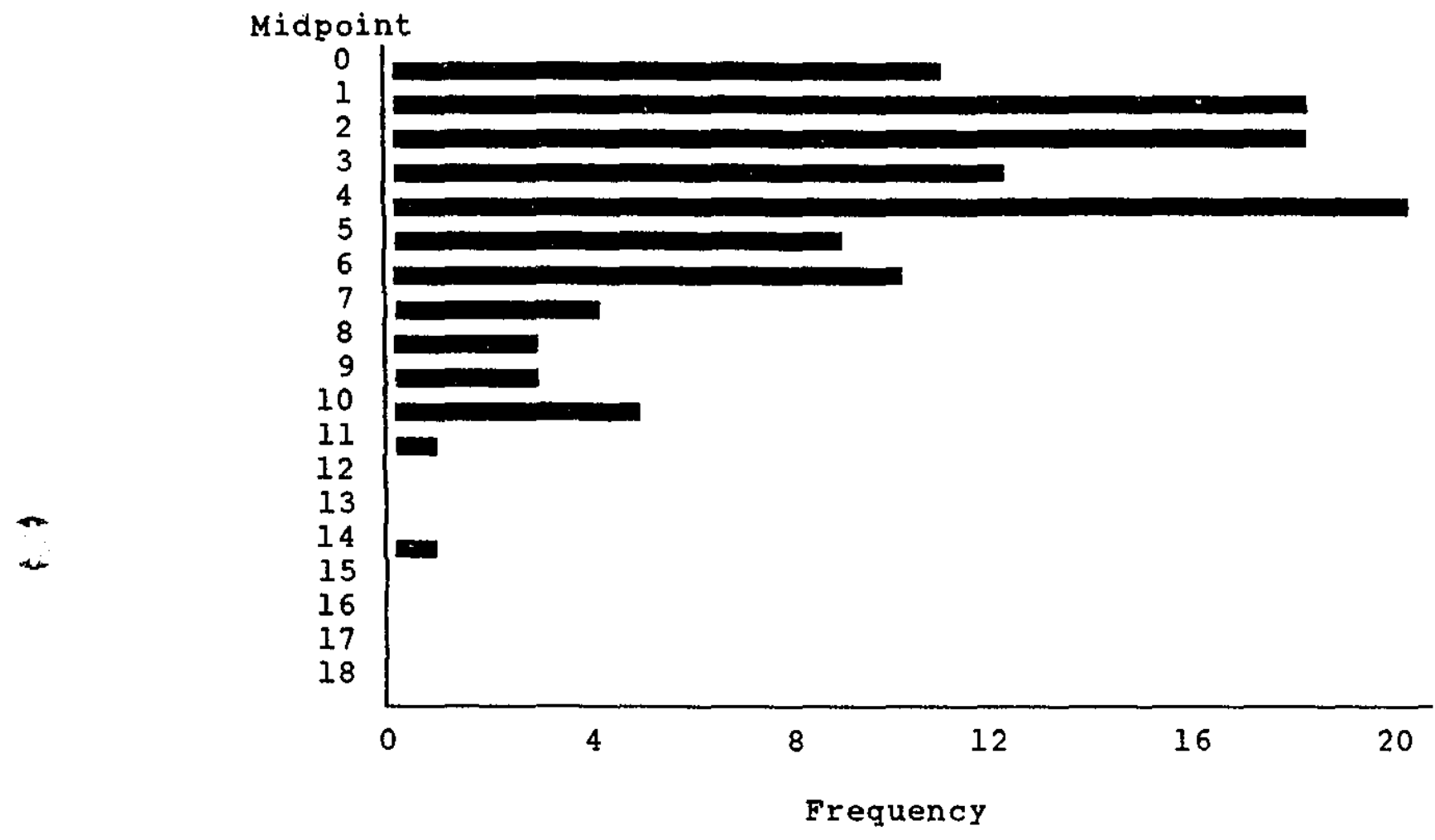

Distribution of physical symptoms among noncaregivers

Figure 8 
Table 16

Frequency ( $\%$ in previous month) of physical symptoms, by caregiver status

\begin{tabular}{|c|c|c|c|c|}
\hline Symptoms & $\begin{array}{l}\text { Care- } \\
\text { givers }\end{array}$ & $\begin{array}{l}\text { Non- } \\
\text { care- } \\
\text { givers }\end{array}$ & $\begin{array}{l}\text { Adjusted } \\
\text { POR* }\end{array}$ & $\begin{array}{r}95 \% \\
\text { CI }\end{array}$ \\
\hline Persistent cough & 14.6 & 7.0 & 3.2 & $1.1,9.3$ \\
\hline Persistent fatigue & 36.9 & 15.7 & 3.4 & $1.5,7.8$ \\
\hline Weight loss & 1.9 & 0 & $* *$ & $* *$ \\
\hline stuffy nose/sneezing & 10.7 & 10.4 & 1.3 & $0.5,3.5$ \\
\hline Weakness/faintness & 23.3 & 10.4 & 2.3 & $0.9,5.7$ \\
\hline Morning fatigue & 54.4 & 38.3 & 2.1 & $1.1,4.0$ \\
\hline Headaches & 43.7 & 24.1 & 2.8 & $1.4,5.8$ \\
\hline skin rash & 8.7 & 9.6 & 0.8 & $0.3,2.5$ \\
\hline Diarrhea & 4.9 & 4.3 & 2.7 & $0.5,15.1$ \\
\hline Shortness of breath & 32.0 & 21.7 & 2.2 & $1.0,4.5$ \\
\hline Joint stiffness & 37.7 & 38.3 & 0.8 & $0.4,1.5$ \\
\hline Joint pain/swelling & 24.3 & 26.1 & 0.6 & $0.3,1.3$ \\
\hline Backache & 45.6 & 33.9 & 1.7 & $0.9,3.3$ \\
\hline Chest pains & 25.2 & 8.7 & 3.3 & $1.2,8.8$ \\
\hline $\begin{array}{l}\text { Indigestion/upset } \\
\text { stomach }\end{array}$ & 25.2 & 28.7 & 1.0 & $0.5,2.0$ \\
\hline Vomiting & 1.0 & 0 & $* *$ & $* *$ \\
\hline
\end{tabular}


Table 16 (continued from previous page)

\begin{tabular}{|c|c|c|c|c|}
\hline symptoms & $\begin{array}{l}\text { Care- } \\
\text { givers }\end{array}$ & $\begin{array}{l}\text { Non- } \\
\text { care- } \\
\text { givers }\end{array}$ & POR* & $\begin{array}{l}95 \% \\
C I\end{array}$ \\
\hline $\begin{array}{l}\text { Sore throat/ } \\
\text { running nose }\end{array}$ & 5.8 & 1.7 & 2.9 & $0.4,19.0$ \\
\hline Unexpected bleeding & 1.0 & 2.6 & 0.1 & $0.0,4.0$ \\
\hline Abdominal pain & 10.7 & 7.8 & 1.5 & $0.5,4.7$ \\
\hline $\begin{array}{l}\text { Eye/ear infection/ } \\
\text { irritation }\end{array}$ & 16.5 & 9.6 & 1.8 & $0.7,4.7$ \\
\hline Toothache & 7.8 & 7.8 & 1.3 & $0.4,4.7$ \\
\hline Bleeding gums & 11.7 & 15.7 & 0.8 & $0.3,2.0$ \\
\hline $\begin{array}{l}\text { Trouble falling } \\
\text { asleep }\end{array}$ & 48.5 & 36.5 & 1.3 & $0.7,2.5$ \\
\hline $\begin{array}{l}\text { Urinating more than } \\
\text { twice a night }\end{array}$ & 27.2 & 12.2 & 2.2 & $1.0,5.3$ \\
\hline
\end{tabular}

* $\quad$ Adjusted $P O R=$ prevalence odds ratio, adjusted for age, sex, education, ethnic group, coping score, social provisions score, support satisfaction score, number of stressful life events, number of chronic conditions, smoking, and alcohol consumption.

** Cannot be calculated - zero prevalence among NCGs 
for. Since two of the symptoms with large PORs (shortness of breath and chest pain) may be associated with heart disease, and since heart disease was reported more frequently among CGs (19.4\%) than among NCGs (12.2\%), the analyses were redone aüding a dummy variable indicating the presence or absence of heart disease. For shortness of breath, the POR changed from 2.2 to 2.1 and, for chest pain, the POR changed from 3.3 to 3.1 . Similarly, although chronic bronchitis was more common among CGs (7.8\%) than NCGs ( $5.2 \%)$, including this variable in the analysis for persistent cough changed the POR only slightly, from 3.2 to 3.1 .

\section{EFFECT MODIFICATION}

The adjusted difference in depression between CGs and NCGs was higher among Jews than non-Jews (table 17). Larger differences were also associated with lower educational status, female sex, lower coping scores, lower social provisions and social support satisfaction scores, higher age, more chronic conditions, a larger number of recent stressful life events, and being the patient's spouse. Regression analyses in which interaction terms were included revealed that kinship tie and age were significant modifiers of the caregiving-depression association (table 18).

Kinship tie and age were highly correlated in this sample, since there were no child CGs in the older age group. collinearity between these two variables might have produced biased or unstable estimates when the interaction term in- 
Table 17

Unadjusted depression scores by caregiver status, and adjusted difference between caregivers and noncaregivers, in subgroups defined

by certain caregiver variables

\begin{tabular}{|c|c|c|c|c|c|}
\hline \multirow[b]{2}{*}{ Variables } & \multirow[b]{2}{*}{$\mathrm{N}$} & \multicolumn{2}{|c|}{$\begin{array}{c}\text { Unadjusted } \\
\text { depression } \\
\text { score }\end{array}$} & \multirow{2}{*}{$\begin{array}{l}\text { Adjusted* } \\
\text { difference } \\
\text { between } \\
\text { CGs and } \\
\text { NCGs }\end{array}$} & \multirow{2}{*}{$\begin{array}{l}95 \% \\
\text { CI }\end{array}$} \\
\hline & & CGs & NCGs & & \\
\hline \multicolumn{6}{|l|}{ Ethnic group } \\
\hline Jewish & 152 & 15.9 & 8.4 & 6.7 & $3.2,10.1$ \\
\hline Not Jewish & 64 & 13.1 & 8.1 & 6.3 & $0.7,11.9$ \\
\hline \multicolumn{6}{|l|}{ Kinship tie } \\
\hline Spouse & 133 & 16.8 & 6.2 & 9.3 & $5.7,12.8$ \\
\hline Child & 83 & 13.2 & $11 \cdot 3$ & 0.2 & $-4.7, \quad 5.1$ \\
\hline \multicolumn{6}{|c|}{$\begin{array}{l}\text { Completed high } \\
\text { school }\end{array}$} \\
\hline No & 98 & 15.3 & 8.9 & 6.9 & $2.6,11.2$ \\
\hline Yes & 118 & 15.6 & 7.8 & 6.4 & $2.3,10.5$ \\
\hline \multicolumn{6}{|l|}{ Sex } \\
\hline Female & 131 & 18.6 & 9.0 & 8.7 & $4.7,12.8$ \\
\hline Male & 85 & 10.4 & 7.0 & 2.7 & $-1.3,6.6$ \\
\hline \multicolumn{6}{|l|}{ Coping } \\
\hline Score $<86$ & 113 & 17.0 & 7.9 & 8.2 & $4.3,12.0$ \\
\hline Score $\geq 86$ & 103 & 13.7 & 8.6 & 5.6 & $1.2,10.1$ \\
\hline
\end{tabular}

(table continues on next page) 
Table 17 (continued from previous page)

\begin{tabular}{|c|c|c|c|c|c|}
\hline \multirow[b]{2}{*}{ Variables } & \multirow[b]{2}{*}{$\mathrm{N}$} & \multicolumn{2}{|c|}{$\begin{array}{c}\text { Unadjusted } \\
\text { depression } \\
\text { score }\end{array}$} & \multirow{2}{*}{$\begin{array}{l}\text { Adjusted* } \\
\text { difference } \\
\text { between } \\
\text { CGs and } \\
\text { NCGs }\end{array}$} & \multirow{2}{*}{$\begin{array}{l}95 \% \\
C I\end{array}$} \\
\hline & & CGs & NCGs & & \\
\hline \multicolumn{6}{|l|}{$\begin{array}{l}\text { Social } \\
\text { provisions }\end{array}$} \\
\hline Score $<78$ & 109 & 18.1 & 10.3 & 6.9 & $2.1,11.6$ \\
\hline Score $\geq 78$ & 107 & 12.1 & 6.6 & 5.2 & $1.8,8.6$ \\
\hline \multicolumn{6}{|l|}{$\begin{array}{l}\text { Support } \\
\text { satisfaction }\end{array}$} \\
\hline Score $<10$ & 151 & 17.5 & 10.2 & 6.5 & $2.7,10.4$ \\
\hline Score $\geq 10$ & 65 & 9.9 & 4.2 & 5.1 & 1.0 \\
\hline \multicolumn{6}{|l|}{ Age } \\
\hline$<65$ years & 107 & 13.0 & 9.7 & 2.2 & $-1.9, \quad 6.3$ \\
\hline$\geq 65$ years & 109 & 17.1 & 6.2 & 9.4 & $5.3,13.4$ \\
\hline \multicolumn{6}{|l|}{$\begin{array}{l}\text { Chronic } \\
\text { conditions }\end{array}$} \\
\hline$<3$ & 139 & 13.8 & 6.8 & 5.3 & 1.5, \\
\hline$\geq 3$ & 77 & 18.4 & 10.9 & 8.5 & $4.0,13.1$ \\
\hline \multicolumn{6}{|l|}{$\begin{array}{l}\text { Recent life } \\
\text { events }\end{array}$} \\
\hline$<4$ & 132 & 13.1 & 7.9 & 5.0 & 1.6, \\
\hline$\geq 4$ & 84 & 18.7 & 8.8 & 8.5 & $3.3,13.7$ \\
\hline
\end{tabular}

* Adjusted for age, sex, education, ethnic group, coping score, social provisions score, support satisfaction score, number of stressful life events, and number of chronic conditions. The potential range of CESD scores was 0-60. 
Table 18

Modifying effect of certain caregiver variables on the depression-caregiving association, controlling for covariates*

\begin{tabular}{|c|c|c|c|}
\hline $\begin{array}{l}\text { Caregiver } \\
\text { variable }\end{array}$ & $\begin{array}{l}\text { Interaction } \\
\text { coefficient** }\end{array}$ & $95 \%$ & CI \\
\hline $\begin{array}{l}\text { Ethnic group } \\
(0=\text { not Jewish, } 1=\text { Jewish })\end{array}$ & 1.71 & -4.93 & 8.35 \\
\hline Kinship tie ( $0=$ spouse, $1=$ child) & $-8 \cdot 30$ & -13.78 & -2.82 \\
\hline $\begin{array}{l}\text { Completed high school } \\
(0=\text { no, 1=yes) }\end{array}$ & -1.00 & -6.52, & 4.53 \\
\hline Sex $(0=$ male, $1=$ female $)$ & 5.05 & -0.48 & 10.58 \\
\hline Coping score $<86$ ( 0 =yes, $1=$ no) & -2.94 & -8.37 & 2.49 \\
\hline $\begin{array}{l}\text { Social provisions score }<78 \\
(0=\text { yes }, 1=\text { no })\end{array}$ & -1.08 & -6.59 , & 4.43 \\
\hline $\begin{array}{l}\text { Support satisfaction score }<10 \\
(0=\text { yes, } 1=\text { no })\end{array}$ & -1.19 & -7.29 & 4.91 \\
\hline Age $<65$ (0=yes, $I=$ no $)$ & 8.18 & 2.73 & 13.63 \\
\hline $\begin{array}{l}\text { Chronic conditions }<3 \\
(0=\text { yes, } 1=\text { no })\end{array}$ & 2.94 & -2.72 & 8.60 \\
\hline $\begin{array}{l}\text { Recent life events }<4 \\
(0=\text { yes, } 1=\text { no })\end{array}$ & 4.77 & -0.75 & 10.28 \\
\hline
\end{tabular}

* The following covariates were included: age, sex, education, ethnic group, coping score, social provisions score, support satisfaction score, number of stressful life events, and number of chronic conditions.

** A positive interaction coefficient indicates that the difference between CGs and NCGs was greater in the subgroup coded 1 than in the subgroup coded 0 . A negative interaction coefficient indicates that the difference between CGs and NCGs was lower in the subgroup coded 1 than in the subgroup coded 0 . The potential range of CESD scores was $0-60$. 
volving kinship tie was evaluated, and age was included as a covariate. To examine this possibility, the analysis was repeated excluding age from the model: the estimates for the interaction coefficient from the two analyses were almost identical.

For physical symptoms, a larger difference between CGs and NCGs was observed among non-Jews than Jews (table 19). Larger differences were also associated with being the patient's spouse, lower educational status, female sex, lower social provisions score, higher age, and more chronic conditions. Age was the only variable with a significant interaction term (table 20).

\section{CAREGIVER HEALTH IN RELATION TO CHARACTERISTICS OF THE DEMENTED PATIENT'S DISEASE}

The correlations among the variables describing the demented patient's disease are shown in table 21. Although some of the correlations were low, they were all in the expected direction. Greater behavior disturbance was associated with more functional impairment. Greater cognitive impairment (indicated by lower MMSE scores) was highly correlated with greater functional impairment. Longer duration of disease was associated with greater functional and cognitive impairment.

Unadjusted CESD scores among CGs, by characteristics of the demented patient's disease, are shown in table 22 . Higher CG depression scores were associated with higher lev- 
Table 19

Unadjusted number of physical symptoms by caregiver status, and adjusted difference between caregivers and noncaregivers, in subgroups defined by certain caregiver variables

\begin{tabular}{|c|c|c|c|c|c|}
\hline \multirow[b]{2}{*}{ Variables } & \multirow[b]{2}{*}{$\mathrm{N}$} & \multicolumn{2}{|c|}{$\begin{array}{l}\text { Unadjusted } \\
\text { number of } \\
\text { physical } \\
\text { symptoms }\end{array}$} & \multirow{2}{*}{$\begin{array}{l}\text { Adjusted* } \\
\text { difference } \\
\text { between } \\
\text { CGs and } \\
\text { NCGs }\end{array}$} & \multirow{2}{*}{$\begin{array}{l}95 \% \\
\text { CI }\end{array}$} \\
\hline & & CGs & NCGs & & \\
\hline \multicolumn{6}{|l|}{ Ethnic group } \\
\hline Jewish & 151 & 5.2 & 3.9 & 1.0 & $-0.0,1.9$ \\
\hline Not Jewish & 64 & 5.2 & 3.5 & 1.9 & $0.3,3.4$ \\
\hline \multicolumn{6}{|l|}{ Kinship tie } \\
\hline Spouse & 132 & 6.1 & 3.9 & 1.8 & $0.7,2.9$ \\
\hline Child & 83 & 3.6 & 3.6 & 0.1 & $-1.1,1.2$ \\
\hline \multicolumn{6}{|c|}{$\begin{array}{l}\text { Completed high } \\
\text { school }\end{array}$} \\
\hline No & 97 & 5.8 & 3.9 & 1.8 & $0.4,3.3$ \\
\hline Yes & 118 & 4.6 & 3.6 & 0.7 & $-0.3,1.6$ \\
\hline \multicolumn{6}{|l|}{$\operatorname{sex}$} \\
\hline Female & 131 & 6.2 & 4.4 & 1.6 & $0.4,2.8$ \\
\hline Male & 84 & 3.6 & 2.8 & 0.7 & $-0.3,1.8$ \\
\hline \multicolumn{6}{|l|}{ Coping } \\
\hline Score $<86$ & 112 & 5.5 & 3.8 & 1.3 & $0.2,2.3$ \\
\hline Score $\geq 86$ & 103 & 4.9 & 3.7 & 1.4 & $0.1,2.7$ \\
\hline
\end{tabular}


Table 19 (continued from previous page)

\begin{tabular}{|c|c|c|c|c|c|}
\hline \multirow[b]{2}{*}{ Variables } & \multirow[b]{2}{*}{$\mathrm{N}$} & \multicolumn{2}{|c|}{$\begin{array}{l}\text { Unadjusted } \\
\text { number of } \\
\text { physical } \\
\text { symptoms }\end{array}$} & \multirow{2}{*}{$\begin{array}{l}\text { Adjusted* } \\
\text { difference } \\
\text { between } \\
\text { CGs and } \\
\text { NCGs }\end{array}$} & \multirow{2}{*}{$\begin{array}{l}95 \% \\
\text { CI }\end{array}$} \\
\hline & & CGs & NCGs & & \\
\hline
\end{tabular}

Social

provisions

$\begin{array}{llllll}\text { Score }<78 & 108 & 5.6 & 3.9 & 1.5 & 0.2,2.8 \\ \text { Score } \geq 78 & 107 & 4.7 & 3.6 & 0.9 & -0.1,1.9\end{array}$

support

satisfaction

$\begin{array}{rrrrrr}\text { Score }<10 & 150 & 5.4 & 4.1 & 1.2 & 0.1,2.2 \\ \text { Score } \geq 10 & 65 & 4.6 & 3.0 & 1.3 & -0.1,2.7\end{array}$

Age

$\begin{array}{llllll}<65 \text { years } & 107 & 3.7 & 3.5 & 0.3 & -0.8,1.3 \\ \geq 65 \text { years } & 108 & 6.2 & 4.1 & 2.1 & 0.8,3.3\end{array}$

Chronic conditions

$\begin{array}{rrrrrr}<3 & 138 & 4.0 & 2.8 & 0.9 & 0.0,1.8 \\ \geq 3 & 77 & 7.3 & 5.5 & 1.4 & -0.3,3.1\end{array}$

Recent 1ife events

$\begin{array}{rrrrrr}<4 & 131 & 4.7 & 3.5 & 1.0 & 0.1,2.0 \\ \geq 4 & 84 & 5.9 & 4.2 & 1.2 & -0.4,2.7\end{array}$

* Adjusted for age, sex, education, ethnic group, coping score, social provisions score, support satisfaction score, number of stressful life events, number of chronic conditions, sinoking, and alcohol consumption. 


\section{Table 20}

Modifying effect of certain caregiver variables on the association between physical symptoms and caregiving, controliing for covariates*

\begin{tabular}{|c|c|c|c|}
\hline $\begin{array}{l}\text { Caregiver } \\
\text { variable }\end{array}$ & $\begin{array}{l}\text { Interaction } \\
\text { coefficient** }\end{array}$ & $95 \%$ & CI \\
\hline $\begin{array}{l}\text { Ethnic group } \\
\text { (0=not Jewish, } 1=\text { Jewish) }\end{array}$ & -0.64 & -2.50 & 1.22 \\
\hline Kinship tie ( $0=$ spouse, $1=$ child $)$ & -1.45 & -3.02 & 0.12 \\
\hline $\begin{array}{l}\text { Completed high school ( } 0=\text { no, } \\
\text { l=yes) }\end{array}$ & -1.23 & -2.79 & 0.33 \\
\hline Sex $(0=$ male, $1=$ female $)$ & 0.75 & -0.82 & 2.31 \\
\hline Coping score $<86$ (0=yes, $1=$ no) & -0.41 & -1.93 & 1.11 \\
\hline $\begin{array}{l}\text { Social provisions score }<78 \\
\text { (0=yes, } 1=\text { no) }\end{array}$ & -0.87 & -2.40 & 0.66 \\
\hline $\begin{array}{l}\text { Support satisfaction score }<10 \\
\text { (0=yes, } 1=\text { no) }\end{array}$ & -0.19 & -1.90 & 1.53 \\
\hline Age $<65$ (0=yes, $1=$ no $)$ & 1.73 & 0.19 & 3.27 \\
\hline $\begin{array}{l}\text { Chronic conditions }<3 \\
(0=\text { yes, } 1=\text { no })\end{array}$ & 0.70 & -0.89 & 2.30 \\
\hline $\begin{array}{l}\text { Recent Iife events }<4 \\
(0=y e s, 1=\text { no })\end{array}$ & 0.39 & -1.16 & 1.94 \\
\hline
\end{tabular}

* The following covariates were included: age, sex, education, ethnic group, coping score, social provisions score, support satisfaction score, number of stressful life events, number of chronic conditions, smoking, and alcohol consumption.

** A positive interaction coefficient indicates that the difference between CGs and NCGs was greater in the subgroup coded 1 than in the subgroup coded 0 . A negative interaction coefficient indicates that the difference between CGs and NCGs was lower in the subgroup coded 1 than in the subgroup coded 0 . 


\section{Table 21}

Correlations* among patient variables

1

2

3

4

1 Behavior disturbance

1.00

2 Functional impairment

$0.29 \quad 1.00$

3 MMSE score

$\begin{array}{lll}-0.08 & -0.51 \quad 1.00\end{array}$

4 Duration of dementia

0.05

0.29

$-0.30$

1.00

* Pearson correlation coefficients 
Table 22

Mean CESD score among caregivers, by characteristics of the demented patient's disease

\begin{tabular}{|c|c|c|}
\hline Characteristics & Number & $\begin{array}{c}\text { Mean } \\
\text { CESD score }\end{array}$ \\
\hline \multicolumn{3}{|l|}{ Functional impairment } \\
\hline Mild or moderate impairment & 48 & 13.3 \\
\hline Severe impairment & 16 & 12.8 \\
\hline Total impairment & 37 & 19.4 \\
\hline \multicolumn{3}{|l|}{ MMSE score } \\
\hline Less than 16 & 32 & 12.0 \\
\hline $16-21$ & 31 & 18.5 \\
\hline More than 21 & 28 & 15.2 \\
\hline \multicolumn{3}{|l|}{ Duration of disease (years) } \\
\hline Less than 1.5 & 27 & 15.3 \\
\hline $1 \cdot 5-3$ & 37 & 17.3 \\
\hline More than 3 & 34 & 14.1 \\
\hline \multicolumn{3}{|l|}{ Behavior disturbance score } \\
\hline Less than 13 & 35 & 11.9 \\
\hline $13-24$ & 36 & 15.8 \\
\hline 25 or more & 32 & 19.0 \\
\hline
\end{tabular}


els of functional impairment and greater behavioral disturbance among the patients. CG depression was highest in the intermediate categories of cognitive impairment (MMSE scores between 16 and 21) and duration of dementia (between 1.5 and 3 years).

For each of the four patient variables, regression analyses were carried out which included the patient variable in question as well as the nine covariates. Since the univariate analysis indicated that the relationship of CG depression to patient cognitive impairment and to duration of dementia might not be linear, these variables were not treated as continuous in the regression analyses. Rather, three categories of approximately equal size were created and the variable was entered into the model as a pair of dummy variables. The results of these analyses show that the patient's behavior disturbance was significantly associated with CG depression, even after controlling for the confounding variables (table 23). For cognitive impairment, CGs of patients in the intermediate category had higher depression scores than CGs of patients in either the lowest or highest categories, although the difference did not achieve statistical significance. The patient's functional impairment and the duration of dementia were not significantly associated with CG depression.

The crude number of physical symptoms among CGs was higher when the patient's behavior disturbance was higher and when disease duration was longer (table 24). The number 
Table 23

Results of regression of CESD score among caregivers on various characteristics of the demented patient's disease, controlling for covariates*

Variable

Regression

coefficient**

95\% CI

Severity of patient's

functional impairment

1.66

$-0.18,3.50$

(range 1-6)

Patient's behavior

0.19

0.03,

0.35

disturbance score

(range 0-112)

Patient's MMSE score
$16-21$ vs $<16$
4.51
$-1.04,10.05$
$>21$ vs $<16$
2.35
$-3.20, \quad 7.90$

Duration of dementia (years)
$1.5-3$ vs $<1.5$
2.31
$-2.92,7.54$
$>3$ vs $<1.5$
$-1.02$
$-6.49 \quad 4.45$

* The following covariates were included: age, sex, education, ethnic group, coping score, social provisions score, support satisfaction score, number of stressful Iife events, and number of chronic conditions.

** The coefficient from the regression model which included the patient variable in question as well as the covariates, but not the other patient variables examined in this table 


\section{Table 24}

Number of physical symptoms among caregivers, by characteristics ot the demented patient's disease

\begin{tabular}{|c|c|c|}
\hline Characteristics & Number & $\begin{array}{l}\text { Number of } \\
\text { physical } \\
\text { symptoms }\end{array}$ \\
\hline \multicolumn{3}{|l|}{ Functional impairment } \\
\hline Mild or moderate impairment & 48 & 4.7 \\
\hline Severe impairment & 16 & 3.9 \\
\hline Total impairment & 37 & 6.5 \\
\hline \multicolumn{3}{|l|}{ MMSE score } \\
\hline Less than 16 & 32 & 4.4 \\
\hline $16-21$ & 31 & 6.7 \\
\hline More than 21 & 28 & 4.8 \\
\hline \multicolumn{3}{|l|}{ Duration of disease (years) } \\
\hline Less than 1.5 & 27 & 4.6 \\
\hline $1 \cdot 5-3$ & 37 & 5.3 \\
\hline More than 3 & 34 & 5.6 \\
\hline \multicolumn{3}{|l|}{ Behavior disturbance score } \\
\hline Less than 13 & 35 & 4.4 \\
\hline $13-24$ & 36 & 5.1 \\
\hline 25 or more & 32 & 6.2 \\
\hline
\end{tabular}


of physical symptoms was lowest in the intermediate category of patient functional impairment, and it was highest in the intermediate category of patient cognitive impairment. Because of the possibility of nonlinear associations with CG physical symptoms, each of these two variables was treated as a pair of dichotomous dummy variables in the regression analyses. There was a marginally significant positive assnriation between the patient's behavior disturbance and the CG's physical symptoms (table 25). None of the coefficients for the other patient variables was statistically significant after controlling for covariates. 
Table 25

Results of regression of physical symptoms among caregivers on various characteristics of the demented patient's disease, controlling for covariates*

\begin{tabular}{lcc}
\hline Variable & $\begin{array}{l}\text { Regression } \\
\text { coefficient** }\end{array}$ & $95 \%$ CI \\
\hline $\begin{array}{l}\text { Patient's behavior } \\
\text { disturbance score } \\
\text { (range 0-112) }\end{array}$ & 0.04 & $-0.00,0.09$ \\
\hline Duration of dementia (years) & 0.00 & $-0.27,0.26$ \\
\hline
\end{tabular}

Severity of patient's

functional impairment

Severe impairment vs mild

or moderate impairment

$0.60-2.30, \quad 1.11$

Total jimpairment vs mild

0.89

$-0.44,2.22$

or moderate impairment

Patient's MMSE score
$16-21$ vs $<16$
1.00
$-0.58,2.57$
$>21$ vs $<16$
0.17
$-1.48, \quad 1.81$

* The following covariates were included: age, sex, education, ethnic group, coping score, social provisions score, support satisfaction score, number of stressful life events, number of chronic conditions, smoking, and alcohol consumption.

** The coefficient from the regression model which included the patient variable in question as well as the covariates, but not the other patient variables examined in this table 


\section{CHAPTER VII}

\section{DIscussion}

\section{DEPRESSION}

The results of this study suggest that family caregivers of elderly patients with dementia have a signifi-cantly higher frequency of depressive symptoms than comparable family members of elderly nondemented persons. The mean CESD score of CGs was almost twice as high as that of NCGs (15.5 vs 8.2 , respectively) and the difference remained highly significant even after adjusting for covariates. As for clinical significance, the adjusted difference between the groups was 6.6 , which is equivalent to more than two very frequent symptoms or three moderately frequent symptoms.

When depression was considered as a dichotomous variable, a similarly large difference between the study groups was observed. The prevalence of depression (defined as a CESD score of 16 or more) was more than twice as high among CGs as NCGs, and the adjusted prevalence odds ratio was 3.8 $(95 \% \mathrm{CI}=1.6,9.1)$.

A significant difference between CGs and NCGs was observed for three of the four CESD subscales; the difference was particularly large for the negative affect subscale. This suggests that the association with caregiving is particularly striking for symptoms such as crying spells, feel- 
ings of loneliness, sadness and depression, and not being able to shake off the "blues".

Several groups of investigators have reported data on depression among CGs of persons with dementia, with reference to a noncaregiving comparison group. For example, Moritz et al. (133) compared CESD scores of spouses of elderly persons with no cognitive impairment and spouses of elderly persons with moderate or severe cognitive impairment. For husbands, the mean CESD score was 5.6 when the wife had no cognitive impairment, 6.6 when the wife's cognitive impairment was moderate, and 10.7 when the wife's cognitive impairment was severe. For wives, there was little difference in depression scores in relation to the husband's level of cognitive impairment. These results differ somewhat from those obtained in our study, in that mean CESD scores in the Moritz et al. study were lower, and the association between depression and spouse's cognitive impairment was observed only among husbands. It should be noted that Moritz et al. used a population-based sampling scheme whereas our sample was drawn from among patients of a geriatric clinic. It is possible that families in which the CG has a high level of distress are more likely to be referred to a specialized geriatric clinic than families in which the CG is not distressed; this would explain why a higher frequency of depressive symptoms was observed in the present study. Furthermore, the Moritz et al. study used a very crude measure (number of errors on the Short Portable Mental status ques- 
tionnaire) to classify persons into categories of cognitive impairment. Since the positive predictive value of such brief screening instruments is low (206), groups of individuals described as "impaired" may actually have included a large number of people with normal cognitive status. The spouses of these individuals cannot really be considered to be CGs and this may account for the absence of large differences in the Moritz et al. study.

A similar method for defining individuals as "demented" was used by Eagles et al. (113). This may explain why these investigators found little difference between CGs and NCGs with respect to mean score on the Leeds Depression Scale. Furthermore, only 31 spouses of cognitively impaired persons were studied; low statistical power may have contributed to the absence of a statistically significant difference.

In the two remaining studies in which there was a control group and in which depression was considered as an outcome variable, significant differences were found between CGs and NCGs. Haley et al. (111) defined CGs as being individuals who had daily responsibility for an elderly relative with a six-month history of cognitive and functional impairment suggestive of dementia, and with a MMSE score of less than 24. These investigators found a statistically significant difference in depression, measured with the Beck Depression Inventory (BDI), between 44 CGs and 44 volunteer comparison subjects, matched for age, sex, race, and marital status. Kiecolt-Glaser et al. $(119,128)$ compared 34 family 
members giving care to a patient with Alzheimer's disease to 34 volunteer controls, matched for age, sex, and education. The difference between the groups with respect to mean BDI score was statistically significant; however, the magnitude of the differeñce was small.

In summary, the results of the present study indicate that CGs suffer from an unusually high frequency of depressive symptoms. Although the findings are not entirely supported by previous studies, the discrepancies can generally be explained by methodological differences. In particular, type II error may have occurred in studies where a large proportion of those classified as demented were probably normal or only mildly demented; in these studies, many people defined as "caregivers" may actually not have been providing any care.

The strong association between caregiving and depression is not unexpected. It can be explained by the fact that those who care for a close relative who has become demented face a situation characterized by chronic stress, social isolation, reduced control over their own lives, and decline in opportunities for positive reinforcement, features that are generally associated with psychosocial explanations of depression $(96,147,160)$. Furthermore, our results are in keeping with current psychological theories which explain depression essentially as a reaction to loss (207). The CG must face the loss of a previously close relationship: this loss may be even more painful than the death of the loved 
one because it does not afford the opportunity to mourn. The magnitude of the association between caregiving and depression is noteworthy, especially since it persisted even after controlling for a rumber of known risk factors for depression. Although it is only through longitudinal research that we can determine whether caregiving is a significant predictor of future depression, the results of the present study do suggest that caregiving is a strong correlate of current depression.

\section{PHYSICAL SYMPTOMS}

In this study, CGs had a significantly higher frequency of physical symptoms than NCGs: the adjusted difference between the groups with respect to the total number of symptoms was 1.2 . When the level of physical symptomatology was considered as a dichotomous variable, similarly large differences were observed. The odds ratio associated with a high level of physical symptoms (defined as greater than the median number of symptoms) was 3.1 (95\% CI $=1.5,6.3)$. only one earlier study compared physical symptoms among CGs and NCGs. Haley et al. (111) found a slightly higher number of symptoms in a group of $44 \mathrm{CGs}$ than in a group of 44 matched comparison subjects; however, the difference was not statistically significant.

The significant difference between CGs and NCGs with respect to physical symptoms, which persisted even after controlling for relevant risk factors such as sex, age, 
chronic conditions, and smoking, suggests that the consequences of caring for an elderly person with dementia are manifested not only by psychological distress, but by a series of somatic symptoms as well. of course, there are empirical and theoretical reasons to believe that depression and physical symptoms are not independent. For example, in this study, the correlation between CESD score and number of physical symptoms was 0.35 among NCGs and 0.59 among CGs, indicating significant overlap between the measures. Examination of the CESD and the physical symptoms checklist suggests, however, that the high correlation was not due simply to the inclusion of identical items in the two instruments. In fact, only three symptoms (sleep disturbance, lack of energy, and decreased appetite or weight loss) appear in both scales. At any rate, it might be argued that the distinction between psychological and somatic symptoms is artificial, given the essential interdependence of mind and body (208) and the degree of anatomic and chemical linkage between the nervous and immune systems (209).

Various mechanisms might be invoked to explain the effect of caregiving stress on depression and physical symptoms. For example, stress might act through a single neurochemical pathway, resulting in a myriad of effects, some of which we characterize as psychological and others which we think of as physical. Alternatively, the stressful situation might lead directly to psychological distress which, in turn, causes changes in the organism which result in somatic 
manifestations. Finally, two or more distinct neurochemical pathways might be involved, each leading to a different set of outcomes, some of which are manifested primarily by affective symptoms, and others by somatic symptoms. Identification of specific mechanisms concerning the effects of stress on physical and psychological health will be one of the major challenges of future research.

In the absence of prior hypotheses and given the large number of statistical tests performed, the analyses concerning individual physical symptoms can only be considered to be exploratory. still, the results suggest that symptoms commonly thought of as being related to stress and physical exertion, such as fatigue and headache, may be much more common among CGs than among NCGs. Furthermore, symptoms which are often associated with cardiac or respiratory disease were significantly more frequent in the caregiving group, even after controlling for the reported presence of heart disease and chronic bronchitis. One might speculate that the higher frequency of these symptoms reflects higher rates of early, undiagnosed chronic disease among cGs.

\section{EFFECT MODIFICATION}

In the present study, the difference between the study groups was considerably larger in certain subgroups than others. Age was a statistically significant modifier of the association between caregiving and both depression and physical symptoms: the difference between the groups was signif- 
icantly largex among subjects aged 70 years or more than among younger subjects. For both depression and physical symptoms, the difference between CGs and NCGs was substantially larger among spouses than children, although the interaction coefficient was not statistically significant in the analysis involving physical symptoms. Furthermore, for depression, the difference between CGs and NCGs was substantially larger among females than males, and among those who had experienced a larger number of stressful life events in the six months preceding interview; for physical symptoms, the difference between the groups was greater among those with lower educational status.

only two groups of investigators have studied the modifying effect of certain variables on the association between caregiving and health. Kiecolt-Glaser et al. (128) found that the upsetting aspects of social relationships were a strong predictor of depression among CGs but not among NCGs. A similar relationship was not observed for the helpful aspects of social support. Moritz et al. (133) found that the association between subjects' depression and their spouse's cognitive impairment was stronger for husbands than for wives. These investigators also found that the husband's depression was positively associated with his wife's cognitive impairment only among those whose financial support was inadequate and among those who relied on their children for financial support. There was some evidence of effect 
moaification with respect to other social support variables, but the interactions did not reach statistical significance. The absence of any association between coping and the healti indicators requires comment. In univariate analysis, depression and physical symptoms were slightly more frequent among those with lower scores on the F-COPES scale than among those with high scores; however, coping did not confound the association between caregiving and the health indicators. Furthermore, although the differences between CGs and NCGs were slightly higher among those with low coping scores than among those with higher scores, there was no evidence that coping modified the association between caregiving and the health indicators in any substantial way.

It is intuitively attractive to think that coping might modulate the effect of stress on health. It is axiomatic that individuals modify their behavior or emotions in the face of adversity, and that these modifications often lead to the reduction or elimination of negative outcomes. In keeping with this, modern theories of stress emphasize the ability of the individual to adapt to or "cope with" demands or threats encountered in the environment (210). Furthermore, in research on CGs of persons with dementia, several studies have shown an association between coping and wellbeing, although the presence and strength of association that was found depends on the outcome measure and type of coping which was studied $(106,115,123,144)$. 
One explanation for the absence of an association between coping and health in this study is that the comparison of coping levels in the two study groups was not a fair one, since one group was exposed to significant stress whereas the other was not. A transactional conceptualization of coping implies that the person and the environment are in a dynamic, mutually reciprocal relationship (211). Thus, subjects in the CG group would be expected to have modified their coping strategies in response to the caregiving situation whereas NCGs would not have had the impetus to make such adjustments. If this is the case, then the coping scale could not be said to measure the same phenomenon among CGs and NCGs.

A related difficulty concerns the inability to draw causal inferences from a cross-sectional study of this kind. Thus, even if we had observed a positive association between coping and health, it would have been impossible to determine whether better coping skills caused people to be in better health or whether good health allowed people to cope more effectively. A more valid approach might be to determine whether current coping levels predict future health problems. Even such a longitudinal approach, however, is fraught with problems of interpretation since all the variables of interest (coping, $C G$ health, and the intensity of the stress to which the CG is exposed) are likely to change over time. 
Finally, the results of these analyses might have been different if a more refined approach to conceptualization and measurement of coping had been adopted. For example, in this study, coping was measured by an overall score, based on the self-reported use of 29 different coping strategies. However, it may be that certain coping styles or combinations of strategies, rather than simply the overali frequency of use, are associated with better or worse outcomes. Furthermore, the efficiency of different coping styles in reducing the effects of stress is likely to be highly dependent on characteristics both of the individual and of the specific environmental stresses that he or she faces (212). Thus, more refined analyses might reveal whether certain CG coping styles are effective at certain stages of the demented patient's disease, whi?e others are more effective when the environmental demand changes.

\section{ASSOCIATION BETWEEN PATIENT CHARACTERISTICS AND CAREGIVER HEALTH}

Raw CESD scores among CGs were 11.9, 15.8, and 19.0 in three categories of increasing patient behavioral disturbance. Furthermore, regression analysis revealed that CG depression was significantly associated with greater behavioral disturbance in the patients, even after relevant confounders were controlled for. The number of CG physical symptoms was $4.4,5.1$, and 6.2 in the three categories of patient behavior disturbance; patient disturbance had 
marginal statistical significance in the regression analysis which controlled for confounding variables.

These results are in keeping with those obtained in previsus research: the patient's behavioral disturbance was associated with greater health problems among CGs in almost every study in which this variable was included. The fact that, in this study, strong associations between patient behavior disturbance and CG depression and physical symptoms were observed even after controlling for a series of important CG characteristics, supports the importance of behavior disturbance as a correlate of CG health.

In this study, CGs caring for a patient in the intermediate category of cognitive impairment had higher levels of depression than those caring for patients in lower or higher categories. This finding may simply be an artefact resulting from the use of a cross-sectional design. That is, it may be that CGs of patients in the highest category of cognitive impairment represent a highly selected group, in which CGs with high levels of health problems are the most likely to have abandoned the caregiving role. However, to the extent that the observed association between patient cognitive impairment and CG depression is a real one, it can be understood in the context of the natural history of dementia, and on the basis of the argument that behavioral disturbance is the characteristic of most significance to CGs. Thus, patients in the intermediate stages of the disease, as measured by cognitive impairment, are likely to be those with 
the highest level of manifest behavioral disturbance. As the disease progresses towards the terminal stage, the patient becomes less agitated and, paradoxically, may become easier to care for.

Although dementia, from the diagnostic and therapeutic point of view, is almost always defined in terms of its cognitive and functional manifestations, the results of this and other studies suggest that the manifestation of primary salience to the CG is behavioral disturbance. In reality, it is not surprising that the aspects of the patient's disease which cause the CGs the most distress are those which cause them irritation and embarrassment, which are unpredictable, and over which they may have little control. This finding also underscores the importance of carefully delineating the various dimensions of disease severity when studying the impact of dementia on CGs.

\section{METHODOLOGICAL CONSIDERATIONS}

\section{A. Internal validity}

A major aspect of internal validity concerns the comparability of the study groups. In this study, CGs tended to be older and less educated than NCGs; CGs were also less likely to use alcohol or tobacco. However, differences between the groups with respect to these variables were relatively small, and it is likely that the use of multivariate 
analytic techniques eliminated any confounding caused by the unbalanced distribution of these variables.

CGs and NCGs also differed with respect to ethnic group. Although the study groups were selected from among patients at the same hospital, referral patterns of the geriatrics and ophthalmology services from which they were recruited are very different. Thus, despite the fact that some frequency matching was carried out, the proportions of Jews among CGs and NCGs were $84 \%$ and $57 \%$, respectively. Given the size of this difference, the statistical techniques used in this study may not have been adequate to remove all confounding, since the number of subjects in one of the cells (non-Jewish CGs) was small and could provide little information. Thus, it is possible that some residual confounding due to ethnic group persisted in our estimates of the association between caregiving and the two health indicators.

Certain aspects of the data collection procedures may have been sources of bias. The interviewers were aware that we were carrying out a study on the health of the elderly and their families. They were also told that, in order to obtain subjects with a wide spectrum of disability, we included patients having undergone cataract surgery as well as patients from the geriatric assessment unit. They were never given detailed information about the specific study hypotheses. Although they were not informed that the patients who were selected from the geriatric unit all 
suffered from dementia, it is likely that they eventually inferred that this was the case. Furthermore, the nature of the interview itself may have given the interviewers some insight into the research themes which were of interest to us. If they had a preconception concerning the negative impact of caregiving on health, they may have unconsciously influenced the responses given by the study subjects. However, it is unlikely that the bias produced by this subtle phenomenon could have been large enough to produce a substantial exaggeration of the difference between the groups.

The meaning of the interview itself may have been different in the two groups. This is suggested by the fact that the average duration of interview was almost $50 \%$ greater in the CG group than in the NCG group, and by the interviewers' observations that family members of persons with dementia seemed to welcome the opportunity to share their concerns and discuss their problems. Any tendency for the cGs to be more forthcoming than NCGs in the interview situation might have contributed to overestimation of the difference between the groups.

Although about $15 \%$ of the interviews were carried out in French, validated French versions of the study instruments, other than the CESD, were not available. Furthermore, time and budgetary constraints prevented us from carrying out extensive validation and pretesting of the French version of the questionnaire. On the other hand, the study in- 
struments were translated into French by an experienced professional translator and then carefully reviewed by the author who is completely fluent in both English and French. This, together with the fact that only a small proportion of interviews were carried out in French, suggests that Iinguistic nonequivalence is not likely to be an important source of bias in this study. The present study avoided many of the methodological shortcomings observed in previous studies, namely, small sample size, highly selected study samples, lack of comparison groups, inadequate control of confounding, and use of multidimensional outcome variables. However, the crosssectional design that was used limits our ability to infer causal relationships, since the temporal association between variables cannot be determined with certainty. Furthermore, a group of CGs identified at one point in time represent a group of "survivors", that is, a selected sample of the entire cohort of CGs of patients diagnosed around the same time. This selection phenomenon might be a source of bias in analyses of variables which are predictive of abandonment of the caregiving role, as well as variables which are timedependent, such as age and duration of disease. The results of the longitudinal part of our ongoing study will allow more valid specification of the causal associations among variables.

Finally, there was low statistical power for the analyses of effect modification: although the magnitude of sev- 
eral of the interaction coefficients was quite large, the confidence intervals around the estimates were wide. This is a common problem in epidemiologic analysis (213) where sample sizes are rarely large enough to carry out statistically valid tests of interaction. The results of these analyses, although intriguing, should be considered to be exploratory and should serve mainly to provide hypotheses for future research.

\section{B. Generalizability}

In the present study, CGs were identified from among close family members of patients seen at the geriatric assessment unit of a large Montreal hospital. Insofar as diverse social, demographic, and medical factors may influence whether particular patients are referred to a specialized service such as this one, our study group cannot be considered to be a representative sample of all CGs of community-residing patients with dementia. Still, the representativeness of our study sample is probably greater than that of samples studied in previous research, many of which were made up of self-referred volunteers.

Examination of the range of values for cognitive status, functional status, behavioral disturbance, and disease duration suggests that a broad spectrum of disease severity and duration was represented among the demented patients. As for the cataract patients, those with low MMS 
scores and high levels of functional impairment were excluded for reasons of internal validity; among those who were retained in the study, more than $60 \%$ had no functional impairment, one quarter were mildly impaired, and about $12 \%$ were moderately impaired. In other words, the cataract patients were not a highly selected group; rather, they seem to represent a group of elderly individuals who were not particularly healthy nor particularly ill.

In this study, a large proportion of study subjects were Jewish. It has been suggested that cultural and religious values may influence the association between stress and health (69); if this were so, the generalizability of our results would be diminished. In the present study, both the mean CESD score and the mean number of physical symptoms were higher among Jews than among nonJews. However, in the multivariate analyses which we performed, ethnic group was not a significant correlate of either depression or physical symptoms after adjusting for the other covariates. Furthermore, ethnic group was not a significant modifier of the association between caregiving and health; in other words, the difference between CGs and NCGs with respect to depression and physical symptoms was about the same among Jews as it was among non-Jews. These observations lend support to the present study's generalizability.

About $16 \%$ of NCEs had a CESD score of 16 or more, and their mean score was 8.2 . In previous large-scale surveys of 
depression among the elderly, the proportion with a score of 16 or more was between $16 \%$ and $17 \%(151,167,214,215)$; mean CESD scores varied between 8.1 and $10.1(151,167)$. The similarity of our results to those expected on the basis of earlier studies attests to the representativity of our comparison group with respect to one of the major outcome variables.

In order to ensure homogeneity of the study sample, only spouses and children of patients with dementia were included. Thus, the results cannot be generalized to CGs who have some other family or nonfamily relationship with the patient. Since spouses and children account for the majority of CGs of elderly persons with dementia in the community (216), this feature of the study does not substantially limit its generalizability.

About one-third of eligible subjects refused to participate in the study. External validity would be threatened if there were large differences between study participants and nonparticipants with respect to important study variables. Although the age and sex distributions of participants and nonparticipants were very similar, systematic differences with respect to other important variables cannot be excluded. 


\section{IMPLICATIONS}

The results of this study indicate that CGs for elderly relatives with dementia are likely to suffer from a high frequency of psychological and physical morbidity. These results should alert physicians, who are often the only health professionals who maintain continuous contact with the family of the demented patient, to the possibility of health problems among CGs. With careful monitoring of the CGs' health status, appropriate treatment interventions can be undertaken as soon as problems become evident. A focus on prevention is also essential: sensitive to the type of prob-lems that CGs are likely to face, clinicians can make appropriate referrals to community service agencies before the stressful situation becomes critical.

since it seems from this study that CGs experience considerable distress in relation to the patient's behavior, it may be desirable for physicians to regularly evaluate the extent of behavioral disturbance in the patient. The presence of significant disturbance should alert the physician to the possibility that the CG is experiencing physical or psychological problems, or that problems are likely to develop in the near future. Appropriate preventive and therapeutic interventions and referrals can then be undertaken.

These issues are of particular importance since depression and physical symptoms can often be ameliorated with psychological and pharmacological interventions. The patient's behavior disturbance, too, can sometimes be con- 
trolled with appropriate drug therapy. Thus, while there is currently no effective cure for dementia, there are numerous strategies which can be employed by the physician to lessen the overall impact of the disease on the patient and his or her family.

The magnitude of the odds ratios associated with caregiving in this study suggests that caring for an elderly relative with dementia may be a strong risk factor for physical and psychological morbidity. From an epidemiological point of view, this means that more attention should be given to CGs as a subject for future research. Since, as was revealed in this study, CGs have excess rates of physical symptoms, it is possible that they are also at higher risk of physical disease and even death. They may be particularly vulnerable to stress-related conditions such as hypertension, heart disease, and ulcers. Furthermore, the CGs' high frequency of psychological distress and physical symptoms may generate a high rate of consumption of various medications and a high level of medical care utilization. These phenomena deserve examination in future studies.

From the point of view of health planning, this study demonstrates that the impact of dementia cannot be assessed simply in terms of the effect on the patients themselves; the medical, social and economic impact on family cGs must also be recognized. Although many patients with dementia are institutionalized at some point in the course of their disease, the majority of them reside in the community for most 
of the years during which they are ill $(65,66)$. Furthermore, the presence of a capable CG is often the crucial element in keeping patients with dementia out of institutions. Thus, preventing and controlling health problems among CGs may have a significant effect on the economic and social costs incurred by nursing home use.

The results of the present study suggest that CGs might benefit from greater access to community services, such as home care programs, specialized support groups, and home and hospital respite care. There is a pressing need to develop innovative new programs of this type and to evaluate their benefits and costs.

In this study, certain subgroups were identified in which the association between caregiving and health seemed to be particularly strong. If confirmed in future research, this information might guide health planners to target their interventions to the most vulnerable CGs.

In recent years, the number of persons at risk for dementia has steadily increased, as a result of the increasing life expectancy of successive birth cohorts. If this demographic trend continues, and if medical progress continues to result in prolonged survival but not in effective therapeutic or preventive strategies, the number of people with dementia can be expected to become much larger. Although a great deal of research effort is currently aimed at finding a definitive cure for Alzheimer's disease and other dementias, such a cure is not likely to emerge in the foreseeable 
future. In the meantime, vigorous research and planning programs need to be pursued in order to enhance our understanding of the health problems experienced by caregivers of elderly persons with dementia, and to develop appropriate supportive services to help them care for their affected family member at home. 


\section{REFERENCES}

1. American Psychiatric Association Task Force on Nomenclature and Statistics. Diagnostic and statistical manual of mental disorders, 3rd edition. 1980.

2. Khachaturian ZS. Diagnosis of Alzheimer's disease. Arch Neurology 1985;42:1097-1105.

3. Coodley EL. Dementia. Geriat Med Today 1987;6:47-68.

4. Katzman R. Alzheimer's disease. New Engl J Med $1986 ; 314: 964-973$.

5. Gershon S, Herman SP. The differential diagnosis of dementia. J Am Geriatrics Society 1982;30 (suppl):S58s66.

6. Watson WJ, Seiden HS. Alzheimer's disease: a current review. Can Family Physician 1984;30:595-599.

7. Hutton JT. Clinical nosology of the dementing illnesses. In: Maletta GJ, Pirozzolo FJ (eds.). The aging nervous system. Praeger: New York, 1980.

8. McLean S. Assessing dementia. Part I: Difficulties, definitions and differential diagnosis. Aust $\mathrm{N}$ zealand J Psychiatry 1987;21:142-174.

9. Clarfield AM. The reversible dementias: do they reverse? Ann Int Med 1988;109:476-486.

10. Hagnell 0 , Lanke $J$, Rorsman $B$, et al. Current trends in the incidence of senile and multi-infarct dementia: a prospective study of a total population followed over 25 years; the Lundby study. Archiv fur Psychiatrie und Nervenkrankheiten $1983 ; 233: 423-438$.

11. Rocca WA, Amaducci LA, Schoenberg BS. Epidemiology of clinically diagnosed Alzheimer's disease. Ann Neurology $1986 ; 19: 415-424$.

12. Kokmen E, Chandra V, Schoenberg BS. Trends in incidence of dementing illness in Rochester, Minnesota, in three quinquennial periods, 1960-1974. Neurology 1988;38:975980 .

13. Terry RD, Katzman R. Senile dementia of the Alzheimer type. Ann Neurology 1983;14:497-506. 


\section{REFERENCES (continued)}

14. Heston IL, Mastri AR, Anderson E, et al. Dementia of the Alzheimer type: clinical genetics, natural history, and associated conditions. Arch Gen Psychiatry $1981 ; 38: 1085-1090$.

15. Heston LL. Genetics studies of dementia: with emphasis on Parkinson's disease and Alzheimer's neuropathology. In: Mortimer JA, Schuman IM (eds.). The epidemiology of dementia. Oxford University Press: New York, 1981.

16. Davies P. The genetics of Alzheimer's disease: a review and a discussion of the implications. Neurobiology Aging $1986 ; 7: 459-466$.

17. Huff FJ, Auerbach J, Chakravarti A, et al. Risk of dementia in relatives of patients with Alzheimer's disease. Neurology 1988;38:786-790.

18. Heston LL. Down's syndrome and Alzheimer's disease: defining an association. Psychiat Developments $1984 ; 4: 287-294$.

19. Oliver C, Holland AJ. Down's syndrome and Alzheimer's disease: a review. Psychol Med 1986;16:307-322.

20. Gautrin D, Gauthier S. Alzheimer's disease: environmental factors and etiologic hypotheses. Can $J$ Neurol Sciences $1989 ; 16: 375-387$.

21. St. George-Hyslop PH, Tanzi RE, Polinsky RJ, et al. The genetic defect causing familial Alzheimer's disease maps on chroinosome 21. Science 198\%;235:885-890.

22. Roos RP. Alzheimer's disease and the lessons of transmissible virus dementia. In: Mortimer JA, Schuman IM (eas.). The epidemiology of dementia. Oxford University Press: New York, 1982.

23. Amaducci I, Lippi A. Risk factors and genetic background for Alzheimer's disease. Acta Neurol scand 1988;77 (suppl 116):13-18.

24. Deary IJ, Whalley IJ. Recent research on the causes of Alzheimer's disease: what causes neuronal death, and why the specific patterns? Br Med J 1988;297:807-810.

25. Beck JC (mod.). Dementia in the elderly: the silent epidemic. Ann Int Med 1982;97:231-241.

26. Schmidt $G$. Mechanisms and possible causes of Alzheimer's disease. Postgrad Med 1983;73:206-213. 


\section{REFERENCES (continued)}

27. Crapper MCLachlan DR. Aluminum and Alzheimer's disease. Neurobiology Aging 1986;7:525-532.

28. Zatta $P$, Giordano $R$, Corain B, et al. Alzheimer dementia and the aluminum hypothesis. Med Hypotheses $1988 ; 26: 139-142$.

29. Heyman A, Wilkinson WE, Stafford JA, et al. Alzheimer's disease: a study of epidemiological aspects. Ann Neurology $1984 ; 15: 335-341$.

30. French LR, Schuman IM, Mortimer JA, et al. A casecontrol study of dementia of the Alzheimer type. Am J Epidemiology 1985;121:414-421.

31. Amaducci LA, Fratiglioni L, Rocca WA, et al. Risk factors for clinically diagnosed Alzheimer's disease: a case-control study of an Italian population. Neurology $1986 ; 36: 922-931$.

32. Mortimer JA, French LR, Hutton JT, et al. Head injury as a risk factor for Alzheimer's disease. Neurology $1985 ; 35: 264-267$.

33. Shalat SL, Seltzer B, Pidcock C, et al. Risk factors for Alzheimer's disease: a case-control study. Neurology $1987 ; 37: 1630-1633$.

34. Chandra V, Philipose V, Bell PA, et al. Case-control study of late onset "probable Alzheimer's disease". Neurology $1987 ; 37: 1295-1300$.

35. Cummings JL. Multi-infarct dementia: diagnosis and management. Psychosomatics $1987 ; 28: 117-126$.

36. Read SL, Jarvik LF. Cerebrovascular disease in the differential diagnosis of dementia. Psychiat Annals $1984 ; 14: 100-108$.

37. Meyer JS, Judd BW, Tawaklna T, et al. Improved cognition after control of risk factors for multiinfarct dementia. JAMA 1986;256:2203-2209.

38. Meyer JS, Mcclintic KL, Rogers RL, et al. Aetiological considerations and risk factors for multi-infarct dementia. J Neurology Neurosurgery Psychiatry $1988 ; 51: 1489-1497$.

39. Gilroy J, Meyer JS. Medical neurology. Macmillan Publishing Co.: New York, 1975. 
REFERENCES (continued)

40. Van Horn G. Dementia. Am J Med 1987;83:101-110.

41. Royal College of Physicians of London. College Committee on Geriatrics. Organic mental impairment in the elderly: implications for research, education and the provision of services. J Royal College Physicians London $1981 ; 15: 142-167$.

42. Wells CE. Chronic brain disease: an overview. Am J Psychiatry $1978 ; 135: 1-12$.

43. Kral VA. Senescent forgetfulness: benign and malignant. Can Med Assoc J 1962;86:257-260.

44. Kwentus JA, Hart $R$, Lingon $N$, et al. Alzheimer's disease: a review. Am J Med 1986;81:91-96.

45. Molsa PK, Marttila RJ, Rinne UK. Survival and cause of death in Alzheimer's disease and multi-infarct dementia. Acta Neurol Scand 1986;74:103-107.

46. Diesfeldt HFA, Van Houte LR, Moerkens RM. Duration of survival in senile dementia. Acta Psychiat scand $1986 ; 73: 366-371$.

47. Reisberg B, Shulman E, Ferris SH, et al. Clinical assessments of age-associated cognitive decline and primary degenerative dementia: prognostic concomitants. Psychopharmacology Bull 1983;19:734-739.

48. Hachinski VC. Differential diagnosis of Alzheimer's dementia: multi-infarct dementia. In: Reisberg $B$ (ed.). Alzheimer's disease: the standard reference. Free Press: New York, 1983.

49. Barclay LL, Zemcov A, Blass JP, et al. Factors associated with duration of survival in Alzheimer's disease. Biol Psychiatry 1985;20:86-93.

50. Heyman A, Wilkinson WE, Hurwitz BJ, Early-onset Alzheimer's disease: clinical predictors of institutionalization and death. Neurology 1987;37:980984 .

51. Dysken M. A review of recent clinical trials in the treatment of Alzheimer's dementia. Psychiat Ann $1987 ; 17: 178-191$.

52. Meyer JD, Rogers RL, MCClintic $K$, et al. Randonized clinical trial of daily aspirin therapy in multiinfarct dementia: a pilot study. J Am Geriatrics Society $1989 ; 37: 549-555$. 
REFERENCES (continued)

53. Kokmen E. Dementia - Alzheimer type. Mayo Clinic Proc $1984 ; 59: 35-42$.

54. Martin RL. Update on dementia of the Alzheimer type. Hosp Comm Psychiatry 1989;40:593-604.

55. Keyes B, Szpak G. Day care for Alzheimer's disease: profile of one program. Postgrad Med 1983;73:245-250.

56. Nortimer JA, Schuman LM, French LR. Epidemiology of dementia: overview and prospects. In: Mortimer JA, Schuman LM (eds.). The epidemiology of dementia. oxford University Press: New York, 1981.

57. Schoenberg BS, Kokmen E, Okazaki H. Alzheimer's disease and other dementing illnesses in a defined United States population: incidence rates and clinical features. Ann Neurology $1987 ; 22: 724-729$.

58. Henderson AS. The coming epidemic of dementia. Aust $N$ Zealand $J$ Psychiatry 1983;17:117-127.

59. Ineichen B. Measuring the rising tide: how many dementia cases will there be by 2001? Br J Psychiatry $1987 ; 150: 193-200$.

60. Jorm AF, Korten AE, Henderson AS. The prevalence of dementia: a quantitative integration of the literature. Acta Psychiat Scand 1987;76:465-479.

61. Gruenberg EM. Epidemiology of senile dementia. In: Schoenberg BS (ed.). Advances in Neurology, vol. 19. Raven Press: New York, 1978.

62. Ableson J, Paddon P, strohmenger C. Perspectives sur la santé. Ottawa: Statistics Canada, 1983. Cat. 82-540F.

63. Beaulieu G. Les troubles mentaux chez les personnes âgees. Carrefour des affaires sociales 1984;6:19-30.

64. Jorm AF, Rorten AE, Jacomb PA. Projected increases in the number of dementia cases for 29 developed countries: application of a new method for making projections. Acta Psychiat scand 1988;78:493-500.

65. Ory MG, Williams TF, Emr M, et al. Families, informal supports, and Alzheimer's disease: current research and future agendas. Research Aging 1985;7:623-644.

66. Bergmann K. Epidemiological aspects of dementia and considerations in planning services. Dan Med Bull 1985;32 (suppl 1):84-91. 
REFERENCES (continued)

67. Weiler PG. The public health impact Alzheimer's disease. Am J Public Health 1987;77:1157-1158.

68. Huang, LF, Cartwright WS, Hu TW. The economic cost of senile dementia in the United States, 1985. Public Health Rep 1988;103:3-7.

69. Caplan G. The mastery of stress: psychosocial aspects. Am J Psychiatry 1981;138:413-420.

70. Kasl SV. Stress and health. Ann Rev Public Health $1984 ; 5: 319-341$.

71. Margetts EL. Stress, homeostasis, and the human ecological continuum in time - some implications for psychiatry. In: Levi I (ed.). Society, stress and disease, vol. 2. Childhood and adolescence. Oxford University Press: London, 1975.

72. Cobb S. Social support as a moderator of life stress. Psychosom Med 1976;38:300-314.

73. McQueen DV, siegrist J. Social factors in the etiology of chronic disease: an overview. Soc Science Med $1982 ; 16: 353-367$.

74. Billings AG, Moos $\mathrm{RH}$. The role of coping responses and social resources in attenuating the stress of life events. J Behav Med 1981;4:139-157.

75. Vingerhoets AJJM, Marcelissen FHG. Stress research: its present status and issues for fuiure developments. Soc Science Med 1988;26:279-291.

76. Berkman LF. Assessing the physical health effects of social networks and social support. Ann Rev Public Health $1984 ; 5: 413-432$.

77. Thoits PA. Conceptual, methodological, and theoretical problems in studying social support as a buffer against life stress. J Health Soc Behavior 1982;23:145-159.

78. Zimmerman M. Methodological issues in the assessment of life events: a review of issues and research. Clin Psychology Rev 1983;3:339-370.

79. Paykel ES. Contribution of life events to causation of psychiatric illness. Psychol Med 1978;8:245-253.

80. Potasznik H, Nelson G. Stress and social support: the burden experienced by the family of a mentally ill person. Am J Comm Psychology 1984;12:589-607. 
REFERENCES (continued)

81. Brown GW, Birley JLT, Wing JK. Influence of family life on the course of schizophrenic disorders: a replication. Br J Psychiatry 1972;121:241-258.

82. Brocklehurst JC, Morris $P$, Andrews $K$, et al. Social effects of stroke. Soc Science Med 1981;15A:35-39.

83. Breslau N, Staruch KS, Mortimer EA. Psychological distress in mothers of disabled children. Am J Diseases Children $1982 ; 136: 682-686$.

84. Breslau N, Weitzman M, Messenger K. Psychologic functioning of siblings of disabled children. Pediatrics $1981 ; 67: 344-353$.

85. Walker CL. Stress and coping in siblings of childhood cancer patients. Nursing Research 1988;37:208-212.

86. Marcus $L$, Jaeger $V$. The elderly as family caregivers. Can J Aging 1985;3:33-43.

87. Sanford JRA. Tolerance of debility in elderly dependants by supporters at home: its significance for hospital practice. Br Med J 1975;3:471-473.

88. Cantor MH. Strain among caregivers: a study of experience in the United States. Gerontologist $1983 ; 23: 597-604$.

89. Snyder $B$, Keefe $K$. The unmet needs of family caregivers for frail and disabled adults. Social Work Health Care $1985 ; 10: 1-14$.

90. Fengler AP, Goodrich N. Wive- of elderly disabled men: the hidden patients. Gerontologist 1979;19:175-183.

91. Koopman-Boyden PG, Wells LF. The problems arising from supporting the elderly at home. $\mathrm{N}$ Zealand Med $\mathrm{J}$ $1979 ; 89: 265-268$.

92. Sainsbury $P$, Grad De Alarcon $J$. The psychiatrist and the geriatric patient: the effects of community care on the family of the geriatric patient. J Geriat Psychiatry 1970;1:23-41.

93. Rabins PV. Management of dementia in the family context. Psychosomatics $1984 ; 25: 369-373$.

94. Aronson MK, Lipkowitz R. Senile dementia, Alzheimer's type: the family and the health care delivery system. $J$ Am Geriatrics Society 1981;29:568-571. 


\section{REFERENCES (continued)}

95. Teusink JP, Mahler S. Helping families cope with Alzheimer's disease. Hosp Comm Psychiatry 1984;35:152156.

96. Fiore J, Coppel DB, Becker J, et al. Social support as a multifaceted concept: examination of important dimensions for adjustment. Am J Comm Psychology $1986 ; 14: 93-111$.

97. Niederehe G, Fruge E. Dementia and family dynamics: clinical research issues. J Geriat Psychiatry $1984 ; 17: 21-56$.

98. Morycz RK. Caregiving strain and the desire to institutionalize family members with Alzheimer's disease. Research Aging 1985:7:329-361.

99. Wilder DE, Teresi JA, Bennett RG. Family burden and dementia. In: Mayeux R, Rosen WG (Eds.). The dementias. Raven Press: New York, 1983.

100. Montgomery RJV, Stull DE, Borgatta EF. Measurement and the analysis of burden. Research Aging 1985;7:137-152.

101. Gilleard CJ, Boyd WD, watt G. Froblems in caring for the elderly mentally infirm at home. Arch Gerontology Geriatrics 1982;1:151-158.

102. Gilleard CJ, Belford H, Gilleard E, et al. Emotional distress amor,yst the supporters of the elderly mentally infirm. Br J Psychiatry 1984;145:172-177.

103. Gilhooly MLM. The impact of care-giving on care-givers: Factors associated with the psychological well-being of people supporting a dementing relative in the community. Br J Med Psychology 1984;57:35-44.

104. Pagel MD, Becker J, Coppel DB. Loss of control, selfblame, and depression: an investigation of spouse caregivers of Alzheimer's disease patients. J Abnormal Psychology 1985;94:169-182.

105. Pratt CC, Schmall VL, Wright S, et al. Burden and coping strategies of caregivers to Alzheimer's patients. Family Relations 1985;34:27-33.

106. Coppel DB, Burton C, Becker J, et al. Relationships of cognitions associated with coping reactions to depression in spousal caregivers of Alzheimer's disease patients. Cog Therapy Research 1985;9:253-266. 
REFERENCES (continued)

107. Zarit SH, Reever KE, Bach-Peterson J. Relatives of the impaired elderly: correlates of feelings of burden. Gerontologist 1980;20:649-655.

108. Fitting M, Rabins P, Lucas MJ, Eastham J. Caregivers for dementia patients: a comparison of husbands and wives. Gerontologist $1986 ; 26: 248-252$.

109. George LK, Gwyther LP. Caregiver well-being: a multidimensional examination of family caregivers of demented adults. Gerontologist 1986;26:253-259.

110. Scott JP, Roberto KA, Hutton JT. Families of Alzheimer's victims: family support to the caregivers. J Am Geriatrics Society 1986;34:348-354.

111. Haley WE, Levine EG, Brown SL, et aí. Psychological, social, and healtr consequences of caring for a relative with senile dementia. J Am Geriatrics Society $1987 ; 35: 405-411$.

112. Eagles JM, Craig A, Rawlinson F, et al. The psychological well-being of supporters of the demented elderly. Br J Psychiatry 1987;150:293-298.

113. Eagles JM, Beattie JAG, Blackwood GW, et al. The mental health of elderly couples. I. The effects of a cognitively impaired spouse. Br J Psychiatry $1987 ; 150: 299-303$.

114. Deimling GT, Bass DM. Symptoms of mental impairment among elderly adults and their effects on family caregivers. J Gerontology 1986;41:778-784.

115. Haley WE, Levine EG, Brown SL, et al. Stress, appraisal, coping and social support as predictors of adaptational outcome among dementia caregivers. Psychology Aging $1987 ; 2: 323-330$.

116. Pratt $C$, wright S, Schmall V. Burden, coping and health status: a comparison of family caregivers to community dwelling and institutionalized Alzheimer's patients. J Gerontol Social Work 1987;10:99-112.

117. Drinka TJK, Smith JC, Drinka PJ. Correlates of depression and burden for informal caregivers of patients in a geriatrics referral clinic. J Am Geriatrics Society 1987;35:522-525.

118. Birikel RC. Toward a social ecology of the home-care household. Psychology Aging 1987;2:294-301. 


\section{REFERENCES (continued)}

119. Kiecolt-Glaser JK, Glaser R, Shuttleworth EC, et al. Chronic stress and immunity in family caregivers of Alzheimer's disease victims. Psychosom Med 1987;49:523535 .

120. Anthony-Bergstone CR, Zarit SH, Gatz M. Symptoms of psychological distress among caregivers of dementia patients. Psychology Aging 1988;3:245-248.

121. Gilleard CJ, Gilleard E, Gledhill K, et al. Caring for the elderly mentally infirm at home: $a_{4}$ survey of the supporters. J Epidemiology Comm Health 1984;38:319-325.

122. Liptzin B, Grob MC, Eisen SV. Family burden of demented and depressed elderly psychiatric inpatients. Gerontologist $1988 ; 28: 397-401$.

123. Quayhagen MP, Quayhagen M. Alzheimer's stress: coping with the caregiving role. Gerontologist $1988 ; 28: 391-$ 396.

124. Fiore $J$, Becker $J$, Coppel DB. Social network interactions: a buffe: or a stress? Am J Comm Psychology $1983 ; 11: 423-439$.

125. Pagel $M$, Becker J. Depressive thinking and depression: relations with personality and social resources. J Personality Soc Psychology 1987;52:1043-1052.

126. Pagel MD, Erdly WW, Becker J. Social networks: we get by with (and in spite of) a little help from our friends. J Personality Soc Psychology 1987;53:793-804.

127. Whittick JE. Dementia and mental handicap: emotional distress in carers. Br J Clin Psychology 1988;27:167172 .

128. Kiecolt-Glaser JK, Dyer CS, Shuttleworth EC. Upsetting social interactions and distress among Alzheimer's disease family caregivers: a replication and extension. Am J Comm Psychology 1989;16:825-837.

129. Pett MA, Caserta MS, Hutton AP, et al. Intergenerational conflict: middle-aged women caring for demented older relatives. Am J orthopsychiatry 1988;58:405-417.

130. Novak M, Guest C. Caregiver response to Alzheimer's disease. Int J Aging Human Development 1989;28:67-79. 
REFERENCES (continued)

131. Morris LW, Morris RG, Britton PG. Social support networks and formal support as factors influencing the psychological adjustment of spouse caregivers of dementia sufferers. Int J Geriat Psychiatry 1989;4:4751 .

132. Morris LW, Morris RG, Britton PG. The relationship between marital intimacy, perceived strain and depression in spouse caregivers of dementia sufferers. $\mathrm{Br} J$ Med Psychology 1988;61:231-236.

133. Moritz DJ, Kasl SV, Berkman LF. The health impact of living with a cognitively impaired elderly spouse: depressive symptoms and social functioning. J Gerontology $1989 ; 44:$ S17-27.

134. Pruchno RA, Resch NL. Husbands and wives as caregivers: antecedents of depression and burden. Gerontologist $1989 ; 29: 159-165$.

135. Cohen D, Eisdorfer C. Depression in family members caring for a relative with Alzheimer's disease. J Am Geriatrics Society 1988;36:885-889.

136. Nygaard HA. Strain on caregivers of demented elderly people living at home. Scand $J$ Primary Health Care $1988 ; 6: 33-37$.

137. Pruchno RA, Resch NL. Aberrant behaviors and Alzheimer's disease: mental health effects on spouse caregivers. J Gerontology 1989;44:S177-182.

138. Zarit SH, Todd PA, Zarit JM. Subjective burden of husbands and wives as caregivers: a longitudinal study. Gerontologist $1986 ; 26: 260-266$.

139. Scharlach AE. A comparison of employed caregivers of cognitively impaired and physically impaired elderly persons. Research Aging 1989;11:225-243.

140. Motenko AK. The frustrations, gratifications, and wellbeing of dementia caregivers. Gerontologist $1989 ; 29: 166-172$.

141. Morris LW, Morris RG, Britton PG. Cognitive style and perceived control in spouse caregivers of dementia sufferers. Br J Med Psychology 1989;62:1.73- 79.

142. Whittick JE. Dementia and mental handicap: attitudes, emotional distress and caregiving. Br J Med Psychology $1989 ; 62: 18 i-189$. 
REFERENCÉS (continued)

143. Pruchno RA, Potashnik SL. Caregiving spouses: physical and mental health in perspective. J Am Geriatrics Society $1989 ; 37: 697-705$.

144. Pruchno RA, Resch NL. Mental health of caregiving spouses: coping as mediator, moderator, or main effect? Psychology Aging $1989 ; 4: 454-459$.

145. Cohen J. Statistical power analysis for the behavioral sciences. Revised edition. Academic Press: New York, 1977 .

146. Matthews SH. The burdens of parent care: a critical evaluation of recent findings. J Aging Studies $1988 ; 2: 157-165$.

147. Morris RG, Morris IW, Britton PG. Factors affecting the emotional wellbeing of the caregivers of lementia sufferers. Br J Psychiatry 1988;153:147-156.

148. Wen CP, Tsai SP, Gibson RL. Anatomy of the healthy worker effect: a critical review. J Occup Med $1983 ; 25: 283-289$.

149. Haley WE, Pardo KM. Relationship of stage of dementia to caregiver stress and coping. Presented at the American Psychological Association meeting: New York, 1987 .

150. Haley WE, Brown SL, Levine EG. Family caregiver appraisals of patient behavioral disturbance in senile dementia. Clin Gerontologist $1987 ; 6: 25-34$.

151. Berkman LF, Berkman CS, Kasl S, et al. Depressive symptoms in relation to physical health and functioning in the elderly. Am J Epidemiology 1986;124:372-388.

152. Leavy RL. Social support and psychological disorder: a review. J Comm Psychoiogy 1983;11:3-21.

153. Bankoff EA. Social support and adaptation to widowhood. J Marriage Family 1983;45:827-839.

154. Ruberman W, Weinblatt E, Goldberg JD, et al. Psychosocial influences on mortality after myocardial infarction. New Engl J Med 1984;311:552-559.

155. Cohen S, Wills TA. Stress, social support, and the buffering hypothesis. Psychol Bull 1985;98:310-357. 
REFERENCES (continued)

156. Schradle SB, Dougher MJ. Social support as a mediator of stress: theoretical and empirical issues. Clin Psychology Rev 1985;5:641-661.

157. Folstein MF, Folstein SE, McHugh PR. "Mini-Mental State": a practical method for grading the cognitive state of patients for the clinician. I Psychiat Research 1975;12:189-198.

158. Duke University Center for the study of Aging and Human Development. Multidimensional functional assessment: the OARS methodology. Duke University: Durham, 1978.

159. Applegate WB, Miller ST, Elam JT, et al. Impact of cataract surgery with lens implantation on vision and physical function in elderly patients. JAMA $1987 ; 257$ : 1064-1066.

160. Becker J, Morrissey E. Difficulties in assessing depressive-like reactions to chronic severe external stress as exemplified by spouse caregivers of Alzheimer patients. Psychology Aging 1988;3:300-306.

161. Toseland RW, Rossiter CM. Group interventions to support family caregivers: a review and analysis. Gerontologist $1989 ; 29: 438-448$.

162. Romans-Clarkson SE, Clarkson JE, Dittmer ID, et al. Impact of a handicapped child on mental health of parents. Br Med J 1986;293:1395-1397.

163. Rodway MR, Elliott J, Sawa RJ. Intervention with families of the elderly chronically ill: an alternate approach. J Gerontol Social Work 1987;10:51-60.

164. Radloff LS. The CES-D scale: a self-report depression scale for research in the general population. Appl Psychol Meas $1977 ; 1: 385-401$.

165. Weissman MM, Sholomskas D, Pottenger M, et al. Assessing depressive symptoms in five psychiatric populations: a validation study. Am J Epidemiology 1977;106:203-214.

166. Radloff LS, Locke BZ. The Community Mental Health Assessment Survey and the CES-D scale. In: Weissman MM, Myers JK, Ross CE (eds). Community surveys of psychiatric disorders. Rutgers University Press: New Brunswick NJ, 1986. 
REFERENCES (continued)

167. Murrell SA, Himmelfarb S, Wright KH. Prevalencs of depression and its correlates in older adults. Am J Epidemiology 1983;117:173-185.

168. Phifer JF, Murrell SA. Etiologic factors in the onset of depressive symptoms in older adults. J Abnormal Psychology 1986;95:282-291.

169. Norris FH, Murrell SA. Transitory impact of life-event stress on psychological symptoms in older adults. J Health Soc Behavior $1987 ; 28: 197-211$.

170. Mahard RE. The CES-D as a measure of depressive mood in the elderly Puerto Rican population. J Gerontology $1988 ; 43: 24-25$.

171. Goldberg EL, Van Natta P, Comstock GW. Depressive symptoms, social networks and social support of elderly women. Am J Epidemiology 1985;121:448-456.

172. Himmelfarb S, Murrell SA. Reliability and validity of five mental health scales in older persons. J Gerontology $1983 ; 38: 333-339$.

173. Lawton MP, Brody EM, Saperstein AR. A controlled study of respite service for caregivers of Alzheimer's patients. Gerontologist $1989 ; 29: 8-16$.

174. Pennebaker JW. The psychology of physical symptoms. Springer-Verlag: New York, 1982.

175. Attanasio V, Andrasik F, Blanchard EB, et ai. Psychometric properties of the SUNYA revision of the Psychosomatic Symptom Checklist. J Behav Med $1984 ; 7: 247-258$.

176. Taylor DG, Aday LA, Andersen R. A social indicator of access to medical care. J Health Soc Behavior $1975 ; 16: 39-49$.

177. Aday LA, Andersen R. Development of indices of access to medical care. Health Administration Press: Ann Arbor, 1975.

178. Aáy IA. Health care in the United States. Sage Publications: Beverly Hills, 1980.

179. Shapiro MF, Ware JE, Sherbourne CD. Effects of cost sharing on seeking care for serious and minor symptoms. Ann Int Med $1986 ; 104: 246-251$. 
REFERENCES (continued)

180. Anthony JC, LeResche $L$, Niaz U, et al. Limits of the "Mini-Mental state" as a screening test for dementia and delirium among hospital patients. Psychol Med $1982 ; 12: 397-408$.

181. Nelson A, Fogel BS, Faust D. Bedside cognitive screening instruments: a critical assessment. $J$ Nerv Ment Disease $1986 ; 174: 73-83$.

182. Anthony $J$, Folstein $M$, Kramer M. Limits of the "MiniMental state" as a screen for severe cognitive impairment in the community. Presented at the society for Epidemiologic Research conference: Chapel Hill NC, 1985 .

183. George LK, Fillenbaum GG. OARS methodology: a decade of experience in geriatric assessment. J Am Geriatrics society $1985 ; 33: 607-615$.

184. Kane RA, Kane RL. Assessing the elderly: a practice guide to measurement. Lexington Books: Lexington, 1981.

185. Lawton MP, Brody EM. Assessment of older people: selfmaintaining and instrumental activities of daily living. $J$ Gerontology 1969;9:179-186.

186. Hirschfeid $M$. Homecare versus institutionalization: family caregiving and senile brain disease. Int $J$ Nursing stuaies $1983 ; 20: 23-32$.

187. Zarit SH, Zarit JM. The Memory and Behavior Problems Checklist and the Burden Interview. Unpublished manuscript, 1983.

188. Greene JG, Smith $R$, Gardiner $M$, et al. Measuring behavioural disturbance of elderly demented patients in the community and its effects on relatives: a factor analytic study. Age Ageing 1982;11:121-126.

189. Yesavage JA, Adey M, Werner PD. Development of a geriatric behavioral self-assessment scale. J Am Geriatrics Society 1981;29:285-288.

190. Scott J, Wiegand G, Niederehe G. Measuring behavioral problems and dimensions of family caregiving in senile dementia. Presented at the 37 th Annual Scientific Meeting of the Gerontological Society of America: San Antonio TX, 1984.

191. Statistics Canada. The health of Canadians: report of the Canada Health Survey. Health and Welfare Canada: 1981 . 
REFERENCES (continued)

192. Murrell SA, Norris FH, Hutchins GL. Distribution and desirability of life events in older adults: population and policy implications. J Comm Psychology 1984;12:301311 .

193. Weinberger M, Darnell. JC, Martz BL, et al. The effects of positive and negative life changes on the selfreported health status of elderly adults. J Gerontology $1986 ; 41: 114-119$.

194. Ross CE, Mirowsky J. A comparison of life-eventweighting schemes: change, undesirability, and effectproportional indices. J Health Soc Behavior $1979 ; 20: 166-177$.

195. Cornoni-Huntley J, Brock DB, Ostfeld AM, et al. (eds.). Established populations for epidemiologic studies of the elderly. National Institute on Aging. NIH Publication No. 86-2443, 1986.

196. Olson DH, MCCubbin HI, Barnes H, et al. Family inventories. Family Social Science, University of Minnesota: St. Paul, 1982 .

197. Barber CE. Correlates of subjective burden among adult sons and daughters caring for aged parents. J Aging studies $1988 ; 2: 133-144$.

198. Cutrona CE. Objective determinants of perceived social support. J Personality Soc Psychology 1986;50:349-355.

199. Russell D, Cutrona C. The provisions of social relationships and adaptation to stress. Presented at the American Psychological Association meeting: Toronto, 1984 .

200. Weiss RS. The provisions of social relationships. In: Rubin $\mathrm{Z}$ (ed.). Doing untc others. Prentice-Hall: Englewood Cliffs NJ, 1974.

201. Stokes JP. Predicting satisfaction with social support from social network structure. Am $J$ Comm Psychology $1983 ; 11: 141-152$.

202. Noelker LS, Wallace RW. The organization of family care for impaired elderly. J Family Issues 1985;6:23-44.

203. Stoller EP. Parental caregiving by adult children. J Marriage Family 1983;45:851-858.

204. Cronbach LJ. Coefficient alpha and the internal structure of tests. Psychometrika 1951;16:297-334. 
REFERENCES (continued)

205. Green LW, Lewis FM. Measurement and evaluation in health education and health promotion. Mayfield Publishing Company: Palo Alto, California, 1986.

206. Strain JJ, Fulop G. Screening devices for cognitive capacity (editorial). Ann Int Med 1987;107:583-585.

207. Wasylenki D. Depression in the elderly. Can Med Assoc J $1980 ; 122: 525-533$.

208. Lipowski ZJ. Psychiatry: mindless or brainless, both or neither? Can J Psychiatry 1989;34:249-254.

209. Laudenslager ML. The psychobiology of loss: lessons from humans and nonhuman primates. J Soc Issues $1988 ; 44: 19-36$.

210. Rutter M. Resilience in the face of adversity: protective factors and resistance to psychiatric disorder. Br J Psychiatry 1985;147:598-611.

211. Folkman S, Lazarus RS, Gruen RJ, et al. Appraisal, coping, health status, and psychological symptoms. J Personality Soc Psychology 1986;50:571-579.

212. Pearlin LI, Schooler C. The structure of coping. J Health Soc Behavior 1978;19:2-21.

213. Greenland $S$. Modeling and variable selection in epidemiologic analysis. Am J Public Health 1989;79:340349 .

214. Frerichs RR, Aneshensel CS, clark VA. Prevalence of depression in Los Angeles County. Am J Epidemiology 1981;113:691-699.

215. Kennedy GJ, Kelman HR, Thomas C, et al. Hierarchy of characteristics associated with depressive symptoms in an urban elderly sample. Am J Psychiatry 1989;146:220225.

216. Stone R, Cafferata GL, Sangl J. Caregivers of the frail elderly: a national profile. Gerontologist 1987;27:616626. 
APPENDIX 1

\title{
THE HEALTH OF PERSONS GIVING CARE TO THE DEMENTED ELDERLY: A CRITICAL REVIEW OF THE IITERATURE
}

\author{
Mona Baumgarten
}

Journal of Clinical Epidemiology (1989) 


\title{
THE HEALTH OF PERSONS GIVING CARE TO THE DEMENTED ELDERLY:
} A CRITICAL REVIEW OF THE LITERATURE

\author{
MONA BAUMgarTEN* \\ Department of Epidemiology and Biostatistics. McGill University and Community Health \\ Department. St Justine Hospital. Montreal. Quebec. Canada H3T IC5
}

(Receited in recised form 5 June 1989)

\begin{abstract}
The majority of the demented eiderly live at home. usually cared for by their spouse or an adult child. Clinical impressions suggest that caring for an older person suffering from a dementing disorder may lead to physical and mental health problems for the caregiver. A critical review of the research literature on this topic was carried out. The review revealed that a multitude of physical and mental health outcomes as well as numerous correlates of health problems have been studied in relation to caregiving. Furthermore. several methodological problems were identified in the studies reviewed: inadequate sample size. unrepresentative study samples. uncontrolled confounding factors. inappropriate study design. multudimensional outcome measures, and absence of comparison groups. The diversity of outcomes studied and the numerous methodological problems make it dificult to make statements about the causal effect of caregiving on health. or to assess the public health impact of caring for a demented elderly person. Nevertheless, the work done to date suggests interesting directions for future research.
\end{abstract}

Dementia Alzheimer's diseuse Curegivers Chronic illness Elderly

\section{INTRODUCTION}

Senile dementia is a serious problem with numerous medical. social, and economic ramintcations. The public health importance of this disense stems. first. from its high frequency in the elderly population. It has been estimated that between $3 \%$ and $6 \%$ of all persons aged 65 years or more suffer from severe cognitive impairment $[1-4]$ whereas, among those aged 85 years or more. the prevalence is at least $15 \%$ $[4,5]$. Since the number of elderly persons is expected to continue to grow in the years to come, the prevalence of dementing disorders is likely to increase in the future. Furthermore. the senile demented often require specialized medical. social, and home care services: therefore. the

-All correspondence should be addressed to: M. Baum. garten. St Justine Community Health Department. 3175 Cote St Catherine. Montresl. Quebee. Canada H3T ICS. continuing increase in the number of individuals suffering from dementia may have important implications in terms of the cost of the health care system.

The majority of people suffering from a dementing disease live in the community, often cared for by a close family member, usually the spouse or an adult child [6.7]. The public health impact of dementia, therefore. may extend beyond the patients themselves to the community caregivers. If the caregivers are found to be at particularly high risk of certain health problems. then it may be necessary to define them as a target group for health interventions and services of various kinds. Furthermore, since the presence of a capable caregiver is often the crucial factor in keeping the demented patient in the community, preventing and treating health problems among the caregivers may reduce the likelihood of the demented patient being institutionalized. 
The idea that caregivers may be at risk for various health problems is supported by a very large body of experimental and observational evidence showing that stressful experiences can result in negative consequences for the individual's health [8]. Caring for any seriously ill person may be stressful for the caregiver, and numerous diseases (e.g. cancer. stroke. schizophrenia, heart disease) have been studied in this context $[9-16]$. However, several characteristics of dementia make it a particularly difficult disease to cope with. Demented patients progressively lose their ability to perform domestic tasks and to maintain their own personal hygiene and financial affairs. They may exhibit inappropriate social and sexual behaviors, and various psychiatric symptoms. They often wake during the night and wander around the house. They may become incontinent and ultimately lose the ability to recognize close family members. Furthermore. dementia is a disease for which there will probably not be an effective cure in the foreseeable future. The etiology of the disease is unknown. but the possibility of infectious or hereditary transmission is widely discussed in the scientific and popular press. Finally. since the caregivers themselves are often elderly. they may be particularly susceptible to the stresses of caregiving. For all these reasons. it seems plausible that caregivers would experience high levels of depression, anxiety. social isolation. and stress-related physical complaints [17, 18].

Clinical observation suggests that caring for a demented relative does produce significant negative effects on various aspects of the caregiver's psychological and physical health. In recent years. a certain number of studies have been carried out on this theme. The purpose of the present work was to identify and critically review these studies. Findings of the studies were summarized with respect to three major questions concerning the physical and psychological heaith of caregivers for persons suffering from dementia: frequency of health problems, changes in the frequency of problems over time, and factors affecting the frequency of problems. These findings will be summarized. methodological characteristics of the studies will be presented. theoretical considerations will be discussed. and recommendations concerning future research will be made.

\section{METHOD}

\section{Ilentification of studies}

The medical and socia! science literature since 1970 was searched. in order to identify all studies on the health of persons giving care to the frail elderly. An initial automated search was carried out. using MEDLINE and PSYCINFO: subsequently, the reference lists of the identified articles were manually examined in order to identify additional papers. Studies were excluded if less than $80 \%$ of the study patients suffered from Alzheimer's disease or some other dementing disorder, unless the specific purpose was to compare health problems among caregivers of demented and nondemented persons. The choice of $80 \%$ as a minimum proportion of demented patients. although arbitrary, corresponded to the goal of selecting studies in which all or most of the patients were demented. Anecdotal, nonquantitative reports were excluded as were studies where the major focus was on institutionalization of the demented patient. on service utilization in households where there is a demented elderly person. or on the evaluation of interventions aimed at alleviating problems among caregivers. Studies which aimed simply to list the kinds of problems which caregivers found particularly difficult to cope with were also eliminated. No attempt was made to exclude studies on the basis of the type of health variable studied: thus. all studies which included a measurable outcome in terms of physical. psychological. or social well-being of caregivers were considered. There were 28 reports $[19-46]$, ail published since 1980. which met the above criteria.

\section{Methodologic recien of studies}

Six aspects of the design and anaiysis of the 28 studies were examined. First, the source of demented study subjects was classified into one of four categories: (i) general population; (ii) referrals to a medical or diagnostic service: (iii) users of a specialized service (e.g. day hospital. specialized treatment center); and (iv) volunteers (usually recruited through the media. selected physicians, community groups. and/or chapters of the Alzheimer's disease society). in two cases [30,39], subjects were recruited from two sources (e.g. a medical service and the Alzheimer's disease society): the subjects of 
Health of Persons Giving Care to the Demented Elderts

these studies were classified as volunteers. Second. the studies were categorized according to the number of study subjects. Studies which included 84 subjects or more were considered to be large enough to produce reliable results. Although rather arbitrary, this cutoff point was chosen because a sample size of 84 is required to detect a moderately-sized correlation (Pearson correiation coefficient of 0.30 ) with power of $80 \%$ and risk of type I error of 0.05 [47]. Third, studies were classified according to whether they were cross-sectional or included a follow-up period. Fourth. studies were divided into those which included a comparison group and those which did not. Studies in which results for caregivers were compared with normative data or with data from earlier surveys [29.40] were not considered to include a comparison group. Fifth. the ape of outcome variable was examined. Multidimensional measures were defined as scales designed to assess global levels of caregiver strain or burden. These scales usually combine various aspects of burden. such as physical health. psychological well-being. and financial problems. into one overall score. Measures of specific constructs such as depression. life satisfaction. or negative family relationships were not considered to be multidimensional measures. Finally, studies were categorized according to whether an attempt was made to control for confounding factors. If some factors were controlled for (by stratification or statistical analysis), but it was felt that important potential confounders had been neglected. the study was classified in the category "partial control". In several cases. the studies reviewed generated more than one research report: studies with identical research design. sampie size. and sample description were only counted once. Thus. the results of the methodologic review are based on 24 separate studies.

\section{Substantive retiew of studies}

The 28 research reports were reviewed in the light of three major questions concerning dementia and caregiver health: (1) What is the frequency of health problems among caregivers for the demented elderly relative to the risk among noncaregivers? (2) How does the frequency or severity of health problems among caregivers change over time? (3) What characteristics of the caregiver and of the demented patient tend to be associated with higher levets of morbidity among the caregivers?

\section{RESULTS MI DISCUSSION}

$$
\text { Orervien "if the Studies }
$$

As can be seen from Table 1, the 28 identified studies were characitcrized by a diversity of outcome variables. A total of 25 different outcomes were studied. the most common ones concerning some aspert of mental health. The large number and range of outcomes which have been considered by ditlerent investigators suggest that there is little conceptual clarity about what the impact of siregiving might be. This, in itself. is an interesting finding and suggests that the field would henetit from a more solid theoretical basis to the research.

\section{Methodological Churdryoristics of the Identified Sirmalics}

Methodological charatteristics of the 27 studies are shown in Table 2. Only one of the studies reviewed used a population-based study sample whereus. in about 12" " of the studies, the source of demented subjects wits a medical or diagnostic service. In the remitining studies. subjects were selected from sources which would be likely to produce a higlsly unrepresentative sample: caregivers of pattients receiving specialized services (such as those offered by day hospitals). caregivers participating in some specialized support group. or volunteer subjects recruited through media and community publicity. Since persons who require specialized services or who volunteer for participation in research projects may be unusually resourceful or unusually distressed. we should be cautious in generalizing the results of these studies to the majority of community caregivers for dementia patients [48. 49].

Small sample sizes (fewer than 85 subjects) were used in $62.5 \%$ of the studies reviewed. Thus. only about ont-third of the studies had sample sizes large enough to be likely to yield reliable results. A heavy reliance on significance testing in the absence of sufficient sample size may have produced very low power in many of the studies and this may, in some cases. explain the inconsistency in the results from study to study.

Only two of the studies used a longitudinal study design whereas all of the others were cross-sectional. It should be remembered that data obtained from cross-sectional studies cannot be used to irfer causal relationships. since the temporal sequence of events cannot be determined. Another problem with cross-sectional studies is the serious possibility of selec- 
Table 1. Sample description and caregiver outcome variables in 28 reports reviewed

\begin{tabular}{|c|c|c|}
\hline Reference & Description of sample & $\begin{array}{l}\text { Caregiver outcome } \\
\text { variables stidied }\end{array}$ \\
\hline $\begin{array}{l}\text { Zarit et al.. } \\
\text { 1980 [26] }\end{array}$ & $\begin{array}{l}29 \text { caregivers to community-residing } \\
\text { demented patients attending research and } \\
\text { training center for the elderly }\end{array}$ & Perceived caregiving burden \\
\hline $\begin{array}{l}\text { Gilleiard ef al.. } \\
1982 \text { [19] }\end{array}$ & $\begin{array}{l}46 \text { primary supporters of community- } \\
\text { residing demented patients attending } \\
\text { psychogeriatric day hospitals }\end{array}$ & Strain. negative mood \\
\hline $\begin{array}{l}\text { Wilder et al.. } \\
\text { 1983 [2!] }\end{array}$ & $\begin{array}{l}162 \text { key informants of community-resident } \\
\text { elderly from U.S.-U.K. survey }\end{array}$ & $\begin{array}{l}\text { Perceived "inconvenience" of } \\
\text { caregiving }\end{array}$ \\
\hline $\begin{array}{l}\text { Fiore el al.. } \\
\text { [983 [44] }\end{array}$ & $\begin{array}{l}44 \text { spouse caregivers of Alzheimer } \\
\text { patients referred by physicians. clinics. } \\
\text { and Alzheimer's disease (AD) society }\end{array}$ & Depression \\
\hline $\begin{array}{l}\text { Gtlhooly, } \\
1984 \text { [22] }\end{array}$ & $\begin{array}{l}37 \text { supporters of community-resident } \\
\text { demented patients attending day hospital. } \\
54 \% \text { of caregivers lived with patient }\end{array}$ & Mental health, morale \\
\hline $\begin{array}{l}\text { Gilleard et al.. } \\
\text { 1984 [20] }\end{array}$ & $\begin{array}{l}224 \text { supporters of community-resident } \\
\text { elderly persons ( } 87 \% \text { demented) atlending } \\
\text { or referred to geriatric day hospitals }\end{array}$ & Psychiatric morbidity \\
\hline $\begin{array}{l}\text { Gilleard ef al.. } \\
\text { 1984 [4I] }\end{array}$ & $\begin{array}{l}129 \text { supporters of psychogeriatric day } \\
\text { hospital patients. almost all of whom } \\
\text { were demented }\end{array}$ & Caregiver strain, burden \\
\hline $\begin{array}{l}\text { Coppel el al., } \\
1985[25]\end{array}$ & $\begin{array}{l}68 \text { spouse caregivers of Alzheimer } \\
\text { patients referred by physicians. clinics. } \\
\text { and } A D \text { society }\end{array}$ & Depression \\
\hline $\begin{array}{l}\text { Pagel et al.. } \\
\text { 1985 [23] }\end{array}$ & Same as Coppel et al. [25] & Depression \\
\hline $\begin{array}{l}\text { Pratt ef al.. } \\
1986 \text { [24] }\end{array}$ & $\begin{array}{l}240 \text { caregivers to } A \dot{D} \text { patients recruited } \\
\text { from } A D \text { society members and workstop } \\
\text { attendees. } 62 \% \text { of patients lived in the } \\
\text { community }\end{array}$ & Perceived caregiving burden \\
\hline $\begin{array}{l}\text { Deimling and Bass. } \\
1986[34]\end{array}$ & 586 family caregivers to impaired elders & $\begin{array}{l}\text { Negative changes in family } \\
\text { relationships. restriction in } \\
\text { social activities. depression. } \\
\text { changes in physical health }\end{array}$ \\
\hline $\begin{array}{l}\text { Fiore et al.. } \\
1986 \text { [27] }\end{array}$ & Same as Coppei et al. [25] & $\begin{array}{l}\text { Depression, psychological } \\
\text { symptoms. physical symptoms }\end{array}$ \\
\hline $\begin{array}{l}\text { Fitting et al. } \\
\text { [986 [28] }\end{array}$ & $\begin{array}{l}54 \text { spouse-earegivers of community- } \\
\text { resident demented patients of one } \\
\text { hospital clinic }\end{array}$ & $\begin{array}{l}\text { Psychological functioning. } \\
\text { perceived caregiving burden }\end{array}$ \\
\hline $\begin{array}{l}\text { George and Gwyther. } \\
1986[29]\end{array}$ & $\begin{array}{l}510 \text { caregivers of demented patients. } \\
\text { recruited through media. physicians. } \\
\text { nursing inmes. etc. } 66 \% \text { of patients lived } \\
\text { in the community. } 53 \% \text { of earegivers lived } \\
\text { with patient }\end{array}$ & $\begin{array}{l}\text { Physician visits. self-rated } \\
\text { health, stress symptoms. affect } \\
\text { baiance. life satisfaction. use of } \\
\text { psychotropic medications. } \\
\text { financial well-being. soctal } \\
\text { activities. satisfaction with } \\
\text { social activities }\end{array}$ \\
\hline $\begin{array}{l}\text { Scott et al.. } \\
1986[30]\end{array}$ & $\begin{array}{l}23 \text { primary caregivers of community- } \\
\text { residing demented patients of one } \\
\text { physician and adult activity center }\end{array}$ & Perceived caregiving burden \\
\hline $\begin{array}{l}\text { Eagles et al. } \\
1987[32]\end{array}$ & $\begin{array}{l}\text { Supporters of } 40 \text { demented and } 39 \\
\text { nondemented elderly subjects attending a } \\
\text { general medical practice. All patients } \\
\text { resided in the community }\end{array}$ & $\begin{array}{l}\text { Psychiatric morbidity, stress. } \\
\text { mood }\end{array}$ \\
\hline $\begin{array}{l}\text { Eagles et al. } \\
1987[33]\end{array}$ & $\begin{array}{l}274 \text { community-resident elderly married } \\
\text { couples from a general medical practice. } \\
\text { In } 31 \text { couples, one of the spouses was } \\
\text { demented }\end{array}$ & $\begin{array}{l}\text { Psychiatric morbidity. depression. } \\
\text { anxiety }\end{array}$ \\
\hline
\end{tabular}


Health of Persons Giving Care to the Demented Elderly

Table 1-Continued

\begin{tabular}{|c|c|c|}
\hline Reierente & Description of sampie & $\begin{array}{l}\text { Caregiver oulcome } \\
\text { variaties studies }\end{array}$ \\
\hline $\begin{array}{l}\text { Huley "ut wh. } \\
\text { 1987 [31] }\end{array}$ & $\begin{array}{l}44 \text { primary caregivers of community- } \\
\text { dwelling demented patients recruited } \\
\text { through media, physicians. AD society. } \\
\text { Control group: } 44 \text { eideriy persons not } \\
\text { giving care to a demented person. } \\
\text { secruited through churches. etr }\end{array}$ & $\begin{array}{l}\text { Depression. life satisfaction. } \\
\text { changes in family relationships, } \\
\text { physical symptoms. self-rated } \\
\text { physical health. health care } \\
\text { utilization. prescription } \\
\text { mediration. social activities. } \\
\text { satisfaction with social support }\end{array}$ \\
\hline $\begin{array}{l}\text { Huley et al.. } \\
\text { 1987 [35] }\end{array}$ & $\begin{array}{l}54 \text { caregivers of community dwelling } \\
\text { demented patients recruited through media. } \\
\text { AD society, social services }\end{array}$ & $\begin{array}{l}\text { Depression. life satisfaction. } \\
\text { self-rated health }\end{array}$ \\
\hline $\begin{array}{l}\text { Pratl of al. } \\
1987 \text { [36] }\end{array}$ & Same as Pratt et al. [24] & Burden. morale. self-rated hinalth \\
\hline $\begin{array}{l}\text { Drinki et al. } \\
\text { 1987 [37] }\end{array}$ & $\begin{array}{l}127 \text { caregiven of patients referred to a } \\
\text { specialized geriatrics clinic. } \\
35 \text { demented patients and } 17 \text { other } \\
\text { patients for whom information was } \\
\text { available on severity of dementia and } \\
\text { depression among the caregivers }\end{array}$ & Depression \\
\hline $\begin{array}{l}\text { Birke! RC. } \\
1987 \text { [38] }\end{array}$ & $\begin{array}{l}20 \text { تaregivers of demented patients. } 20 \\
\text { caregivers of physically impsired elderiy. } \\
\text { recruited through media. community } \\
\text { agencies. etc. }\end{array}$ & $\begin{array}{l}\text { Stress. !norale. psychiatric } \\
\text { symptoms }\end{array}$ \\
\hline $\begin{array}{l}\text { Kiecoll-Glaser "t al.. } \\
1987 \text { [39] }\end{array}$ & $\begin{array}{l}34 \text { caregivers of } A D \text { patients. recruited } \\
\text { through two physiciuns and } A D \text { society }\end{array}$ & $\begin{array}{l}\text { Physician visits. sick days. } \\
\text { self-rated health, sleep habits. } \\
\text { depression. life satistiation. } \\
\text { mental health. social support. } \\
\text { loneliness. immune function }\end{array}$ \\
\hline $\begin{array}{l}\text { Patyel at ul.. } \\
1987[+6]\end{array}$ & Sume us Coppel af al. [2S] & Depression \\
\hline $\begin{array}{l}\text { Pugel and Becker. } \\
1987[45]\end{array}$ & Sume as Cuppel et al. [25] & Depression \\
\hline $\begin{array}{l}\text { Anthony-Bergstone } \\
\text { af wh. igss [40] }\end{array}$ & $\begin{array}{l}\text { 184 primary caregivers of demented } \\
\text { patients recruited for training program } \\
\text { to assist limily members of dementia } \\
\text { patients }\end{array}$ & $\begin{array}{l}\text { Obsessive-compulsive tendencies. } \\
\text { depression. anxiety. hustifity. } \\
\text { psychoticism }\end{array}$ \\
\hline $\begin{array}{l}\text { Quashagen and Quatyhagen. } \\
\text { 1985 [+3] }\end{array}$ & $\begin{array}{l}58 \text { fumily members of } A D \text { patients } \\
\text { recruited through AD society support } \\
\text { groups }\end{array}$ & $\begin{array}{l}\text { Well-being (composite of life } \\
\text { satisfuction. perceived physical } \\
\text { health. and perceived emutional } \\
\text { health) }\end{array}$ \\
\hline $\begin{array}{l}\text { Liptzin } a t d . . \\
1988 \text { [4]] }\end{array}$ & $\begin{array}{l}\text { Caregivers of } 38 \text { patients ( } 11 \text { demented. } \\
27 \text { depressed) admitted to the geriatric } \\
\text { unit of a psychiatric hospital }\end{array}$ & Perceived curegiving burden \\
\hline
\end{tabular}

tion bials. A cross-section of patients and their caregivers represent a group of "survivors". in which those who took up the caregiving role but had to abandon it along the way are not included. Thus, a sample of caregivers chosen at one point in time may not be representative of the entire cohort of caregivers of patients diagnosed around the same time. The longer the duration of the dementia. the more likely it is that the subjects represent a particularly healthy or resistant group. This phenomenon, which. if confirmed. could be referred to as a "healthy caregiver effect", is conceptually similar to the "healthy worker effect" observed in ocsupational health reseirch [50].
A. comparison group was included in only seven of the studies. In iour of these studies [3i-33,39], caregivers were cimpared with noncaregivers whereas, in three $s$ :udies [37, 38, 42]. caregivers for demented patients were compared with caregivers of patients $w$ th other impairments. In the absence of a con parison group. it is impossible to quantify the impact of caregiving, since "background" l:vels of morbidity cannot be controlled for. Comparison groups are also necessary if we are to study effect modification. i.e. the differential effect of certain factors on caregivers and noncaregivers.

In more than $45 \%$ of the studies. a muitidimensional measure of caregiver burden or 
Table 2. Methodological characteristics of at studies reviewed

\begin{tabular}{|c|c|c|c|}
\hline Charasteristic & $\begin{array}{l}\text { Relerence } \\
\text { numbers }\end{array}$ & $\begin{array}{l}\text { Number of } \\
\text { stuvies }\end{array}$ & $\begin{array}{l}\text { Percent of } \\
\text { studies }\end{array}$ \\
\hline \multicolumn{4}{|l|}{$\begin{array}{l}\text { Source of demented } \\
\text { subjects }\end{array}$} \\
\hline $\begin{array}{l}\text { General population } \\
\text { Medical service }\end{array}$ & $\begin{array}{lll}21 & & \\
28 & 39\end{array}$ & 1 & +2.2 \\
\hline Specialized service & $\begin{array}{l}28,32.33 \\
19.20,22,26,37,40 \mathrm{~min}\end{array}$ & $\begin{array}{l}3 \\
8\end{array}$ & $\begin{array}{l}12.5 \\
33.3\end{array}$ \\
\hline Volunteers & $23-25.29-31.35 .38,39$ & 11 & $\begin{array}{l}33.3 \\
4 \leq .8\end{array}$ \\
\hline Not stated & 34 & 1 & 4.2 \\
\hline \multicolumn{4}{|l|}{ Nunher of study subjects } \\
\hline 88 or more & $\begin{array}{l}20,21,24,29,33,34,37 . \\
40,41\end{array}$ & 9 & 37.5 \\
\hline Fewer than 85 & $\begin{array}{l}\text { 19. 22. 23. } 25.26 .28 . \\
30-32.35 .38 .39 .42-44\end{array}$ & 15 & 62.5 \\
\hline \multicolumn{4}{|l|}{ Sindy design } \\
\hline $\begin{array}{l}\text { Longitudinal } \\
\text { Cross-sectional }\end{array}$ & $\begin{array}{l}\text { 20. } 23 \\
\text { 19. } 21.22 .24-26.28-35 . \\
37-4 .\end{array}$ & 22 & $\begin{array}{r}8.3 \\
91.7\end{array}$ \\
\hline \multicolumn{4}{|l|}{ Compurisom group } \\
\hline Yes & $31-33.37-39.42$ & 7 & 29.2 \\
\hline No & $\begin{array}{l}19-26.28-30.34 .35 . \\
40.41 .43 .44\end{array}$ & 17 & 70.8 \\
\hline \multicolumn{4}{|l|}{ Outcome rariables } \\
\hline $\begin{array}{l}\text { No multidimensional } \\
\text { measures }\end{array}$ & $\begin{array}{l}20-23.25 .29 .31,33-35 . \\
39.43 .44\end{array}$ & 13 & 54.2 \\
\hline $\begin{array}{l}\text { Multidimensional and } \\
\text { other measures }\end{array}$ & 19. 28, 32. 37. 38. 40. 41 & 7 & 29.2 \\
\hline $\begin{array}{l}\text { Multidimensional } \\
\text { meusures only }\end{array}$ & $24.26,30.42$ & 4 & 16.7 \\
\hline \multicolumn{4}{|l|}{ Comtrol of confounding } \\
\hline Multivariate analysis & $\begin{array}{l}19-21.23 .25,28.29 .31, \\
34.35 .37,39\end{array}$ & 12 & 50.0 \\
\hline $\begin{array}{l}\text { Purtial control } \\
\text { No control }\end{array}$ & $\begin{array}{l}30.32 .33 .38 .40 .41 .43 \\
22.24 .26 .42 .44\end{array}$ & $\begin{array}{l}7 \\
5\end{array}$ & $\begin{array}{l}29.2 \\
20.8\end{array}$ \\
\hline
\end{tabular}

Note: Rei. [36] had the same methodological characteristics as Ref. [24].

Reis [27] and [45] had the same methodological characteristics as Rei. [25].

Rei: [46] had the same methodological characteristics as Ref. [23].

strain was used alone or in combination with other measures. These multidimensional scales are typicilly made up of a series of items related to physical. psychological. social, and firancial problems and provide a summary score of the strain associated with caregiving. Some of the multidimensional scales are made up of subscales which can be used to characterize different facets of the caregiving experience, but most of the studies reviewed did not use the scales in this way. Although summary scores have been widely used and provide a convenient way of obtaining a global measure of overall impact. they are of little value in understanding specific dimensions of caregiving. Furthermore. since the yuestions in these scales usually refer specifi. cally to the caregiving situation. they cannot be used in studies where the objective is to compare caregivers and noncaregivers. Another drawback of these scales is that the questions often explicitly require the respondent to relate caregiving to its impact. For example. the caregiver may be asked whether caring for the demented patient has affected his or her social activities. Therefore. the stressful situation and its impact are intertwined. making it impossible to quantify the effect of the stressor on the cutcorne $[29,31]$.

Finally, $50 \%$ of the studies did not use an adequate analytic technique to control for potential confounding factors. Lack of control of confounding could lead investigators to identify spurious associations between variables or to overlook significant associations between variables.

\section{Substantice Findings of the Reviewed Studies}

\section{(I) Frequency of health problems}

Only four of the studies reviewed provided information on the frequency of health problerns among caregivers relative to the frequency among noncaregivers. Eagles et al. [32] found 
that supporters of demented and nondemented subjects did not differ with restact to their scores on the General Fiexith Questionnaire (GHQ), a widely-used measure of psychiatric morbidity and emótional distress. However, supporters of demented patients had much higher scores on the Relatives Stress Scale (RSS), and marginally higher scores on the Relatives' Mood Scale (RMS). This finding is not surprising. since the RSS and RMS were developed specifically to measure the impact of caring for a demented relative and the questions are phrased in such $z$. way that caregivers for the demented would be more likely to report distress. In another study by the same group of investigators. Eagles et al. [33] reported no significant difference between spouses of demented and nondemented elderly subjects with respect to various measures of psychological health. This negative finding may be explained by the fact that the demented subjects in this study did not suffer from a high level of behavioral disturbance. Haley et al. [31] found that caregivers had more chronic conditions. prescription medications, doctor visits. and depression than noncaregivers. They also had lower self-rated overall henith. lower life satisfaction. and worse family relationships. There was little difference between the grouji with respect to their scores on a health status questionnaire. the frequency of physical symptoms. or the number of social contacts and close relationships. Kiecolt-Giaser et al. [39] found no significant differences between caregivers and noncaregivers with respect to physican visits. sick days. self-rated health. sleep habits, social support or loneliness. However. caregivers had significantly more depression. lower life satisfaction. and worse menta!' '-aith. They also had significantly lower immune function than noncaregivers on four out of six measures of immune function: the differences could not be explained by differences in nutritional status. In summary, given the small number of studies and the diversity of outcomes studied. it is difficult to draw reliable conclusions about the magnitude of the impact of caregiving on health.

In three studies. caregivers of patients with dementia were compared to caregivers of eiderly patients with other impairments. Drinka et al. [37] found no significant difference in depression scores between caregivers of dementia patients and caregivers of other severely impaired elderly patients. Similarly, Liptzin et al. [42] found no significant difference in the burden scores of caregivers of depressed and demented patients admitted to the geriatric unit of a psychiatric hospital. Birkel [38], on the orher hand, found that caregivers of demented patients experienced more strain and psychological distress than caregivers of physically impaired patients. Thus. the evidence concerning the impact of caring for patients with dementia as opposed to caring for patients with other health problems is inconclusive.

\section{(2) Changes in caregiver. health over time}

Only two studies have provided any empirical information on changes in saregiver health over time. Gillearc et al. [20] found. at 3-month follow-up, a significant increase in the frequency of psychological symptoms but no change in physical health rating. Pagel et al. [23.46] found that changes in depression over 10 months were small.

Haley ind Pardo [51] have proposed several modeis to piedict changes in caregiver health over time. The first model is based on the "wear and tear" hypothesis. According to this model, both dementia patients and their caregivers experience a progressive deterioration in their functioning as the jatient's symptoms worsen and the caregiver becomes more and more overwhelmed by the stressful situation. According to the second model, the caregiver learns to adapt to the caregiving situation despite progressive worsening of the patient's symptoms. and either stabilizes or improves in functioning over time: this model is called the "adaptation model". The third model is based on the "trait hypothesis". In this model. the caregiver's preexisting level of coping skills. resources, and social supports allow him or her to maintain a constant level of functioning despite worsening of the patient's condition. Unfortunately, it is impossible, on the basis of the sparse evidence furnished by the existing literature, to refute or support the proposed models of change in caregiver health over time.

\section{(3) Correlates of health problems among care- givers}

In most of the studies reviewed, the objective was to identify correlates of various health problems among individuals caring for a demented person. A very large number of different correlates and outcomes were considered in the 28 studies reviewed: in faci, more than 200 different correlate/outcome associations were reported in these studies. Cleariy, it would be 
nearly impossible to summarize the findings of these studies with respect to all variables which might be predictive of health problems among caregivers. Therefore, only a small number of selected variables will be discussed.

Caregiver's age. In four studies $[20,22$. $24,45]$, no association was found between the caregiver's age and the outcome variable. Fiore et al. [27] found that older caregivers had more psychologicol symptoms than younger caregivers. but that physical symptoms and depression did not vary much with age. In contrast. Gilleard et al. [41] found that younger supporters experienced more strain and burden than oider supporters. Haley et al. [35] found that there was a significant negative correlation between caregiver age and self-rated health, but that there was no significant correlation between caregiver age and life satisfaction or depression. When interpreting these inconsistent results with respeci: to caregiver's age. several methodological factors must be kept in mind. First, age may be predictive both of greater health problems and of "survival" as a caregiver: older and sicker caregivers may be more likely to abandon the caregiving role and. therefore. to be underrepresented in cross-sectional samples. Second, different health outcomes may be affected in different ways by caregiver age: given the large variety of outcomes examined in these studies, the inconsistent results may not be surprising. Finally, the effect of increasing age on a large number of psychological and physical health measures is well known: what would be of more interest would be the modifying effect of ase on the association between caregiving and health. Effect modification can only be studied winen a comparison group is included.

Kinship tie between carer and patient. Several investigators have studied the variable "kinship tie" by. for example. comparing the health of caregivers who are close relatives of the patient with the health of caregivers who are more distantly related. The rationale for studying this variable is that those who are more closely related may experience more stress as a result of adopting the caregiving role than those who have a more distant kinship tie. However, it should be recognized that the variable "kinship tie" comprises three components: age. sex, and family closeness. Therefore. in order to study the association between family closeness per se and caregiver health. it is essential to control for caregiver age and sex. Five investigators $[20,26.32,36,43]$ found no effect of inship tie on various measures of caregiver health. Gilhooly [22] found no association between kinship tie and morale: however. the ments! health of those who were ciesely related to the patient was poorer than those who were more distantly related. None of these studies adjusted for caregiver age or sex. On the other hand. George and Gwyther [29] found that spouse caregivers reported more doctor visits, lower self-rated health, more stress symptoms. more psychotropic medication use, lower affect balance, and less life satisfaction than nonspouse caregivers. even after adjusting for caregiver age.

Seterity of patient's disease. If the demented patient's disease is viewed as the stressor to which the caregiver is exposed, then it seems plausible that the more severe the disease symptoms, the more likely it is that the caregiver will suffer negative health consequences. However. the association between diseuse severity and caregiver health may be a complex one. There are at least three dimensions of disease severity in dementia: cognitive impairment. functional impairment, and behavioral disturbance. Caregivers may respond quite differently to these three manifestations of decline in the patient. In fact. it has been suggested that caregivers perceive behavioral problems as being more stressful than either functional impairment or cognitive symptoms [34, 52]. This increased stressfulness may be related to the unpredictability and uncontrollability of behavioral disturbance [52], or to the fact that behavioral symptoms necessitate more care and supervision of the patient than do cognitive or functional deficits [34].

The empirical evidence regarding disease severity and caregiver health is conflicting. Looking first at cognitive status. several investigators $[21,22,26,30,35]$ found no association between the patient's cognitive status and caregiver health. Eagles et al. [32] found a significant correlation between the patient's cognitive status and the Relatives' Stress Scale but not the Relatives' Mood Scale or the GHQ. The same investigators [33] found a significant correlation between the mental status scores of female patients and their husband's level of depression; however. there was no association between the patients mental statur, scores and the caregivers' anxiety or GHQ score. Thus. notwithstanding a few exceptions, it would seem that the association between the patient's cognitive status and caregiver heaith is not strong. On 
the other hand. Deimling and Bass [34] found, using path an:3lysis. that cognitive status was strongly associated with the patient's behavioral and functional probtems which, in turn, had a strong influence on the caregiver's activity restriction, physical health, family relationships. and depression.

As for the patient's functional status, four investigators $[19,22,23,26]$ tound no association between functional inpairmtent and caregiver health. In one study, the patient's activity limitation was a significant predictor of perceived "inconvenience" of caregiving [21]. Deimling and Bass [34] found that the patients' functional status was significandly correlated with the caregivers' activity restriction and physical health change but not with their family relationships or depressive symptoms. Hialey et al. [35] found that the patient's ability to perform basic activities of daily living (ADL) (such as bathing, eating, and walking) was not significancly correlated with caregiver's depression. life satisfaction. or self-rated heaith problems; the patient's ability to perform instrumental ADL (such as meal preparation, banking, and housework) was highly correlated with the caregiver's depression score but not with life satisfaction or self-rated health problems. In the study by Fitting et al. [28], the patient's impairment was associated with perceived bulden among younger wives and older husbands only. The large variety of outcome measures used in these studies mav explain the diversity of results obtained. Also, it may be that the association between patient functional status and caregiver health is not strong and that large sample sizes would be required in order to identify statistically significant correlations.

Finally. in most studies $[19-21,25,29,32$. 34.39 .41 , a strong association between the severity of the patient's behavioral disturbance and caregiver health was found although, in two studies [26.35], no such association was observed. Overall, then, there seems to be some support for the hypothesis that behavioral manifestations of dementia are more predictive of problems for the caregiver than are cognitive or functional impairment.

Social support. Objective and subjective dimensions of social support have been found to be associated with a large number of health measures. both in clinical samples and in the general population [ $53-66]$. However, contradictory results have beet obtained concerning the effect of social support on well-being among caregivers. In five studies [20,22.24, 27, 41], no such effect was identified. In six other studies $[26,29,30,35,43,45\}$, high levels of support were found to be associated with better caregiver outcomes. Pagel et al. [46] found that the amount of upser produced by the social network was positively correlated with depression, while the amount of perceived heipfulness of the social network was not correlated with depression. Social support was operationalized in very different ways in these studies, ranging from presence of a confidant to amount of instrumental help, and this may explain the divergent findings. The caregiver's satisfaction with the social support he or she received was associated with better health in both of the studies in which this question was considered [22. 27].

It has been suggested that social support may be an effect modifier in the stress/health association by acting as a protective buffer for individuals experiencing a stressful situation while having little effect on those who are not exposed to stress [57-59]. Comparing caregivers and noncaregivers with respect to the effect of social support on health could shed light on the potential buffering effect of social support. Unfortunately, none of the 28 studies reviewed examined this phenomenon.

\section{SUMMARY AND RECOMMENDATIONS}

In summary; despite the fact that there are now a relatively large number of studies on the impact of caring for an elderly person suffering from dementia, several important questions remain unanswered. Specifically, very little is known about the risk of health problems among caregivers relative to noncaregivers, or about changes in caregiver health over time. Furthermore, although much information is available on correlates of heaith problems among caregivers. the large number of health variables studied and the methodological shortcomings of the studies (in particular, small sample size. cross-sectional study design. and unsatisfactory control of confounding factors) make it difficuit to draw reliable conclusions from this information.

Investigators involved in studying the health consequences of caring for a demented elderly person are faced with numerous difficulties. First, the relationship between caregiving and health varies greatly from individual io individual, and from situation tc situation. Thus, 
simple dose-response or stressor-outcome modeis are not likely to be adequate. Secondly, the relationship between health and various aspects of the caregiving situation is a dynamic one; one cannot assume that the factors which one chooses to study as independent variables will be stable over time. In fact. these factors may change as a function of the caregiver's heaith. producing a complex web of potentially confounded associations. Even in longitudinal research, the instability of predictor variables over time poses a serious challenge for the analysis and interpretation of results. Thirdly. difficult measurement problems plague this area of research and investigators may encounter difficulties in selecting or developing conceptually plausible. methodologically sound outcome measures. Finally, serious practical problems may arise when attempting to design methodologically adequate studies. In many communitie: it may be difficult to identify adequate sampling frames, and sufficient numbers of study subjects may simply not be available. Recruitment of well-defined study populistions is made more difficult by the fact that the caregivers must often be identified on the basis of the characteristics of the patient with dementia rather than on the characteristics of the study subjects themselves. Finally. in longitudinal studies. attrition by hospitalization. institutionalization. or death is likely to be a substantial problem.

It is a tribute to the eariy investigators in this field (such as Zarit [26] in the United States and Gilleard [19.20.41] in the United Kingdom), that they succeeded in collecting valuable information on the impact of caregiving despite the difficulties mentioned above. However. major challenges remain for future research in this field. In the following paragraphs. I will outline the areas in which particular efforts are required.

\section{Quantification of risk}

It will be important in future research to quantify the excess health risk experienced by caregivers. In order to do this. it is essential to include appropriate comparison groups so that "background" leveis of health problems can be controlled for. Quantification of risk is important both from an etiological and a public health point of view, and should be a prionsy objective in future research efforts.
Identification of risk fuctors and protectice facto's

A promising area of research is the identification of characteristics which are associated with particularly good or particularly poor outcomes. For example. it would be useful to confirm the finding that memory loss and functional deterioration are less disruptive to the caregivers than the behavioral manifestations of the disease. It might be especially interesting to study potentially modifiable characteristics. such as coping skills. service utilization, and social support. If it is discovered that some of these modifiable characteristics have prognostic value. then planners of health services could target these factors in their future interventions.

\section{Design and measurement}

More effort should be applied to improved measurement of factors associated with caregiving and its potential effects. First, the choice of health outcomes to be studied should be based on sound theoretical considerations. Particular emphasis should be put on measuring the specific effects of caregiving, rather than combining diverse phenomena into one global measure. Furthermore, whenever possible, investigators should adopt more rigorous study designs, including such features as comparison groups, longitudinal follow-up, and use of representative study samples. Finally, there may be substantial variabilty within groups of demented patients with respect to characteristics such as age. sex. and duration and severity of disease. Since these characteristics may have an important impact on caregiver health. they must be accounted for, either in the design or the analysis stage. when carrying out studies of the effects of caregiving.

\section{Characterizing changes over time}

Changes over time in both dependent and independent variables should be studied and the complex association berween these changes described.

Ultimately, the goal is to intervene to prevent heaith problems among people caring for a demented relative in the community. Results of observational studies can provide useful information for the planning of innovative programs. However, it is essential that these studies be rigorously conducted, in order to prevent wasted resources and unjustified expectations in the target population. 
Hewth of Persons Giving Care to the Demented Elderly

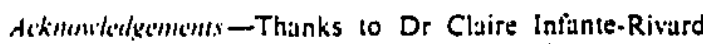
and D. Terry Tunnerban for their thodyhtful comments.

This study was supported by grants from the Quebec Healt: Researsh Fund (FRSQi dnd from the Aiziteimer Society of Canada.

\section{REFERE.YCES}

1. Mortimer JA. Epiderniology of dementia: international comparisons. In: Brody JA. Maddox GL. Eds. Epidemiology and Aging: an Intemntional Perspective. New York: Springer: 1988.

2. Rocca WA. Amaducci L.A. Schoenberg BS. Epidemiology of clinically diagnosed Alzheimer's disease. Ann Neurol 1986: $19: 415 \rightarrow 24$.

3. Ineichen B. Measuring the rising tide: how many dementia cases will there be by 2001? Br J Psychiat 1987: 150: 193-200.

4. Jorm AF. Korten AE. Henderson AS. The prevalence of dementia: a quantitative integration of the literature. Acta Psychiat Scand 1987: 76: $465-799$.

S. Weissman M.M. Myers JK. Tischler GL et al. Psychiatric disorders (DSM-III) and cugnitive impairment among the elderly in a U.S. urban community. Acta Psychiat Scand 1985: 71: 366-379.

6. Ory MG. Williams TF. Emr M al al. Famiiies, informal supports, and Alzheimer's disease: current research and future ugendas. Res Aging 1985: 7: 623-6.44.

7. Bergmann K. Epidemioiogical aspects of dementia and considerations in planning services. Dan Med Bull 1985: 32 (Suppl. 1): 84-91.

8. Maes S. Vingerhuets A. Van Heck G. The study of stress and diseuse: some developments and requirements. Soc Sci thed 1987: 25: 567-578.

9. Lewis FM. The impact of euncer on the fumily: a critical analysis of the research literature. Patient Educ Counseling 1986: 8: 269-289.

10. Brocklehurst JC. Morris P. Andrews K et ul. Social effects of stroke. Soc Sei . Med 1981: 15A: 35.39.

11. Wilde DT. Legh-Smith J. Hewer RL. Elfects of living with and looking after survivors of at stroke. Br. Med J 1986: 293: $418-420$.

12. Potasznik H. Neison G. Stress and social support: the turden experienced by the fumily of a mentally iil person. Am J Comm Psychol 1984: 12: 589-607.

13. Brown GW. Birby JLT. Wing JK. Intluence of family life on the course of schizophrenic disorders: a replication. Br J Psychiat 1972: 121: 241-258.

14. Breslau N. Weitzman M. Messenger K. Psychologic functioning of siblings of diabied children. Pediatries 1981: 67 : 344-353.

15. Breslau N. Sturuch KS. Mortimer E.t. Psychological distress in mothers of dissbled children. Am $J$ Dis Children 198:: 136: 68:-686.

16. Schulz R. Tompkins C.A. Rau MT. A longitudinal study of the psychosocial impact of stroke on primary support persons. Psychol Aging 1988: 3: $131-141$.

17. Becker J. Morrissey E. Difficulties in assessing depressive-like reactions to chronic severe external stress as exemplified by spouse caregivers of Aizheimer patients. Psychoi Aging 1988: 3: 300-306.

18. Given CW. Collins CE. Given BA. Sources of stress among families caring for reiatives with Alzheimer's dise:use. Nurs Clin N Am 1988: 23: 69-81.

19. Gilleard CJ. Boyd WD. Watt G. Problems in earing for the elderiy mentully intirm at home. Arch Gerontol Geriat: 1982: 1: 151-is8.

20. Gilleard CJ. Belford H. Giileard E et al. Emotional distress amongst the supporters of the eloerly mentally intim. Br J Psychiat 1984: 145: 172-177.

21. Wilder DE. Teresi JA. Bennett RG. Family burden and dementia. In: Mayeux R. Rosen WG. Eds. The Dementias, New York: Ridven Press: 1983.

22. Gilhooly MLM. The impact of care-giving on sare-givsts: factors associated with the psychologienl well-being of people supporting dementing relative in the community. Br J Med Psychol 1984: 57: $35+4$.

23. Pagel MD. Becker J. Coppel D8. Loss of control. self-blame. and depression: an investigation of spouse taregivers of Alzheimer's disease patients. J Abnormal Psychol 1985: 94: 169-18?.

24. Pratt CC. Sctmall VL. Wright $S$ et al. Burden and cuping strategies of caregivers to Alzheimer's patients. Family Relations 1985: 34: 27-33.

25. Coppe! DB. Burton C. Becker J et al. Relationships of cognitions associated with coping reactions to depresion in spousal caregivers of Alzheimer's disease patients. Cog Ther Res 1985: 9: 253-266.

26. Zarit SH. Reever KE. Bach-Peterson J. Relatives of the impaired elderly: correlates of feelings of burden. Gerontologist 1980: 20: 649-655.

27. Fiore J. Coppel DB. Becker I et al. Social support as

- a multi-faceted concept: examinution of important dimerisions for adjustment. Am J Comm Psychol 1986: 14: 93-111.

28. 'Fitting M. Rabins P. Lucus MJ et al. Caregivers for dementia patients: a comparison of husbands and wives. Gerontologist 1986: 26: 248-252.

29. George LK. Gwyther LP. Caregiver well-being: a multidimensional eximination of family caregivers of demented adults. Gerontologist 1986: 26: 253-259.

30. Scotl JP. Roberto KA. Hutton JT. Families of Alzheimer's victims: fumily support to the earegivers. J Am Geriatr Soc 1986: 34: 348-354.

31. Haley WVE. Levine EG. Brown SL et al. Psychological. social, and health consequences of caring for a relative with senile dementia. J Am Geriatr Soc 1987: 35: +05. +11 .

32. Eugles JM. Craig A. Rawlinson F ef al. The psychological well-being of supporters of the demented elderly. Br J Psychiat 1987: 150: 293-298.

33. Eigies JM. Beattie JAG. Blackwood GW ol al. The mental health of elderiy couples. I. The effects of a cognitively impuired spouse. Br J Psychiat 1987: 150: 299-303.

34: Deimling GT. Bass DM. Symptoms of mental impuirment among elderly adults and their effects on family caregivers. J Gerontol 1986: 41: 778-784.

35. Haiey WE. Levine EG. Brown SL et al. Stress. appraisal. coping and social support as predictors of adaptational outcome among dementia caregivers. Psychol Aging 1987: 2: 323-330.

36. Pratt C. Wright S. Schmall V. Burdett. coping and health status: a comparison of family caregivers to community dwelling and institutionalized Aizheimer's patients. $j$ Gerontol Soc Work 1987: 10: 99-112.

37. Drinka TJK. Smith JC. Drinka PJ. Correlates of depression and burden for informal caregivers of patients in a geriatries referral clinic. J Am Geriatr Soc 1987: 35: 522-525.

38. Birkel RC. Toward a social ecology of the home-care tousehold. Psychol Aging 1987: 2: 294-301.

39. Kiecolt-Giaser JK. Glaser R. Shuttleworth EC et al. Thronic stress and immunity in family caregivers of Alzheimer's disease victims. Psychosom Med 1987: 49: 523-535.

40. Anthony-Bergstone CR. Zarit SH. Gatz M. Symptoms of psychological distress among caregivers of dementias patients. Psychol Aging 1988: 3: 245-248.

41. Gilleard CJ. Gilleard E. Gledhill K el al. Caring for the elderly mentally infirm at home: a survey of the supporters. J Epidemiol Commun Health 1984: 38: 319-325. 
42. Liptzin B. Grot MC. Eisen SV. Family burden of demented and depressed e!den:y osyejiatric inpatiestis. Gerontologist 1988: 28: 397-401.

43. Quayhagen MP. Quayhagen M. Alzheimer's stress: coping with the cafregiving role. Gerontologist 1988; 28 : 39!-396.

4. Fiore J. Becker J. Coppe! DB. Social network interactions: a buter or a stress? Am J Comm Psychol 1983: 11: $423-439$.

45. Pagel M. Becker J. Depressive thinking and depression: relations with personality and social resources. J Pers Soe Psychol 1987: 52: 1043-1052.

46. Pagel MD. Erdly WW, Becker J. Social networks: we get by with (and in spite of) a little help from our friends. J Pers Soc Psychol 1987: 53: 793-804.

47. Cohen J. Statistical Power Analysis for the Behaviora! Sciences. revised edition. New York: Academic Press: 1977.

48. Matthews SH. The burdens of parent care: a critical evaluation of recent findings. J Aging Studies 1988: ?: $157-165$.

49. Morris RG. Morris LW, Britton PG. Factors affecting the emotional wellbeing of the caregivers of dementia sufferers. Br J Psychiat 1988: 153: 147-156.

50. Wen CP. Tsai SP. Gibson RL. Anatomy of the healthy worker effect: a critical review. J Occup .Med 1983: 25: 283-289.
51. Haley WE. Pardo KM. Relationship of stage of dementia to caregiver stress and coping. Piesented at American Psychological Association Meetings. New' York. August 1987.

52. Haley WE. Brown SL. Levine EG. Family caregiver appraisals of patient behavioral disturbance in sentie dementia. Clin Gerontol 1987: 6: $25-31$.

53. Berkman LF. Berkman CS. Kas! $S$ ef al. Depressive symptoms in relation to physical health and functioning in the elderly. Am J Epidemiol 1986: 124: 372-388.

54. Leavy RL. Social support and psychological disorders: a review. J Comm Psychol 1983; 11: 3-21.

55. Bankoff EA. Social support and adaptation to widowhood. J Marriage Family 1983: 45: 827-839.

56. Ruberman W, Weinblatt E. Goidberg JD et al. Psychosocial influences on mortality after myocardial infarction. N Engl J Med 1984: 311: 552-559.

57. Cohen S. Wills TA. Stress, social support, and the buffering hypothesis. Psychol Bull 1985: 98: 310-357.

58. Thoits PA. Conceptual. methodological. and theoretical problems in studying social support as a buffer against life stress. J Health Soc Behav 198:: 23: $145-159$.

59. Schradle SB. Dougher MJ. Social support as a mediator of stress: theoretical and empirical issues. Clin Psychol Rev 1985: 5: 641-661. 


\section{APPENDIX 2}

Sample description and major findings of 46 reports reviewed

Zarit et al., 1980 (107)

29 caregivers to community-residing demented patients. Mean age: 65 years; 86\% females; 62\% spouses. Recruited from research and training center for the elderly.

Cognitive status, functional status, behavioral problems, duration of dementia, kinship tie were not significantly correlated with perceived burden. Frequency of family visits was significantly correlated with perceived burden.

Gilleard et al., 1982 (101)

46 primary supporters of community-residing demented patients attending psychogeriatric day hospitals. $39 \%$ spouses.

Problems of "demand" (i.e., patient needs attention, is noisy, creates clashes) contributed most to supporters' strain and negative mood. Number of disability problems was not related to supporters' strain or negative mood after controlling for "demand" problems.

wilder et al., 1983 (99)

162 key informants of community-resident elderly from US-UK survey.

Behavioral and functional problems but not cognitive status were significant predictors of perceived "inconvenience" of caregiving. Type of living arrangements was not strongly associated with "inconvenience". 
SUMMARY OF STUDIES (continued)

Fiore et al., 1983 (124)

44 spouses caregivers of patients with AD. $25 \%$ of patients institutionalized. Referred by AD society, plysicians, clinics, nursing homes.

43\% of caregivers met RDC criteria for depression. Extent of upset produced by social network was significantly associated with depression; extent of perceived helpfulness of network was not.

Gilhooly, 1984 (103)

37 supporters of demented patients attending day hospital. 54\% co-resident. Mean age: 58.9 years; $84 \%$ female; $26 \%$ spouses.

None of the supporters had severe psychiatric symptoms. The following were not significantly associated with mental health or morale of the supporter: patient's cognitive and functional impairment; caregiver's age; caregiver's social support; quality of past relationship between patient and carer; employment or marital status of carer. Better mental health and morale were associated with: longer duration of dementia; not living with patient; more frequent home help visits; satisfaction with help from relatives. There was no significant association between kinship tie and morale; caregivers with greater kinship distance from patient had better mental health. Male caregivers had significantly higher morale but not better mental health.

(continued on next page) 
SUMMARY OF STUDIES (continued)

Gilleard et al., 1984 (102)

224 supporters of elderly persons (87\% demented) attending or referred to day hospital. Mean age: 62.2 years; $77 \%$ female. All patients were community-resident.

$68 \%$ of supporters were "cases" by General Health Questionnaire (GHQ) criteria. Number of problems relating to the patient's level of disturbance and "demand", quality of past relationship between patient and carer, and self-rated current health status were all significantly associated with GHQ score. A lower proportion of male than female caregivers were GHQ "cases". There was no association between GHQ score and: kinship tie between patient and carer; caregiver's age; utilization of professional services; or caregiver's social support. At three-month follow-up, supporters showed significant decline in GHQ score but not in self-rated health.

Gilleard et al., 1984 (121)

129 supporters of psychogeriatric day hospital patients, almost all of whom were demented. Spouses $37.9 \%$, children $43.4 \%$. Mean age: 61.0 years.

Number of patient behavior problems was significantly correlated with caregiver strain and burden. Duration of dementia was not associated with burden or strain among older caregivers; among younger caregivers it was significantly associated with burden but not strain. Caregivers who lived with a male patient had more burden and strain than those who lived with a female patient or those who

lived apart from a male patient. Younger supporters suffered more strain and burden than older supporters. Among older supporters, there was a significant association between professional support and strain but not burden; among younger supporters, professional support was not associated with either strain or burden. Social support was significantly associated with strain or burden. Poorer premorbid relationship was associated with greater burden and strain. 
Coppel et al., 1985 (106)

68 spouse caregivers of Alzheimer patients referred by physicians, clinics, Alzheimer's disease (AD) society. Mean age: 65.8 years; $63 \%$ female. $69 \%$ of patients were communityresident

Aversiveness of patient's unpredictable behavior was related to caregiver's depression. Level of depression was similar for carers of patients in institutions as for carers of patients in the community.

Page]. et al., 1985 (104)

See Coppel et al. (106) for sample description. 38 subjects were available for follow-up.

Functional status of patient was not correlated with depression in the caregiver. Perceived loss of control over spouse behavior predicted depression in the caregiver. Changes in depression over 10-month period were small.

Pratt et al., 1985 (105)

240 caregivers to $\mathrm{AD}$ patients recruited from $\mathrm{AD}$ society members and workshop attendees. Mean age: 61.3 years; $58 \%$ spouses. $62 \%$ of patients lived in community.

79\% of caregivers said that caring had greatly or moderately affected their health. Perceived burden was not significantly associated with: patient's residential status; caregiver's age, sex, income, or education; use of comunity services; presence of confidant; or membership in support group. Use of internal coping strategies, spiritual support, and caregiver's current health status were significantly associated with perceived burden. 
SUMMARY OF STUDIES (continued)

Deimling and Bass, 1986 (114)

586 family caregivers to impaired elders. Mean age: 64.2 years; 55\% spouses.

Patient's cognitive status had little direct effect on negative family relationships, caregiver's activity restriction, physical health, or depression. Patient's behavioral disturbance was significantly associated with negative family relationships, caregiver's physical health, depression, and activity restriction. Patient's social functioning had a strong effect on negative family relationships, caregiver's health and depression, but not on activity restriction. Patient's functional impaiment had strong effect on caregiver's health, depression, and activity restriction, but not on negative family relationships.

Fiore et al., 1986 (96)

See Coppel et al. (106) for sample description.

No significant correlation between months since diagnosis of patient's dementia and caregiver depression, psychological symptoms, or physical symptoms. older caregivers had more psychological symptoms but not more physical symptoms or depression. Those of higher socioeconomic status had more physical but not psychological symptoms. Availability and use of social support were not significantly associated with depression, or psychological or physical symptoms. Caregiver's satisfaction with social support was significantly associated with depression and psychological symptoms, but not physical symptoms. 
Fitting et al., 1986 (108)

54 spouse caregivers of demented patients of one hospital clinic. Mean age: 67.9 years; 48\% female. All patients resided in the community.

Higher functional impairment was associated with greater burden among younger wives and older husbands. Higher functional impairment was associated with more depression among wives only. Husbands reported less depression than wives.

\section{George and Gwyther, 1986 (109)}

510 caregivers of demented patients, recruited from media, physicians, nursing homes, etc. Mean age: 57 years; $71 \%$ women; $54 \%$ spouses. $66 \%$ of patients lived in the community. $53 \%$ of caregivers lived with patient.

Self-rated health and number of doctor visits were about the same as in previous community surveys. Mental health was much lower and psychotropic medication use was much higher than in previous surveys. Caregivers had fewer social activities than respondents in earlier. surveys. Severity of patient's symptoms was associated with lower self-rated health, higher levels of stress, and less time relaxing among caregivers. Duration of dementia was not associated with psychological, social, physical, or financial well-being. Those who lived with patient had lower mental health, social activities, and support satisfaction but not physical health. Spouses had more doctor visits, stress, and use of psychotropic medications. They had lower self-rated health, affect balance, life satisfaction. Those who needed more social support had worse mental health and self-rated health, and fewer social activities. 
SUMMARY OF STUDIES (continued)

Scott et al., 1986 (110)

23 primaxy caregivers of demented patients of one physician and adult activity center. Mean age: 64.4 years; $65 \%$ women; $87 \%$ spouses.

Patient's cognitive status had no effect on caregiver burden. Those who reported that they got enough social support reported the least burden.

Zarit et al., 1986 (138)

33 wives and 31 husbands caring for demented patients in the community. Recruited through clinic, support groups, and AD society. Mean age: 67.7 years.

Among caregivers of patients who were still living at home two years after initial

interview, the mean burden score had decreased from 33.6 at time 1 to 29.2 at time 2 . Among caregivers of patients who had been institutionalized in the intervening two years, the mean burden score decreased from 43.5 at time 1 to 23.4 at time 2 .

Eagles et al., 1987 (112)

Supporters of 40 demented and 39 nondemented elderly subjects attending a general medical practice. Mean age: 64.9 years; $73 \%$ female; $52 \%$ spouses.

Supporters of demented and nondemented subjects differed significantly with respect to Relatives' Stress Scale (RSS), differed marginally with respect to Relatives' Mood Scale (RMS), and did not differ with respect to GHQ score. There was a sigrificant correlation between patient's cognitive status and RSS but not RMS or GHQ. There was a significant correlation between patient's behavior problems and RSS, RMS, and GHQ. Kinship tie between patient and carer did not affect RSS, RMS, or GHQ. 
Haley et al., 1987 (111)

44 primary caregivers of demented patients recruited from media, physicians, AD society. 44 elderly persons not caring for demented subject recruited from media, churches, etc. Caregivers: $34 \%$ spouses; $80 \%$ female.

Caregivers had more self-rated health problems, chronic conditions, prescription medications, and doctor visits than noncaregivers. There was little difference between groups with respect to health status questionnaire and physical symptoms. Caregivers had more depression, lower life satisfaction, and worse family relationship than noncaregivers. There was little difference between caregivers and noncaregivers with respect to social contacts, and close relationships. Caregivers were less satisfied with social network and had fewer activities with friends than noncaregivers.

Haley et al., 1987 (115)

54 caregivers of community-residing demented patients recruited through media, AD society, social services. Mean age: 56.1 years; $80 \%$ female; $28 \%$ spouses.

There was no significant correlation between patient's cognitive or behavioral problems, or duration of dementia and caregiver depression, life satisfaction or self-rated health. There was no significant correlation between these outcomes and patient's ability to carry out activities of daily living, or caregiver income or education. High levels of social support predicted life satisfaction and self-rated health but not depression. Caregiver's self-confidence in handling problems did not significantly predict life satisfaction, depression, or self-rated nealth. Caregiver's subjective appraisals of problems significantly predicted depression and life satisfaction, but not self-rated health. coping skills were significantly correlated with self-rated health but not with depression or life satisfaction. 
SUMMARY OF STUDIES (continued)

Kiecolt-Glaser et al., 1987 (119)

34 caregivers of Alzheimer patients of two physicians and participants of AD society. Mean age: 59.3 years; $68 \%$ female; $59 \%$ spouses, $38 \%$ children. 34 controls recruited through advertising and personal contacts. Mean age: 60.3 years; $68 \%$ female.

No significant difference between caregivers and noncaregivers with respect to doctor visits, sick days in last six months, self-rated health, risk factors (cigarette smoking, alcohol intake, weight loss), social support, or loneliness. Caregivers had significantly more depression, and lower life satisfaction and mental health. Caregivers had significantly reduced immune function for four of six measures; the differences could not be explained by differences in nutritional status. Caregivers of more behaviorally disturbed patients had more depression, more loneliness, and fewer social contacts. Residential status had no effect on depression, life satisfaction, mental health, or selfrated health. Participants of AD support group were less lonely but there was no difference with respect to other outcomes.

Eagles et al., 1987 (113)

274 elderly married couples from a general medical practice. In 31 couples, one of the spouses was demented. $65 \%$ of spouses of demented subjects were female.

There was no significant difference between spouses of demented and nondemented subjects with respect to GHQ score, depression, or anxiety. There was a significant correlation between wife's mental status score and husband's depression. There was no significant correlation between mental status and GHQ or anxiety.

(continued on next page) 
SUMMARY OF STUDIES (continued)

Pagel and Becker, 1987 (125)

See Coppel et al. (106) for sample description.

41\% of caregivers met RDC criteria for depression. There was no significant association between caregiver depression and duration of disease, patient's residence (institution or community), caregiver's age or socioeconomic status. Females were slightly more depressed than males. Caregiver's social support and self-esteem were significantly associated with depression.

Pagel et al., 1987 (126)

See coppel et al. (106) for sample description.

$41 \%$ met RDC criteria for depression. Upset produced by social network was significantly associated with depression, whereas perceived helpfulness of network was not.

Anthony-Bergstone et al., 1988 (120)

184 primary caregivers of dementia patients recruited through training program designed to assist family members of patients with dementia. $24 \%$ husbands, $28 \%$ wives, $33 \%$ daughters, $7 \%$ sons, $8 \%$ others.

older women (aged 60 years or more) scored significantly higher than age-adjusted normative data on the following subscales of the Brief Symptom Inventory: obsessivecompulsive, depression, anxiety, hostility, psychoticism. older men scored significantly higher than normative data on the hostility subscale only. Younger women scored significantly higher than normative data on the obsessive-compulsive, anxiety, and hostility subscales. 
SUMMARY OF STUDIES (continued)

Quayhagen and Quayhagen, 1988 (123)

58 family members of $A D$ patients recruited through $A D$ society support groups. $29 \%$ husbands, 45\% wives, 26\% daughters. Mean age (spouses): 67.0 years; (daughters): 53.9 years.

Spouses and daughters had similar levels of well-being. Wives had less respite time. Different coping strategies were associated with well-being in spouses and children. Correlation of social support with well-being was higher for wives and daughters than for husbands.

Liptzin et al., 1988 (122)

Caregivers of 38 patients (11 demented, 27 depressed) admitted to the geriatric unit of a psychiatric hospital.

There was no significant difference in burden scores between caregivers of depressed and demented patients. Caregivers of demented patients who lived in the community had higher burden scores than caregivers of demented patients in nursing homes.

Cohen and Eisdorfer, 1988 (135)

46 relatives of 27 community-resident patients with dementia seen at a geriatric diagnostic and treatment clinic. $39 \%$ spouses. $48 \%$ co-resident. $70 \%$ female.

$26 \%$ of caregivers met DSM-III criteria for unipolar depression. Depression was more common among caregivers who lived with the patient. There was no difference between depressed and nondepressed caregivers in their perception of internal vs external locus of control. 


\begin{abstract}
Nygaard, 1988 (136)
46 caregivers of patients with dementia, randomly chosen from among patients receiving services from home nurse center.

There was no significant correlation between caregiver strain and patient's cognitive status. Higher strain among caregivers was significantly associated with increased behavioral disturbance in the patient, longer duration of dementia, and poor current health status in the caregiver. Female caregivers had higher strain scores than males.
\end{abstract}

Morris et al., 1988 (132)

20 comresident spouse caregivers of patients with $A D$, recruited from $A D$ society, day center, and day hospital. Mean age: 68 years.

15\% had Beck Depression Inventory scores above the usual cutoff for depression. The existence of a poor premorbid relationship between spouses was associated with more strain and depression in the caregivers.

Whittick, 1988 (127)

37 daughters of patients with dementia at a psychogeriatric day hospital. Mean age: 50 years. 63 mothers of young mentally handicapped children. Mean age: 36 years. 45 mothers of mentally handicapped adults. Mean age: 53 years. Data obtained by mail questionnaire.

The mean GHQ score for caregivers of patients with dementia was 10.4. The mean score in the general population is 3.1. Mothers of young handicapped children had a mean score of 5.0 , and mothers of handicapped adults had a mean score of 4.0. There was no significant relation between patient disability and the caregivers' GHQ scores. 
Kiecolt-Glaser et al., 1989 (128)

34 caregivers of AD patients of two physicians and participants in local support groups. $50 \%$ of patients lived with caregiver, $29 \%$ were institutionalized, and $21 \%$ lived elsewhere. $59 \%$ spouses, $38 \%$ adult children. 34 noncaregivers recruited through advertising, community groups, and personal contacts. Groups matched on age, sex, and education.

Caregivers had significantly higher scores on the Beck Depression Inventory than noncaregivers, although the difference was not very large. The troublesomeness and frequency/upset of the patient's behavior was significantly related to depression in the caregiver. Kinship tie with the patient and support group membership were not significantly related to caregiver depression. Upset of social support, but not perceived helpfulness of social support, was a significant predictor of depression in caregivers but not in noncaregivers.

Pett et al., 1988 (129)

81 caregivers of patients with dementia recruited through 50 support groups in $16 \mathrm{U} . \mathrm{S}$. states. $88 \%$ were daughters of the patient; $31 \%$ were co-resident. $33 \%$ of patients were institutionalized. Mean age: 47 years. 95\% married, 59\% had children living at home. 100\% female.

High risk of burden and reduced life satisfaction in caregivers was not significantly associated with the patient's functional status or sex, or with the caregiver's coping skills, social support, age, income, current health status, or employment status. Those at high risk were significantly less likely to have a confidant and less satisfied with help received from social network. Caregivers experienced more burden and more financial costs when they lived with the patient than when the patient lived elsewhere in the community or in an institution. 
Novak and Guest, 1989 (130)

30 spouses of patients with SDAT identified through hospitals, clinics, and community services in Manitoba. All co-resident. 77\% female. Mean age: 72 years.

There was a significant relation between caregiver burden and patient functional status. There was no significant association between burden and the duration of caregiving. The longer the interval since the patient had been diagnosed, the lower was caregiver burden.

Morris et al., 1989 (131)

20 co-resident spouse caregivers of patients with $A D$, recruited from AD society, day center, and day hospital. Mean age: 68 years.

Higher caregiver depression and strain associated with more behavioral disturbance in the patient. Receipt of a greater amount of formal support was associated with less strain in the caregiver, but not lower depression. More social support was associated with lower depression and less strain.

Moritz et al., 1989 (133)

318 married couples who participated in large-scale epidemiologic survey of the elderly in the community. Mean age: 74 years.

Sleep complaints were not more common among caregivers of a cognitively impairea spouse than others. Lower cognitive status in the wife was significantly associated with depression in the husband. Lower cognitive status in the husband was not significantly associated with depression in wives. Those who relied on their children for financial support were most at risk for depression. Social support was not a significant modifier of the caregiving-depression association, although statistical power was low. 
SUMMARY OF STUDIES (continued)

Pruchno and Resch, 1989 (134)

315 persons caring for a spouse with dementia in the community, identified through advertising, community organizations, hospitals, support groups. $68 \%$ female.

More behavioral disturbance in the patient was associated with more burden in the spouse. Wives experienced more burden than husbands. Current health status of the caregiver was a good predictor of depression.

Pruchno and Resch, 1989 (137)

262 spouse caregivers of patients with dementia in the community, identified through advertising, community organizations, hospitals, support groups. $67 \%$ female. Mean age: 69.8 years.

Increases in asocial and disoriented behaviors in the patient were associated linearly with increases in burden, perceived consequences of caregiving, and impact on social life among caregivers. For forgetful behaviors, increases in frequency from "none" to "sometimes" were also associated with these outcomes in the caregivers, but a high level of forgetful behavior was associated with lower caregiver impact.

Scharlach AE, 1989 (139)

332 employees of California insurance company giving help to an older person, 106 ( $32 \%$ ) of whom were cognitively impaired. $66.7 \%$ female. $19.9 \%$ aged 50 or more.

Caregivers of cognitively impaired persons reported higher levels of physical, emotional and financial strain than caregivers of physically impaired older persons. They also had greater impact on employment-related events. 
SUMMARY OF STUDIES (continued)

Motenko, $1989(140)$

50 women caring for a husband with dementia at home. Recruited from AD Society support groups, hospital memory clinic, advertising. Mean age: 70.4 years.

Greater gratification from caregiving was associated with greater well-being while more frustration was associated with lower well-being. Change in marital closeness relative to before the husband's illness was associated with reduced gratification from caregiving.

Morris et al., 1989 (141)

20 spouse caregivers of patients with dementia. Recruited from AD Society, day hospital, day center. $65 \%$ female. Mean age: 68 .

Depression and strain were significantly correlated with the caregivers' perception that the stress they were experiencing would continue and the expectation that it would affect all areas of their lives. For depression, these correlations were not significant after controlling for the severity of the demented patient's behavioral disturbance. Depression and strain were significantly correlated with the caregivers' perceived lack of control over their own emotional reaction and over the dementia patient's behavior.

Whittick, 1989 (142)

37 daughters of patients with dementia at a psychogeriatric day hospital. Mean age: 50 years. 63 mothers of young mentally handicapped children. Mean age: 36 years. 45 mothers of mentally handicapped adults. Mail questionnaire.

Daughters of demented parents were more likely to see their caring role in a negative way and were more inclined to favor institutional care than mothers of handicapped children or adults. 
SUMMARY OF STUDIES (continued)

Pruchno and Potashnik, 1989 (143)

315 persons caring for a spouse with dementia in the community, identified through advertising, community organizations, hospitals, support groups. $68 \%$ female. Mean age: 70.1 years. Comparison data from previous community surveys.

Caregivers were more depressed, expressed higher levels of negative affect, were more likely to use psychotropic drugs, and had more symptoms of psychological distress than the general population. Caregivers also had higher than expected rates of diabetes, arthritis, ulcers, and anemia, but their use of medical services was the same or lower than that of the general population. Male caregivers had fewer sick days and somatic symptoms, lower psychotropic drug use, lower rates of hypertension, arthritis and depression, and higher rates of emphysema than female caregivers. There was no difference between male and female caregivers with respect to the frequency of doctor visits and hospitalization, self-rated health, or affect balance.

Pruchno and Resch, 1989 (144)

315 persons caring for a spouse with dementia in the community, identified through advertising, community organizations, hospitals, support groups. 68\% female. Mean age: 70.2 years.

"Wishfulness" and "intrapsychic" coping strategies mediated the relationship between degree of stress from caring on the one hand, and depression and anxiety on the other hand. These same two coping strategies had direct effects on obsessive-compulsive symptoms, somatization, and interpersonal sersitivity. "Instrumental" strategies had a direct effect on positive affect. In some cases, greater use of coping strategies was associated with more psychological distress. None of the coping strategies were effect modifiers of the stress-distress association. 


\section{APPENDIX 3}

\section{CENTER FOR EPIDEMIOLOGIC STUDIES DEPRESSION SCALE}

\section{(English)}

Now I would like to ask you about how you have been feeling. I will read you a list of ways you might have felt or behaved. Please tell me how often you felt this way during the past week:

1. Rarely or none of the time (less than 1 day)

2. Some or a little of the time (1-2 days)

3. Occasionally or a moderate amount of time (3-4 days)

4. Most or all of the time (5-7 days)

1. I was bothered by things that don't usually bother me.

2. I did not feel like eating; my appetite was poor. ${ }^{2}$

3. I felt that I could not shake off the blues even with help from my family or friends. I

4. I felt that I was just as good as other people. ${ }^{3}$

5. I had trouble keeping my mind on what I was doing.

6. I felt depressed. 1

7. I felt that everything I did was an effort. ${ }^{2}$

8. I felt hopeful about the future. ${ }^{3}$

9. I thought my life had been a failure.

10. I felt fearful.

11. My sleep was restless.

12. I was happy. ${ }^{3}$

13. I talkred less than usual.

14. I felt lonely. 1

15. People were unfriendly. 4

16. I enjoyed life. ${ }^{3}$

17. I had crying spelis. ${ }^{1}$ 
CENTER FOR EPIDEMIOLOGIC STUDIES DEPRESSION SCALE (cont'd)

18. I felt sad. ${ }^{1}$

19. I felt that people dislike me.4

20. I could not get 'going'.2

Subscales:

1 Negative affect subscale

2 Somatic subscale

3 Positive affect subscale

4 Interpersonal subscale 


\section{CENTER FOR EPIDEMIOLOGIC STUDIES DEPRESSION SCALE}

(French)

J'aimerais maintenant vous demander comment vous vous êtes senti dernièrement. Je vais vous lire une liste

d'impressions que vous auriez pu ressentir. Pourriez-vous m'indiquer la fréquence avec laquelle vous avez éprouvé ces sentiments durant la semaine écoulée: rarement, quelquefois, assez souvent ou la plidpart du temps?

1. Rarement ou jamais (moins d'un jour)

2. Quelquefois ( 1 à 2 jours)

3. Assez souvent ( 3 à 4 jours)

4. La plupart du temps ou toujours (5 à 7 jours)

1. J'étais contrarié(e) par des choses qui ne me dérangent pas d'habitude

2. Je n'avais pas envie de manger; je manquais d'appetit.

3. Je sentais que je ne pouvais pas me sortir de la

"déprime" même avec l'aide de ma famille et de mes amis

4. J'avais le sentiment d'être aussi bon que les autres.

5. J'avais du mal à me concentrer sur ce que je faisais.

6. Je me sentais déprimé(e).

7. J'avais l'impression que tout ce que je faisais me demandait un effort

8. J'étais confiant(e) en l'avenir.

9. Je pensais que ma vie était un échec.

10. Je me sentais craintif (craintive).

11. Mon sommeil était agité.

12. J'etais heureux (heureuse).

13. Je parlais moins que d'habitude.

14. Je me sentais seul(e).

15. Les gens étaient peu aimables.

16. Je profitais de la vie. 
CENTER FOR EPIDEMIOLOGIC STUDIES DEPRESSION SCALE (cont'd)

17. J'avais des crises de larmes.

18. Je me sentais triste.

19. J'avais l'impression que les gens ne m'aimaient pas.

20. Je manquais d'entrain. 


\section{APPENDIX 4 \\ ADAY AND ANDERBEN'B PHYBICAL BYMPTOMS CHECKLIGT \\ (English)}

In the past 30 days, have you had any of the following complaints?

$$
\begin{aligned}
& \text { 0. No } \\
& \text { 1. Yes }
\end{aligned}
$$

1. Cough any time during the day or night (which lasted for three weeks or more)

2. Feeling tired for weeks at a time for no special reason

3. Unexplained loss of over ten pounds in weight

4. Nose stuffed up or sneezing (for two weeks or more)

How often have you had the following complaints?

0 . Not at all

1. Once or twice during the month

2. About once a week

3. Almost every day

5. Sudden feelings of weakness or faintness

6. Getting up some mornings tired and exhausted even with your usual amount of rest

7. Headaches

8. Skin rash or breaking out on any part of the body

9. Diarrhea (loose bowel movements) for four or five days

10. Shortness of breath even after light work

11. Waking up with stiff or aching joints or muscles

12. Pains or swelling in any joint during the day

13. Backaches

14. Pains in or near the heart 
ADAY AND ANDERSEN'S PHYSICAL SYMPTOMS CHECKLIST (continued)

15. Indigestion or upset stomach

16. Vomiting for a day or more

17. Sore throat or running nose (with a fever of at least $100^{\circ} \mathrm{F}\left(37.8^{\circ} \mathrm{C}\right)$ for at least two days)

18. Unexpected bleeding from any part of the body (not caused by accident or injury)

19. Abdominal pains (pains in the belly or gut) (for at least a couple of days)

20. Any infections, irritations, or pains in the eyes or ears

21. Toothache

22. Bleeding gums

23. Trouble falling asleep at night

24. Having to get up more than twice a night to urinate 


\section{ADAY AND ANDERSEN'S PHYSICAL SYMPTOMS CHECKLIST}

(French)

Au cours des 30 derniers jours, avez-vous ressenti un des malaises suivants?

0. Non

1. Oui

1. Toux apparaissant à n'importe quel moment de la journée ou de la nuit (et qui dura trois semaines ou plus)

2. Sensation de fatigue pendant des semaines entières pour aucune raison particulière

3. Perte de poids inexpliquée de plus de $4,5 \mathrm{~kg}$ ( 10 livres)

4. Nez bouché ou éternuement (pendant deux semaines ou plus)

A quelle fréquence avez-vous ressenti les malaises suivants?

0 . Pas du tout

1. Une ou deux fois pendant le mois

2. Environ une fois par semaine

3. Presque tous les jours

5. Sensation soudaine de faiblesse ou d'évanouissement

6. Vous réveiller fatigué et épuisé certains matins malgré votre quantité habituelle de sommeil

7. Maux de tête

8. Rougeurs ou éruption cutanée sur n'importe quelle partie du corps

9. Diarrhée (selles molles) pendant quatre ou cinq jours

10. Essoufflement même après un léger effort

11. Articulations raides ou endolories au réveil

12. Douleurs ou enflure à n'importe quelle articulation durant la journée

13. Maux de dos

14. Douleurs au coeur ou dans la région cardiaque

(continued on next page) 
ADAY AND ANDERSEN'S PHYSICAL SYMPTOMS CHECKLIST (continued)

15. Indigestion ou estomac dérangé

16. Vomissements pendant une journée ou plus

17. Mal de gorge ou écoulement nasal (avec une fièvre d'au moins 37,80 (1000F) pendant au moins deux jours)

18. Saignement inattendu de n'importe quelle partie du corps (et non causé par un accident ou une blessure)

19. Douleurs abdominales (douleurs au ventre ou aux intestins) (pendant au moins deux jours)

20. Infections, irritations ou douleurs quelconques aux yeux ou aux oreilles

21. Mal de dents

22. Saignement des gencives

23. Difficulté à s'endormir la nuit

24. Etre obligé de vous lever plus de deux fois par nuit pour uriner 


\section{APPENDIX 5 \\ MINI-MENTAL STATE EXAMINATION \\ (English)}

Now I would like to ask you some questions to check your concentration and memory.

[Score:

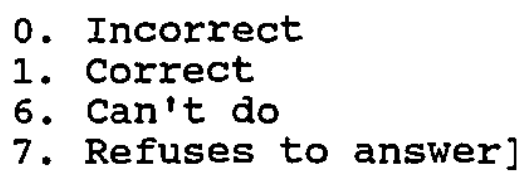

1. What is the Date?

Month?

Year?

Day?

Season?

2. Where are we?

[PROBE FOR:] Street number?

$$
\begin{aligned}
& \text { Street? } \\
& \text { City? } \\
& \text { Province? } \\
& \text { Country? }
\end{aligned}
$$

3. I am going to name three objects. After I have said them, I want you to repeat them. Remember what they are because I am going to ask you to name them again in a few minutes. Please repeat the three items for me:

'Apple'... 'Table'... 'Penny'.

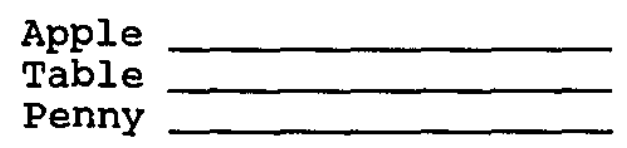

[SCORE FIRST TRY. REPEAT OBJECTS AGAIN.]

4. Could you please take 7 away from 100 , then subtract 7 from that number and then keep subtracting 7 from each new number until I tell you to stop.

[STOP AFTER FIVE ANSWERS. COUNT ERROR WHEN DIFFERENCE BETWEEN NUMBERS IS NOT EQUAL TO 7.]

[RECORD ANSWERS : ]

[ALTERNATE: IF LESS THAN FIVE CORRECT ANSWERS ON PRECEDING QUESTION, ASK THE FOLLOWING QUESTION.] 
MINI-MENTAL STATE EXAMINATION (continued)

Now I am going to spell a word forwards and I want you to spell it backwards. The word is WORLD, W-O-R-L-D. Spel1 'world' backwards. [REPEAT ONCE IF NECESSARY, BUT NOT AFTER SPELLING STARTS. GIVE ONE POINT FOR EACH CORRECT IUETTER UP TO POINT WHERE AN ERROR IS MADE.] [RECORD ANSWER: ]

5. Now, what are the names of the three objects I asked you to remember?

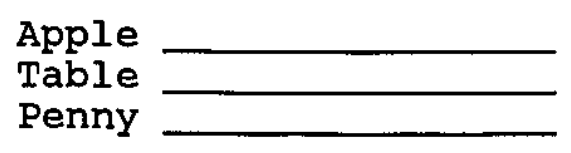

6. [SHOW WRISTWATCH.] What is this called?

[SHOW PENCIL.] What is this called?

7. I would like you to repeat a phrase after me:

'No ifs, ands or buts.'

[ALLOW ONLY ONE TRIAI.]

8. Read the words on this page and then do what it says.

[HAND 'CLOSE YOUR EYES' SHEET. CORRECT IF SUBJECT CLOSES EYES.]

9. I am going to give you a piece of paper. When I do, take the paper in your right hand, fold the paper in half with both hands, and put the paper down on your lap.

Right hand Folds In lap

10. Write any complete sentence on this piece of paper for me.

[SENTENCE SHOULD HAVE A SUBJECT AND A VERB, AND MAKE SENSE. SPELLING AND GRAMMAR ERRORS ARE OKAY.]

11. Here is a drawing. Please copy the drawing on the same paper.

[CORRECT IF THE TWO FIVE-SIDED FIGURES INTERSECT SO THAT THEIR JUNCTURE FORMS A FOUR-SIDED FIGURE AND IF ALL ANGLES IN THE FIVE-SIDED FIGURES ARE PRESERVED.] 


\section{MINI-MENTAL 8TATE EXAMINATION}

\section{(French)}

J'aimerais maintenant vous poser des questions pour vérifier votre concentration et votre mémoire.

[ Indiquez:
0 . Incorrect
1. Correct
6. Incapable
7. Refuse de répondre]

1. Quelle date sommes-nous?

Quel mois?

Quelle année?

Quel jour?

Quelle saison?

2. où sommes-nous? Adresse?

Rue?

Ville?

Province?

Pays?

3. Je vais vous nommer trois objets. Après les avoir nommer, je voudrais que vous les répétiez. Mémorisezles parce que je vais vous demander de me les nommer encore dans quelques minutes. S'il vous plait répétez les trois items: "Pomme", "Table", "Chien".

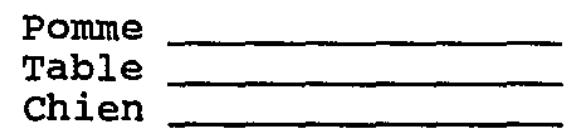

[INDIQUEZ LE POINTAGE DU PREMIER ESSAI. ENSUITE REPETEZ LES OBJETS.]

4. Pouvez-vous soustraire 7 de 100 , ensuite soustrayez 7 de votre réponse et continuez de soustraire 7 de chaque nouvelle réponse jusqu'à ce que je vous dise d'arrêter.

[ARRETEZ APRES 5 REPONSES. COMPTEZ UNE ERREUR LORSQUE LA DIFFERENCE ENTRE LES REPONSES N'EGALE PAS 7.]

[INSCRIRE LES REPONSES:

[QUESTION ALTERNATIVE: SI MOINS DE CINQ BONNES REPONSES A LA QUESTION PRECEDENTE, POSEZ LA QUESTION SUIVANTE.]

(continued on next page) 
MINI-MENTAL STATE EXAMINATION (continued)

Maintenant je vais épeler un mot du début à la fin et je veux que vous l'épeliez en commençant par la fin. Le mot est MONDE, $M-O-N-D-E$. Epelez "monde" en commençant par la fin. [REPETEZ UNE FOIS SI NECESSAIRE, MAIS PAS LORSQUE L'EPELLATION A COMMENCE. INDIQUEZ UN POINT POUR CHAQUE BONNE LETTRE JUSQU'AU POINT OU IL Y A UNE ERREUR.]

[INSCRIRE LAA REPONSE:

5. Maintenant, nommez-moi les trois objets que je vous ai demandé de mémoriser.

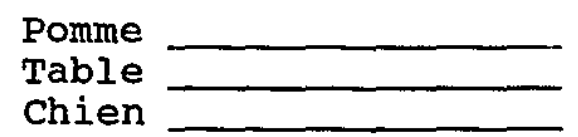

6. [POINTEZ VOTRE MONTRE.] Quel est cet objet? [POINTEZ VOTRE CRAYON.] Quel est cet objet?

7. J'aimerais que vous répétiez une phrase après moi:

'Pas de ci ni de ça'. [UN SEUL ESSAI EST PERMIS.]

8. Lisez les mots sur cette page et faites ce qu'ils disent.

[REMETTRE ILA FEUILLE 'FERMEZ VOS YEUX' - CORRECT SI LE SUJET FERME LES YEUX.]

9. Je vais vous donner une feuille de papier. Lorsque je vous la donnerai, prenez-la avec votre main droite, pliez la feuille en deux avec vos deux mains, et posezla sur vos genoux.

Main droite

Plier

Genoux

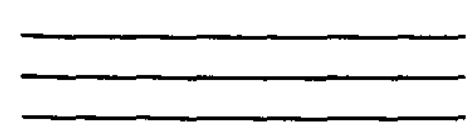

10. Ecrivez une phrase complète sur cette feuille de papier.

[LA PHRASE DOIT AVOIR UN SUJET ET UN VERBE, ET ELLE DOIT AVOIR UN SENS. LES FAUTES D'ORTHOGRAPHE ET DE GRAMMAIRE SONT ACCEPTEES.] 
MINI-MENTAL STATE EXAMINATION (continued)

11. Voici un dessin. S.V.P. copiez le dessin sur la même feuille.

[CORRECT SI LES DEUX FIGURES ONT CINQ COTES ET

S'ENTRECOUPENT POUR QUE LEUR JONCTION FORME UNE FIGURE A QUATRE COTES ET QUE TOUS LES ANGLES DES FIGURES A CINQ COTES SONT CONSERVES.] 


\section{APPENDIX 6 \\ OARS ACTIVITIES OF DAILY IIVING QUESTIONNAIRE}

(English)

Now I'd like to ask you about some of the activities of daily living, things that we all need to do as a part of our daily lives. I would like to know if at this time (subject) can do these activities without any help at all, or if he/she needs some help to do them, or if he/she can't do them at all. If you provide help to (subject), I will also ask you to tell me about how many hours per week you devote to helping.

[IF SUBJECT NEEDS HELP OR IS COMPLETELY UNABLE TO DO THE ACTIVITY, ASK (a).

(a) Do you help (subject) with this activity?

0 . no

1. yes (number of hours per week

which you devote to helping:

1. Can (subject) eat

2. without help (able to feed himself/herself completely)

1. with some help (needs help with cutting, etc.)

0 . or is (subject) completely unable to feed him self/herself.

2. Can (subject) dress and undress

2. without help (able to pick out clothes, dress and undress)

1. with some help

0 . or is (subject) completely unable to dress and undress himself/herself

3. Can (subject) take care of his/her own appearance, for example, combing his/her hair and (for men) shaving

2. without help

1. with some help

0 . or is (subject) completely unable to maintain his/her appearance himself/herself. 


\section{OARS ACTIVITIES OF DAILY LIVING QUESTIONNAIRE (continued)}

4. Can (subject) walk

2. without help (except from a cane)

1. with some help from a person or with the use of a walker, of crutches, etc.

o. or is (subject) completely unable to walk.

5. Can (subject) get in and out of bed

2. without any help or aids

1. with some help (either from a person or with the aid of some device)

0 . or is (subject) completely dependent on someone else to lift him/her.

6. Can (subject) take a bath or shower

2. without help

1. with some help (need help getting in and out of the tub, or need special attachments on the tub)

0 . or is (subject) completely unable to bathe himself/herself.

7. Does (subject) ever have trouble getting to the bathroom on time?

2. No

0 . Yes

8. Can (subject) use the telephone

2. without help, including looking up numbers and dialing

1. with some help (can answer phone or dial operator in an emergency, but needs a special phone or help for getting the number or for dialing)

0 . or is he/she completely unable to use the telephone.

9. Can (subject) get to places out of walking distance

2. without help (can travel alone on buses, taxis, or drive own car)

1. with some help (needs someone to help or go with him/her when traveling)

0 . or is he/she unable to travel unless emergency arrangements are made for a specialized vehicle like an ambulance. 


\section{OARS ACTIVITIES OF DAILY LIVING QUESTIONNAIRE (continued)}

10. Can (subject) go shopping for groceries or clothes (assuming he/she has transportation)

2. without help (taking care of all shopping needs, assuming he/she has transportation)

1. with some help (need someone to go with him/her on all shopping trips)

o. or is he/she completely unable to do any shopping.

11. Can (subject) prepare his/her own meals

2. without help (plan and cook full meals himself/herself)

1. with some help (can prepare some things but unable to cook full meals)

0 . or is (subject) completely unable to prepare any meals.

12. Can (subject) do own housework

2. without help (can scrub floors, etc.)

1. with some help (can do light housework but needs help with heavy work)

0 . or is he/she completely unable to do any housework.

13. Can (subject) take own medicine

2. without help (in the right doses at the right time)

1. with some help (able to take medicine if someone prepares it for him/her and/or reminds him/her to take it)

0 . or is he/she completely unable to take his/her medicine.

14. Can (subject) handle his/her own money

2. without help (write checks, pay bills, etc.)

1. with some help (can manage day-to-day buying but needs help with managing his/her checkbook and paying bills)

o. or is (subject) completely unable to handle money. 


\section{OARS ACTIVITIES OF DAILY LIVING QUESTIONNAIRE}

\section{(French)}

J'aimerais vous poser quelques questions au sujet des activités quotidiennes, autrement dit ce que nous avons tous besoin de faire dans la vie de tous les jours. Je voudrais savoir si actuellement (sujet) est capable sans aucune aide, capable avec de l'aide, ou incapable d'accomplir les tâches suivantes. Si vous donnez de l'aide à (sujet), je vous demanderais également de $m$ 'indiquer environ combien $d$ 'heures par semaine vous y consacrez.

1. Est-ce que (sujet) peut manger

2. sans aide (peut s'alimenter entièrement seul)

1. avec de l'aide (a besoin d'aide à couper les aliments, etc.)

0 . est absolument incapable de s'alimenter

2. Est-ce que (sujet) peut s'habililer et se déshabiller

2. sans aide (peut choisir des vêtements, s'habiller et se déshabiller)

1. avec de l'aide

0 . est absolument incapable de s'habiller et se déshabiller

3. Est-ce que (sujet) peut veiller lui(elle)-même à son apparence (ex.: se coiffer et (pour les hommes) se raser

2. sans aide

1. avec de l'aide

0 . est absolument incapable de prendre soin lui(elle)-même de sa personne

4. Est-ce que (sujet) peut marcher

2. sans aide (sauf d'une canne)

1. avec de l'aide de quelqu'un ou en se servant de béquilles, d'une marchette, etc.

0 . est absolument incapable de marcher

5. Est-ce que (sujet) peut se mettre au lit et se relever

2. sans aide ni appareil quelconque

1. avec de l'aide (soit de la part de quelqu'un, soit au moyen d'un appareil)

0 . est absolument incapable de se mettre debout sans l'aide de quelqu'un 
OARS ACTIVITIES OF DAILY LIVING QUESTIONNAIRE (continued)

6. Est-ce que (sujet) peut prendre un bain ou une douche

2. sans aide

1. avec de l'aide (il faut que quelqu'un l'aide à entrer ou sortir de la baignoire ou que celle-ci soit munie d'un dispositif spécial)

0 . est absolument incapable de prendre un bain ou une douche

7. Arrive-t-il que (sujet) arrive "trop tard" aux toilettes?

2. Non

0 . Oui

8. Est-ce que (sujet) peut téléphoner

2. sans aide, y compris pour consulter l'annuaire et composer le numéro

1. avec de l'aide (peut répondre au téléphone ou appeler I'opérateur en cas d'urgence, mais a besoin d'un téléphone spécial ou d'aide pour trouver le numéro ou le composer)

0 . est absolument incapable d'utiliser le téléphone

9. Est-ce que (sujet) peut se rendre à un endroit trop éloigné pour qu'on puisse y aller à pied

2. sans aide (peut voyager seul en autobus, en taxi, ou en conduisant sa propre voiture)

1. avec de l'aide (a besoin que quelqu'un l'aide ou l'accompagne lors des déplacements)

0 . est incapable de se déplacer sauf $\mathbf{s i}$ on met à sa disposition, en cas a'urgence, un véhicule spécialisé (ex.: une ambulance)

10. Est-ce que (sujet) peut faire ses courses chez l'épicier ou aller s'acheter des vêtements (en autant qu'il (elle) dispose de moyens de transport)

2. sans aide (fait lui(elle)-même ses courses, en autant qu'il (elle) dispose de moyens de transport)

1. avec de l'aide (a besoin que quelqu'un 1 'accompagne chaque fois qu'il (elle) fait des courses)

0 . est absolument incapable de faire des courses

(continued on next page) 
OARS ACTIVITIES OF DAILY LIVING QUESTIONNAIRE (continued)

11. Est-ce que (sujet) peut préparer ses repas

2. sans aide (en organisant et en préparant lui (elle)-même des repas complets)

1. avec de l'aide (peut préparer certains plats mais n'est pas capable de préparer lui (elle)-même des repas complets)

0 . est absolument incapable de préparer des repas

12. Est-ce que (sujet) peut faire son ménage

2. sans aide (peut laver le plancher, etc.)

1. avec de l'aide (peut faire des travaux legers mais a besoin d'aide pour les gros travaux)

0 . est absolument incapable de faire du ménage

13. Est-ce que (sujet) peut prendre ses médicaments

2. sans aide (en prenant la bonne dose et au moment qui convient)

1. avec de I'aide (peut prendre ses médicaments si quelqu'un les prépare et/ou le lui rappelle)

0 . est absolument incapable de prendre ses médicaments

14. Est-ce que (sujet) peut gérer son argent

2. sans aide (en rédigeant des chèques, payant les factures, etc.)

1. avec de l'aide (peut faire ses achats quotidiens mais a besoin d'aide pour utiliser son chéquier et payer ses factures)

0 . est absolument incapable de se servir d'argent 
APPENDIX 7

\section{VALIDITY AND RELIABILITY OF THE DEMENTIA BEHAVIOR DISTURBANCE SCALE}

Mona Baungarten, Rubin Becker, and Serge Gauthier Journal of the American Geriatrics Society (1990), in press 


\title{
Validity and Reliability of the Dementia Behavior Disturbance Scale
}

\author{
Mona Baumgarten, MSc, Rubin Becker, MD, and Serge Gauthier, MD
}

\begin{abstract}
Behavioral disturbance is a common and distinctive feature of Alzheimer's disease and other dementias. Existing instruments designed to quantify behavior disturbance among patients with dementia tend to be quite heterogeneous, including many items that do not refer to behavioral disturbance as such, but rather to cognitive, psychological, or somatic symptoms, or functional impairments. A 28-item Dementia Behavior Disturbance (DBD) scale was developed to avoid some of the problems encountered with the older instruments. In two samples of patients with dementia $(n=50$ and $n=46)$, the most common symptoms were repetitive questions, losing or hiding things, lack of interest in daily activities, nocturmal
\end{abstract}

wakefulness, unwartanted accusations, excessive daytime sleeping, and pacing. The coefficient of internat consistency was greater than .80 in both samples, and the correlation between scores obtained from the same sub. jects at a two-week interval was moderately high (Pearson's correlation coefficient $=.71$ ). There was a relatively high correlation between DBD scores and scores on Greene's Behavior and Mood Disturbance scale, and higher DBD scores were associated with increased duration and severity of disease. These preliminary results indicate that the DBD may be a useful and valid measure of one dimension of the dementia syndrome. J Am Geriatr Soc 38:000-000, 1990
$\mathrm{B}$ ehavioral disturbance is a common and distinctive feature of Alzheimer's disease and other dementias. ${ }^{1.2}$ Familiar behavioral symptoms among patients with dementia include aggressiveness, repetitive gestures and questions, wandering, and hoarding. ${ }^{3.4}$ Although it is not known whether changes in behavior result from disease-related neurochemical imbalance, from psychological reactions to the cognitive deficits associated with the dementing process, or from concomitant physical or psychiatric illness, ${ }^{2.5}$ behavior disturbance is an important phenomenon, both for clinicians and researchers. In clinical practice, quantification of behavior disturbance is heipful in determining disease severity and prognosis and in assessing the potential impact of the patient's disease on the family. Clinical evaluation of behavior disturbance is of particuar interest because beha vioral symptoms are potentially controllable by pharmacologic intervention. ${ }^{6}$ In the research setting, the severity of the patient's behavior disturbance may be an important predictive variable in prognostic studies, or it may be a major out.

From Mecill University and the St. Justine. Jewish Ceneral, and Montreal General Hospitals. Montreai, Canado.

Funding for this research was provided by the Quebec Health Research Fund (FRSQ) and the Alzheimer Society of Canada.

Address correspondence and reprint requests to Mona Baumgarten, MSc. Community Health Department. St. Justine Hospital, 3175 Cote St. Cathe:ine. Montreal. Quebec, H3T IC5. Canada. come variable in experimental trials of new treatments. Behavior disturbance is particularly salient in studies of the impact of caring for a demented patient on the health of family caregivers, because caregivers often rate behavior problems as one of the most stressful aspects of caring. 7.8

In previous studies, various characteristics of the dementia syndrome have been studied under the rubric of "behavior disturbance"; these include psychiatric problems, functional incapacity, somatic symptoms, and cognitive impairment. However, we felt that it was more useful from a conceptual and pragmatic point of view to adopt a more restrictive definition, one based on a single dimension of the dementia syndrome. Thus, we defined behavior disturbance as the outward manifestation of some underlying cognitive, psychological, or physiological deficit-regardless of etiology - likely to cause stress to those caring for the patient.

There have been several investigations in which the prevalence of individual behavioral symptoms among demented patients has been reported. ${ }^{3.46 .6 .79-12}$ Also, some clinical rating scales for dementia incorporate questions related to behavioral disturbance. ${ }^{13-18}$ For example, the Alzheimer's Disease Assessment Scale ${ }^{19}$ includes ratings of delusions, hallucinations, and pacing to be made on the basis of direct clinical observation. Similarly, the Sandoz Clinical Assessment-Geriatric scale $^{14}$ asks the clinical exarniner to rate the patient's irritability, bothersomeness, and hostility. 
Despite the usefulness of such rating scales in clinical assessments, the focus of our interest was on structured instruments that could be used outside of the clinical setting to quantify beha vior disturbance among patients with dementia. Several such scales were identified: Greene et al's 31 -item Behavior and Mood Disturbance (BMD) scale:o; Zarit and Zarit's 30-item Memory and Behavior Problems Checklist (MBPC)"; Niederehe's Behavior Problems Checklist (BPC) 22, a 52-item modifcation of Zarit and Zarit's MBPC; the 20-item Self-Assessment Scale-Geriatric (SASG) developed by Yesavage et al ${ }^{23}$; Scott et al's 53-item BPC'4; Moore et al's 20 -item Functional Dementia Scale (FDS) ${ }^{25}$; Reisberg et al's 25-item BEHAVE-AD;: Gilleard et al's 25-item problem checklist ${ }^{26}$; and Teri et al's BPC. ${ }^{27}$ In all cases except the SASG, these scales are meant to be admiristered to a respondent, usually the primary caregiver, who is familiar with the patient. In the case of the SASG, the questions are administered direetly to the mildly or moderately demented patient, a procedure whose valid. ity has not been estabilished.

Although the nine scales were all developed to measure behavior among patients with dementia, many in fact appear to be made up of a heterogeneous set of items, some of which do not refer to behavioral disturbance as we have defined it, but rather to cognitive, psychological, or somatic symptoms, or to functional impairments. For example, Zarit and Zarit's MBPC ${ }^{21}$ includes items that assess cognitive and psychiatric symptoms (eg, "trouble remembering recent events," "not recognizing a familiar place," and "appears sad or depressed"). Greene et al's BMD 20 includes disparate items such as "mood changes for no apparent reason," "appears unhappy and depressed." "fails to recognize familiar people," and "sits around doing nothing." Teri et al's"7 checklist incorporates questions about the occurrence of cognitive symptoms (eg. "loss of memory," "confusion," and "disorientation"), functional impairment (eg, "unable to walk without assistance"), and affective probiems (eg, "unusually sad and depressed"). In some cases, such as Scott et al's BPC." Moore's et al's FDS, ${ }^{25}$ and Niederehe's BPC,:2 the heterogeneity was intentional, in that multiple dimensions of dementia were specified a priori and the subscale structure allowed for the separate examination of the various dimensions. However, only a minority of the items refer specifically to behavior.

The Dementia Behavior Disturbance (DBD) scale was developed to avoid some of the problems encountered with the eariier scales. The objective of the present study was to examine various aspects of the validity and reliability of the DBD scale. Specifically, we aimed to determine the intemal consistency, test-retest reliability, and construct validity of the DBD scale.

\section{MATERIALS AND METHODS}

Development of the DBD scale The DBD scale was developed by two physicians (R. B. and S. G.) with specialties in geriatrics and neurology and with extensive clinical experience caring for demented patients. The choice of items was based partly on earlier scales and partly on clinical experience. DBD items were sampled from all the major domains of beha vior disturbance usu. ally associated with dementia: passivity, agitation, eating disturbances, aggressiveness, diumal thythm dis. turbances, and sexual misdemeanor. $1.6,9.10 .20$

In keeping with our definition of behavioral distur. bance, the scale was designed so as to include only items that refer to specific observable behaviors, and not to psychological, physical, or cognitive symptoms (the items appear in Table 1). In some cases, the distinction between behavioral and psychological symptoms was subtle. For example, a patient who makes unwarranted accusations is most likely experiencing symptoms of paranoia. Nevertheless, the item we included in our scale referred to observable behavior (accusations) and not to the ideation associated with the behavior (paranoia). This, we believe, increases the conceptual clarity of our scale.

The 28-item scale was designed to be used in an interview format, with the patient's primary caregiver as the respondent. However, it can also be used as part of a self-administered questionnaire completed by the care. giver. Each behavior is rated on a Likert-type scale with five possible responses corresponding to the frequency of the behavior in the preceding week $(0=$ never, $4=$ all the time). Thus, higher scores indicate more disturbance.

Subjects Subjects were obtained from two different sources. Sample 1 was recruited from among community-residing patients seen at a geriatric assessment unit located in a Montreal teaching hospital. The patients had all received a clinical diagnosis of dementia, according to DSM-III criteria, ${ }^{29}$ on the basis of complete medical history-taking, physical examination with thorough neurologic evaluation, and mental status testing. They all had a history of cognitive decline of at least six months duration and were participating in a larger study of the health consequences of caring for the demented elderly. Of the 52 patients in the study, two were excluded because of incomplete information on behavior. Our DBD scale and Greene's BMD scale were administered in the course of a home interview with the patient's primary family caregiver.

Sampie 2 consisted of community-residing patients who were participating in the titration phase of a study of the effectiveness of tetrahydroaminoacrine (THA) in the treatment of Alzheimer's disease. ${ }^{30}$ The patients had all received a elinical diagnosis of Alzheimer's disease 
TABLE 1. PERCENTAGE OF SUBJECTS WHO EXKIBITED BEHAVIORAL SYMPTOMS SOMETIMES, OFTEN, OR ALWAYS IN THE PRECEDING WEEK

\begin{tabular}{|c|c|c|c|}
\hline DBD items & Sample I $(x-50)$ & Sample $2(n=46)$ & Both Sarrples $(x=96)$ \\
\hline $\begin{array}{l}\text { Asks samne question repeatedly } \\
\text { Loses, misplaces, or hides things } \\
\text { Lack of interest in daily activities } \\
\text { Wakes up at night for no obvious reason } \\
\text { Makes unwarranted accusations } \\
\text { Sleeps excessively during the day } \\
\text { Paces up and down } \\
\text { Repeats the same action over and over } \\
\text { Is verbally abusive, curses } \\
\text { Dresses inappropriately } \\
\text { Cries or laughs inappropriately } \\
\text { Refuses to be helped with personal care } \\
\text { Hoards things for no obvious reason } \\
\text { Moves arms or legs in a restless or agitated way } \\
\text { Empties drawers or closets } \\
\text { Wanders in the house at night } \\
\text { Gets lost outside } \\
\text { Refuses to eat } \\
\text { Overeats } \\
\text { Is incontinent of urine } \\
\text { Wanders aimiessly outside or in the house during the day } \\
\text { Makes physical attacks (hits, bites, scatches, kicks, spits) } \\
\text { Sceams for no reason } \\
\text { Makes inappropriate sexual advances } \\
\text { Exposes private body parts } \\
\text { Destroys property or clothing } \\
\text { Is incontinent of stool } \\
\text { Throws food }\end{array}$ & $\begin{array}{r}76.0 \\
54.0 \\
52.0 \\
38.0 \\
26.0 \\
32.0 \\
30.0 \\
36.0 \\
26.0 \\
20.0 \\
22.0 \\
22.0 \\
22.0 \\
20.0 \\
14.0 \\
16.0 \\
2.0 \\
18.0 \\
14.0 \\
16.0 \\
8.0 \\
10.0 \\
12.0 \\
8.0 \\
2.0 \\
4.0 \\
4.0 \\
0\end{array}$ & $\begin{array}{r}67.4 \\
76.1 \\
50.0 \\
30.4 \\
41.3 \\
26.1 \\
23.9 \\
15.2 \\
23.9 \\
28.3 \\
17.4 \\
17.4 \\
15.2 \\
15.2 \\
15.2 \\
13.0 \\
26.1 \\
6.5 \\
8.7 \\
4.3 \\
13.0 \\
4.3 \\
0 \\
2.2 \\
4.3 \\
2.2 \\
0 \\
2.2\end{array}$ & $\begin{array}{r}71.9 \\
64.6 \\
51.0 \\
34.4 \\
33.3 \\
29.2 \\
27.1 \\
-\quad 26.0 \\
25.0 \\
24.0 \\
19.8 \\
19.8 \\
18.8 \\
17.7 \\
14.6 \\
14.6 \\
13.5 \\
12.5 \\
11.5 \\
10.4 \\
10.4 \\
7.3 \\
6.3 \\
5.2 \\
3.1 \\
3.1 \\
2.1 \\
1.0\end{array}$ \\
\hline
\end{tabular}

and were classified as being at stage 4 (moderate cognitive decline) or stage 5 (moderately severe decline) as defined by Reisberg's Global Dementia Scale. ${ }^{31}$ Interviews were carried out at home with the patient's primary caregiver at the beginsing of the study and at the end of each two-week period. During the first two weeks of the study, all patients received placebo. Most of the analyses presented in this paper are based on data from the first interview; test-retest reliability was deternined using data from the first and second interviews. Of the 51 potential subjects, 46 had complete information on behavior at both interviews.

Measures For both samples 1 and 2, cognitive status was determined using the Miri-Mental Status (MMS) test. 32 MDIS scores vary between 0 and 30, a lower score indicating more cognitive impairnent. In sample 1 , functional status was measured using the Older Amexicans Researeh and Service (OARS) activities of daily living (ADL) scale. ${ }^{33} \mathrm{An}$ algorithm developed by OARS researchers ${ }^{34}$ was used to create three categories of functional status (mild impairment, moderate impairment, and severe or total impairnent) on the basis of the ADL scale scores. In sample 2, functional status was measured using the Rapid Disability Rating Scale
(RDRS). ${ }^{35}$ Three categories were created on the basis of the frequency distribution of RDRS scores: less than 25, 25 to 29 , and 30 or more.

Analysis The total DBD score was calculated as the sum of the responses to the individual items, yielding a possible maximum score of 112. If the answer to one of the 28 questions was missing, the missing value was replaced by the mean of the 27 remaining items. None of the subjects had more than one missing item. Intemal consistency was measured using Cronbach's $\alpha$ coeffcient. ${ }^{36}$ Test-retest reliability was estimated using Pearson's correlation coefficient and using the intraclass correlation coefficient; because the resuits using the two approaches were almost identical, only the Pearson correlation coefficient will be presented.

\section{RESULTS}

Descriptive Statistics Demographic and cinical characteristies of the two samples of patients are shown in Table 2. Subjects in sample 1 were older and less likely to be female than those in sample 2. They had slightly higher MMS scores, indicating less cogritive impairment. Sample 1 was largely made up of Jewish patients; about half of these patients had only an ele- 
TABLE 2. DEMOGRAPHIC AND CLINICAL CHARACTERISTICS OF STUDY SUBJECTS

\begin{tabular}{|c|c|c|}
\hline & $\begin{array}{l}\text { Sample } 1 \\
(n-50)\end{array}$ & $\begin{array}{c}\text { Sample } 2 \\
(n=46)\end{array}$ \\
\hline age (years) (so) & $77.8(6.2)$ & $68.9(8.2)$ \\
\hline $\begin{array}{l}\% \text { female } \\
\% \text { married }\end{array}$ & $\begin{array}{l}46.0 \\
78.0\end{array}$ & \\
\hline$\%$ Jewish & 82.0 & NA \\
\hline $\begin{array}{l}\text { \% completed elementary school } \\
\text { only. }\end{array}$ & 56.0 & NA \\
\hline Mean MMS score (SD). & $19.8(5.9)$ & $17.9(4.3)$ \\
\hline $\begin{array}{l}\text { Mean duration of derrientia } \\
\text { (months) (SD) }\end{array}$ & $29.4(25.9)$ & NA \\
\hline $\begin{array}{l}\text { \% with mild or modrate ADL } \\
\text { impaiment }\end{array}$ & 53.5 & NA \\
\hline $\begin{array}{l}\% \text { with stage } 4 \text { dimentia by } \\
\text { Reisberg critesia }\end{array}$ & NA & 47.1 \\
\hline
\end{tabular}

mentary school education, and almost $80 \%$ were married.

In sample 1, the DBD scores ranged from 1 to 52 , with a mean of 18.0 (standard deviation [so] -12.8 ). In sample 2, the scores varied between 2 and 51 , with a mean of 16.8 (SD = 12.1). In both samples, the scores were slightly skewed to the left of the distribution.

The percentage of subjects who exhibited each of the $D B D$ behavioral symptoms sometimes, often, or always in the week preceding interview is shown in Table 1. The most common symptoms were repetivive questions, losing or hiding things, lack of interest in daily activities, nocturnal wakefulness, unwarranted accusations, "excessive daytime sleeping, pacing, repetitive gestures, and verbal abusiveness. The more severe and violent behaviors were less frequent: indecent exposure, screaming, physical attacks, inappropriate sexual advances, incontinence, food throwing, and destruction of property or clothing.

TABLE 3. ITEM-TOTAL CORRELATIONS AND INTERNAL CONSISTENCY COEFFICIENTS FOR DBD SCALE

\begin{tabular}{|c|c|c|c|}
\hline \multirow[b]{2}{*}{ DBD Items } & \multicolumn{3}{|c|}{$\begin{array}{l}\text { Correlation Between Item } \\
\text { and Total Score }\end{array}$} \\
\hline & Sample $1(n-50)$ & Sample $2(n-46)$ & Both Samples $(n-96)$ \\
\hline Asks the same question repeatedly & 0.44 & 0.41 & 0.43 \\
\hline Loses, misplaces, or hides things & 0.40 & 0.54 & 0.43 \\
\hline Lack of interest in daily activities & 0.39 & 0.68 & 0.52 \\
\hline Wakes up at night for no obvious reason & 0.40 & 0.62 & 0.50 \\
\hline Makes unwarranted accusations & 0.61 & 0.50 & 0.54 \\
\hline Sleeps excessively during the day & 0.39 & 0.41 & 0.40 \\
\hline Paces up and down & 0.61 & 0.61 & 0.61 \\
\hline Repeats the same action over and over & 0.58 & 0.56 & 0.57 \\
\hline Is verbaily abusive, curses & 0.62 & 0.40 & 0.53 \\
\hline Dresses inappropriately & 0.64 & 0.69 & 0.66 \\
\hline Cries or laughs inappropriately & 0.53 & 0.37 & 0.16 \\
\hline Refuses to be helped with personal care & 0.41 & 0.40 & 0.41 \\
\hline Hoards things for no obvious reason & 0.29 & 0.37 & 0.33 \\
\hline Moves ams or legs in a restless or agitated way & 0.55 & 0.51 & 0.53 \\
\hline Empties drawers or closets & 0.46 & 0.58 & 0.51 \\
\hline Wanders in the house at rigit & 0.59 & 0.55 & 0.57 \\
\hline Gets lost outside & 0.29 & 0.29 & 0.22 \\
\hline Refuses to eat & 0.57 & 0.04 & 0.39 \\
\hline Overeats & 0.25 & 0.25 & 0.25 \\
\hline Is incontinent of urine & 0.20 & 0.48 & 0.29 \\
\hline $\begin{array}{l}\text { Wanders aimlessly outside or in the house during } \\
\text { the day }\end{array}$ & 0.62 & 0.64 & 0.60 \\
\hline Makes physical attacks & 0.47 & 0.37 & 0.43 \\
\hline Screams for no reason & 0.35 & 0.32 & 0.32 \\
\hline Makes inappropriate sexual advances & 0.28 & -0.01 & 0.19 \\
\hline Exposes private body parts & 0.51 & 0.54 & 0.49 \\
\hline Destroys property or clothing & 0.31 & 0.26 & 0.29 \\
\hline Is incontizent of stool & 0.26 & $\because$ & 0.20 \\
\hline Throws food & 0.37 & -0.06 & 0.07 \\
\hline $\begin{array}{l}\text { Average item-total correlation } \\
\text { Coeffcient of intemal consistency }\end{array}$ & $\begin{array}{l}0.44 \\
0.83\end{array}$ & $\begin{array}{l}0.42 \\
0.84\end{array}$ & $\begin{array}{l}0.42 \\
0.83\end{array}$ \\
\hline
\end{tabular}

"Undefined because item mean is equal to 0 
Internal Consistency In sample 1, correlations between the individual items and the totaI DBD score varied from .20 to .64; the average item - total correlation was .44 and the coefficient of internal consistency was 0.83 (Table 3). In sample 2, the item - total correlations varied between -.06 and .69 , with a mean correlation of .42; the coefficient of internal consistency was .84 in sample 2.

Test-Retest Reliability In sample 2, the mean DBD score at the baseline interview was 16.8. At the second interview, two weeks later, the mean score was 14.5. The Pearson coefficient of correlation between DBD scores at the two interviews was .71.

Construct Valldity Two approaches were used to study the construct validity of our behavior disturbance scale. The first was to examine the correlation between the DBD scale and Greene's BMD scale, using data from sample 1. The correlation between the DBD score and the total BMD score was .73; there was a correlation of .46 with the apathetic/withdrawn subscale, .72 with the active/disturbed subscale, and .59 with the mood disturbance subscale.

The second approach was to examine the mean DBD scores in subgroups defined on the hasis of variables one would expect to be associated with behavior disturbance. Most of the results were in the expected direction. In sample 1, higher DBD scores were associated with longer duration of disease, and more cognitive and functional impairment, although none of the differences was statistically significant at $\alpha=.05$ (Table 4). In sample 2, DBD scores were not associated with cognitive impairment. However, DBD scores were higher for pa- tients with more clinically severe dementia and for patients with greater functional impairment $(P<.01)$.

The scales used to measure functional impairment included items related to incontinence. Because the DBD also includes items on incontinence, it is possible that the associations between the functional scales and the DBD were spuriously inflated. Therefor\%, the means were recalculated after removing the incor. itence questions from the DBD. The results were very similar, and all the associations were approximately of the same magnitude and in the same di-ection.

\section{DISCUSSION}

We have developed a behavior disturbance scale that, we believe, incorporates some of the positive features of earlier scales and avoids some of their problems. The DBD scale is designed to measure a single construct: manifest behavioral symptoms associated with dementia. The scale's relatively high internal consistency coefficient suggests that the items of the scale do, in fact, measure a single underlying phenomenon. Most of the correlations between the individual items and the total score were quite strong, lending further support to the scale's internal consistency. However, three of the item-total correlations in sample 2 were close to zero, suggesting that it might be possible to exclude these items (inappropriate sexual advances, refusing to eat, and throwing food) from the scale. As the item-total correlations for these items were considerably higher in sample 1, we have opted to retain these items until further work is done to shed light on the issue.

The test-retest reliability of the scale was only moderate. However, a correlation of .71 between scores ob.

TABLE 4. MEAN DBD SCORES IN VARIOUS SUBGROUPS OF PATIENTS

\begin{tabular}{|c|c|c|c|c|}
\hline & \multicolumn{2}{|c|}{ Sample 1} & \multicolumn{2}{|c|}{ Sample 2} \\
\hline & Mean Score & $n$ & Mean Score & $\pi$ \\
\hline \multicolumn{5}{|l|}{$\begin{array}{l}\text { Duration of dementia } \\
\text { (months) }\end{array}$} \\
\hline 24 months or less & 16.4 & 22 & NA & 一 \\
\hline More than 24 months & 20.0 & 21 & NA & - \\
\hline \multicolumn{5}{|l|}{ MMS score } \\
\hline Less than 20 & 19.7 & 19 & 17.0 & 29 \\
\hline 20 or more & 15.3 & 23 & 16.5 & 17 \\
\hline \multicolumn{5}{|l|}{ Functional status" } \\
\hline Mild impairment & 9.8 & 6 & $11.9 \dagger$ & 14 \\
\hline Moderate impairment & 20.7 & 17 & $12.6 \dagger$ & 16 \\
\hline Severe or total impairment & 19.6 & 20 & $25.3 \dagger_{i}$ & 16 \\
\hline \multicolumn{5}{|l|}{ Cinical severity of dementia } \\
\hline Reisberg's stage 4 & NA & - & 14.3 & 21 \\
\hline Reisberg's stage 5 & NA & - & 18.9 & 25 \\
\hline
\end{tabular}

NA = dala not available.

-Different definitions used in samples 1 and 2 see text.

tP<.01. 
$+$

IACS-MARCH 1990-VOL 38. NO. 3

THE DEMENTIA BEHAVIOR DISTURBANCE SCALE 000

tained with a two-week interval is probably as high as can be expected, given the fluctuating nature of behavioral symptoms in dementia.

The construct validity of the DBD scale is supported by the relatively high correlation with Greent: DAMD scale and, in particular, with the BMD active/disturbed subscale. Furthermore, examination of the relationship between scale scores and several clinical variables revealed that, in general, increased behavioral disturbance was positively associated with disease duration and severity, as well as with cognitive and functional inpairment. This gives further indirect evidence of the scale's validity.

Unfortunately, there is no "gold standard" to which measures of behavior disturbance among demented patients can be compared. Therefore, it is impossible to determine the criterion validity of the DBD scale. In the present study, we have presented preliminary results mindicating that the DBD may be a useful, valid measure if one dimension of the dementia syndrome. Future work should focus on determining the DBD scale's validity and reliability in larger samples and in different settings.

\section{REFERENCES}

1. Fairbum CG, Hope RA: Changes in behaviour in dementa: a neglected research atea. Br J Psychiatry 152:406, 1988

2. Reisberg B, Borenstein J, Franssen E, et al: Remediable behavioral symptomatology in Alzheimer's disease. Hoop Community Psychiatry 37:1199, 1986

3. Argyle N, Jestice S, Brook CRB: Psychogeriatric patients: their supporters' problems. Age Ageing 14:355, 1985

4. Rabins PV, Mace NL, Lucas M]: The impact of dementis on the family. JAMA 248:333, 1982

5. O'Connor M: Disturbed behaviour in dementia - poychiatric or medical problem? Med J Aust 147:481, 1987

6. Reisberg B, Borenstein J, Salob SP, et al: Behavioral symptoms in Alzheimer's disease: phenomenology and treatment. I Clin Psychiatry 48(Suppl):9, 1987

7. Haley WE, Brown SL, Levine EG: Fa.nily caregiver appraisals of patient behavioral disturbarice in senile dementia. Cin Gerontologist 6:25, 1987

8. Deimling GT, Bass DM: Symptoms of mental impairnent among elderiy adults and their effects on family caregivers. I Gerontol 41:778, 1986

9. Rubin EH, Morris JC, Berg L: The progression of personality changes in senile dementia of the Alzheimer's type. I Am Geriat Soc 35:721, 1987

Rubin EH, Morris jC, Storandt $M$, et al: Behavioral changes in patients with mild senile dementia of the Alzheimer's type. Psychiatry Res 21:55, 1987

11. Drevets WC, Rubin EH: Psychotic symptoms and the longitudinal course of senile dementia of the Alzheimes type. Biol Poy. chiatry 25:39, 1989

12. Swearer JM, Drachman DA, O'Donnell BF, et al: Troublesome and disruptive behaviors in dementia: relationahips to diz gnosis and disease severity. I Am Geriatr Soc 36:784, 1988

13. Schwartz GE: Development and validation of the Geriatric Evaluation by Relatives Rating Instrument (GERR). Psychol Rep 53:479, 1983

14. Venn RD: The Sandoz Clinical Awearnent-Geriatric (SCAG) cale: a general -purpose psychogerlatric rating scale. Gerontology 29:185, 1983

15. Rosen WG, Mohs RC, Davis KL: A new rating ecale for Alzheimer's disease. Am J Paychiatry 141:1356, 1984

16. Winslow GS, Ballinger BR, McHarg AM: Standardlsed paychiatric interview in elderly demented patients. Br I Paychiatry $147: 545,1985$

17. Bucht $G$, Adolfsson R: The Comprehensive Paychopathological Rating Scale in patients with dementla of Alzheimer type and multiinfarct dementia. Acta Psychiatr Scand 68:263, 1983

18. Linn MW: Physical and Mental Impaiment-of-Function Evaluation (PAMIE). Psychopharmacol Bull 24:755, 1988

19. Mohs RC, Cohen Li Alzheimer's Disease Asseament Scale (ADAS). Psychopharmacol Bull 24:627, 1988

20. Greene JG, Smith R, Gardlner M, et al: Measuring behavioural disturbancey of elderly demented patients in the community and its effects on relatives: a factor analytic study. Age Ageing $11: 121,1982$

21. Zarit SH, Zarit fM: The Memory and Behavior Problems Checkiist and the Burden interview. Unpublished manusaipt, 1983

22. Niederehe G: TRIMS Behavioral Problems Checkliit (BPC). Psychopharmacol Bull 24:771, 1988

23. Yeavage JA, Adey M, Wemer PD: Development of a geriatric behavioral self-assessment scale. J Am Geriatr Soc 29:285, 1981

24. Scott I, Wiegand G. Niederehe G: Measuring behavioral problems and dimensions of family caregiving in senile dementia, Presented at the 37th Annual Scientific Meeting of the Gerontological Sociery of America, San Antonto, Texas, 1984

25. Moore $\Gamma$, Bobula JA, Short TB, et al: A functional dementia scale. J Fam Pract 16:499, 1983

iv. Gilleard CJ, Boyd WD, Watt G: Probleme in carting for the elderly mentally infirm at home. Arch Gerontol Gerlatr 1:151, 1982

27. Teri L, Borson S. Kiyak HA, et al: Behavioral disturbance, cognltive dysfunction, and functional skill: prevalence and selation. ship in Alzheimer's disease. I Am Geriatr Soc 37:109, 1989

28. Fairbum CG, Hope RA: Changes in eating in dementia. Neurobiol Aging 9:28, 1988

29. American Psychiatric Association Task Force on Nomenclature and Statistics: Diagnoste and statistical manual of mental dis. orders, 3rd ed. 1980

30. Gauthier S, Masson H. Gauthier L, et al: Tetrahydroaminoacridine and lecithin in Alzheimer's disease. Presented at the International Symposium on Advances in Alzheiners Therapy: Cholinesterase Inhibitors, Springeeld, Dlinois, 1988

31. Reisberg B, Shulman E, Ferris SH, et al: Clinical aweuments of age-associated cognitive decline and primary degenerative dementia: prognostic concomilants. Psychopharmacol Bull 19:734. 1983

32. Folstein MF, Folstein SE, MeHugh PR: "Mini-Mental State": a practical method for grading the cogritive otate of patients for the clinician. I Psychiatr Res 12:189, 1975

33. Duke University Center for the Study of Aging and Human Development: Multidimensional Functional Aweasment: the OARS Methodology. Durham, Duke University Preas, 1978

34. George LK, Fullenbaum GG: OARS methodology: a decade of experience in geriatric assessment. I Am Geriatr Soc 33:607, 1985

35. Linn MW, Linn 8S: The Rapid Disability Rating Scale-2. J Am Geriatr Soc 30:378, 1982

36. Cronbach LJ: Coefficient alpha and the intemal structure of tests. Psychometrika 16:294, 1951 


\section{APPENDIX 8 \\ BOCIODEMOGRAPHIC QUESTIONS ASKED AT INTERVIEW \\ (English)}

Now, I will ask you a few general questions about yourself.

1. How old are you today? years

2. What is your marital status?

1. married

2. widowed

3. separated

4. never married

5. divorced

6. other (specify:

3. Where were you born?

[IF NOT BORN IN CANADA.] What year did you first move to Canada?

4. What is your ethnic group?

1. French Canadian

2. Jewish

3. Other (specify:

5. How far did you go in school?

1. no formal education

2. some elementary school education

3. completed elementary school

4. some high school education

5. completed high school

6. some postsecondary education

7. completed at least one university degree

8. other (specify:

6. Do you live with (subject)? 1. Yes

0. No

7. Whom else do you live with?

Number

Spouse

Children

Siblings

Other relatives (specify:

Friends

Other (specify:

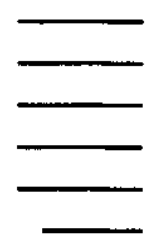

(continued on next page) 
SOCIODEMOGRAPHIC QUESTIONS (continued)

[IF RESPONDENT LIVES WITH CHILDREN.] How old are children?

8. Are you working now? [ONLY CONSIDER REMUNERATED WORK.] 0 . No

1. Yes - part time

2. Yes - full time

9. What kind of work have you done for most of your life? [PROBE FOR JOB TITLE AND TYPE OF COMPANY, INDUSTRY OR BUSINESS.]

10. In what year did you retire?

11. What is your date of birth?

$\overline{\text { (month) (day) (year) }}$ 


\section{BOCIODEMOGRAPHIC QUESTIONS ASKED AT INTERVIEW}

\section{(French)}

Maintenant, je vous poserai quelques questions générales sur vous-même.

1. Quel âge avez-vous aujourd'hui? ans

2. Quel est votre état civil?
1. marié (e)
2. veuf (veuve)
3. séparé (e)
4. jamais marié(e)
5. divorcé(e)
6. autre (spécifier:

3. où êtes-vous nè (e)?

[SI PAS NE AU CANADA.] En quelle année avez-vous

déménagé au canada?

4. Quel est votre groupe ethnique?

1. Canadien français

2. Juif

3. Autre (spécifier:

5. Jusqu'où avez-vous poursuivi vos études?

1. aucune éducation formelle

2. quelques années à l'école primaire

3 . école primaire terminée

4. quelques années à l'école secondaire

5. école secondaire terminée

6. quelques années d'études postsecondaires

7. au moins un diplôme d'études universitaires

8. autre (spécifier:

6. Demeurez-vous avec (sujet)? 1. oui 0. Non

7. Avec qui d'autre habitez-vous? Nombre

Conjoint (e)

Enfants

Frères ou soeurs

Autre parenté (spécifier:

Amis

Autre (spécifier:

[SI REPONDANT DEMEURE AVEC DES ENFANTS.] Quel âge ont les enfants? 
220

SOCIODEMOGRAPHIC QUESTIONS (continued)

8. Travaillez-vous en ce moment? [TRAVAIL REMUNERE SEULEMENT . ]

0 . Non

1. oui - à temps partiel

2. oui - à temps complet

9. Quel genre de travail avez-vous fait pour la plus grande partie de votre vie? [INSCRIRE LE TITRE D'EMPLOI ET IE TYPE DE COMPAGNIE, DE COMMERCE OU D'INDUSTRIE.]

10. En quelle année avez-vous pris votre retraite?

11. Quelle est votre date de naissance?

(mois) (jour) (annèe) 


\section{APPENDIX 9 \\ CHRONIC CONDITIONS AS ASKED IN CANADA HEALTH SURVEY \\ (English)}

The following questions concern long-term health problems. Do you presently suffer from:

0. No
1. Yes

1. Anemia

2. Skin allergies

3. Hay fever or other allergies

4. Asthma

5. Arthritis or rheumatism

6. Cancer (tumor or malignancy)

7. Paralysis

8. Diabetes

9. Emphysema or chronic bronchitis

10. Epilepsy

11. High blood pressure (hypertension)

12. Heart disease

13. Kidney disease

14. Urinary (or prostate) disorders

15. Stomach ulcers

16. Thyroid problems (e.g., goiter)

17. Missing legs or arms

18. Missing fingers or toes

19. Glaucoma

(continued on next page) 
222

CHRONIC CONDITIONS (continued)

20. Liver or gall bladder disease

21. Circulation trouble in arms or legs

22. Parkinson's disease

23. Multiple sclerosis

24. Cerebral palsy

25. Muscular dystrophy

26. Effects of polio

27. Other (specify: 


\section{CHRONIC CONDITIONS AS ASKED IN CANADA HEALTH SURVEY \\ (French)}

Les questions qui suivent portent sur les problèmes de santé de longue durée. Souffrez-vous présentement de:

$$
\text { 1. Non }
$$

1. Anémie

2. Allergies cutanées

3. Rhume des foins ou autres allergies

4. Asthme

5. Arthrite ou rhumatisme

6. Cancer (tumeur)

7. Paralysie

8. Diabète

9. Emphysème ou bronchite chronique

10. Epilepsie

11. Haute pression (hypertension)

12. Maladie du coeur

13. Maladie du rein

14. Maladies des voies urinaires (ou de la prostate)

15. Ulcères d'estomac

16. Troubles de la thyroïde (ex.: goitre)

17. Jambes ou bras manquants

18. Doigts ou orteils manquants

19. Glaucome

20. Maladie du foie ou de la vésicule biliaire

(continued on next page) 
CHRONIC CONDITIONS (continued)

21. Troubles de la circulation sanguine (bras ou jambes)

22. Maladie de Parkinson

23. Sclérose en plaques

24. Paralysie cérébrale

25. Dystrophie musculaire

26. Effets de la polio

27. Autre (spécifier: 


\section{APPENDIX 10}

\section{LOPES LIFE EVENTS SCALE}

\section{(English)}

Now I would like to ask you about certain events that can happen to people. Could you tell me whether any of the following events happened to you in the last six months.

0 . No

1. Yes

Someone in your close family died:

1. brother or sister

2. spouse

3. child

4. parent (specify:

5. grandchild

Someone in your close family had a new illness or injury:

6. brother or sister

7. spouse (specify:

8. child

9. parent (specify:

10. grandchild

11. You or a close family member needed to go into hospital (specify:

12. A good friend of yours died.

13. A friend had a new illness or injury.

14. You had a new illness or injury.

15. Your home needed major repairs.

16. You had to take more responsibility for a family member (specify: 
LOPES LIFE EVENTS SCALE (continued)

17. You had less money to live on.

18. Your child had a new problem with money.

19. You stopped going to church (synagogue) activities.

20. A friend or neighbor moved away.

21. You lost a pet.

22. There was a crime against you or someone you know.

23. You stopped going to recreation activities.

24. Your child moved farther away.

25. You knew someone who committed suicide or attempted.

26. Your child got divorced.

27. Your child had a new problem in marriage.

28. You took out a large loan.

29. There was a new conflict with a family member.

30. You lost your job or your business.

31. You lost your home.

32. You had a new problem in your marriage.

33. You got divorced.

34. You separated from your spouse because of conflict. 


\section{LOPES LIFE EVENTS BCALE}

(French)

Maintenant, j'aimerais vous parler de certains événements qui peuvent arriver aux gens. Pouvez-vous me dire si un ou plusieurs des événements suivants vous est arrivé au cours des six derniers mois?

0. Non

1. Oui

Un membre de votre famille proche est décédé:

1. frère ou soeur

2. conjoint(e)

3. enfant

4. parent (spécifier:

5. petit-enfant

Un membre de votre famille proche a contracté une maladie ou a subi une blessure:

6. frère ou soeur

7. conjoint(e) (spécifier:

8. enfant

9. parent (spécifier:

10. petit-enfant

11. Vous ou un membre de votre famille proche avez dû être hospitalisé (spécifier:

12. Un(e) bon(ne) ami(e) est décédé(e).

13. Un(e) ami(e) a contracté une maladie ou a subi une blessure.

14. Vous avez contracté une maladie ou subi une blessure.

15. Votre maison a eu besoin de réparations majeures. (continued on next page) 
LOPES LIFT EVENTS SCALE (continued)

16. Vous avez dû prendre plus de responsabilités pour un membre de votre famille (spécifier:

17. Vous aviez moins d'argent pour vivre.

18. Votre enfant a eu de nouveaux problèmes d'argent.

19. Vous avez cessé ci'assister aux activités paroissiales (de la synagogue)

20. Un(e) ami(e) ou un(e) voisin(e) a déménagé.

21. Vous avez perdu un animal.

22. Il $y$ a eu un crime contre vous ou quelcqu'un que vous connaissez.

23. Vous avez cessé de participer aux activités de loisirs.

24. Votre enfant est déménagé plus loin.

25. Vous avec connu quelqu'un qui s'est suicidé ou qui a fait une tentative de suicide.

26. Votre enfant s'est divorcé.

27. Votre enfant a connu un nouveau problème conjugal.

28. Vous avez emprunté une importante somme d'argent.

29. Il y a eu un nouveau conflit avec un membre de votre famille.

30. Vous avez perdu votre emploi ou votre commerce.

31. Vous avez dû quitter votre domicile.

32. Vous avez connu un nouveau problème conjugal.

33. Vous vous êtes divorcé(e).

34. Vous vous êtes séparé(e) de votre conjoint(e) à cause de conflits 
APPENDIX 11

CIGARETTE SMOKING QUESTIONS FROM CANADA HEALTH SURVEY

(English)

1. Do you smoke every day?

0. No (current non-smoker) ... [GO TO QUESTION 2.]

1. Yes (current smoker) ... [GO TO QUESTION 4.]

2. FOR CURRENT NON-SMOKERS:

In the past, did you ever smoke every day?
0 . No
1. Yes (ex-smoker)
... [GO TO NEXT PAGE.]
... [GO TO QUESTION 3.]

3. FOR EX-SMOKERS:

How old were you when you first started to smoke every day?

How old were you when you stopped smoking every day?

What did you usually smoke?

$$
\begin{aligned}
& \text { 1. cigarettes } \\
& \text { 2. cigars } \\
& \text { 3. pipe } \\
& \text { 4. cigarillo }
\end{aligned}
$$

About how many cigarettes per day did you usually smoke?

[GO TO NEXT PAGE.]

4. FOR CURRENT SMOKERS:

At what age did you start smoking every day?

What do you usually smoke?

$$
\begin{aligned}
& \text { 1. cigarettes } \\
& \text { 2. cigars } \\
& \text { 3. pipe } \\
& \text { 4. cigarillo }
\end{aligned}
$$

About how many cigarettes per day do you usually smoke? 


\section{CIGARETTE SMOKING QUESTIONS FROM CANADA HEALTH SURVEY}

\section{(French)}

Maintenant, j'aimerais vous poser quelques questions sur l'usage du tabac.

1. En ce moment, fumez-vous tous les jours?

$$
\left.\begin{array}{llll}
0 . & \text { Non (non-fumeur) } & \ldots & {[\text { A LA QUESTION }} \\
\text { 1. Oui (fumeur) } & \ldots & {[\text { A LA QUESTION }}
\end{array}\right]
$$

2. POUR LES NON-FUMEURS:

Dans le passé, avez-vous déjà fumé tous les jours?

0. Non

1. Oui (ex-fumeur)

3. POUR LES EX-FUMEURS:

A quel âge avez-vous commencé à fumer tous les jours? ans

A quel âge avez-vous cessé de fumer tous les jours? ans

Qu'est-ce que vous fumiez habituellement?

1. les cigarettes

2. les cigares

3. la pipe

4. les cigarillos

Environ combien de cigarettes fumiez-vous habituellement par jour? cigarettes (ou cigares ou cigarillos ou pipes)

[A LA PAGE SUIVANTE.]

4. POUR LES FUMEURS:

A quel âge avez-vous commencé à fumer tous les jours? ans 
CIGARETTE SMOKING QUESTIONS (continued)

Qu'est-ce que vous fumez habituellement?

1. les cigarettes

2. les cigares

3. la pipe

4. les cigarillos

Environ combien de cigarettes fumez-vous habituellement par jour?

cigarettes (ou cigares ou cigarillos ou pipes) 


\section{ARPENDIX 12}

\section{QUESTIONS ON ALCOHOL CONSUMPTION FROM EPESE SURVEY}

\section{INSTRUMENT}

\section{(English)}

1. Over the last month, how often have you had beer or ale? times

[IF RESPONDENT DRANK BEER AT LEAST ONCE, ASK (a).]

(a) When you had beer or ale, how many cans or bottles did you usually have at one time? cans or bottles

2. Over the last month, how often have you had wine? times

[IF RESPONDENT DRANK WINE AT LEAST ONCE, ASK (a).]

(a) When you had wine, how many glasses did you usually have at one time?

$$
\text { glasses }
$$

3. Over the past month, how often have you had liquor? times

[IF RESPONDENT DRANK LIQUOR AT LEAST GNCE, ASK (a).]

(a) When you had liquor, how many drinks did you usually have at one time?

drinks 
QUESTIONS ON ALCOHOL CONSUMPTION FROM EPESE SURVEY

\section{INSTRUMENT}

\section{(French)}

1. Au cours du dernier mois, combien de fois avez-vous pris de la bière?

$$
\text { fois }
$$

[SI IE REPONDANT A BU DE LA BIERE AU MOINS UNE FOIS, DEMANDEZ (a) . ]

(a) Quand vous avez pris de la bière, combien de cannettes ou de bouteilles avez-vous habituellement bues à chaque fois?

cannettes ou bouteilles

2. Au cours du dernier mois, combien de fois avez-vous pris du vin?

$$
\text { fois }
$$

[SI LE REPONDANT A BU DU VIN AU MOINS UNE FOIS, DEMANDEZ (a) . ]

(a) Quand vous avez pris du vin, combien de verres avez-vous habituellement bus à chaque fois?

verres

3. Au cours du dernier mois, combien de fois avez-vous pris de la boisson forte?

fois

[SI LE REPONDANT A BU DE LA BOISSON FORTE AU MOINS UNE FOIS, DEMANDEZ (a).]

(a) Quand vous avez pris de la boisson forte, combien de verres avez-vous habituellement bus à chaque fois? verres 


\section{APPENDIX 13 \\ F-COPES (COPING SRILLS SCALE)}

(English)

In this section, I will ask you some questions concerning how you usually deal with problems or difficulties. Please tell me to what extent you agree or disagree with each of the following statements.
1. Strongly disagree
2. Moderately disagree
3. Neither agree nor disagree
4. Moderately agree
5. Strongly agree

1. When I face problems or difficulties, I share them with relatives

2. When I face problems or difficulties, I seek encouragement and support from friends

3. When I face major problems or difficulties, I know I have the power to solve them

4. When I face problems or difficulties, I seek information and advice from persons in other families who have faced similar problems

5. When I face problems or difficulties, I seek advice from relatives (children, brothers or sisters, etc.)

6. When I face problems or difficulties, I ask neighbors for favors and assistance

7. When I face problems or difficulties, I seek assistance from community agencies and programs designed to help people in my situation

8. When I face problems or difficulties, I know that I have the strength within myself to solve them

(continued on next page) 
F-COPES (continued)

9. When I face problems or difficulties, I accept gifts and favors from neighbors (e.g., food, taking in mail, etc.)

10. When I face problems or difficulties, I seek information and advice from the family doctor

11. When I have problems, I face them 'head-on' and try to get solutions right away

12. When I have problems or difficulties, I respond by watching television

13. When I face problems or difficulties, I respond by showing that I am strong

14. When I face problems or difficulties, I respond by attending church services (or going to synagogue)

15. When I face probjems or difficulties, I respond by accepting stressful events as a fact of life

16. When I face problems or difficulties, I share concerns with close frienas

17. I know luck plays a big part in how well I am able to solve problems

18. I accept that difficulties occur unexpectedly

19. When I face problems or difficulties, I respond by doing things with relatives (get-togethers, dinners, etc.)

20. When I face problems or difficulties, I seek professional counseling and help

21. When I face problems or difficulties, I respond by believing I can handle them myself

22. When I face problems or difficulties, I respond by participating in church or synagogue activities

23. When I face a problem, I respond by defining it in a more positive way so that I do not become too discouraged

24. I ask relatives how they feel about problems or difficulties I face 
236

F-COPES (continued)

25. I feel that no matter what I do to prepare, I will have difficulty handling problems

26. When I face problems or difficulties, I seek advice from a minister, priest, or rabbi

27. I believe that, if I wait long enough, my problems will go away

28. When I face problems or difficulties, I share them with neighbours

29. When I face problems, I respond by having faith in God 


\section{F-COPES (COPING SRILLS SCALE)}

\section{(French)}

Dans cette section, je vous poserai des questions sur votre façon habituelle d'affronter les problèmes ou difficultés. Veuillez me dire si vous êtes d'accord ou pas d'accord avez chacun des énoncés suivants.

1. Fortement en désaccord

2. Modérément en désaccord

3. Ni d'accord, ni en désaccord

4. Modérément d'accord

5. Fortement d'accord

1. Lorsque je fais face à des problèmes ou difficultés, je les partage avec ma famille ou ma parenté

2. Lorsque je fais face à des problèmes ou difficultés, je cherche de l'encouragement et du support auprès de mes ami (e)s

3. Lorsque je fais face à des problèmes ou difficultés majeurs, je sais que j'ai la capacité de les résoudre

4. Lorsque je fais face à des problèmes ou difficultés, je cherche de l'information et des conseils auprès de membres d'autres familles qui ont fait face à des problèmes semblables

5. Lorsque je fais face à des problèmes ou difficultés, je cherche des conseils auprès de ma famille (enfants, frères ou soeurs, etc.)

6. Lorsque je fais face à des problèmes ou difficultés, je demande aux voisin(e)s des services et de l'aide

7. Lorsque je fais face à des problèmes ou difficultés, je cherche de l'aide auprès des services et programmes communautaires institués pour aider les gens dans ma situation

8. Lorsque je fais face à des problèmes ou difficultés, je sais que j'ai la force de les résoudre moi-même

9. Lorsque je fais face à des problèmes ou difficultés, j'accepte des cadeaux et services des voisin(e)s (ex.: de la nouriture, un service tel que rentrer le courrier, etc.) 


\section{F-COPES COPING SKILLS SCALE (continued)}

10. Lorsque je fais face à des problèmes ou difficultés, je cherche de l'information et des conseils auprès du médecin de famille

11. Quand je fais face à des problèmes, je les aborde de front en essayant d'y trouver des solutions immédiates

12. Lorsque je fais face à des problèmes ou difficultés, je réagis en regardant la télévision

13. Lorsque je fais face à des problèmes ou difficultés, je réagis en montrant que je suis fort(e)

14. Lorsque je fais face à des problèmes ou difficultés, je réagis en assistant à des services religieux

15. Lorsque je fais face à des problèmes ou difficultés, je réagis en acceptant les événements stressants comme faisant partie de la vie

16. Lorsque je fais face à des problèmes ou difficultés, je partage mes préoccupations avec des ami(e)s intimes

17. Je sais que la chance joue un grand rôle dans ma capacité à résoudre mes problèmes

18. J'accepte le fait que les difficultés surgissent sans avertir

19. Lorsque je fais face à des problèmes ou difficultés, je réagis en faisant des choses avec la famille ou la parenté (rencontres, soupers, etc.)

20. Lorsque je fais face à des problèmes ou difficultés, je cherche de l'aide et des conseils professionnels pour m'aider à résoudre mes difficultés

21. Lorsque je fais face à des problèmes ou difficultés, je réagis en croyant que je peux m'occuper de mes propres problèmes

22. Lorsque je fais face à des problèmes ou difficultés, je réagis en participant aux activités paroissiales (ou de la synagogue)

23. Lorsque je fais face à des problèmes ou difficultés, je réagis en les considérant de façon plus positive afin de ne pas trop me décourager 
F-COPES COPING SKILLS SCALE (continued)

24. Je demande aux membres de la famille ou de la parenté comment ils se sentent face aux problèmes ou difficultés que je vis

25. Je sens que quelque soit la façon que je me prépare, j'aurai de la difficultè à trouver des solutions à mes problèmes

26. Lorsque je fais face à des problèmes ou difficultés, je cherche des conseils auprès du curé, du prêtre, ou du rabbin

27. Je crois que si j'attends assez longtemps, mes probièmes disparaitront

28. Lorsque je fais face à des problèmes ou difficultés, je les partage avec mes voisins

29. Lorsque je fais face à des problèmes ou difficultés, je réagis en croyant en Dieu 


\section{APPENDIX 14 \\ SOCIAL PROVISIONS SCALE}

(English)

The next set of questions refer to your current relationships with friends, family members, coworkers, community members, and so on. Please tell me to what extent you agree that each statement describes your current relationships with other people. Use the following scale to give me your opinion.

$$
\begin{aligned}
& \text { 1. Strongly disagree } \\
& \text { 2. Disagree } \\
& \text { 3. Agree } \\
& \text { 4. Strongly agree }
\end{aligned}
$$

1. There are people I can depend on to help me if I really need it.

2. I feel that I do not have close personal relationships with other people.

3. There is no one I can turn to for guidance in times of stress.

4. There are people who depend on me for help.

5. There are people who enjoy the same social activities I do.

6. Other people do not view me as competent.

7. I feel personally responsible for the well-being of another person.

8. I feel part of a group of people who share my attitudes and beliefs.

9. I do not think other people respect my skills and abilities.

10. If something went wrong, no one would come to my assistance.

11. I have close relationships that provicie me with a sense of emotional security and well-being.

12. There is someone I could talk to about important decisions in my life. 
SOCIAL PROVISIONS SCALE (continued)

13. I have relationships where my competence and skill are recognized.

14. There is no one who shares my interests and concerns.

15. There is no one who really relies on me for their wellbeing.

16. There is a trustworthy person I could turn to for advice if I were having problems.

17. I feel a strong emotional bond with at least one other person.

18. There is no one I can depend on for aid if I really need it.

19. There is no one I feel comfortable talking about problems with.

20. There are people who admire my talents and abilities.

21. I lack a feeling of intimacy with another person.

22. There is no one who likes to do the things I do.

23. There are pecple I can count on in an emergency.

24. No one needs me to care for them. 


\section{SOCIAL PROVISIONS SCALE}

\section{(French)}

Les questions suivantes ont trait à vos relations actuelles avec vos ami(e)s, les membres de votre famille, vos compagnons (compagnes) de travail, les membres de votre communauté, et ainsi de suite. Dites-moi S.V.P. jusqu'à quel point vous êtes d'accord que chaque énoncé décrit vos relations actuelles avec les gens.

1. Fortement en désaccord

2. En désaccord

3. D'accord

4. Fortement d'accord

1. Il y a des gens sur qui je peux compter si j'ai vraiment besoin d'aide.

2. Je trouve que je n'entretiens pas de relation personnelle intime avec d'autres personnes.

3. Il n'y a personne à qui je peux demander conseils dans des moments difficiles.

4. Il $y$ a des personnes qui comptent sur moi pour les aider.

5. Il $y$ a des personnes qui aiment les mêmes activités sociales que moi.

6. Les autres ne me considèrent pas compétent(e).

7. Je me sens personnellement responsable du bien-être d'une autre personne.

8. Je sens que $j$ 'appartiens à un groupe de gens qui partagent les mêmes opinions et croyances.

9. Je ne crois pas que les autres respectent mes talents et mes aptitudes.

10. Si quelque chose allait mal, personne ne viendrait m'aider.

11. J'entretiens des relations intimes qui m'apportent une sécurité et un bien-être émotionnels

12. Il y a quelqu'un avec qui je pourrais discuter des decisions importantes de ma vie. 
SOCIAL PROVISIONS SCALE (continued)

13. J'entretiens des relations où ma compétence et mes talents sont reconnus

14. Il n'y a personne qui partage mes intérêts et préoccupations.

15. Il $n^{\prime} y$ a personne qui compte vraiment sur moi pour son bien-être.

16. Il y a une personne fiable sur qui je pourrais compter pour demander des conseils $s i$ j'avais des problèmes

17. J'ai un lien émotionnel fort avec au moins une autre personne.

18. Il n'y a personne sur qui je peux compter si j'ai vraiment besoin d'aide.

19. Il n'y a personne avec qui je me sens à l'aise pour parler de mes problèmes.

20. Il y a des personnes qui admirent mes talents et mes aptitudes.

21. Ca ine manque d'être intime avec une autre personne.

22. Il n'y a personne qui aime faire les choses que je fais.

23. Il y a des personnes sur qui je peux compter en cas d'urgence.

24. Personne n'a besoin de moi. 


\section{SOCIAL SUPPORT SATISFACTION SCALE}

(French)

1. Je suis satisfait(e) du support émotionnel que je reçoit de mes relations avec les autres.

1. Fortement en désaccord

2. En désaccord

3. D'accord

4. Fortement d'accord

2. Je suis satisfait(e) de l'aide pratique que je reçoit de mon entourage.

1. Fortement en désaccord

2. En désaccord

3. D'accord

4. Fortement d'accord

3. En tout et partout, je suis satisfait(e) de mes relations avec les autres?

1. Fortement en désaccord

2. En désaccord

3. D'accord

4. Fortement d'accord 
SOCIAL PRDVISIONS SCALE (continued)

13. J'entretiens des relations où ma compétence et mes talents sont reconnus

14. Il n'y a personne qui partage mes intérêts et préoccupations.

15. Il n'y a personne qui compte vraiment sur moi pour son bien-être.

16. Il $y$ a une personne fiable sur qui je pourrais compter pour demander des conseils si j'avais des problèmes

17. J'ai un lien émotionnel fort avec au moins une autre personne.

18. Il n'y a personne sur qui je peux compter si j'ai vraiment besoin d'aide.

19. Il n'y a personne avec qui je me sens à l'aise pour parler de mes problèmes.

20. Il y a des personnes qui admirent mes talents et mes aptitudes.

21. Ca me manque d'être intime avec une autre personne.

22. Il n'y a personne qui aime faire les choses que je fais.

23. Il y a des personnes sur qui je peux compter en cas d'urgence.

24. Personne n'a besoin de moi. 
$\pi$

\section{APPENDIX 15}

\section{BOCIAL SUPPORT BATISFACTION SCALE}

\section{(English)}

1. I am satisfied with the emotional support that my relationships give me.

1. Strongly aisagree

2. Disagree

3. Agree

4. Strongly agree

2. I am satisfied with the practical help that I get from the people I knovi.

1. Strongly disagree

2. Disagree

3. Agree

4. Strongly agree

3. Overall, I am satisfied with my relationships with other people.

1. Strongly disagree

2. Disagree

3. Agree

4. Strongly agree 


\section{SOCIAL SUPPORT SATISFACTION SCALE}

\section{(French)}

1. Je suis satisfait(e) du support émotionnel que je reçoit de mes relations avec les autres.

1. Fortement en désaccord

2. En désaccord

3. D'accord

4. Fortement d'accord

2. Je suis satisfait(e) de l'aide pratique que je reçoit de mon entourage.

1. Fortement en désaccord

2. En désaccord

3. D'accord

4. Fortement d'accord

3. En tout et partout, je suis satisfait(e) de mes relations avec les autres?

1. Fortement en désaccord

2. En désaccord

3. D'accord

4. Fortement d'accord 


\section{APPENDIX 16 \\ FORMAL SERVICES USED BY HOUSEHOLD \\ (English)}

Now, I will ask you about services which your family might be receiving. Do you or (subject) receive any of the following servises and, if so, about how often do you receive them?

1. Yes 0 . No

[IF YES, ANSWER (a) and (b).]

(a) Source:

1. Through a public agency

2. Through a private agency

3. Through a volunteer agency

(b) Client:

1. Respondent (hours per month:

2. Subject (hours per month:

1. Homemaker or cleaning lady

2. Home nurse

3. Physical therapist (at home or elsewhere)

4. Occupational therapist (at home or elsewhere)

5. Social worker (at home or elsewhere)

6. Day hospital

7. Day center

8. Recreational programs (e.g., church groups, Golden Age)

9. Respite care at home

10. Respite care in hospital or foster home

11. Meals on wheels

12. Other services (specify: 


\section{FORMAL BERVICES USED BY HOUSEHOLD}

\section{(French)}

Maintenant, je vais vous parler des services que votre famille pourrait recevoir. Est-ce que vous ou (sujet) recevez (reçoit) un ou plusieurs des services suivants. si oui, à quelle fréquence les recevez-vous (reçoit-il)?
1. Oui
0. Non

[SI OUI, DEMANDEZ (a) ET (b).]

(a) Source:

1. Par un organisme publique

2. Par un organisme privé

3. Par un organisme bénévole

(b) Bénéficiaire:

1. Répondant (nombre d'heures par mois:

2. Sujet

(nombre d'heures par mois:

1. Aide-ménagère ou femme de ménage

2. Infirmière à domicile

3. Physiothérapeute (à domicile ou ailleurs)

4. Ergothérapeute (à domicile ou ailleurs)

5. Travailleur social (à domicile ou ailleurs)

6. Hôpital de jour

7. Centre de jour

8. Programmes de loisirs (ex.: groupes paroissiaux, l'Age d'or, etc.)

9. Service de répit à la maison

10. Service de répit à l'hôpital ou au foyer d'accueil

11. Popotte roulante

12. Autre service (spécifier: 


\section{APPENDIX 17 \\ CONSENT FORMS \\ (English)}

DEMENTIA PATIENTS

THE HEALTH OF THE ELDERLY AND THEIR FAMILIES

I hereby consent to participate in a study on the health of the elderly and their families. I understand that an interviewer will contact me and a member of my immediate family within a few weeks in order to ask us questions concerning our health. The interview will last approximately one hour and will take place at a time and place which is convenient for us. I will also be contacted one year later for a follow-up interview. I understand that the information which I provide will be treated with strict confidentiality and will only be used for the purposes of this research. My participation or nonparticipation in this project will in no way affect the medical care which I receive.

Date $\begin{aligned} & \text { Patient's } \\ & \text { signature }\end{aligned}$

Family member's signature

[FRANCAIS AU VERSO.]

(continued on next page) 
CONSENT FORMS (continued)

CATARACT PATIENTS

THE HEALTH OF OLDER PEOPLE AND THEIR FAMILIES

I hereby consent to participate in a study on the health of older people and their families. I understand that an interviewer will contact me and a member of my immediate family within a few months in order to ask us questions concerning our health. The interview will last approximately one hour and will take place at a time and place which is convenient for us. I will also be contacted one year later for a follow-up interview. I understand that the information which I provide will be treated with strict confidentiality and will only be used for the purposes of this research. My participation or nonparticipation in this project will in no way affect the medical care which I receive.

Date signature

[FRANCAIS AU VERSO.] 


\section{CONSENT' FORMS}

(French)

\section{DEMENTIA PATIENTS}

Par la présente, j'accepte de participer à une étude sur la santé des personnes âgées et de leur famille. Je comprends qu'un interviewer me contactera ainsi qu'un membre de ma famille d'ici quelques semaines, afin de nous poser des questions au sujet de notre santé. L'entrevue durera environ une heure et aura lieu au moment et à l'endroit qui. nous conviennent. On communiquera également avec nous dans un an pour une entrevue complementaire. Il est entendu que les renseignements que je fournirai seront traités de façon strictement confidentielle et qu'ils ne seront utilisés que pour les fins de la présente étude. Ma participation ou non participation à ce projet n'affectera en aucune manière les soins médicaux que je reçois.

Date Signature du patient

signature d'un membre de la famille

[ENGLISH ON OTHER SIDE.]

(continued on next page) 
CONSENT FORMS (continued)

\section{CATARACT PATIENTS}

Par la présente, j'accepte de participer à une étude sur la santé des personnes âgées et de leur famille. Je comprends qu'un interviewer me contactera ainsi qu'un membre de ma famille d"ici quelques mois, afin de nous poser des questions au sujet de notre santé. I'entrevue durera environ une heure et aura litu au moment et à l'endroit qui nous conviennent. On communiquera également avec nous dans un an pour une entrevue complementaire. Il est entendu que les renseignements que je fournirai seront traités de façon strictement confidentielle et qu'ils ne seront utilisés que pour les fins de la présente étude. Ma participation ou non participation à ce projet n'affectera en aucune manière les soins médicaux que je reçois.

Date Signature

[ENGLISH ON OTHER SIDE.] 
APPENDIX 18

DETAILED RESULTS OF REGRESSION ANALYSIS OF CESD SCORE ON THE CAREGIVING VARIABLE, ADJUSTING FOR COVARIATES 


\section{Table AI}

Results of regression of CESD score on caregiver status, controlling for covariates

\begin{tabular}{lccc}
\hline Variable & $\begin{array}{l}\text { Regres- } \\
\text { sion } \\
\text { coefficient }\end{array}$ & $\begin{array}{l}\text { Standard } \\
\text { error of } \\
\text { coefficient }\end{array}$ & $\begin{array}{l}\text { Proba- } \\
\text { bility }\end{array}$ \\
\hline Caregiver status & 6.6 & 1.4 & 0.0000 \\
Sex & 4.0 & 1.3 & 0.0029 \\
Stressful Iife events & 1.0 & 0.3 & 0.0033 \\
Social provisions score & -0.3 & 0.1 & 0.0016 \\
Chronic conditions & 1.2 & 0.4 & 0.0056 \\
Ethnic group & 0.8 & 1.5 & 0.5928 \\
Coping score & 0.0 & 0.1 & 0.9494 \\
Education & -0.4 & 1.5 & 0.7780 \\
Age & -0.1 & 0.1 & 0.0022 \\
Social support & -1.3 & 0.6 & 0.0250 \\
satisfaction & & & 0.0000 \\
Constant & 47.4 & 8.1 & \\
\hline
\end{tabular}

Multiple $R$

Adjusted $\mathrm{R}^{2}$

Regression

Residual

$F=$

12.14
0.61

0.37

0.34
Standard

error of

bility
0.0000

0.0029

0.0033

0.5928

0.9494

0.7780

0.0022

0.0250

Adjusted $\mathrm{R}^{2} \quad 0.34$

10

205
Sum of squares
10483.62

17698.32

Probability $=0.0000$
Mean square

1048.36

86.33 
Table A2

Correlation among independent variables included in regression analyses which had CESD score as dependent variable

1

2
3

4

5

6

$$
\begin{array}{r}
1.00 \\
-.15
\end{array}
$$$$
.31
$$$$
-.41
$$$$
-.33
$$

$-.09$

$$
1.00
$$

.04

$$
.64
$$$$
\begin{array}{r}
.64 \\
-.01
\end{array}
$$

.22

.22
-.05

.04

$-.16$

$$
\begin{array}{r}
1.00 \\
.05
\end{array}
$$

$-.10$

.10

$-.18$

1.00

.13

.29

$-.13$

.31

$\begin{array}{rr}.13 & -.06 \\ -.10 & -.37\end{array}$

-.01
.22

$-.06$

.01

$-.09$

.37
.04

$$
\begin{array}{rr}
.10 & 1.00 \\
.03 & -.28 \\
-.07 & .08 \\
-.15 & .36 \\
-.00 & .09 \\
.24 & -.01
\end{array}
$$

$\begin{array}{rr}1.00 & \\ -.06 & 1.00 \\ -.50 & .15 \\ .16 & .06 \\ .06 & -.25\end{array}$

$8 \quad 9$

10

11

Legend:

1 CESD score (mean=11.6, $\mathrm{SD}=11.4$, potential range 0-60, higher score indicates more depression)

2 Caregiver status ( $0=\mathrm{NCG}, 1=\mathrm{CG})$

3 Social support satisfaction score (mean=9.3, $\mathrm{SD}=1.5$, potential range 0-12, higher score indicates greater satisfaction)

4 Social provisions score (mean=78.1, $\mathrm{SD}=9.9$, potential range 0-96, higher score indicates greater social provisions)

5 Number of stressful life events in previous six months (mean=3.3, SD=2.0)

Number of chronic conditions (mean=2.1, SD=1.7)

Completed high school ( $0=$ no, $1=y e s)$

Jewish $(0=$ no, $1=$ yes $)$

Age (mean $=63.4, S D=13.9$ )

Sex ( $0=$ male, $1=$ female)

coping score (mean=85.0, $\mathrm{SD}=13.6$, potential range $0-145$, higher score indicates greater coping skills) 
Figure A1

Frequency distribution of standardized residuals, regression of depression score on caregiver status, controlling for covariates

Standardized

residual

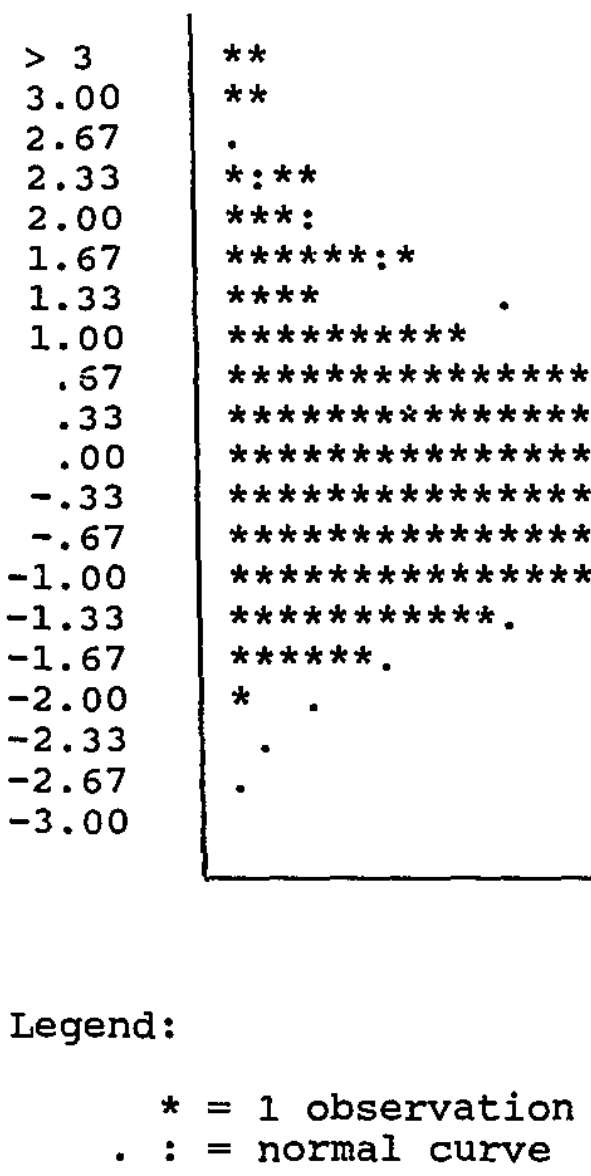

Frequency 
Figure A2

observed standardized residual (expressed as percentile) versus expected standardized residual (expressed as percentile), regression of depression score on caregiver status, controlling for covariates

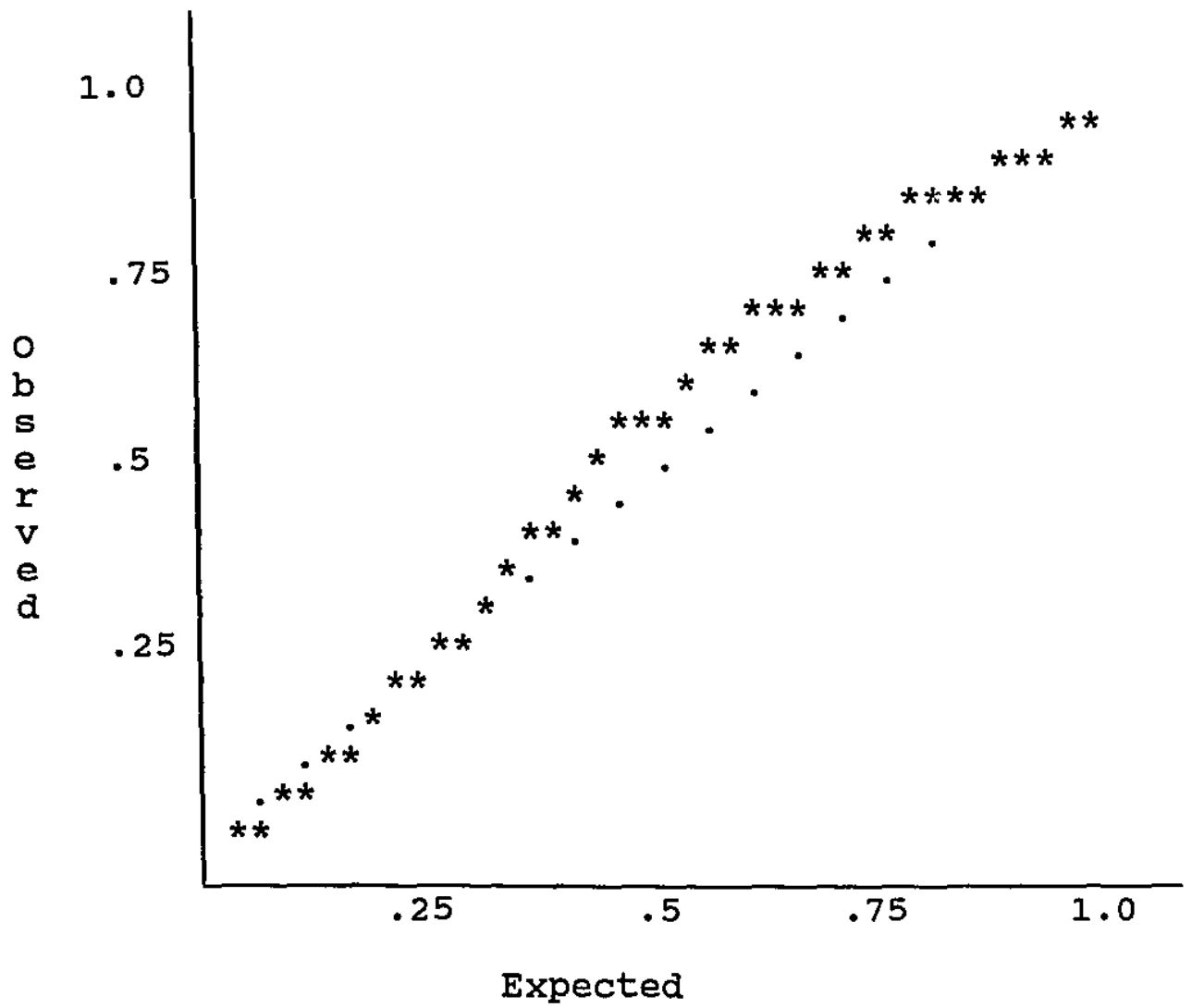


APPENDIX 19

DETAILED RESULTS OF REGRESSION ANALYSIS OF NUMBER OF PHYSICAL SYMPTOMS

ON THE CAREGIVING VARIABLE, ADJUSTING FOR COVARIATES 
Table A3

Results of regression of number of physical symptoms on caregiver status, controlling for covariates

\begin{tabular}{lccc}
\hline & $\begin{array}{l}\text { Regres- } \\
\text { sion } \\
\text { coefficient }\end{array}$ & $\begin{array}{l}\text { standard } \\
\text { error of } \\
\text { coefficient }\end{array}$ & $\begin{array}{l}\text { Proba- } \\
\text { bility }\end{array}$ \\
\hline Caregiver status & 1.2 & 0.4 & 0.0030 \\
Sex & 1.8 & 0.4 & 0.0000 \\
Stressful life events & 0.2 & 0.1 & 0.0836 \\
Social provisions score & -0.0 & 0.0 & 0.6924 \\
Alcohol consumption & -0.0 & 0.0 & 0.3639 \\
Chronic conditions & 0.8 & 0.1 & 0.0000 \\
Coping score & 0.0 & 0.0 & 0.9807 \\
Cigarette smoking & 0.0 & 0.0 & 0.4298 \\
Education & -0.1 & 0.4 & 0.8982 \\
Ethnic group & -0.2 & 0.5 & 0.6429 \\
Age & 0.0 & 0.0 & 0.8262 \\
Social support & -0.2 & 0.2 & 0.3567 \\
satisfaction & & & \\
Constant & 2.7 & 2.4 & 0.2639 \\
\hline
\end{tabular}

$\begin{array}{ll}\text { Multiple } \mathrm{R} & 0.62 \\ \mathrm{R}^{2} & 0.38 \\ \text { Adjusted } \mathrm{R}^{2} & 0.35\end{array}$

$\begin{array}{lccc} & \text { DF } & \text { Sum of squares } & \text { Mean square } \\ \text { Regression } & 12 & 926.10 & 77.17 \\ \text { Residual } & 202 & 1488.89 & 7.37 \\ \text { F } & 10.47 & \text { Probability }=0.0000 & \end{array}$


Tab?e A4

Correlation among independent variables included in regression analyses which had number of physical symptoms as dependent variable

\begin{tabular}{|c|c|c|c|c|c|c|c|c|c|c|c|c|c|}
\hline & $\begin{array}{c}1 \\
1.00\end{array}$ & 2 & 3 & 4 & 5 & 6 & 7 & 8 & 9 & 10 & 11 & 12 & 13 \\
\hline $\begin{array}{l}1 \\
2\end{array}$ & .22 & 1.00 & & & & & & & & & & & \\
\hline 3 & -.22 & -.16 & 1.00 & & & & & & & & & & \\
\hline 4 & -.18 & -.10 & .64 & 1.00 & & & & & & & & & \\
\hline 5 & .14 & .03 & -.01 & .04 & 1.00 & & & & & & & & \\
\hline 6 & .51 & .04 & -.16 & -.18 & .09 & 1.00 & & & & & & & \\
\hline 7 & -.13 & -.10 & .10 & .30 & .02 & -.28 & 1.00 & & & & & & \\
\hline 8 & .10 & .30 & -.13 & -.06 & -.07 & .09 & -.06 & 1.00 & & & & & \\
\hline 9 & .20 & .23 & -.10 & -.36 & -.14 & .36 & -.49 & .15 & 1.00 & & & & \\
\hline 10 & .30 & .00 & -.09 & .03 & -.01 & .09 & .16 & .06 & -.09 & 1.00 & & & \\
\hline 11 & -.01 & -.05 & .23 & .22 & .23 & -.01 & -.06 & -.24 & -.05 & -.00 & 1.00 & & \\
\hline 12 & -.18 & -.14 & .15 & .11 & -.09 & -.15 & -.01 & -.30 & -.10 & -.12 & .03 & 1.00 & \\
\hline 13 & .02 & -.08 & .02 & -.11 & -.08 & .13 & -.15 & -.02 & .09 & -.20 & -.08 & .14 & 0 \\
\hline
\end{tabular}

\section{Legend:}

1 Number of physical symptoms (mean=4.4, SD=3.4)

Caregiver status ( $0=\mathrm{NCG}, 1=\mathrm{CG})$

Social support satisfaction score (mean=9.3, $\mathrm{SD}=1.5$, potential range 0-12, higher score indicates greater satisfaction)

4 Social provisions score (mean=78.1, SD=9.9, potential range 0-96, higher score indicates greater social provisions)

5 Number of stressful life events in previous six montls (mean=3.3, $\mathrm{SD}=2.0$ )

6 Number of chronic conditions (mean $=2.1, \mathrm{SD}=1.7$ )

7 Completed high school ( $0=$ no, 1=yes)

8 Jewish $(0=$ no, $1=$ yes $)$

9 Age (mean=63.4, $\mathrm{SD}=13.9)$

10 Sex ( $0=$ male, $1=$ female)

11 Coping score (mean=85.0, $\mathrm{SD}=13.6$, potential range $0-145$, higher score indicates greater coping skills)

12 Alcohol consumption in previous month (ounces of absolute alcohol) (mean=6.4, $\mathrm{SD}=15.9$ )

13 Lifetime cigarette smoking (pack-years) (mean=1.1, SD=1.7) 


\section{Figure $\mathbf{A} 3$}

Frequency distribution of standardized residuals, regression of number of physical symptoms on caregiver status, controlling for covariates

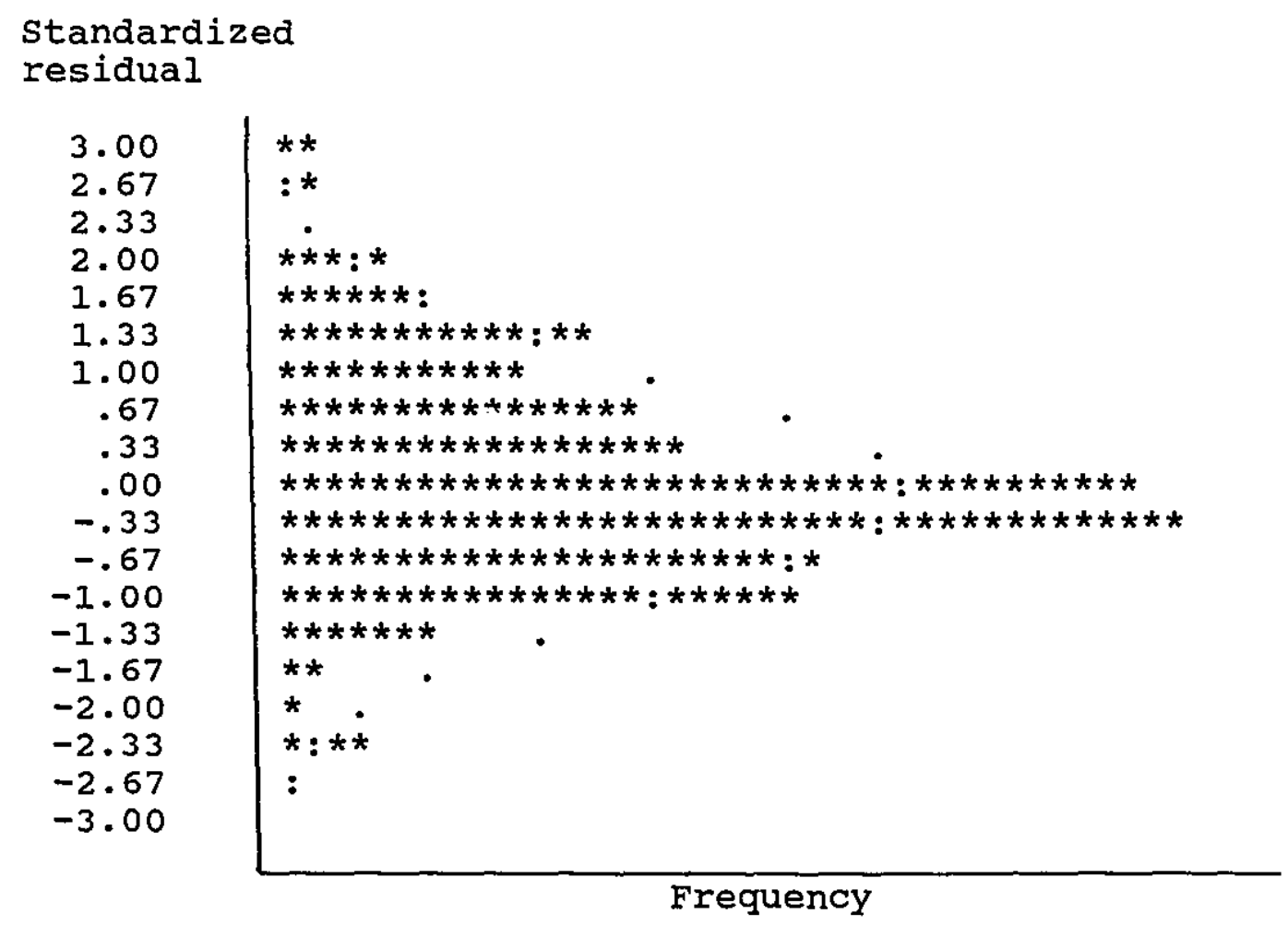

\section{Legend:}

* $=1$ observation

- : normal curve 


\section{Figure A4}

observed standardized residual (expressed as percentile) versus expected standardized residual (expressed as percentile), regression of number of physical symptoms on caregiver status, controlling for covariates

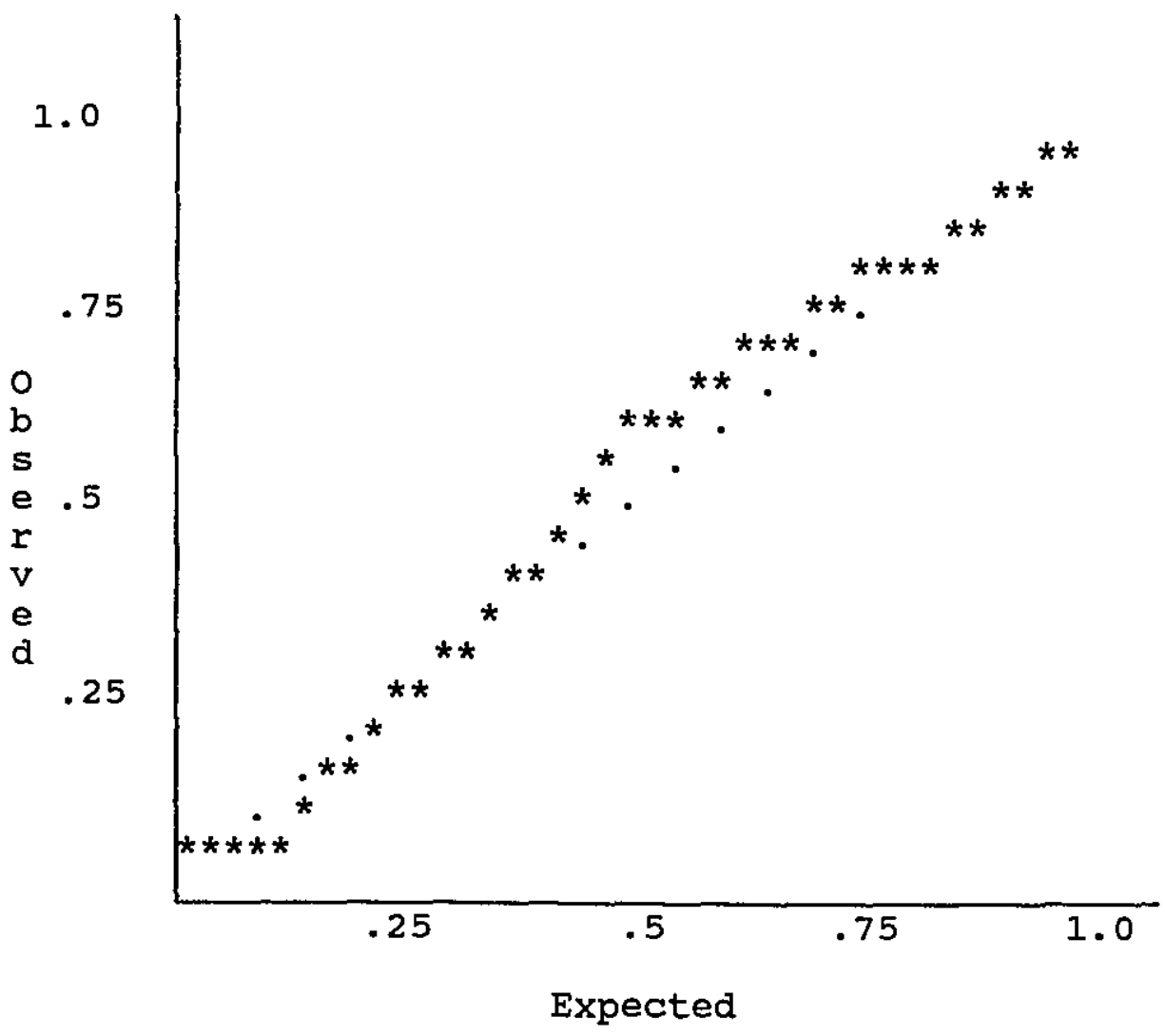

